
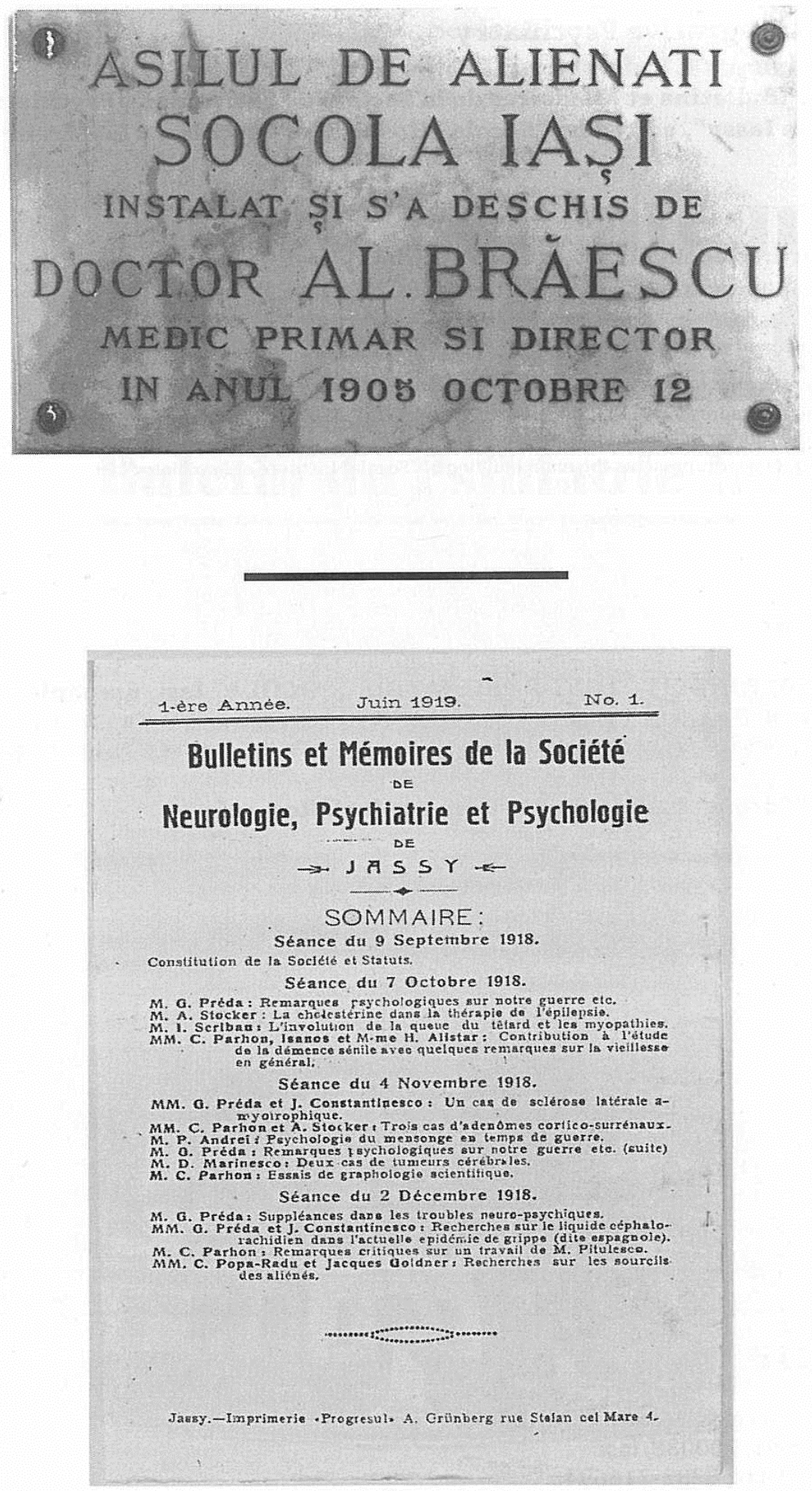


\section{Bulletin of Integrative Psychiatry}

New series of "Bulletins et Mémoires de la Société de Neurologie, Psychiatrie et Psychologie de Iassy", edited by "Socola" Hospital of Psychiatry Iaşi from 1919 to 1946

Editorial Board: "Socola" Institute of Psychiatry Iaşi

Address: Şoseaua Bucium nr. 36, cod poştal 700282, Iaşi, România

Images on the first page represent: Inaugural board of "Socola" Hospital of Psychiatry Iaşi The cover of the first number of "Bulletins et Mémoires de la Société de Neurologie, Psychiatrie et Psychologie de Iassy"

The image on the first cover represents the main building of "Socola" Institute of Psychiatry Iasi

ISSN: 1453-7257

\section{Copyright @ 2017 INSTITUTUL DE PSIHIATRIE „SOCOLA" Iaşi, România}

The papers published in "The Bulletin of Integrative Psychiatry" are protected by copyright. Their full or partial publication in other journal is allowed only with the written approval of "SOCOLA" Institute of Psychiatry Iaşi, Romania.

Published by "Socola" Institute of Psychiatry Iaşi, Romania

\section{"Gr. T. Popa" Pullisher}

University of Medicine and Pharmacy Iaşi $16^{\text {th }}$ Universităţii Str.

All rights of this work are reserved to the authors and „Gr.T. Popa" Publisher Iaşi. No part of this publication may be reproduced or transmitted by any means, electronical or mechanical, including photocopying without written permission from the authors or publisher. 


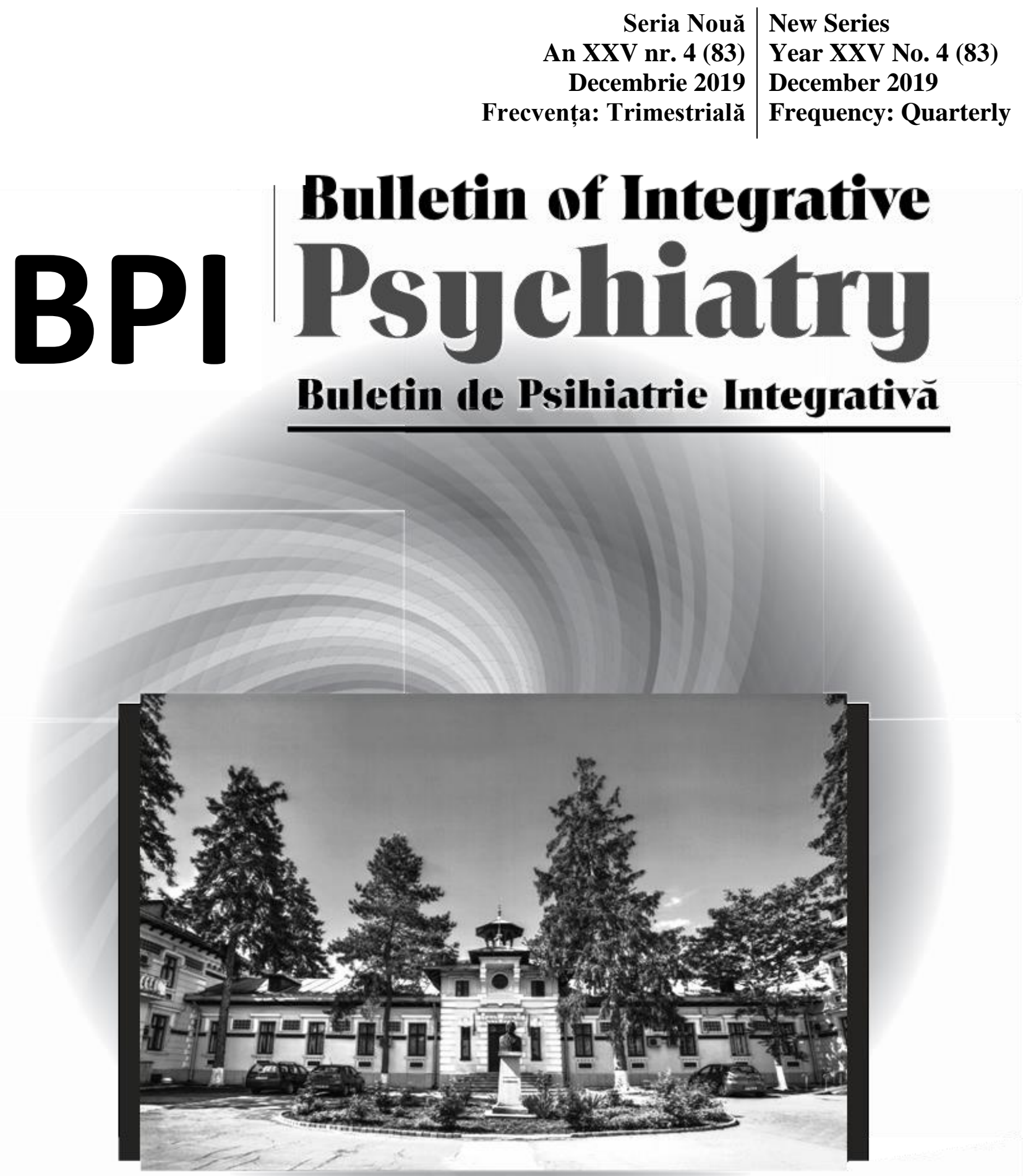

Official Publication of

"SOCOLA" INSTITUTE OF PSYCHIATRY

Iași, Romania 


\section{PUBLISHER: "SOCOLA" INSTITUTE OF PSYCHIATRY IAȘI}

\section{EDITORIAL BOARD}

Editor in chief:

Professor Vasile Chiriţă MD, $\mathrm{PhD}$, Honorary

Member of the Romanian Academy of Medical

Science

Deputy editors:

Prof Roxana Chiriţă MD, PhD, "Grigore T. Popa"

U. M. Ph., Iasi, Romania

Prof Cristinel Ştefănescu MD, PhD, “Grigore T.

Popa" U. M. Ph., Iasi, Romania

Prof Călina Gogălniceanu, "Al. I. Cuza”

University, Faculty of Letters, Iasi, Romania

Laura Pricop-researcher, PhD, "Al. I. Cuza"

University-Interdisciplinary Research in Social-

Human Sciences Iasi, Romania

Romeo P. Dobrin MD, PhD, “Grigore T. Popa” U. M. Ph., Iasi, Romania

Alexandra Boloş MD, PhD, "Grigore T. Popa" U.

M. Ph., Iasi, Romania

Alin Ciobica- researcher, PhD, "Al. I. Cuza"

University, Iasi, Romania

Radu Andrei MD, PhD, "Socola" Institute of

Psychiatry, Iasi, Romania

Associated editors:

Andreea Silvana Szalontay MD, PhD, "Grigore T. Popa" U. M. Ph., Iasi, Romania

Ovidiu Alexinschi MD, PhD, "Socola" Institute of Psychiatry, Iasi, Romania

Ilinca Untu MD, “Grigore T. Popa” U. M. Ph., Iasi, Romania

\section{Administrative Board:}

Ana Caterina Cristofor MD, $\mathrm{PhD}$, "Grigore T.

Popa" U. M. Ph., Iasi, Romania

Dania Radu MD, “Grigore T. Popa” U. M. Ph., Iasi,

Romania

Elena Popescu MD, "Socola" Institute of

Psychiatry, Iasi, Romania

Petronela Nechita MD, PhD, "Socola" Institute of

Psychiatry, Iasi, Romania

\section{Designer}

Matei Palimariciuc MD, "Socola" Institute of Psychiatry, Iasi, Romania
ADVISORY BOARD:

\author{
ALLILAIRE J.F. (France) \\ ANDREI ELENA MIHAELA (Romania) \\ ASTĂRĂSTOAE VASILE (Romania) \\ BĂLĂCEANU-STOLNICI CONSTANTIN \\ (Romania) \\ BILD WALTER (Romania)
}

BURLEA (CIUBARĂ) ANA-MARIA (Romania)

BURLUI VASILE (Romania)

CÂȘLARU DIANA (Romania)

COSMAN DOINA (Romania)

COSMOVICI NICOLAE (Romania)

COSSCIUG ION (Republic of Moldavia)

CĂRUNTU IRINA (Romania)

DAFINOIU ION (Romania)

DAVIDSON MICHAEL (Israel)

DEHELEAN LIANA (Romania)

DI FIORINO MARIO (Italy)

ENĂTESCU VIRGIL(Romania)

ENĂTESCU VIRGIL RADU (Romania)

FODOREANU LIANA (Romania)

FORNA NORINA CONSUELA (Romania)

GABOŞ-GRECU IOSIF(Romania)

GEORGESCU ȘTEFAN OCTAVIAN (Romania)

GOGĂLNICEANU PETRUŢ(UK)

HABOT SIMON (Israel)

HULUBAŞ ADINA (Romania)

KAMPITS PETER (Austria)

KNIGHT BERNARD (USA)

LADEA MARIA(Romania)

LAZARESCU MIRCEA (Romania)

LEPPEE MARCEL (Croatia)

MANEA MIRELA(Romania)

MARINESCU DRAGOS (Romania)

MICLUȚIA IOANA(Romania)

NACU ANATOL (Republic of Moldavia)

NIREŞTEAN AUREL (Romania)

NISHARA BRIAN (Canada)

OPREA VALENTIN (Republic of Moldavia)

PRELIPCEANU DAN(Romania)

PIANI FRANCESCO (Italy)

PRUS ELENA(Republic of Moldavia)

RUJESCU DAN (Germany)

SCRIPCARIU VIOREL (Romania)

SCRIPCARU CĂLIN(Romania)

STOCKMAN RENE (Belgium)

ȘERBAN IONELA LĂCRĂMIOARA (Romania)

TIMOFTE DANIEL (Romania)

TUDOSE CĂTĂLINA(Romania)

NUNO VIEIRA DUARDE (Portugal)

YOUNG ALLAN (UK) 
The Bulletin of Integrative Psychiatry tries to continue the tradition initiated at "Socola" Hospital in 1919, when a group of intellectuals, medical doctors and personalities from other professions founded the Society of Neurology, Psychiatry and Psychology in Iaşi. Even from its beginnings, the Society edited a journal entitled "Bulletins et Mémoires de la Société de Neurologie, Psychiatrie et Psychologie de Iassy", the first publication of the kind in Romania, which was unique also by its vision and opening towards biology, psychology, sociology and philosophy and by its prestigious board of editors: C. I. Parhon, Gh. Preda, Constantin Fedeleș, Arnold Stocker, P. Andrei, Corneliu Popa-Radu, I. A. Scriban, well known personalities, some of them being physicians of great culture and scientific qualification.

Starting from 1920, the Association and its Bulletin, born and edited at "Socola", due to their remarkable scientific activity have contributed to the organization of 18 congresses, which are mentioned in the description of "Socola" Hospital activities.

In 1947, the last number of "The Bulletin of the Society", edited in French, was banned as a result of the interdictions imposed by extremist tendencies. From its first number in 1919 and until 1947, "The Bulletin of the Society" published 2,412 articles.

The journal or "The Bulletin of the Society" has appeared under several titles: "Bulletin et Mémoires de la Société de Neurologie, Psychiatrie et Psychologie de Iassy" (between 1919 and 1922), then "Bulletin de l'Association des Psychiatres Roumains" and from 1923 it has changed its title several times.

After the year 1947, all publications at "Socola" Hospital were included in the "Medico-Surgical Journal of the Society of Physicians and Naturalists in Iași", another prestigious scientific journal which has been published without interruption since 1886.

Starting from 1994, Professor Dr. Tadeusz Pirozynski, Professor dr. Petru Boișteanu, Professor dr. Vasile Chiriță, Conf. dr. Radu Andrei and Dr. M. E. Berlescu have revived the tradition of publications at "Socola" Hospital, editing the new "Bulletin of Integrative Psychiatry".

At the end of 2014, "Socola" Hospital became the "Socola" Institute of Psychiatry, which has increased its responsibilities regarding medical assistance, scientific research, didactic activity, professional training and also the development of editorial activity. 
Journal B+ CNCS and Indexed IDB by Index Copernicus, DOAJ, Erih Plus, Gale Cengage, CEEOL

Editorial contact: contact@buletindepsihiatrie.ro

Publisher contact:

\author{
„, Gr. T. Popa" Publisher \\ University of Medicine and Pharmacy Iaşi \\ $16^{\text {th }}$ Universităţii Str. \\ Tel. 0232301678 \\ www.umfiasi.ro
}




\section{Summary}

\section{Editorial / 9}

Schizophrenia Between the Dilemmas of Conceptual Framing / 11

Dania-Andreea Radu, Ilinca Untu

\section{Articles / 15}

Studying the effects of Salvia spp. extract in a valproic-acid induced rat model of autism and its possible metabolic relevance / 17

Samson Guenné, Nabèrè Ouattara, Radu Lefter, Daniel Timofte, Adama Hilou, Martin Kiendrebéogo

Mini-review on the psychiatric comorbidities in epilepsy - possible relevance for some metabolic changes? / 29

Raluca Elena Duță, Cristina Elena Nedelcu, Alin Ciobîca, Daniel Timofte

The renin-angiotensine system and psychiatric disorders in pregnancy and post-partum / 43

Roxana Mihaela Barbu, Cristina Maria Gavrilescu, Elena Cojocaru, Crînguta Paraschiv, Ionuț R. Popescu, Walther Bild

Importance of CAIDE risk score for the early diagnosis of Alzheimer dementia / 49 Ioana A. Sandu, Adina C. Ilie, Ramona Ștefăniu, Anca I. Pîslaru, Irina M. Abdulan, Ioana D. Alexa, Cristinel Ștefãnescu

Impact of cardiac anomalies in the prognosis of patients with velo-cardio-facial syndrome / 55

Alexandra Maștaleru, Maria-Magdalena Leon-Constantin, Irina Abdulan, Alexandra Jitaru, Eva Gavril, Mitu Florin

Alternative therapies and management of dementia in Alzheimer's disease / 63 Laura Cristina, Dana Făget, Vasile Chiriță, Roxana Chiriță, Mirela Manea

The impact of biochemical control on the quality of life of patients with acromegaly / 71 Emilia Solomon, Cristina Preda, Cristina Maria Gavrilescu, Radu Gheorghe Solomon, Dumitru Brănișteanu 
Antipsychotic treatment in patients with dementia receiving palliative care: efficiency, fall risk and cognitive impact / 79

Tudor Florea, Elena-Rodica Popescu, Matei Palimariciuc, Roxana Chiriță

Pemphigus vulgaris triggered by psychological stress / 89

Teona Asavei, Elena Porumb-Andrese, Dan Vâță, Mihaela Paula Toader, Adriana Ionela Pătrașcu, Alina Ioana Halip, Ioana Adriana Popescu, Laura Gheucă Solovăstru

Psycho-affective Implications in Dermatoaesthetics / 95

Teona Asavei, Elena Porumb-Andrese, Dan Vâță, Mihaela Paula Toader, Adriana Ionela Pătrașcu, Alina Ioana Halip, Ioana Adriana Popescu, Laura Gheucă Solovăstru

The effect of antipsychotic treatment in hebephrenic schizophrenia on hospitalization indicators in an adult inpatient and outpatient population / 101

Matei Palimariciuc, Tudor Florea, Vlad Teodor Iacob, Bianca Georgiana Secrieru, Roxana Chiriță

Humanistic contributions / 117

Health communication between theory and medical practice: the case of Romania / 119 Laura Pricop, Roxana Chiriță, Ana Caterina Cristofor

Traditional "roots" as a remedy for living abroad. A perspective on Romanian immigrants' behaviour / 129

Adina Hulubaș

Case reports / 137

Anxiety and panic disorders in the dental office / 139

Crînguța Paraschiv, Irina Eșanu, Roxana Mihaela Barbu, Diana Luchian, Irina Gavril, Cristina Maria Gavrilescu

Book review / 147

Mihai Șleahtițchi

Instructions for authors / 151 


\section{Editorial}





\section{Schizophrenia Between the Dilemmas of Conceptual Framing}

\section{Dania-Andreea Radu, Ilinca Untu}

Dania Andreea Radu - M.D., psychiatrist, Ph.D. Student, "Socola” Institute of Psychiatry, Iaşi, Romania, Grigore T.Popa University of Medicine and Pharmacy, Iași, Romania

Ilinca Untu - M.D., Psychiatrist, Ph.D. Student, "Socola” Institute of Psychiatry, Iaşi, Romania, Grigore T.Popa University of Medicine and Pharmacy, Iași, Romania

The term "schizophrenia" dates back about 100 years. Before the valid name was established today, this disorder, as a symptomatic group, was defined by Emil Kraepelin in 1887 -dementia praecox. Despite the absence of an early nosological classification, schizophrenia has been a medical and social reality that has accompanied the whole history of mankind from its beginnings to the present. In ancient Egypt, a series of thought disorders were foreshadowed which overlap in part with what is nowadays the positive, negative and cognitive symptoms of schizophrenia, but the pathological psychiatric manifestations passing as heart disorders, considered as the seat of the spirit. In ancient Greece and Rome, there is the social perception of mental illness without framing what it means to be a series of benchmarks that differentiate individual nosological entities. In the paleo-christian and medieval period, all persons considered "abnormal", either as a result of mental illness, mental retardation or physical deformities, were treated in the same way. Early theories assumed that mental disorders were caused by the evil possession of the body, and the proper treatment was then to exorcise these demons, through various means, from harmless treatments, such as exposing the patient to certain types of music, to some dangerous and sometimes deadly, such as be the release of evil spirits by making holes in the patient's skull.

In the 19th century, Benedict Morel launched the term demence precoce which defined a multitude of symptoms that overlap today with the positive elements of schizophrenia. Shortly, Emil Kraepelin draws a concrete differentiation between dementia praecox and manic depression, thus achieving a conceptual delimitation of two major psychiatric disorders. Dementia praecox is thus considered to be a suffering of the brain which involves also deterioration of cognitive function. 


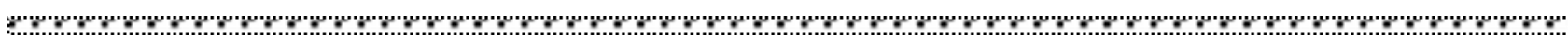

Kraepelin distinguishes three main forms of this disorder - paranoid, disorganized and catatonic. Eugen Bleuler replaced in literature the preceding term with that of SCHIZOPHRENIA, thus defining the schism among thoughts, emotions and behavioral reactions (clinical features that include those exposed by Kraepelin delusional ideas and hallucinations). This is also the first to describe the symptoms of schizophrenia as positive and negative. By changing the name of this major psychiatric disorder, the confusion promoted by the term introduced by Kraepelin is removed and it is established that schizophrenia exists without cognitive impairment and that schizophrenia does not belong to the same diagnostic spectrum with dementia. However, the new term, meant to dissolve any confusion about the nature of the disease, leads to the overlap of schizophrenia, in the collective mind, on the split of personality (multiple personality).

Over the years, Wirsch has analyzed the intuitive classification of the schizophrenia patient, according to whom "the praecox feeling" has nothing to do with mimicry and pantomime, nor with the poor emotional contact of schizophrenia, but with a certain way of being - daseinsweise - a certain way of being in the world and belonging to it. $\mathrm{He}$ argued that this intuitive recognition of schizophrenia is not about guessing or supposing but about being absolutely sure. Muller-Suur argues that the intuitive perception of the elements of schizophrenia does not involve understanding vague, inaccurate elements, but a definite incomprehensibility. Thus a change of perception emerges from being in the world to a specific, individual but incomprehensible order. What is incomprehensible, but perceived intuitively as something well defined, are basic structures of our being that are changed, such as temporality, spatiality and interaction with others. After 100 years of studies, schizophrenia remains a chronic disorder, with a still inaccurate nosological classification. Professor Pull argues that there are no pathognomonic symptoms, with patients with the same diagnosis having different forms of disease manifestation. Although there are standardized interviews and operational definitions, schizophrenia resembles their Babel tower, some of them (eg DSM criteria) confronting practitioners with equivocal standardized diagnostic elements. The lack of stable boundaries between schizophrenia and manicdepressive psychosis, has led to the emergence of an intermediate nosological entity, which borrows the fundamental symptoms of both - schizoaffective disorder.

The thinking of American psychiatrists, which was dominated until the immediate post-World War II period, by the terminology and thinking promoted by Freud's psychoanalysis. In the 1960s, most American psychiatrists abdicated from the Freudian ideological current, as a reaction to the lack of therapeutic response to its methods and to avoid removing psychiatry outside the medical field. In addition, Spitzer and others have relied on the biological approach to mental disorders.

In the 1970s, Gerald Klerman introduced the term neo-Kraepelian, created in a manifesto in which he listed nine claims that led to a new diagnostic system in psychiatry for 16 major psychiatric disorders, his work becoming one of the most cited in psychiatry. This manifesto claims that psychiatry is a real branch of medicine that should use modern scientific methods and base their practice on scientific 
s

evidence. At the same time, he states that psychiatry treats people who are ill and need treatment for mental illness and that there is a border between sick and normal, and mental illnesses are not myths, even if there are mental disorders with subtle clinical manifestation. Mental illnesses are not myths. There are several mental disorders, not a single mental illness that brings together all the psychopathological manifestations. It is the task of psychiatry, as in other medical specialties, to investigate the causes, diagnosis and treatment of mental illness. The orientation of the psychiatrists must be channeled predominantly on the biological coordinate, imposing a real preoccupation with the diagnostic and classification criteria. The diagnostic criteria must be codified, and the criteria must be validated by appropriate scientific methods. Further, medical schools should promote these criteria and not impair them, as has long been the case, improving the relevance and validity of diagnoses by requiring the use of statistical techniques.

In the trend of minimizing the role of psychiatry, R D Laing, a Scottish psychiatrist, along with David Cooper and Thomas Szasz developed the concept of "antipsychiatry", Laing being against TEC and the new antipsychotics and arguing that schizophrenia is "a theory not a fact". Szasz has stated throughout his career that mental illness is a metaphor for human life problems and that mental illness is not a "disease" in the true sense; "There are no biological or chemical tests nor biopsy or necropsy findings for verifying DSM diagnoses." The term has become widely used to refer to a variety of criticisms of psychiatry and the concept of mental illness. In fact, "antipsychiatry" had an important contribution, today the "treatment" being a "bio-psycho-social" and has contributed to the reintegration of patients with schizophrenia into a society that until recently institutionalized and marginalized them. DSM III (1980) has remained in history as the most influential edition of DSM, appearing as a reaction to the request of health insurance companies, to have clear diagnoses and implicit criteria (Previous Research Diagnostic Criteria and DSM III, were used benchmarks vague, inaccurate diagnoses). Since 1980, almost all the studies conducted have been linked to the same diagnostic algorithm.

The history of schizophrenia research overlaps the chronology of recurring themes - several promising clues that have been abandoned and a series of explanatory models, never fully confirmed, but never denied. Most contemporary research ideas are rediscovered early observations and hypotheses (the first decades following Kraepelin's nosological classification). Numerous studies, however small in scope, of an anatomical-pathological nature, have shown the presence of disturbances that especially affect the limbic region and do not appear as an evolutionary degenerative process, but the result of an evolutionary disturbance in the perinatal period. Epidemiological data related to schizophrenia are relevant depending on the issue of comparability of diagnosis over time.

Today's reality calls for schizophrenia to reach more than 23 million people worldwide, but it is not as common as other mental disorders. World statistics show that it is more common in men than women (12 million vs. 9 million) (1.4 X more common in men than women), being associated with considerable disabilities and interferes with socio-professional performance. People with schizophrenia are 2-3 times more 
likely to die at an earlier age than the general population, especially on the basis of cardiovascular, metabolic and infectious diseases. The stigmatization, discrimination and violation of human rights continue to be major obstacles to the socio-professional and educational integration of people with schizophrenia. More than $50 \%$ of people with schizophrenia do not receive adequate care. In low-income countries, 90\% of people with schizophrenia are subtracted. Reduced access to health services is the main reason for this situation. At the same time, people with schizophrenia are much less willing to seek help on their own, compared to the general population.

Schizophrenia remains an undeniable major psychiatric disorder as a clinical reality, but controversial, which still holds a series of questions regarding the correctness of the diagnostic criteria, related to the etiopathogenesis, as well as its multiple implications. The answers are not easy to give, especially since they are, in turn, dependent on other questions that lead to them, in a whirlwind of philosophical, medical, sociological and political dilemmas. What is a mental illness? What does treatment mean? Is treatment necessary? What does it mean to be a psychiatrist? And what does it mean to be patient? To what extent are the definitions of the concepts of "disease" and "treatment" related to a political system, a certain social order? To what extent is medicine itself dependent on power regimes? What is the mind, be it "healthy" or "sick"? What does it mean to be schizophrenic when schizophrenia is a so-called "functional" condition, in other words a disease without an obvious anatomical basis, whose pathology is not linked (at least for now) to any specific objective evidence. 
BP Bulletin of Integrative

Psychiatry

Bulctin de Psihiatrie Integrativa

\section{Articles}





\title{
Studying the effects of Salvia spp. extract in a valproic-acid induced rat model of autism and its possible metabolic relevance
}

\author{
Samson Guenné, Nabèrè Ouattara, Radu Lefter, \\ Daniel Timofte, Adama Hilou, Martin Kiendrebéogo
}

\begin{abstract}
Samson Guenné - Laboratory of Applied Biochemistry and Chemistry (LA.BIO.C.A), University Joseph KI-ZERBO, Ouagadougou 03, Burkina Faso

Nabèrè Ouattara - University of Dedougou, BP 176, Laboratory of Applied Biochemistry and Chemistry (LA.BIO.C.A), University Joseph KI-ZERBO, Ouagadougou 03, Burkina Faso

Radu Lefter - Center of Biomedical Research, Romanian Academy, Iași, B dul Carol I, no 8, Romania

Daniel Timofte - Grigore T.Popa" University of Medicine and Pharmacy, 16, Universitatii Street, 700115, Iași, Romania

Adama Hilou - Laboratory of Applied Biochemistry and Chemistry (LA.BIO.C.A), University Joseph KI-ZERBO, Ouagadougou 03, Burkina Faso

Martin Kiendrebéogo - Laboratory of Applied Biochemistry and Chemistry (LA.BIO.C.A), University Joseph KI-ZERBO, Ouagadougou 03, Burkina Faso
\end{abstract}

\begin{abstract}
Autism or autism spectrum disorder (ASD) is a human neuropsychiatric disorder with social and communication difficulties. Medicinal plants have a diversified and inexhaustible therapeutic potential. The aim of this study was to evaluate potentials of Salvia spp. essential oils on rat model of ASD memories. Social interaction test was used to confirm that rats treated with valproic acid have produced rats with autism spectrum disorder. Y-maze task and Radial arm-maze task were used to evaluate the effects of salvia spp. essential oils on rat with ASD memory. The most time spent by the rat in the empty box $(25.33 \pm 8.55 \mathrm{~s})$ and the least time $(58.53 \pm 6.07 \mathrm{~s})$ spent with the new rat by the test rat compared to the control rat, showed that valproic acid had an effect on pregnant rats who gave pups with ASD. The percentage of spontaneous alternation increasing in Y-maze for rats with ASD treated with Salvia spp. essential oil $(79.27+3.08 \% ; P=0.03, F=6.29)$ compared to control rats and rats treated only with valproic acid showed that Salvia spp. essential oil significantly improved short-term memory in rats and corrected rat learning memory. This research showed that Salvia plant extracts have shown in vivo pharmacological properties and have proven the merits of various traditional uses of these plants in psychiatric disorders.
\end{abstract}


Autism spectrum disorder, Salvia spp., memory.

\section{INTRODUCTION}

Autism or autism spectrum disorder (ASD) is a human neuropsychiatric disorder that manifests itself through social and communication difficulties with stereotypical and conservative behaviors. This psychiatric disorder, that causes are not well known, has an impact on child or adult life quality. Adults living with autism spectrum disorder may have a normal or below-standard IQ, which poses a social integration problem for them (1). Anatomically, children with ASDs have a modified cerebral procession compared to that of control children. This change affects amygdala, and hippocampus (2,3). The hippocampus is one of the most important compartments of the brain. Indeed, it is involved in memory, spatial navigation and behavioral inhibition $(4,5,6,7)$. Therefore, this modification of amygdala and hippocampus impact autism spectrum disorder (8). This disorder, which significantly reduces the life quality of people with autism, does not have a specific drug treatment. There are only treatments for relief of some symptoms. For example, oxytocin or melatonin or antiepileptics were used to treat some symptoms $(9,10,11,12)$.

This lack of effective treatments for autism spectrum disorders makes the search for new bioactive molecules for autism still relevant. The neuropsychiatric diseases animal models use allows a better understanding of these disorders in view to these news bioactive molecules search. Thus, prenatal exposure to valproic acid most often leads to autistic children and this can be transposed to rats or mice $(13,14,15)$.

It is also known that since ancient times plants have always been used in African, Ayurvedic and Chinese medicine for health care because these plants abound in an enormous inexhaustible potential of bioactive molecules (16). Thus, these medicinal plants have been used in traditional medicine for treatments ranging from microbial diseases to metabolic disorders. In this way, our study focused on plants of the Lamiaceae family of the genus Salvia spp to explore their neuropsychiatric profile. In the literature review, many of plants of this genus have psychotropic properties such as Salvia divinorum (Epling \& Játiva-M), Salvia multicaulis Vahl and Salvia cyanescens Boiss and Bal. (17,18). These plants psychotropic properties are due to the presence of secondary metabolites in their extracts.

Thus, the aim of this research was to evaluate effects of Salvia spp. essential oils on the memory of rat model of ASD.

Some previous studies have indeed shown that essential oils from Salvia genus plants have neuro-psychotropic properties $(19,20)$.

In our study, major experiments in neuropsychiatry were used to assessment states of rats social interaction and working and reference memory to evaluate volatile compounds from Salvia spp. contribution in autism treatment.

\section{MATERIALS AND METHODS}

\subsection{Plant material and essential oil}

\section{extraction}

Salvia spp. aerial parts were collected and dried away from sunlight, pulverized and weighed.

Essential oils of the dried powder of Salvia spp. were extracted by hydro-distillation with water vapor according to the method described by the 7th edition of European Pharmacopoeia using a Neo Clevenger type apparatus.

The volume of the essential oil was measured and ranked for $100 \mathrm{~g}$ dry plant material.

\subsection{Animals}

Thirty female and Male Wistar rats weighing respectively $238.40 \pm 18.70 \mathrm{~g}$ and $310 \pm$ $48.60 \mathrm{~g}$ at the start of the experiment were used. The animals were housed in a temperature and light-controlled room $\left(22^{\circ} \mathrm{C}\right.$, a $12 \mathrm{~h}$ cycle starting at 08:00 h) and were fed and allowed to drink water ad libitum. All 


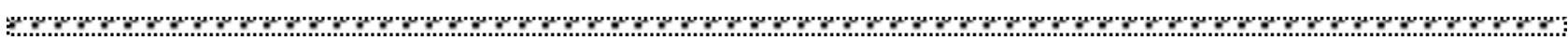

behavioral evaluations were performed between $9 \mathrm{~h}$ and $16 \mathrm{~h}$, respecting the current legislation for animal studies and indications of the local comities.

\subsection{Chemicals}

To carry out our research, we used valproic acid purchased from Sigma Aldrich Chemie (Steinheim, Germany).

\subsection{Experimental design}

Rats were divided into seven (7) groups (six animals per group) for the experiment performed: (1) control group $(0.9 \% \mathrm{NaCl}),(2)$ VPA $500 \mathrm{mg} / \mathrm{kg}$ treated group, (3) VPA 300 $\mathrm{mg} / \mathrm{kg}$ treated group, (4) VPA $500 \mathrm{mg} / \mathrm{kg}+$ Salvia spp. volatile oil 1\% group, (5) VPA $500 \mathrm{mg} / \mathrm{kg}+$ Salvia spp. volatile oil $3 \%$ treated group, (6) VPA $300 \mathrm{mg} / \mathrm{kg}+$ Salvia spp. volatile oil 1\% treated group, and (7) VPA $300 \mathrm{mg} / \mathrm{kg}+$ Salvia spp. volatile oil $3 \%$ treated group. Inhalation method was used 60 min per day during 21 successive days for Salvia spp. volatile oil treated groups.

\section{5. Experiments training}

\subsubsection{Social interaction test (SIT)}

The social interaction test assesses rat sociability and social novelty. The apparatus consists of three rectangular compartments 19 x $45 \mathrm{~cm}$ connected by two doors. The two outer boxes have two cages. After Salvia spp. essential oil exposition, the test involves two steps. In the first step, one of the extreme cases contains a rat and one empty and the test rat was placed in the middle box. The rat test can freely explore the two extreme cases. In the second step, the 2 external boxes contain the rats and the same test rat was placed in the middle box and freely explores the two outer boxes (21). The parameters evaluated were:

1. The number of entries in each outer compartment

2. The time spent in each outer compartment

3 . The number of contacts with another rat or with the empty cage

4. The contact time with another rat or the empty cage

\subsubsection{Y-maze task}

Short-term memory was assessed by spontaneous alternation behavior in the Ymaze task. The $\mathrm{Y}$-maze used in the present study consisted of three arms (A, B and C) (35 cm long, $25 \mathrm{~cm}$ high and $10 \mathrm{~cm}$ wide) and an equilateral triangular central area. $1 \mathrm{~h}$ after Salvia spp. essential oil inhalation, rats were placed at the end of one arm and allowed to move freely through the maze for $8 \mathrm{~min}$. An arm entry was counted when the hind paws of the rat were completely within the arm. Spontaneous alternation behavior was defined as entry into all three arms on consecutive choices. The number of maximum spontaneous alternation behaviors was then the total number of arms entered minus 2 and percent spontaneous alternation was calculated as (actual alternations/ maximum alternations $) \times 100$. Spontaneous alternation behavior is considered to reflect spatial working memory, which is a form of shortterm memory (22).

\subsubsection{Radial arm-maze task}

The radial 8 arm-maze used in the present study consisted of 8 arms, numbered from 1 to $8(48 \mathrm{~cm} \times 12 \mathrm{~cm})$, extending radially from a central area $(32 \mathrm{~cm}$ in diameter). The apparatus was placed $50 \mathrm{~cm}$ above the floor and surrounded by various extra-maze visual cues placed at the same position during the study. At the end of each arm there was a food cup that had a single $50 \mathrm{mg}$ food pellet. Prior to the performance of the maze task, the animals were kept on restricted diet and body weight was maintained at $85 \%$ of their freefeeding weight over a week period, with water being available ad libitum. Before the actual training began, three or four rats were simultaneously placed in the radial maze and allowed to explore for $5 \mathrm{~min}$ and take food freely. The food was initially available throughout the maze but was gradually restricted to the food cup. The animals were trained for 5 days to run to the end of the arms and consume the bait. To evaluate basal activity of rats in radial 8 arm-maze, the rats were given 5 consecutive training trials per day to run to the end of the arms and consume 
the bait. The training trial continued until all the 5 baits had been consumed or until 5 min has elapsed. Criterion performance was defined as consumption of all 5 baits or until 5 min had elapsed. After adaptation, all rats were trained with 1 trial per day. Briefly, $1 \mathrm{~h}$ after Salvia spp. essential oil exposition, each animal was placed individually in the center of the maze and subjected to working and reference memory tasks, in which same 5 arms (numbers 1, 2, 4, 5 and 7), were baited for each daily training trial. The other 3 arms (numbers 3, 6 and 8) were never baited. An arm entry was counted when all four limbs of the rat were within an arm. The experiment was performed for 10 consecutive days.

Measures were made of the number of working memory errors (entering an arm containing food, but previously entered), reference memory errors (entering an arm that was not baited). The time taken to consume all five baits was also recorded. Reference memory is regarded as a long-term memory for information that remains constant over repeated trials (memory for the positions of baited arms), whereas working memory is considered a short time memory in which the information to be remembered changes in every trial (memory for the positions of arms that had already been visited in each trial) (23).

\section{DATA ANALYSIS}

All results were expressed as mean \pm standard error of the mean (S.E.M). Behavioral activities of rats were statistically analyzed with analysis of variance (one way and twoway ANOVA). Tukey's test was used to determine level of significance of all results obtained on XLSTAT 7.1. Results were regarded as significant at $\mathrm{p}<0.05$.

\section{RESULTS}

\subsection{Rats Social behavior after valproic acid administration}

The social interaction of rats treated with valproic acid and their desire to make new social discoveries are represented by figures 1 (a, b, c, d) and figures 2 (a, b, c, d). Three doses of valproic acid were used (500; 300 and $150 \mathrm{mg} / \mathrm{kg}$ body weight).

The figure 1 shows that rats from valproic acid-treated rats as well as normal rats explored the three compartments of the device (room 0 and 1 and center). This mobility of rats was proof that they have physique and their motor nerve centers in good condition. Also, this figure shows that rats resulting from VPA treatment spent less time in the box with another rat (room1) and more time in the empty box. This comparison shows that these rats with a behavioral lack have an ASD with a tendency to loneliness. 

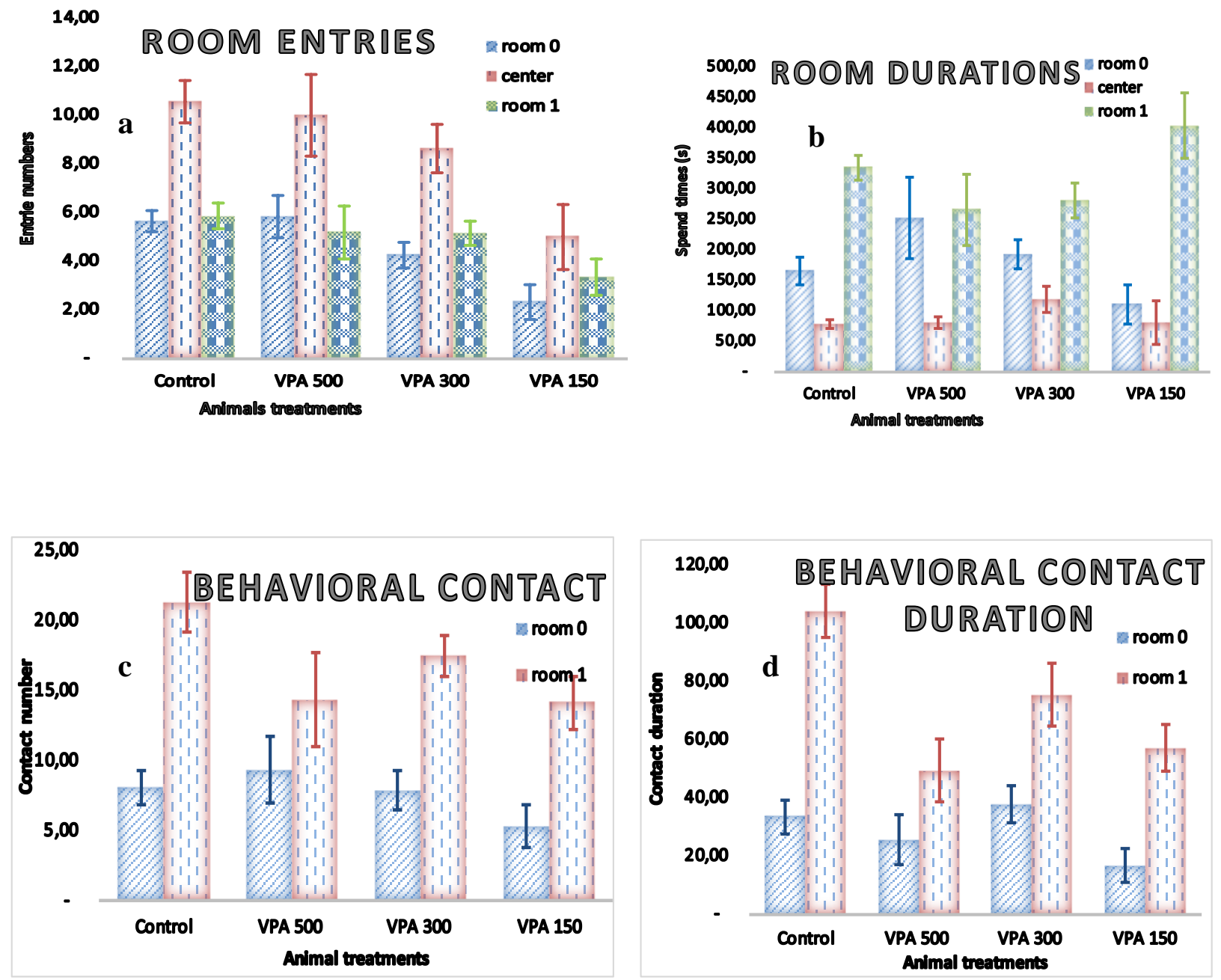

Figure 1: Rat social interactions

The figure 2 shows again that rats from valproic acid-treated rats as well as normal rats explored the three compartments of the device (room 1 and 2 and center). In this test second part, in the previous empty box (room 0) a new rat (room 2) was introduced. Rats treated with VPA spent less time in the new rat box (room 2) and more time in the old rat box (room 1) compared to normal rat comportments. These observations support the fact that rats treated with VPA have a behavioral disorder that is most likely autism.

\subsection{Effects of Salvia spp. essential oil on $A S D$ rat memories}

\subsubsection{Effects on short term memory}

The percentages of spontaneous alternance showed that valproic acid (VPA $500 \mathrm{mg} / \mathrm{kg}$, $\mathrm{P}=0.009, \mathrm{~F}=8.38$ and $\mathrm{VPA} 300 \mathrm{mg} / \mathrm{kg}, \mathrm{P}=$ $0.002, \mathrm{~F}=11.50$ ) have negative impacts on short-term memory of rats compared to the control group. Also, Salvia spp. essential oil (1\%) had a positive impact on autistic group compared to VPA $300 \mathrm{mg} / \mathrm{kg}$ treated rats (P $=0.03, \mathrm{~F}=6.29)$ by improving rats spontaneous alternance (figure 3 ). 

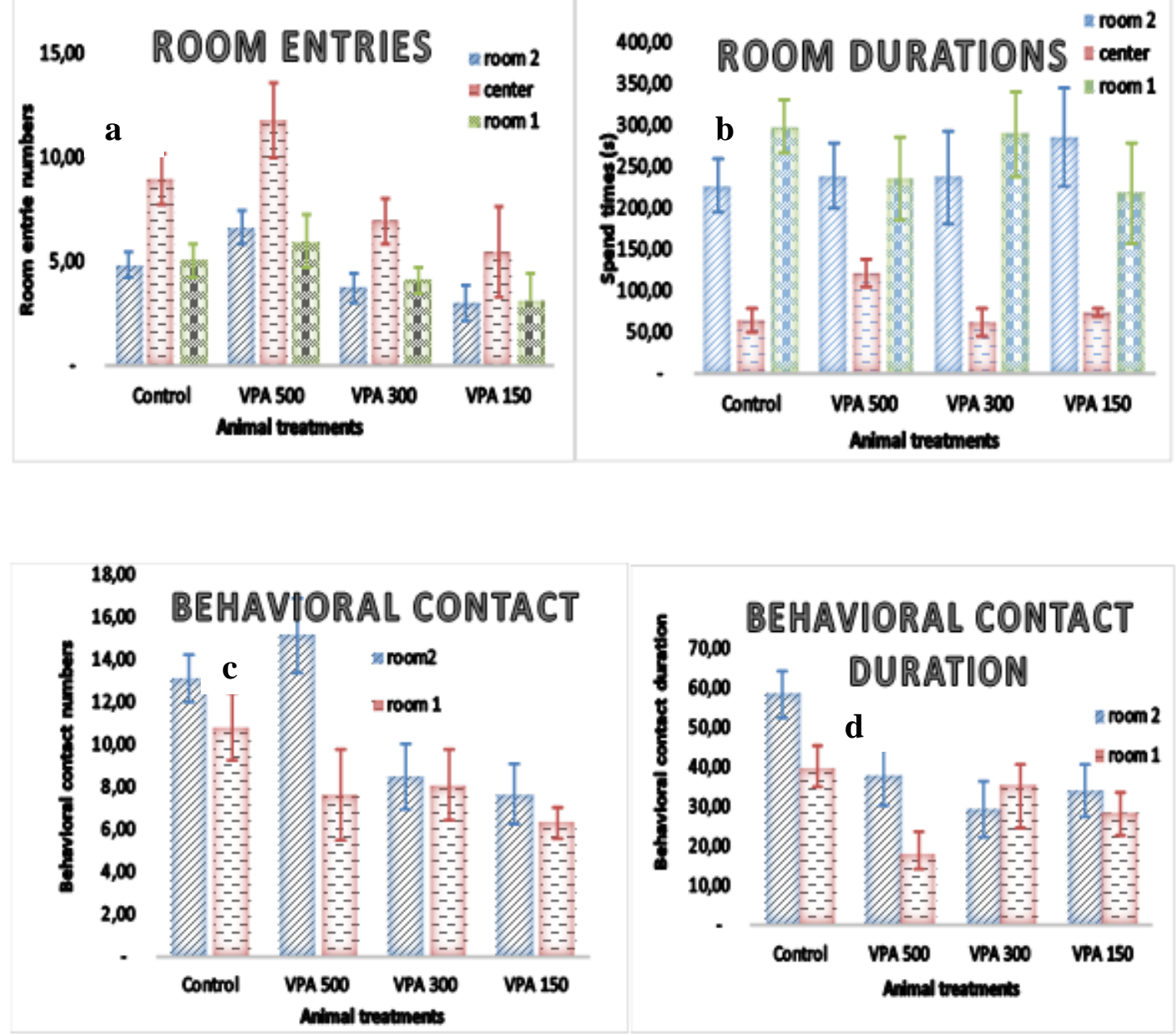

Figure 2: Rat novel discovery capacity

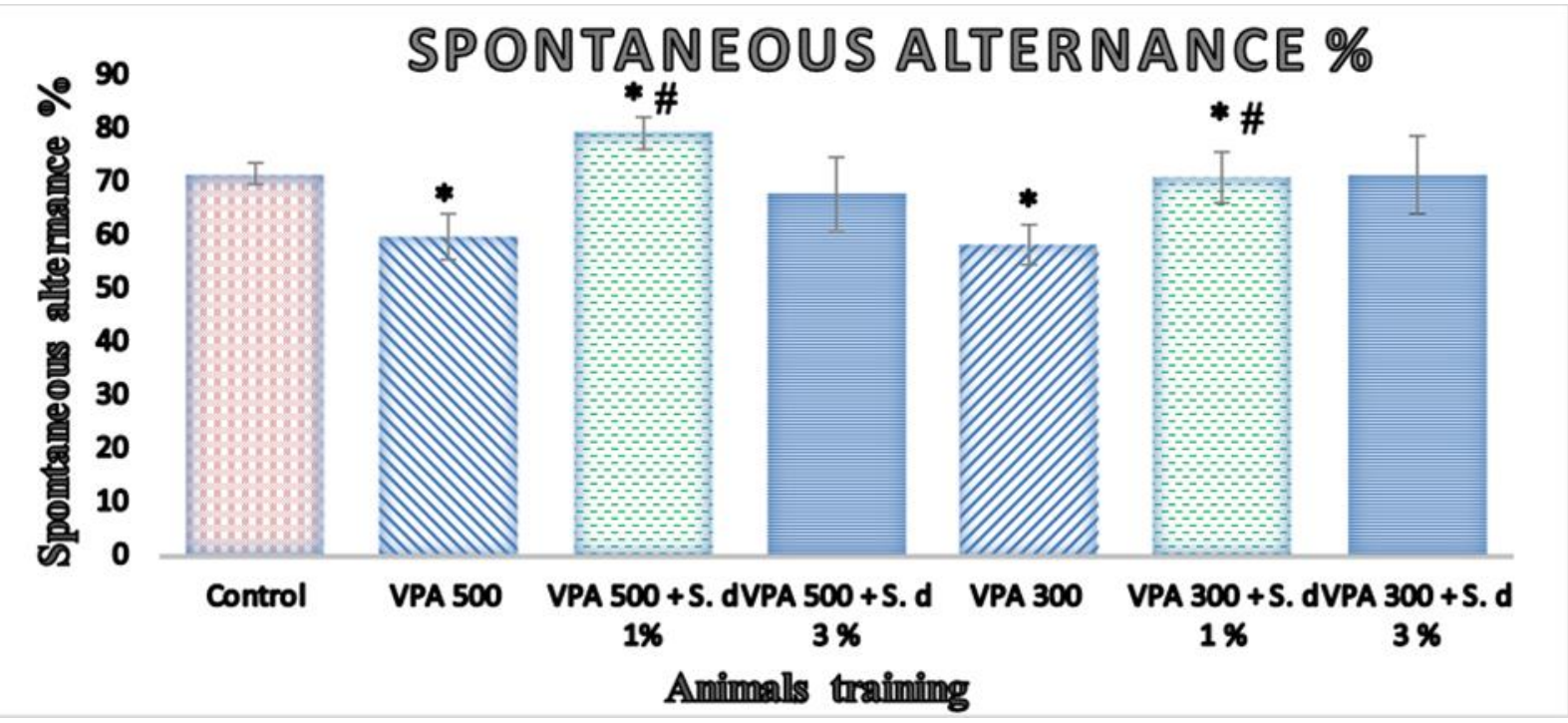

Figure 3: Salvia spp. essential oil impact on short memory using Y-maze

The values are mean \pm S.E.M. $\left(\mathrm{n}=6\right.$ per test). ${ }^{*} \mathrm{p}<0.05$ vs. control; ${ }^{*} \mathrm{p}<0.05$ vs. VPA 500 or 300 . 


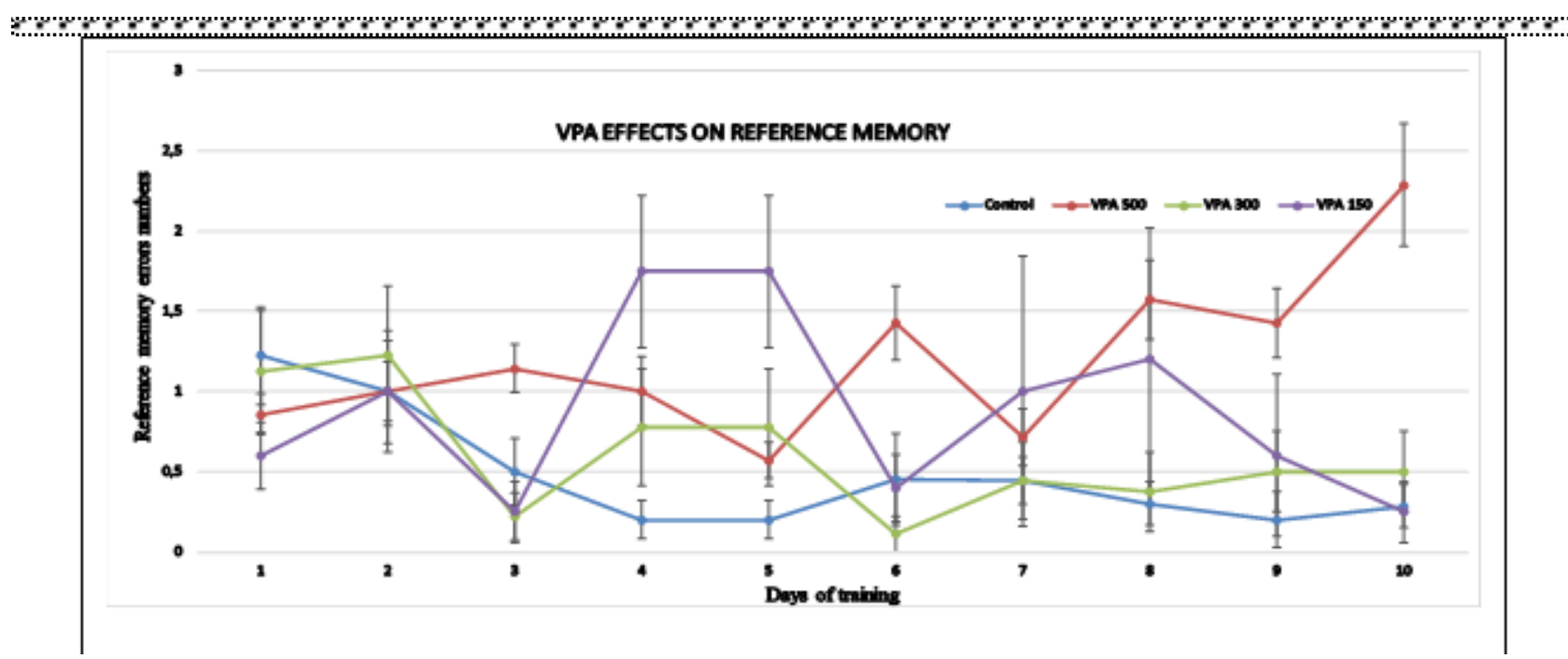

Figure 4: Valproic acid effect on rat reference memories

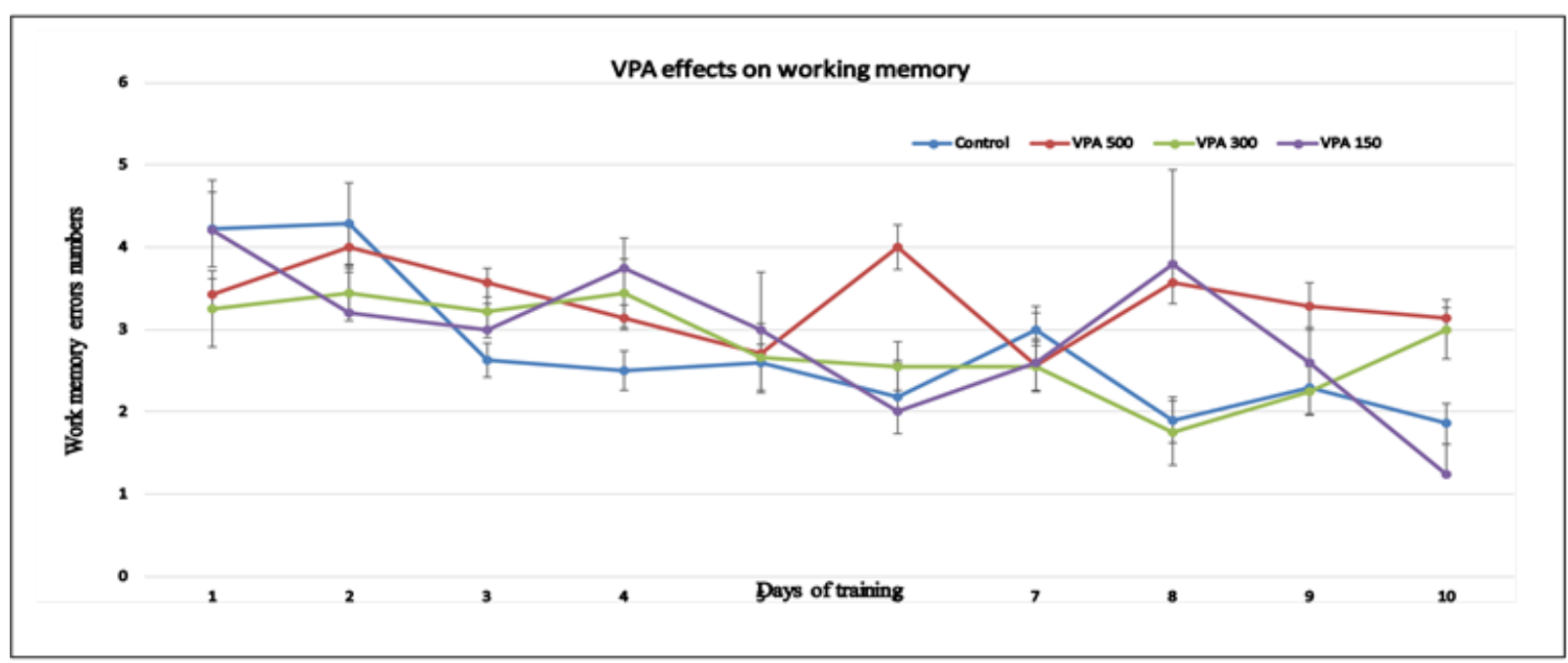

Figure 5: Valproic acid effect on rat working memories

\subsubsection{Reference and work memories disturbances in radial-maze}

Compared to the control group, valproic acid $150 \mathrm{mg} / \mathrm{kg}$ has no impact on rats working and reference memories. In contrast, valproic acid 300 and $500 \mathrm{mg} / \mathrm{kg}$ of body weight showed a negative effect on working and reference memories of rats (Figure 4 and 5).

This deficiency of working memory in people living with ASD is very well proven (24)(25). Based on the results obtained, valproic acid doses of 300 and $500 \mathrm{mg} / \mathrm{kg}$ body weight were more effective in the production process of rats with ASD.

\section{DISCUSSION}

Previous phytochemical studies on one specie plant from Salvia spp genus have shown that
Salvia divinorum principal chemical compound was Salvinorin A, a psychoactive diterpene. Also, others compound have been identified with even lower contents in the leaves of this plant; salvinorin $\mathrm{B}$, salvinorin $C$, salvinorin $D$, salvinorin $E$, salvinorin $F$, divinatorin $\mathrm{A}$, divinatorin $\mathrm{B}$, divinatorin $\mathrm{C}$, Presqualene alcohol, (E)-phytol and ( \pm ) hardwickiic acid (26) (27) (28); (29).

Phytochemical studies on essential oil from Salvia spp. have contributed to isolate and identify many compounds (Monoterpene hydrocarbons, Oxygenated monoterpenes, Sesquiterpene hydrocarbons, Oxygenated sesquiterpenes) and the majority of which are: Benzene, 1,3-bis(m-pheoxypheoxy), $\alpha$-pinene, camphene, $\quad \beta$-pinene, 1,8-cineole, $\beta$ caryophyllene, calarene, $\alpha$-eudesmol, $\quad \beta$ selinene and valeranone (30). Many of these 
.

compounds, like Salvinorin A, alpha pineme, camphene... have an effect on the nervous system (31) (32).

In fact, valproic acid is an inhibitor of GABA transaminase, an enzyme that catabolizes GABA (4-aminobutanoate (GABA) + 2oxoglutarate $\rightleftharpoons$ succinate semialdehyde $+\mathrm{L}-$ glutamate). Indeed the $\gamma$-aminobutyric acid (GABA) is the major inhibitory neurotransmitter in the central nervous system of mammals and birds. Its inhibiting effect is balanced by the exciting role of glutamate in nervous system. The imbalance between the GABA and glutamate is causing some neurological disorders including epilepsy. In addition, the submission a female during early pregnancy to valproic acid is likely to lead fetuses with malformations in the neural tube, with cognitive deficit, but also autism (33) (34) (35).

Previous studies have shown that subjects with autism had some working memory deficits but not on short- and long-term memories or on new learning process. Also, cerebral areas rich in GABA receptor (e.g., amygdala, septum, hippocampus, entorhinal cortex) lesion poses an acquisition and consolidation problem during the memory process (36) (37) (38).

Our present study showed that the essential oil from Salvia spp. significantly enhances the adverse impact of VPA on short-term memory. The Salvia spp. essential oil would have molecules that would prevent valproic acid from inhibiting GABA transaminase by a complexing reaction with valproic acid or by facilitating the activity of GABA transaminase. However, Bahr Group (2019) (39) studies on the psychoactive power of essential oils have shown that they have effects on major neurotransmitters involved in neuropsychiatric disorders production.

It is well documented that oxidative stress negatively influences neuropsychiatric disorders; the beneficial effect of salvia species in neuropsychiatric disorders is enhanced with antioxidant potential of these plants extracts (40).
In addition, all these data could also have a metabolic relevance. It is well documented that metabolic dysfunction addition to the genetic and environmental causes have assigned to ASD. It is known also, there is a mitochondrial dysfunction in this disorder. Indeed, mitochondria play a crucial role in the energy production process in the body and especially that the brain consumes nearly $20 \%$ of the body's energy for a mass of about $2 \%$ of total body weight. This contribution makes mitochondria a particularly important organelle in the central nervous system. Previous studies have shown that one-third of children with ASD had some of their metabolic parameters (lactate and/or the lactate-to-pyruvate, pyruvate, carnitine, and ubiquinone) higher than the standards (41) (42). In addition, epilepsy is often associated with ASD with disruption of several blood mediators such as the nervous system mediators (creatine, cholesterol, pyridoxine, biotin, carnitine, $\gamma$-aminobutyric acid, purine, pyrimidine, and amino acid metabolism and urea cycle) (43). Further on, it will be up to us to determine these parameters in rats with TSA treated with Salvia spp. essential oil compared to normal controls.

The number of rats treated with Salvia Spp. essential oil entries into A, B and C arms of the Y-maze showed that this oil improved energy production in these rats with ASD. Also, the components of Salvia spp. essential oil have acted like omega-3 fatty acids by improving the cognitive function of rats with ASD (44).

Also plant extract could reduce some metabolic deficiencies, as it was shown before in the case of metabolic syndrome (hypertension, hyperglycemia/insulin resistance, excess abdominal fat and dyslipidemia) that these following plants (Cinnamomum cassia, Cinnamomum verum, Artemisia dracunculus, Momordica charantia, Trigonella foenum-graecum, Vaccinium angustifolium, Vitis vinifera, Crataegus laevigata, Crataegus monogyna, Crataegus curvisepala, Crataegus tanacetifolia and Hoodia gordonii) are used differently to treat associated diseases (45); of 


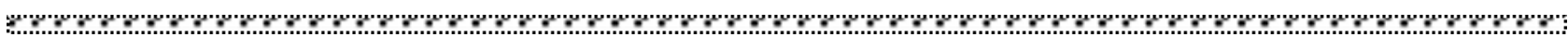

Diabetes of which several plants (Acacia arabica, Achyranthes aspera, Acosmium panamense, Aegle marmelose, Allium sativum, Allium sativum, Andrographis paniculate, Annona squamosa, Argyreia nervosa, Artemisia herba, Averrhova bilimbi, Azadirachta indica, Barleria prionitis, Biophytum sensitivum, Brassica nigra, Bryonia alba, Caesalpinia bonducella, Cajanus cajan, Carum carvi, Casearia sculenta, Chamaemelum nobile, Cichorium intybus, Citrulus colocynthis, Coriandrum sativum, Dorema aucheri, Eclipta Alba, Fraxinus excersior, Helicteres isora, Hypoxis hemerocallidea, Lepidium sativum, Mangifera indica, Myrcia bella, Nigella sativa, Ocimum sanctum, Origanium vulgare, Phyllanthus amarus, Prangos ferulacea (L.) lindl, Rhus coriaria, Salacia reticulate, Securinegra virosa) are used for its treatment (46); and obesity, whose apple polyphenols significantly reduce the risk of its installation (47).
All these therapeutic capacities of these plants prove once again that these medicinal plants remain a considerable hope of molecules with neuropsychiatric activity research.

\section{Conclusion}

Salvia spp. essential oil was used to assess its ability to improve the learning memory of the autistic rat. Rats with ASD were obtained by injecting three test doses of valproic acid into pregnant rats. Two doses of this GABA transaminase inhibitor were more effective. Also, two doses of Salvia spp. essential oil were used for our tests. These two doses of essential oil significantly improved the rat's short-term memory and corrected the rat's learning memory.

This study once again showed that Salvia plant extracts have shown in vivo pharmacological properties and have proven the merits of various traditional uses of these plants.

\section{ACKNOWLEDGEMENTS AND DISCLOSURES}

The authors like to thank Prof. L.H. from Cuza University for kindly providing the Salvia sp. extract. The authors are stating that there is no conflict of interest to disclose, except for Radu Lefter which is supported by a Young Teams grant offered by UEFISCDI Romania, no. PN-III-P11.1-TE-2016- 1210, contract no. 58 from 02/05/2018.

\section{REFERENCES}

1. Howlin P, Moss P. Adults with autism spectrum disorders [Internet]. Vol. 57, Canadian Journal of Psychiatry. 2012 [cited 2019 Oct 21]. p. 275-83. Available from: www.TheCJP.ca

2. Sparks BF, Friedman SD, Shaw DW, Aylward EH, Echelard D, Artru AA, et al. Brain structural abnormalities in young children with autism spectrum disorder. Neurology. 2002 Jul 23;59(2):184-92.

3. Brieber S, Neufang S, Bruning N, Kamp-Becker I, Remschmidt H, Herpertz-Dahlmann B, et al. Structural brain abnormalities in adolescents with autism spectrum disorder and patients with attention deficit/hyperactivity disorder. $\mathbf{J}$ Child Psychol Psychiatry Allied Discip. 2007 Dec;48(12):1251-8.

4. Kim JJ, Diamond DM. The stressed hippocampus, synaptic plasticity and lost memories. Nat Rev Neurosci [Internet]. 2002 [cited 2019 Oct 23];3(6):453-62. Available from: http://web.b.ebscohost.com/ehost/pdfviewer/pdfviewer?vid=0\&sid=ac1d41bb-5056-4a6f-90be-d1daa4aaad96\%40pdcv-sessmgr04

5. Peigneux P, Laureys S, Fuchs S, Collette F, Perrin F, Reggers J, et al. Are spatial memories strengthened in the human hippocampus during slow wave sleep? Neuron [Internet]. 2004 Oct 28 [cited 2019 Oct 23];44(3):535-45. Available from: https://www.sciencedirect.com/science/article/pii/S0896627304006452

6. Richardson MP, Strange BA, Dolan RJ. Encoding of emotional memories depends on amygdala and hippocampus and their interactions. Nat Neurosci. 2004 Mar;7(3):278-85.

7. Rubin RD, Watson PD, Duff MC, Cohen NJ. The role of the hippocampus in flexible cognition and social behavior. Vol. 8, Frontiers in Human Neuroscience. Frontiers Media S. A.; 2014. 
(1) 8. Girardeau G, Zugaro M. Hippocampal ripples and memory consolidation [Internet]. Vol. 21, Current Opinion in Neurobiology. Elsevier Current Trends; 2011 [cited 2019 Oct 23]. p. 452-9. Available from: https://www.sciencedirect.com/science/article/pii/S0959438811000316

9. Malow B, Adkins KW, McGrew SG, Wang L, Goldman SE, Fawkes D, et al. Melatonin for sleep in children with autism: A controlled trial examining dose, tolerability, and outcomes. J Autism Dev Disord. 2012;42(8):1729-37.

10. Dadds MR, MacDonald E, Cauchi A, Williams K, Levy F, Brennan J. Nasal oxytocin for social deficits in childhood autism: A randomized controlled trial. J Autism Dev Disord. 2014 Mar;44(3):521-31.

11. Hirota T, Veenstra-Vanderweele J, Hollander E, Kishi T. Antiepileptic medications in autism spectrum disorder: A systematic review and meta-analysis. Vol. 44, Journal of Autism and Developmental Disorders. Springer New York LLC; 2014. p. 948-57.

12. Yatawara CJ, Einfeld SL, Hickie IB, Davenport TA, Guastella AJ. The effect of oxytocin nasal spray on social interaction deficits observed in young children with autism: A randomized clinical crossover trial. Mol Psychiatry. 2016 Sep 1;21(9):1225-31.

13. Christensen J, Grnøborg TK, Srøensen MJ, Schendel D, Parner ET, Pedersen LH, et al. Prenatal valproate exposure and risk of autism spectrum disorders and childhood autism. JAMA - J Am Med Assoc. 2013 Apr 24;309(16):1696-703.

14. Lefter R, Cojocaru D, Ciobica A, Paulet IM, Serban IL, Anton E. Aspects of animal models for major neuropsychiatric disorders. Arch Biol Sci. 2014;66(3):1105-15.

15. Al-Amin MM, Rahman MM, Khan FR, Zaman F, Mahmud Reza H. Astaxanthin improves behavioral disorder and oxidative stress in prenatal valproic acid-induced mice model of autism. Behav Brain Res [Internet]. 2015 Jun 1 [cited 2019 Oct 23];286:112-21. Available from: https://www.sciencedirect.com/science/article/pii/S0166432815001205

16. Guenné S, Ouattara N, Meda N-TR, Kinda PT, Ouédraogo N, Ciobica A, et al. Relevance of Chrysanthellum americanum (L.) Vatke Extracts in Rat Liver Protection. Int J Biochem Res Rev. 2019 Mar 7;1-10.

17. Orhan I, Kartal M, Naz Q, Ejaz A, Yilmaz G, Kan Y, et al. Antioxidant and anticholinesterase evaluation of selected Turkish Salvia species. Food Chem [Internet]. 2007 Jan 1 [cited 2019 Nov 6];103(4):1247-54. Available from: https://www.sciencedirect.com/science/article/pii/S0308814606008168

18. Ahern NR, Greenberg CS. Psychoactive herb use and youth: A closer look at salvia divinorum. J Psychosoc Nurs Ment Health Serv. 2011;49(8):16-9.

19. Imanshahidi M, Hosseinzadeh H. The pharmacological effects of Salvia species on the central nervous system. Vol. 20, Phytotherapy Research. 2006. p. 427-37.

20. Lopresti AL. Salvia (Sage): A Review of its Potential Cognitive-Enhancing and Protective Effects. Vol. 17, Drugs in R and D. Springer International Publishing; 2017. p. 53-64.

21. Kaidanovich-Beilin O, Lipina T, Vukobradovic I, Roder J, Woodgett JR. Assessment of social interaction behaviors. Journal of Visualized Experiments. Journal of Visualized Experiments; 2010.

22. Bild W, Hritcu L, Stefanescu C, Ciobica A. Inhibition of central angiotensin II enhances memory function and reduces oxidative stress status in rat hippocampus. Prog Neuro-Psychopharmacology Biol Psychiatry [Internet]. 2013 $\begin{array}{lllllll}\text { Jun } & 3 & \text { [cited } & 2019 & \text { Nov } & 6 \text {; } 43: 79-88 . & \text { Available }\end{array}$ https://www.sciencedirect.com/science/article/pii/S027858461200320X

23. Mladin C, Ciobica A, Lefter R, Popescu A, Bild W. Deuterium-depleted water has stimulating effects on longterm memory in rats. Neurosci Lett [Internet]. 2014 Nov 7 [cited 2019 Nov 6];583:154-8. Available from: https://www.sciencedirect.com/science/article/pii/S0304394014007745

24. Russell J, Jarrold C, Henry L. Working memory in children with autism and with moderate learning difficulties. J Child Psychol Psychiatry Allied Discip. 1996;37(6):673-86.

25. Lind SE. Memory and the self in autism: A review and theoretical framework [Internet]. Vol. 14, Autism. 2010 [cited 2019 Oct 29]. p. 430-56. Available from: http://www.sagepub.co.uk/journalspermissions.nav

26. Bigham AK, Munro TA, Rizzacasa MA, Robins-Browne RM. Divinatorins A-C, new neoclerodane diterpenoids from the controlled sage Salvia divinorum. J Nat Prod. 2003 Sep 1;66(9):1242-4.

27. Siebert DJ. Localization of salvinorin A and related compounds in glandular trichomes of the psychoactive sage, Salvia divinorum. Ann Bot. 2004;93(6):763-71.

28. Harding WW, Tidgewell K, Schmidt M, Shah K, Dersch CM, Snyder J, et al. Salvinicins A and B, new neoclerodane diterpenes from Salvia divinorum. Org Lett. 2005 Jul 7;7(14):3017-20.

29. Bertea CM, Luciano P, Bossi S, Leoni F, Baiocchi C, Medana C, et al. PCR and PCR-RFLP of the 5S-rRNA-NTS region and salvinorin $\mathrm{A}$ analyses for the rapid and unequivocal determination of Salvia divinorum. Phytochemistry [Internet]. $2006 \quad$ Feb 1 [cited 2019 Oct 30];67(4):371-8. Available from: https://www.sciencedirect.com/science/article/pii/S0031942205006771

30. Sharifi-Rad M, Ozcelik B, Altın G, Daşkaya-Dikmen C, Martorell M, Ramírez-Alarcón K, et al. Salvia spp. plants-from farm to food applications and phytopharmacotherapy [Internet]. Vol. 80, Trends in Food Science and Technology. Elsevier; 2018 [cited 2019 Nov 4]. p. 242-63. Available from: https://www.sciencedirect.com/science/article/pii/S0924224418301158

31. Hamidpour M, Hamidpour R, Hamidpour S, Shahlari M. Chemistry, pharmacology, and medicinal property of sage (salvia) to prevent and cure illnesses such as obesity, diabetes, depression, dementia, lupus, autism, heart disease, 
2. and cancer. J Tradit Complement Med [Internet]. 2014 Apr 1 [cited 2019 Oct 30];4(2):82-8. Available from: https://www.sciencedirect.com/science/article/pii/S2225411016302206

32. Aduma K. Role of Alpha-Pinene in the Development of Autism Spectrum Disorders. South Carolina Jr Acad Sci [Internet]. 2018 Apr 14 [cited 2019 Oct 30]; Available from: https://scholarexchange.furman.edu/scjas/2018/all/77

33. Herman JP, Mueller NK, Figueiredo H. Role of GABA and glutamate circuitry in hypothalamo-pituitaryadrenocortical stress integration. In: Annals of the New York Academy of Sciences. New York Academy of Sciences; 2004. p. 35-45.

34. Meador KJ, Baker GA, Browning N, Clayton-Smith J, Combs-Cantrell DT, Cohen M, et al. Cognitive function at 3 years of age after fetal exposure to antiepileptic drugs. N Engl J Med. 2009;360(16):1597-605.

35. Jentink J, Loane MA, Dolk H, Barisic I, Garne E, Morris JK, et al. Valproic acid monotherapy in pregnancy and major congenital malformations. N Engl J Med. 2010;362(23):2185-93.

36. Hughes C, Russell J, Robbins TW. Evidence for executive dysfunction in autism. Neuropsychologia [Internet]. 1994 Apr 1 [cited 2019 Oct 30];32(4):477-92. Available from: https://www.sciencedirect.com/science/article/pii/0028393294900922

37. Kalueff A, Nutt DJ. Role of GABA in memory and anxiety. Vol. 4, Depression and Anxiety. 1996. p. $100-10$.

38. Bennetto L, Pennington BF, Rogers SJ. Intact and Impaired Memory Functions in Autism. Child Dev. 1996;67(4):1816-35.

39. Bahr TA, Rodriguez D, Beaumont C, Allred K. The effects of various essential oils on epilepsy and acute seizure: A systematic review [Internet]. Vol. 2019, Evidence-based Complementary and Alternative Medicine. 2019 [cited 2019 Oct 30]. Available from: https://doi.org/10.1155/2019/6216745

40. Georgiev V, Pavlov A. Salvia biotechnology. Salvia Biotechnology. 2018. 1-427 p.

41. Raichle ME, Gusnard DA. Appraising the brain's energy budget. Vol. 99, Proceedings of the National Academy of Sciences of the United States of America. 2002. p. 10237-9.

42. Cheng N, Rho JM, Masino SA. Metabolic dysfunction underlying autism spectrum disorder and potential treatment approaches. Vol. 10, Frontiers in Molecular Neuroscience. Frontiers Research Foundation; 2017.

43. Frye RE. Metabolic and mitochondrial disorders associated with epilepsy in children with autism spectrum disorder [Internet]. Vol. 47, Epilepsy and Behavior. Academic Press; 2015 [cited 2019 Nov 7]. p. 147-57. Available from: https://www.sciencedirect.com/science/article/pii/S1525505014004120

44. Mierau SB, Neumeyer AM. Metabolic interventions in Autism Spectrum Disorder. Neurobiol Dis [Internet]. 2019 $\begin{array}{lllllll}\text { Dec } & 1 & \text { [cited } & 2019 & \text { Nov } & \text { 7];132:104544. } & \text { Available }\end{array}$ https://www.sciencedirect.com/science/article/pii/S0969996119302128

45. Graf BL, Raskin I, Cefalu WT, Ribnicky DM. Plant-derived therapeutics for the treatment of metabolic syndrome. Vol. 11, Current Opinion in Investigational Drugs. 2010. p. 1107-15.

46. Kooti W, Farokhipour M, Asadzadeh Z, Ashtary-Larky D, Asadi-Samani M. The role of medicinal plants in the treatment of diabetes: a systematic review. Electron physician. 2016 Jan 15;8(1):1832-42.

47. Boqué N, Campión J, de la Iglesia R, de la Garza AL, Milagro FI, San Román B, et al. Screening of polyphenolic plant extracts for anti-obesity properties in Wistar rats. J Sci Food Agric. 2013 Mar 30;93(5):1226-32.

\section{Correspondence}

Daniel Timofte,

MD, PhD, professor, “Grigore T.Popa” University of Medicine and Pharmacy, 16, Universitatii Street, 700115, Iasi, Romania, dantimofte@ yahoo.com

Submission: 10 oct 2019

Acceptance: 28 nov 2019 



\title{
Mini - review on the psychiatric comorbidities in epilepsy - possible relevance for some metabolic changes?
}

\author{
Raluca Elena Duță, Cristina Elena Nedelcu, \\ Alin Ciobîcă, Daniel Timofte
}

Raluca Elena Duță - master student, Department of Research, Faculty of Biology, Alexandru Ioan Cuza University, B dul Carol I, no 11, Iasi, Romania

Cristina Elena Nedelcu - clinician psycholog, psychotherapist, Socola Institute of Psychiatry Iaşi, Romania

Alin Ciobîcă - researcher, Department of Research, Faculty of Biology, Alexandru Ioan Cuza University, B dul Carol I, no 11, Iasi, Romania Academy of Romanian Scientists, Splaiul Independentei nr. 54, sector 5, 050094 București, Romania,Center of Biomedical Research, Romanian Academy, Iași, B-dul Carol I, no 8, Romania

Daniel Timofte - MD, PhD, professor, "Grigore T.Popa" University of Medicine and Pharmacy, 16, Universitatii Street, 700115, Iasi, Romania

\begin{abstract}
Epilepsy is one of the most important neurological disorders nowadays, with a variety of studies describing its mechanisms and complex pathophysiology. However, lately there is also an increased interest in understanding the psychiatric comorbities associated with the epileptic pathology. Thus, we will describe here aspects such as the importance of anxiety, depression, personality disorders, the suicidal ideation in epilepsy, as well as the correlations that might exist between the specific treatment for epilepsy and its psychiatric-related effects. In conclusion, it seems that the associated psychiatric manifestations from epilepsy have an increased important in the pathophysiology of this disorder and deserve further investigation.
\end{abstract}

\section{KEYWORDS:}

Psychiatric comorbidities, epilepsy, metabolic

\section{INTRODUCTION}

Epilepsy is one of the most common and disabling (1) serious neurological disorders and affects approximately 50 million people of all ages worldwide, sex and socioeconomic status. Among these individuals, about $80 \%$ of them live in countries that have small or medium gross domestic product. Most often 


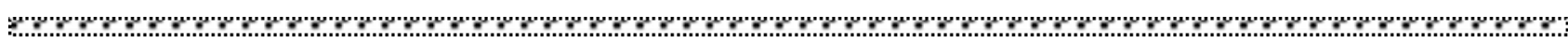
people suffering from this disease and their families have frequent stigma and discrimination problems. EEG-fMRI tests have shown that cognitive networks can be coactivated during epileptiform discharges, thus altering their function and connectivity ovr time $(2,3,4)$.

An epileptic seizure is a transient onset where there is no abnormal signs and/or abnormal symptoms of excessive or synchronous neuronal activity in the brain (5). Crises can be divided into several types and depending on the region: focal - with the origin in the limited network of a sphere of the brain, or they can be generalized by their appearance within and rapidly involving these networks in the two hemispheres $(6,7)$.

Hermann and his colleagues argued in 1986 that the variables that contribute to the psycho-pathological development are divided into three main groups: the clinical factors associated with the natural history of epilepsy, the age at which the disease began, the duration of the seizure and its type, the etiology and seizure control. Medication factors including AED, dose and quantity of active substance, respectively psychosocial factors including astigmatism, perceived discrimination, social and socio-economic support are also important in this context (6). Psychiatric comorbidity has begun to be increasingly studied, although its heuristic value has long been recognized. There is no definition to be used in a uniform manner, comorbidity can be defined as the presence of one or more additional conditions that appear together with another condition that is primary (8). The full exploitation of the mechanisms requires an interdisciplinary approach to the investigation of the topology, the evaluation and the underlying comorbidity methods, as well as certain clinical and epidemiological experimental studies. This more precise specification of the patterns could help to identify the usual biochemical, cognitive markers relevant in the etiology of specific mental disorders, residing in comorbid conditions (9). Epilepsy is a phenomenon as a model in the history of neurology intersected with psychiatry, studying the cognitive, affective interests and behaviour of patients (10).

A model of progression of the symptoms of comorbidity associated with panic disorders is realized from the precursor conditions such as: biological or cognitive vulnerability, anxiety syndrome, situational risk factors in the patient's daily life, followed by the 6 phases: the onset of spontaneous seizures. Panic, and sensibilities disorders, panic, and syndrome agoraphobia, depress major demoralization last phase being dependent behaviour. For most people who are epileptic or their families, the thoughts of this disease, but also what the seizures represent, are caused or can cause comorbid conditions, including behavioural disorders, depression or anxiety, which can lead to suicide (1).

The most common psychological comorbidities are depression and anxiety that are common in patients with epilepsy, being called comorbid disorders. 25-50 \% of epileptic cases present with depression, anxiety, psychotic disorders, cognitive and sonorous per modifications that occur in interictal, ictal or postictal states (8). In certain Neuroscience institutions (Epilepsy Canter of the Institute of Neuroscience, University of Cincinnati), all patients with epilepsy are routinely analyzed and observed if they have depression or anxiety, using the Neurological Depression Inventory for Epilepsy (NDDI-E) Generalized Anxiety 7 (GAD-7), being recommended to make this knowledge of behaviour both in children and adults. 
A good understanding between comorbidity and epilepsy is essential for more pronounced recognition and more effective treatment, but also for informing clinicians about the needs of epileptics. This can be defined by improving the care of these people with epilepsy, together with the observed associations they can help to understand the common mechanisms underlying the link between epilepsy and the specific forms of psychopathology (11). The reported prevalence of comorbid psychopathology in epilepsy varied greatly during the studies and reflected methodological limitations such as possible selection due to the recruitment of epilepsy cases from unrepresentative clinical populations or measurement due to the lack of diagnostic assessment tools to determine psychopathology $(12,13,14,15,16)$.

Apart from this problem being the link between comorbidity and epilepsy, there are also problems such as socio-economic disadvantages and other health problems of people with epilepsy $(17,18)$ that can lead to depression disorders, anxiety and depressive symptoms. Therefore, it is not known to what extent epilepsy may be associated with an increased risk of psychopathology, besides the effect of having a chronic medical or neurological condition (11).

\section{PSYCHIATRIC COMORBIDITIES IN EPILEPSY}

Psychiatric disorders are commonly seen in people with epilepsy and these can negatively influence the course of this condition and lead to an unfavourable response to treatment that contributes to poor quality of life and increased mortality $(17,18)$. However, psychopathology is often unrecognized and untreated in these persons and many questions remain about both the appearances and the nature of the relationships between epilepsy and specific psychiatric conditions (11).
One of the most complex studies on this matter was performed by Rai and his collaborators on psychiatric morbidity for adults that included 7403 detailed interviews with people in England. The epilepsy that was diagnosed by the physician was verified by self-report and extensive interviews were used for diagnosis and screening and this was how psychiatric disorders and neurodevelopmental were evaluated. About one third of the people interviewed with epilepsy met the criteria for ICD-10 diagnosis, which consists of anxiety or depressive disorder, compared with about 1 in 6 people who do not have epilepsy. Individuals with epilepsy at the interview had significant chances of having social phobias, agoraphobia, generalized anxiety disorder, depression, and suicide measures, these were stronger than in patients suffering from another disease (ex: asthma, diabetes). Epileptics have been diagnosed with a higher chance of having an autism spectrum disorder and an increased likelihood of being positive for eating disorders, as compared with people without epilepsy (11).

Psychiatric conditions in patients with epilepsy may also exhibit characteristics that are inconsistent with those commonly seen in different forms of the disorder. These comorbidities may have an increased risk of not being terminated or misleading in cohort studies. However, administrative and electronic health documents are an alternative to potential cohort studies, with validated case definitions, but are missing for many of the psychiatric contracts while psychiatric illness is frequently undetermined and often wrong $(19,20)$. There are patients who suffer from uncontrolled epilepsy, and they may also suffer from excessive or anxiety related to fear of adding to national seizures, loss of work or driving ability, socio-economic depressive status or other psycho protective effects of drugs. The difference between the 
к emotional responses and the predisposition to depressive disorders, being relevant by psychiatric diseases must appear due to the isolation of the biological mechanisms that can underlie both diseases (epilepsy, respectively psychiatric comorbidity) (20).

Cognitive disorders were basic features for unipolar depression, further forming an important criterion for diagnosis (21). This cognitive fear takes on many forms such as reminiscence, lower concentration, difficulties in identifying emotions, prejudices, and a vague reminder of autobiography (22).

\section{DEPRESSION AND EPILEPSY}

Depression is considered the most common psychiatric disorder in people with epilepsy with partial seizures of temporal origin or frontal lobe or in patients with seizures that are not sufficiently controlled $(23,24,25,26)$. The most common symptoms include feelings of archegonia, guilt, but also suicidal ideation. These mood changes are short, stereotypical and appear out of context and appear to be associated with other ictal phenomena (20).

There is in vivo evidence to suggest that patients with depression and epilepsy exhibit neurocognitive network dysfunctions beyond what is seen only in epilepsy (27), being expressed by the potential indicated by the network nodes involved in the priming of pathophysiology of depression in epilepsy (2). However, there is also behavioural evidence that has been made with the help of neuroimaging data, suggesting that the cognitive deficiency that can identify network dysfunctions, if any, with cognitive or psychological affections (28). Functional neuroimaging could indicate that several symptoms of depression may be pathologically associated with two cognitive networks of the brain: the autobiographical memory network (AMN) and the cognitive control network (CNN) (Table no. 1). If the two networks intersect then the AMN is activated when the patient is concerned with introspection and thus the $\mathrm{CCN}$ is inhibited (29)

Depressive mood disorders have an active prevalence and are encountered in $23.1 \%$ of people with epilepsy, the hypotheses of its pathology and the associated factors are: bidirectional relationships (30). Previous studies have shown a national bidirectionality between the 2 disorders as incidence networks being reported with a significant increase for depression before and after diagnosing epilepsy (31).

\begin{tabular}{|l|l|l|}
\hline Networks & Characteristics & Reference \\
\hline AMN & $\begin{array}{l}\text { Self-referential processing, episodic memory, renewal and introspection are } \\
\text { accepted. It includes orbitomesial prefrontal cortex (PFC), rostral anterior } \\
\text { cingulate cortex, hippocampus, posterior cingulate, retrosplenial cortex, } \\
\text { precuneus, and parietal regions important for mental imagery. }\end{array}$ & 2,29 \\
\hline CCN & $\begin{array}{l}\text { Working memory processing, attention and flexible switching between } \\
\text { cognitive sets, dorsolateral recruitment of the PFC and the anterior dorsal } \\
\text { cingulate cortex, with auxiliary nodes in the mesial temporal lobe and } \\
\text { intraparietal sulcus are activated. }\end{array}$ & 2,30 \\
\hline
\end{tabular}

\begin{tabular}{|l|l|l|}
\hline Networks & Characteristics & Reference \\
\hline AMN & $\begin{array}{l}\text { Self-referential processing, episodic memory, renewal and introspection are } \\
\text { accepted. It includes orbitomesial prefrontal cortex (PFC), rostral anterior } \\
\text { cingulate cortex, hippocampus, posterior cingulate, retrosplenial cortex, } \\
\text { precuneus, and parietal regions important for mental imagery. }\end{array}$ & 2,29 \\
\hline
\end{tabular}


Bulletin of Integrative Psychiatry $\bigcirc$ New Series $\bigcirc$ December 2019 ○ Year XXV ONo. 4 (83)/33

\begin{tabular}{|l|l|l|}
\hline \multirow{2}{*}{ CCN } & $\begin{array}{l}\text { Working memory processing, attention and flexible switching between } \\
\text { cognitive sets, dorsolateral recruitment of the PFC and the anterior dorsal } \\
\text { cingulate cortex, with auxiliary nodes in the mesial temporal lobe and } \\
\text { intraparietal sulcus are activated. }\end{array}$ & 2,30 \\
\hline
\end{tabular}

Table I. Characteristics of the two cognitive networks of the brain

\section{DEPRESSION PRE-SEIZURE, SEIZURE AND POSTICTAL}

Depress preictal or prodromal symptoms include depressed mood related panic. It may take from several hours to several days (20). Named and ictal rectal depression is a rare condition with simple expression which is presented by a single partial seizure with episodic dysphoria. Even so, the true prevalence of ictal depression is not yet stable in other studies. These are followed by a change in consciousness as the stroke evolves from a partial evolution to a complex one (20).

Interictal most frequent presentation of depression disorders in patients with epilepsy, being considered as a primary psychiatric disorder (20). Symptoms of depression and its episodes are presented as dysmorphic mood prodromes, can be prolonged on a semi-long term from one day to 3 days before the onset of a seizure, especially by 24 hours . In children, these symptoms are presented by irritability, poor tolerance to frustration and aggressive behavior. (32). Kanner and his colleagues investigated 100 patients with refractory epilepsy, the prevalence rate and clinical features of PS and postictal for three months. The results showed that 43 of the patients regularly experienced a median of about 5 postictal symptoms with an average duration of 24 hours, 25 patients with a history of mood disorders, respectively 11 with anxiety disorders. Postictal depression is for a limited time, with treatment focusing on improved seizure control (33).
Studies published in epilepsy have also listed the following pathogenic mechanisms shared by depression: abnormal activation of the central nervous system (CNS), which has multi neurotransmitters, especially serotonin, neropinefrine, dopamine, GABA and glutamate. There are also structural changes, presenting as atrophic of the temporal and structures with those of the frontal lobe (identified by MRI resolution and volumetric measurement) being found in the amygdaly, hippocampus, entorhinal cortex, temporal, prefrontal and orbital and mesial-frontal lateral neocortex, respectively -a smaller extent in the thalami nuclei and basal ganglia; functional anomalies being identified by positron emission, sion tomography (PET) and single computed tomographic photon emission (SPECT), but also in the frontal lobes, being the basis of the 5HT bond reduction in mesial structures, raphe nuclei, talamus and cingulated girus. In addition, other mechanisms with abnormal functions were found in the hypothalamus-pituitaryadrenal axis anxiety $(20,34)$. Anxiety is also associated with nervousness fear, apprehension and concern, in terms of frequency is the second comorbidity psych IATROS in epileptic patients (15-25\%) (23, $24,26,35,36)$. There it demonstrated that biological variability plays a vague create stress in patients experiencing epileptic seizures, so some researchers have pointed out that's concentration on psycho social predictors variables is leading to anxiety (37, 38). The various forms of anxiety disorders are: generalized anxiety disorder, panic, phobia, obsessive compulsive disorder and post-traumatic disorder. They can 

interactively present the same clinical symptoms autonomous such as tachycardia manifestations as those in the general diaphysis and dyspnea.

population, with neurological factors (TLE) associated with ictal fear (39).

In patients who could be treated with epileptic surgery, this treatment may increase the frequency of anxiety disorders, in some patients it is an onset disorder (40). In pediatric patients, the link between epilepsy and anxiety is harder to observe, the anxiety rate was found to be $16 \%$ in studies conducted by (41), whereas in patients over the age. There are also cross-sectional studies that have shown that the use of primidone, the presence of depression, and a cryptogenic or etiological post-trauma were important predictors for the development of anxiety symptoms (42). Following the research conducted so far, it has been found that there are no specific screening tools for identifying anxiety in patients suffering from epilepsy, but there are some tools that are commonly used in adult patients: the State-Trait Anxiety Scale (STAI). Goldberg depression and anxiety scale, hospital anxiety and depression scale (HADS), Beck's anxiety inventory (BAI), Hamilton anxiety assessment scale (HAM-A or HARS), symptom checklist (SCL-90 -R) and GAD-7 (43).

\section{INTERICTAL ANXIETY AND PHYSIOPATHOLOGY}

Interictal panic consists of episodes lasting between 5 and 20 minutes that can last up to several hours. Feelings of apprehension or anxiety disorder generals (GAD), obsessive compulsive disorder (OCD), post traumatic stress disorder (PTSD), panic disorder (PD) is very intense and is associate with a variety of

In addition, in some patients, the intensity of fear may be so wide that they cannot figure out what is going on around them, without confusion or loss of consciousness, as seen in complex partial seizures. Some patients could also develop agoraphobia due to the fear of experiencing a panic attack in the public (24). In a study on anxiety in patients suffering from epilepsy, a 43-fold increase in agoraphobic anxiety was reported in people without epilepsy, it was considered that this phobia occurs in these patients because of fear of having congestion outside housing (44, 45).

Anxiety disorders are prevalent in life, being evaluated in $22.8 \%$ of the people suffering from epilepsy, having psychotic hypotheses and associated factors such as: tonsil atrophy, GABA-allergic mechanisms, stigma, respectively the impossibility of confiscation (20). There are also studies performed on patients between the ages of 7 and 18 years, respectively the elderly who are experiencing anxiety and depression (Table no. II). In the adult people with epilepsy certain instruments are used to identify if they suffer from anxiety: the state anxiety scale -state (STAI); Goldberg depression and anxiety scale; Hospital Anxiety and Depression Scale (HADS), Beck's Anxiety Inventory (BAI), Hamilton Anxiety Assessment Scale (HAMAA or HARS), A Checklist of Symptoms SCL-90-R and GAD-7 (43).

\begin{tabular}{|l|l|l|}
\hline $\begin{array}{l}\text { Populations with } \\
\text { epilepsy }\end{array}$ & Remarks & Reference \\
\hline $\begin{array}{l}\text { Children and } \\
\text { adolescents }\end{array}$ & $\begin{array}{l}\text { In a study of 44 patients aged between 7 and 18 years, it was } \\
\text { found that there is an anxiety rate of about 26\%. }\end{array}$ & 41 \\
\hline
\end{tabular}


Bulletin of Integrative Psychiatry $\bigcirc$ New Series $\bigcirc$ December $2019 \bigcirc$ Year XXV ONo. 4 (83)/35

\begin{tabular}{|c|c|c|}
\hline & $\begin{array}{l}\text { Another study was conducted on } 35 \text { children and adolescents } \\
\text { between the ages of } 9 \text { and } 18 \text { years. In the group of patients } \\
\text { between the ages of } 9-11 \text { years, there was a significantly higher } \\
\text { trait anxiety, respectively, in the patients between the ages of } 12 \\
\text { and } 18 \text { years, there was a higher anxiety and condition anxiety, } \\
\text { these results were compared with the healthy population. }\end{array}$ & 46 \\
\hline Elderly & $\begin{array}{l}\text { Anxiety disorders in the elderly with epilepsy are difficult to } \\
\text { determine, as little data is known. Many medical conditions are } \\
\text { accompanied by somatic symptoms of anxiety, Certain } \\
\text { medicines used by them such as: steroids, thyroid hormones, } \\
\text { anticholinergic drugs and some antidepressants, can cause } \\
\text { matrix and mental symptoms of anxiety. }\end{array}$ & 36 \\
\hline
\end{tabular}

Table II. Studies performed on populations of patients with epilepsy on anxiety disorders

PREICTAL, ICTAL AND POSTICTAL ANXIETY

Preictal anxiety is defined by the previous symptoms of onset of a crisis, being performed in a period of time from several hours to several days. These premorbid symptoms are stereotypic, helping to predict seizure, anxiety increasing in the days before seizure in patients with partial or complex seizures $(32,46,47)$.

Fear or ictal panic is considered the most common ictal symptom of anxiety of a simple or initial partial seizure of a complex partial seizure and is usually originated in the mesial temporal lobe, but may also exist in the mesial frontal origin. At simple partial seizures these things cannot be observed in certain graphs recorded by the EEG, in relation to the scalp angle the electrodes positioned at the midline and over the suprasilvian regions cannot allow for epileptiform discharges or ictal patterns. The needle ELAS way, scalp recordings are unlikely is to detect epileptiform activity from a simple partial seizure of temporal lobe origin messianic especially those in which the epileptogenic tonsil. At the same time, interictal recordings may fail to recode any interictal discharge, using antero-temporal electrode bases. Sphenoidal electrodes placed under the fluorescence orientation (48) should be used. Epileptic people with ictal panic can sometimes cause interictal panic attacks (36). Postictal anxiety may have relatively common symptoms in patients with partial refractory epilepsy. In a study published in 2004, this comorbidity was studied in 100 PWE patients and it was shown that these symptoms appeared after more than $50 \%$ of the seizures and lasted approximately 24 hours, 32 patients had generalized anxiety, 10 patients reported symptoms of compulsions, and 29 people had postictal symptoms with aspects of agoraphobia (33).

\section{PSYCHOSIS}

Psychotic disorders can be presented as schizophreniform disorders, not being distinguished from those of patients without epilepsy. However, patients with epilepsy and psychosis (POE) have certain characteristics that distinguish them from people who do not have epilepsy. In several studies conducted by Kanner and his collaborators in 1996 and 2004 respectively, the common results included the following: a delay between the onset of psychiatric symptoms and the time of the last seizures, relatively short duration, grouping of symptoms into delusional psychosis similar to vectile, increasing the frequency of generalized seizures secondary to the onset of postictal psychosis (PIP), the 


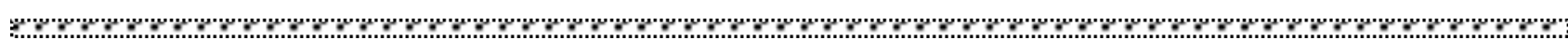

beginning of the PIP after they were confiscated for an average period of more than 10 years and a rapid response to low dose neuroleptic drugs or nezodiazepines (33, 48). In another 8-year study on patients with epilepsy and PIP, the death of 4 out of 14 patients was found, and in 3 patients, chronic psychosis developed (8).

In most cases, insomnia is an initially present symptom in people presenting with recurrent psychotic episodes. These have important localization implications, suggesting the presence of independent bilateral ictal foci. Ictal symptoms and episodes are taken into account each time in the divergence of PIP and POE diagnosis as a whole. Most of the times it is due to the epileptic non-convulsive states, but also the confirmation of the EEG analyzes are essential as a safe psychotic process, such as the catatonic states (lack of reaction) and the mannerisms (automatisms) (8).

\section{PERSONALITY DISORDERS}

The relationship between epilepsy and personality disorders (PD) is often not considered a scientific goal. People with epilepsy are often seen as unstable, introverted and anxious and avoided because of uncertainty. These characteristics correspond to the traits of the C PD cluster (35). In some patients with epilepsy, PD features were detected using a VKP questionnaire (49). These people may suffer from serious emotionality, very ethical as well as spiritual behavior (50), the tendency to be orderly, very detailed, persistent in communication and actions (51), respectively a labile condition with suggestive fathers and immaturity (52). These disorders are estimated to occur in about $4-38 \%$ of people with epilepsy, taking into account the study of heterogeneity (53).

\section{THE TEMPORAL LOBE}

The bidirectional relationship comes from a study of patients with corneal epilepsy of the temporal lobe (TLE), which reveals the progression of psychiatric comorbidity before and after the early control of the offering psychiatric history (54). Personality constructions are considered interactive in nature and are associated with temporal lobe epilepsy. However, there are still no criteria to be elaborated for this to be possible under conditions, and this condition remains controversial (8).

\section{OTHER ATYPICAL SYNDROMES}

Children suffering from epilepsy in combination with attention deficit hyperactivity disorder (ADHD) were asked to perform the same tests as children with only one of the two conditions, so memory types could be analyzed. There were no significant interactions between these conditions, which leads us to think that the three types of patients (children with epilepsy, children with ADHD and children with epilepsy and ADHD) are not significantly different (55).

\section{SUICIDE}

The suicide instinct is the result of one of the comorbid conditions previously presented in relation to epilepsy. In 2017, a study was conducted on the mortality of these patients compared to the global population. The mortality rate (SMR) by suicide in patients with epilepsy was higher (56) than the general population.

From the point of view of suicide attempts, respectively the completed suicide, there are significant differences in the percentage between the population with epilepsy (5$14,3 \%)$ and the general population (1-4,6\%). This standardized mortality ratio of patients with epilepsy appears in those who are institutionalized $(4.6 \%)$ and those with epilepsy in the temporal lobe $(6.6 \%)$, during 


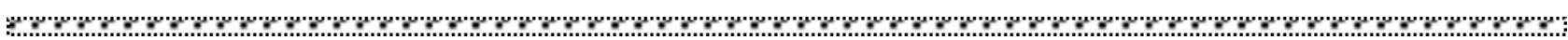

this time it was lower in epileptic persons with new onset (2.1) and those evaluated in tertiary care clinics $(2,3 \%)(20)$.

The suicide rate in patients with epilepsy (PWE) is between 9 and 25 times higher in patients who have seizures of the porous lobe compared to the total population. In the study carried out by Kanner in 2014, out of 100 patients diagnosed with epilepsy, in 13 patients the idea of post-stroke suicide was identified, among them, 10 had a history of major depression are bipolar disorders. Of the 43 patients with postictal depression, 27 of them had concomitant anxiety and 7 reported postictal psychotic symptoms (20).

The putative association between using AED and thinking about a suicide, or complete suicide, is significantly justified. In 2008, the Drug Administration also issued a campaign linking AEDs to suicide. This warning was justified by further analysis of survival and cursing studies conducted on observational cohorts with retrospectives in people with epilepsy, and suggests that the chances of suicidal behavior were 1.84 times higher, as the hazard reports ranged from 1.42 to 2.41 depending on the specific drug after the initiation of AED (20).

\section{PSYCHOTROPIC DRUGS}

Clinical evidence was obtained through questionnaires on human subjects who have epilepsy with different types of seizures, but also people who do not have this condition and have been cataloged as a control. In most cases, the Neurological Disorders Depression Inventory for Epilepsy (NDDI-E) has found that depression is significantly relative to an increased risk of non-adherence to AED drugs, a sense of hopelessness or loss of interest that leads to decreased motivation (57).
Before administering the first dose of antiepileptic drug (AD), it is important to determine if the seizures are associated with the onset or the stroke of an AED. Studies have shown that there is an increased incidence of seizures in people taking maprotiline, amoxepine, clomipramine or bupropion $(58,59)$.

There were cases of patients who were not diagnosed with epilepsy, but following the administration of antidepressant drugs they had the first seizure that was associated with high plasma serum concentrations, a rapid dose, the presence of other drugs with proconvulsive properties and the presence of central nervous system pathology (CNS), abnormal electroencephalon (EEG) and personal and family history of epilepsy (8).

Expression of the toxicity of AED drugs (in terms of frequency: phenobarbital, primidone, topiramate and levetiracetam AED) can be reported as a psychotic disorder. Antidepressants have been particularly controversial in epilepsy. However, it has been noted that the initial concerns were based on ventricular antidepressants (tricyclines and cyclic tetra-antidepressants) in individuals using high doses (60). There are antidepressants that are associated with an increased risk of seizures in epileptic therapy, such as: bupropion, clomipramine, amoxapine, maproline, but they also tend to be associated with increased risk when used at a high dosage level (61).

Treatment of epilepsy may have psychiatric adverse effects consistent with each generation (Table No. III). of agents at the psychological level (20). These psychiatric adverse effects of AEDs are imported because they can affect the etiology of the person. 


\begin{tabular}{|l|l|l|}
\hline Generations & Observation & Reference \\
\hline \multirow{2}{*}{$\begin{array}{l}\text { The first } \\
\text { generation }\end{array}$} & $\begin{array}{l}\text { Benzodiazepines (nitrazapam, clonazepam and cloazam) are associated } \\
\text { bith fatigue and mental retardation, which may induce mood and } \\
\text { Phenytoin causes mental retardation, in rare cases associated with } \\
\text { depression, anxiety and aggression. } \\
\text { Valproic acid is considered a mood stabilizer, but in high doses it can } \\
\text { have adverse effects on the cognitive. } \\
\text { Arbamazepine is considered a state of mind. }\end{array}$ & 62,63 \\
\hline \multirow{2}{*}{$\begin{array}{l}\text { The second } \\
\text { generation }\end{array}$} & $\begin{array}{l}\text { Levetiracetam indicates adverse effects such as behavioral abnormalities, } \\
\text { irritability, aggression and hallucinations. } \\
\text { Topira suggests that there is an irritation between the response and the } \\
\text { dose administered, between drug levels and actual disorders. } \\
\text { It has been proven that a person's mental stress is not related to drugs. }\end{array}$ & 20 \\
\hline
\end{tabular}

Table III. Antiepileptic drugs in both generations

METABOLIC RELEVANCE AND THE "METABOLIC EPILEPSY"

When it comes to the relations between epilepsy and metabolism, there are reports and extensive reviews in the literature on the so-called "Metabolic Epilepsy", which is defined by the Lee group in 2018 as "is a metabolic abnormality which is associated with an increased risk of epilepsy development in affected individuals" (64).

Even more important, as the above authors are describing, it seems that the commune drugs used for treating "normal" epilepsy, are not working in this case, since the mechanistics behind these two are quite different (64). It also seems that diet could be playing an important part in the management of this specific disorder (65).

In fact, in an extensive recent review no less than 14 main mecanistical causes were identified such as: biotinidase deficiency, cerebral folate deficiency, creatine-related disorders, disorders of the urea cycle, folinic acid-responsive seizures, glucose transporter type 1 deficiency syndrome, glutaric aciduria, mitochondrial disorders, molybdenum cofactor deficiency, non-ketotic hyperglycaemia, peroxisomal-related disorders, pyridoxine-dependent epilepsy/ pyridox(am)ine-5'-phosphate oxidase-related deficiency and succinic semialdehyde dehydrogenase (SSADH) Deficiency (64).

In addition, in a related topic there seems to be some related metabolic causes for the epileptic encephalopathy, as described for example by the Yu et al. group in 2013 (66) which are focusing their efforts in describing "defective molecule or mechanism and categorized as small molecule disorders (involving amino and organic acids, fatty acids, neurotransmitters, urea cycle, vitamers and cofactors, and mitochondria) and large molecule disorders (including lysosomal storage disorders, peroxisomal disorders, glycosylation disorders, and leukodystrophies)" in this context (66).

Even more recent papers are also focusing on a so-called diagnostic algorithm for the treatable conditions, for the metabolic manifestations and their evaluation in epilepsy (67). 


\section{CONCLUSIONS}

Psychiatric comorbidity in epilepsy are mainly represented by depression, anxiety, psychosis, personality disorders that sometimes lead to panic, phobia, inattention, irritability, respectively to the thought of suicide and even suicide.

\section{ACKNOWLEDGEMENTS AND DISCLOSURES}

The authors declare that they have no potential conflicts of interest to disclose

\section{REFERENCES}

1. Stafstrom, CE, Carmant, L. Seizures and epilepsy: an overview for neuroscientists. Cold Spring Harbor perspectives in medicine 2015; 5 (6), a022426;

2. Rayner, G. The contribution of cognitive networks to depression in epilepsy. Epilepsy Currents 2017,17 (2), pp. 7883.

3. Pillay, N., Archer, JS, Badawy, RA, et al. Networks underlying paroxysmal fast activity and slow spike and wave in Lennox-Gastaut syndrome. Neurology 2013, 81 (7), pp. 665-673;

4. Liao, W., Zhang, Z., Pan, Z., et al. Default mode network abnormalities in mesial temporal lobe epilepsy: a study combining fMRI and DTI. Human brain mapping 2011; 32 (6), pp. 883-895;

5. Fisher, RS, van Emde Boas, W., Blume, et al. Epileptic seizures and epilepsy: Definitions proposed by the International League Against Epilepsy (ILAE) and the International Bureau for Epilepsy (IBE). Epilepsy 2005; 46, pp. 470-472.

6. Berg, AT, Berkovic, SF, Brodie, MJ et al. Revised terminology and concepts for the organization of seizures and epilepsies: report of the ILAE Commission on Classification and Terminology, 2005-2009. Epilepsy. $2010 ; 51$ (4), pp. 676-685.

7. Hermann, BP, Whitman, S., Hughes, JR, et al. Multietiological determinants of psychopathology and social competence in children with epilepsy. Epilepsy research 1988; 2 (1), pp. 51-60.

8. LaFrance Jr, W. Curt, Andres M. Kanner, and Bruce Hermann. "Psychiatric comorbidities in epilepsy." International review of neurobiology 2008; 83: pp. 347-383.

9. Wittchen, H.-U . Critical Issues in the Evaluation of Comorbidity of Psychiatric Disorders. British Journal of Psychiatry 1996; 168 (S30), pp. 9-16.

10. Goldstein, MA, Harden, CL. Epilepsy and anxiety. Epilepsy \& Behavior 2000; 1 (4), pp. 228-234.

11. Rai, D., Kerr, MP, McManus, S., et al. Epilepsy and psychiatric comorbidity: a nationally representative populationbased study. Epilepsy 2012; 53 (6), pp. 1095-1103.

12. Gaitatzis, A., Trimble, MR, Sander, JW. The psychiatric comorbidity of epilepsy. Acta Neurologica Scandinavica 2004; 110 (4), pp. 207-220.

13. Ottman, R., Lipton, RB, Ettinger, AB, et al. Comorbidities of epilepsy: results from the Epilepsy Comorbidities and Health (EPIC) survey. Epilepsy 2011; 52 (2), pp. 308-315.

14. Tellez-Zenteno, JF, Patten, SB, Jetté, N., et al. Psychiatric comorbidity in epilepsy: a population-based analysis. Epilepsy 2007; 48 (12), pp. 2336-2344.

15. Gaitatzis, A., Carroll, K., Majeed, A., Sander, JW. The epidemiology of comorbidity of epilepsy in the general population. Epilepsy 2004; 45 (12), pp. 1613-1622.

16. Prince, M., Patel, V., Saxena, S., Majet al. No health without mental health. The lancet 2007; 370 (9590), pp. 859 877.

17. Christensen, J., Vestergaard, M., Mortensen, PB, et al. Epilepsy and suicide risk: a population-based case - control study. The Lancet Neurology 2007; 6 (8), pp. 693-698.

18. Thapar, A., Kerr, M., \& Harold, G. Stress, anxiety, depression, and epilepsy: investigating the relationship between psychological factors and seizures. Epilepsy \& Behavior 2009; 14 (1), pp. 134-140.

19. Fiest, Kirsten M., et al. "Systematic review and assessment of validated case definitions for depression in administrative data." BMC psychiatry 2014; 14.1: pp. 289.

20. Josephson, Colin B., Nathalie Jetté. "Psychiatric comorbidities in epilepsy." International review of psychiatry 2017; 29.5 (2017): pp. 409-424.

21. American Psychiatric Association. Diagnostic and statistical manual of mental disorders (DSM-5). American Psychiatric Pub. 2013.

22. Monaco, F. Mood disturbances, psychoses and epilepsy. Epilepsy 1999; 40, pp. 10.

23. Edeh, J., Toone, B .. Relationship between interictal psychopathology and the type of epilepsy. Results of a general practice survey. British Journal of Psychiatry 1987; 151, pp. 95-101.

24. Jacoby, A., Baker, GA, Steen, N., et al. The clinical course of epilepsy and its psychosocial correlates: Findings from a UK Community study. Epilepsy 1996; 37, pp. 148-161.

25. Mendez, MF, Cummings, JL, Benson, DF. Depression in epilepsy. Significance and phenomenology. Archives of Neurology 1986; 43, pp. $766-770$. 
(2)

26. O'Donoghue, MF, Goodridge, DM, Redhead, K., et al. Assessing the psychosocial consequences of epilepsy: A community-based study. Br. J. Gen. Pract 1999; 49, pp. 211-214.

27. Salzberg, M., Taher, T., Davie, M., et al. Depression in temporal lobe epilepsy surgery patients: an FDG-PET study. Epilepsy 2006; 47 (12), pp. 2125-2130.

28. Wilson, SJ, Baxendale, S .. The new approach to classification: rethinking cognition and behavior in epilepsy. Epilepsy \& Behavior 2014; 41, pp. 307-310.

29. Spreng, RN, Grady, CL. Patterns of brain activity supporting autobiographical memory, prospecting, and theory of mind, and their relationship to the default network mode. Journal of cognitive neuroscience 2010; 22 (6), pp. 11121123 .

30. Corbetta, M., Shulman, GL. Goal-directed control and stimulus-driven attention in the brain. Nature reviews neuroscience 2002; 3 (3), pp. 201;

31. Hesdorffer, DC, Ishihara, L., Mynepalli, L., et al. Epilepsy, suicidality, and psychiatric disorders: A bidirectional association. Annals of Neurology 2012; 72, pp. 184-191.

32. Blanchet, P., Frommer, GP. Mood change preceding epileptic seizures. The Journal of Nervous and Mental Disease 1986; 174, pp. 471-476.

33. Kanner AM, Soto A, Gross-Kanner H. Prevalence and clinical characteristics of postictal psychiatric symptoms in partial epilepsy. Neurology 2004; 62: pp. 708-713.

34. Kanner, AM. Depression in epilepsy: A neurobiological perspective. Epilepsy Currents 2005; 5, pp. 21-27.

35. Jones, JE, Hermann, BP, Barry, JJ, et al. Rates and risk factors for suicide, suicidal ideation, and suicide attempts in chronic epilepsy. Epilepsy \& Behavior 2003; 4 (Suppl 3), S31 - S38.

36. Vazquez, B., and Devinsky, O., Epilepsy and anxiety. Epilepsy Behav 2003; 4, S20 - S25.

37. Robertson, MM, Trimble, MR, Townsend, HRA. Phenomenology of depression in epilepsy. Epilepsy 1987; 28 (4), pp. 364-372.

38. Hermann, BP, Whitman, S., Wyler, AR, et al. Psychosocial predictors of psychopathology in epilepsy. The British Journal of Psychiatry 1990; 156 (1), pp. 98-105.

39. Hermann BP, Dikmen S, Schwartz MS, et al. Interictal psychopathology in patients with ictal fear: a quantitative investigation. Neurology 1982; 32: pp. 7-11.

40. Malmgren, K., Sullivan, M., Ekstedt, G., et al. Health-related quality of life after epilepsy surgery: a Swedish multicenter study. Epilepsy 1997; 38 (7), pp. 830-838.

41. Ettinger, AB, Weisbrot, DM, Nolan, EE, et al. Symptoms of depression and anxiety in pediatric epilepsy patients. Epilepsy 1998; 39 (6), pp. 595-599.

42. López-Gómez, M., Espinola, M., Ramirez-Bermudez, J., et al. Clinical presentation of anxiety among patients with epilepsy. Neuropsychiatric disease and treatment 2008; 4 (6), pp. 1235.

43. Kimiskidis, VK, Valeta, T. Epilepsy and anxiety: epidemiology, classification, aetiology, and treatment. Epileptic disorders 2012; 14 (3), pp. 248-256.

44. Beyenburg, S., Mitchell, AJ, Schmidt, D., et al. Anxiety in patients with epilepsy: systematic review and suggestions for clinical management. Epilepsy \& Behavior 2005; 7 (2), pp. 161-171.

45. Gandy, M., Sharpe, L., Perry, KN, et al. Rates of DSM-IV mood, anxiety disorders, and suicidality in Australian adult epilepsy outpatients: a comparison of well-controlled versus refractory epilepsy. Epilepsy \& Behavior 2013 ; 26 (1), pp. 29-35.

46. Oguz A, Kurul S, Dirik E. Relationship of epilepsy-related factors to anxiety and depression scores in epileptic children. J Child Neurol 2002; 17: 37-40.

47. Hughes J, Devinsky O, Feldmann E, et al. Premonitory symptoms in epilepsy. Seizure 1993; 2: 201-3.

48. Kanner, AM, Jones, JC When do sphenoidal electrodes yield additional data to that obtained with antero-temporal electrodes? Electroencephalogr. Gusset. Neurophysiol 1997; 102, pp. 12-19.

49. Swinkels, WAM, Duijsens, IJ, Spinhoven, PH, 2003. Personality disorder traits in patients with epilepsy. Seizure 2003; 12 (8), pp. 587-594.

50. Geschwind, N. Behnavioral Change in Temporal Lobe Epilepsy. Archives of neurology 1997; 34 (8), pp. $453-453$.

51. Blumer, D. Personallty disorders in epilepsy. Neuropsychiatry of personality disorders 1995; pp. 230-263.

52. Schmitz, B., Sander, T. (Eds.). Juvenile myoclonic epilepsy: the Janz syndrome. Routledge 2000.

53. Swinkels, WA, Kuyk, J., van Dyck, R., et al. Psychiatric comorbidity in epilepsy. Epilepsy \& Behavior 2005; 7, pp. 37-50.

54. Jones, JE, Bell, B., Fine, J., et al. A controlled prospective investigation of psychiatric comorbidity in temporal lobe epilepsy. Epilepsy 2007; 48, pp. 2357-2360.

55. Gilliam, F., Kanner, AM Treatment of depressive disorders in epilepsy patients. Epilepsy \& Behavior 2002; 3, pp. $2-9$.

56. Kanner AM, Andres M., Andrey M., et al. "Biomarkers of epileptogenesis: psychiatric comorbidities (?)." Neurotherapeutics 2014; 11.2: 358-372.

57. Ettinger, AB, Good, MB, Manjunath, R. et al. The relationship of depression to antiepileptic drug adherence and quality of life in epilepsy. Epilepsy \& Behavior 2014, 36, pp. 138-143.

58. McConnell, H., Duncan, D. Treatment of psychiatric comorbidity in epilepsy. In " Psychiatric Comorbidity in Epilepsy " (H. McConnell, and P. Snyder, Eds.). American Psychiatric Press, Washington 1998; pp. $245-361$. 
59. Swinkels, J., Jonghe, F. Safety of antidepressants. Int. Gusset. Psychopharmacol 1995; 9, pp. 19-25.

60. Jabbari, B., Bryan, GE, Marsh, EE, et al. Incidence of seizures with tricyclic and tetracyclic antidepressants. Archives of Neurology 1985; 42, pp. 480-481.

61 Kanner, AM Most antidepressant drugs are safe for patients with epilepsy at therapeutic doses: A review of the evidence. Epilepsy \& Behavior 2016; 61, pp. 282-286.

62. Kwan, P., Brodie, MJ Neuropsychological effects of epilepsy and antiepileptic drugs. Lancet 2001; 357, pp. 216222.

63. Mula, M., Sander, JW Negative effects of antiepileptic drugs on mood in patients with epilepsy. Drug Safety 2007; 30, pp. $555-567$.

64. Lin Lin Lee V, Kar Meng Choo B, Chung YS, P Kundap U, Kumari Y, Shaikh MF. Treatment, Therapy and Management of Metabolic Epilepsy: A Systematic Review. Int J Mol Sci 2018; 19, pp. 871.

65. Pong A.W., Geary B.R., Engelstad K.M., Natarajan A., Yang H., De Vivo D.C. Glucose transporter type i deficiency syndrome: Epilepsy phenotypes and outcomes. Epilepsia 2012, 53, pp. 1503-1510

66. Joe Yuezhou Yu and Phillip L. Pearl. Metabolic Causes of Epileptic Encephalopathy. Epilepsy Research and Treatment 2013, pp. 20.

67. van Karnebeek CDM, Sayson B, Lee JJY, Tseng LA, Blau N, Horvath GA and Ferreira CR. Metabolic Evaluation of Epilepsy: A Diagnostic Algorithm With Focus on Treatable Conditions. Front. Neurol 2018, 9, pp. 1016.

\section{Correspondence:}

Alin Ciobîcă,

Researcher, Department of Research, Faculty of Biology, Alexandru Ioan Cuza University, B dul Carol I, no 11, Iasi, Romania Academy of Romanian Scientists, Splaiul Independentei nr. 54, sector 5, 050094 Bucuresti, Romania,Center of Biomedical Research, Romanian Academy, Iasi, B-dul Carol I, no 8, Romania, alinciobica@uaic.ro

Submission: 12 sep 2019

Acceptance: 17 nov 2019 



\title{
The renin - angiotensine system and psychiatric disorders in pregnancy and post - partum
}

\author{
Roxana Mihaela Barbu, Cristina Maria Gavrilescu, Elena Cojocaru, \\ Crînguța Paraschiv, Ionuț R. Popescu, Walther Bild
}

\begin{abstract}
Roxana Mihaela Barbu - MD, PhD, University of Medicine and Pharmacy „Grigore T. Popa”, Iași

Cristina Maria Gavrilescu - MD, PhD, University of Medicine and Pharmacy „Grigore T. Popa”, Iași

Elena Cojocaru - MD, PhD, University of Medicine and Pharmacy „Grigore T. Popa”, Iași Crînguța Paraschiv - MD, PhD, University of Medicine and Pharmacy „Grigore T. Popa”, Iași Ionuț R. Popescu - MD, PhD, University of Medicine and Pharmacy „Grigore T. Popa”, Iași Walther Bild - MD, PhD, professor, University of Medicine and Pharmacy „Grigore T. Popa”, Iași
\end{abstract}

\begin{abstract}
The renin-angiotensin system is one of the most important general and local hormonal systems in the body. Circulating angiotensinogen, under the action of renal or extrarenal renin is transformed into angiotensin $I$. Angiotensin $I$ is a nonapeptide, which is not active per se but by transforming into angiotensin II and by stimulating the secretion of aldosterone. The AT2 receptors are present mainly in the uterus, adrenal gland, but also in the fetus, neonate and in the brain. The renin-angiotensin system is an endocrine system of major importance in physiology and physiopathology, with huge implications in different pathologies, including psychiatric ones. Psychiatric diseases in the perinatal period are a public health problem because of the prevalence, the relative ignorance on this type of pathology and because of the double effect on the mother and on the fetus. Perinatal psychopathology studies the psychological difficulties and psychiatric disorders that can occur during pregnancy and postpartum. It has consequences on the early mother-child relationship as well as the psychotropic treatments that can be given during pregnancy and lactation and their short, medium and long term effect on the newborn, as well as the risks that may occur when treatment is stopped abruptly at the beginning of pregnancy. Conclusions: Considering that the status and type of the myometer angiotensin receptors is very unclear and little studied and that hormonal changes are the main cause for both baby blues and postnatal depression, further physiological, physiopathological and clinical studies are needed to thoroughly assess the involvement of renin-angyotensine-aldosteron system in the psychiatric disorders in pregnancy and postpartum.
\end{abstract}




\section{INTRODUCTION}

The renin-angiotensinsystem (RAS), or reninangiotensin-aldosterone system (RAAS) is a hormonal cascade that functions in the homeostatic control of blood pressure, tissue perfusion and extracellular volume. Circulating angiotensinogen, under the action of renal or extrarenal renin is transformed into angiotensin I. Angiotensin I is a nonapeptide, which is not active per se but by transforming into angiotensin II or stimulating the secretion of aldosterone. The renin-aldosterone system controls sodium and potassium balance, blood volume and blood pressure. Hypovolemia, hyponatremia and other causes of low blood pressure stimulate the secretion of renin and increase aldosterone levels. Aldosterone causes hydrosaline retention, increases blood pressure and loss of potassium. Assessing renin is useful in the different diagnosis of hypertensive patients. The renin-angiotensin system is involved in maintaining the electrolyte balance in the body and thus in controlling blood pressure. The angiotensine II (AT 2) receptors are a class of proteincoupled receptors with angiotensin II; they are resposible for the signal transduction of the vasoconstricting stimulus of angiotensin II. The AT2 receptors are present mainly in the uterus, adrenal gland, but also in the fetus, neonate and in the brain. Drugs that inhibit RAAS are used especially in the treatment of high blood pressure and congestive heart failure, while some drugs are also used in certain kidney diseases to reduce proteinuria $(1,3)$.

\section{THE RENIN - ANGIOTENSIN - ALDOSTERONE SYSTEM IN PREECLAMPSIA}

Preeclampsia is physiologically characterized by plasma volume contraction, intravascular coagulation and intense vasoconstriction. It was initially thought that the reninangiotensin-aldosterone system would be hyperactive, but studies have shown a more complex picture. Plasma renin activity and concentration, in addition, and plasma concentrations of angiotensin II (ANG II) and aldosterone are reduced compared to normal pregnancy. The total concentration of renin is normal, and plasma concentrations of high molecular weight angiotensinogen are increased in preeclampsia, although total angiotensinogen is normal. Plasma renin activity and concentration respond appropriately to physiological stimuli in preeclampsia, except for the release of impaired renin after furosemide, possibly due to prostacycline deficiency. Although the plasma concentrations of angiotensin II are low, there is an increased pressure sensitivity to infused ANG II with unknown mechanisms. The plasma concentration of aldosterone is low, but the ratio of aldosterone concentration to plasma renin concentration is twice as high in preeclampsia than normal pregnancy. This does not appear to be due to changes in potassium, atrial natriuretic peptide, dopamine or ACTH but may be another manifestation of increased (adrenal) sensitivity to ANG II in preeclampsia (2).

There is an inverse relationship between the ratio of active renin to prorenin and the clinical severity of preeclampsia. Understanding the mechanisms that produce these changes in the RAA system in preeclampsia will give strong clues to the general pathogenesis of this disorder. The onset is before, during or after birth. The seizures are of the tonic-clonic type and usually last about a minute. As a result of the crisis, there is usually a period of confusion or coma. Complications of preeclampsia include aspiration pneumonia, cerebral hemorrhage, renal failure, and cardiac arrest $(3,5)$.

Eclampsia is a severe condition and is the last phase of preeclampsia. The pregnant can suffer from epileptic seizures, seizures and loss of consciousness, which can lead to coma or loss of mother and baby's life. Preeclampsia and eclampsia are part of a larger group of disorders known as hypertensive pregnancy disorders (6). 


\section{POST-PARTUM PSYCHIATRIC DISORDERS}

Pregnancy, but especially puerperality, are periods of vulnerability to the appearance or recurrence of psychiatric disorders, the changes due to some: psychic factors: interpersonal and intrapsychic changes; biological factors: hormonal changes and social factors. Pregnancy protects against serious psychiatric episodes, but the psychiatric symptoms that occur during this period are more frequent and more intense than among the general population. Leukemia is a period of increased risk for delusions or depressions often unknown before, with direct effects on the child. Perinatal psychiatry is a border discipline between pediatric psychiatry, adult psychiatry, obstetrics and pediatrics. It aims to address several psychological problems: mental illness of parents, early interactive dysfunctions, training and awareness. It has both a preventive role in identifying the high-risk psychiatric population and in preventing attachment disorders as well as a curative role (10).

Besides the fact that the postpartum period comes after the last trimester, with a lot of fatigue and lack of sleep, combined with the stress of birth, immediately after the expulsion of the placenta, abrupt decreases in hormonal levels during pregnancy occur. Most women, up to $80 \%$, may have periods of marked emotionality, unexplained tears, fears, and may feel painfully a sense of rupture between mother and newborn baby, who suddenly demands the right to a separate existence. of the mother's body (12).

Postpartum sadness, also called baby blues, is normal after birth and affects about $70 \%$ of new moms. The culprits are the radical changes that take place in the mother's life with the birth of the baby, but also the hormonal disorders that occur during the first weeks. Symptoms usually appear within a few days after birth and gradually disappear after the first few weeks. Baby blues are manifested by sudden mood swings, sadness, anxiety, confusion, irritability, difficulties in resting even if the child is asleep, lack of energy, appetite or concentration problems. If the sadness persists even after a maximum of one month, or if the symptoms do not improve, but even worsen, postnatal depression occurs (11).

Unlike baby blues, postpartum depression is a more serious condition, having about the same symptoms, except that these symptoms not only do not disappear after a few weeks after birth, but often worsen. Sometimes, the symptoms become more distressing, the suffering is greater and the life of the fresh mother is significantly affected with a frequency of up to $20 \%$ of women.

A postpartum depressive episode occurs within the first four weeks after birth, and includes several symptoms that are severe enough to affect daily life: sadness, depressive mood; inability to enjoying oneself; feelings of guilt for these states or for other things; fear, anxiety, exaggerated fear of hurting the child; the feeling of being overtaken by events; sleep problems caused by mental distress; crying accesses; the idea of harming themselves, headaches, tingling or numbness of the limbs. Chest pain and palpitations may also be symptoms of postpartum depression. Some mothers who suffer from postpartum depression develop new phobias, panic attacks or nightmares. The feeling of guilt goes often together with that of inadequacy and hostility both to oneself or to the others. Severe concentration or memory problems also occur. In more severe cases, the mother may even have negative child-oriented thoughts or suicidal thoughts. Although it usually appears after birth and progressively progresses, postpartum depression can also develop suddenly, anytime in the first year of life of the child. Statistics show that about $10 \%$ of mothers suffer from postnatal depression (12).

The status and type of myiometer angiotensin receptors have always been very unclear and little studied. A report from 1996, using human myometrial fragments, observed a number of distinct features, both at the level of the uterine smooth muscle per se and at the level of the smooth vascular musculature in 
the uterine wall. Angiotensin II significantly increases muscle contractility stimulated by electric field, and by stimulating angiotensin receptors increases the amount of calcium available in smooth muscle cells, which amplifies the effect of electrical stimulation (7).

Blocking studies have shown that in the female uterine musculature binding is almost exclusively to AT2 receptors, sensitive to PD123177, and very little to AT1 receptors (losartan blockers). Also, the vascular myometrium has shown a clear preference for binding, significantly stronger for angiotensin II, compared with the myometer with dissected vessels, which shows that the essential presence of the receptors is especially at the level of the vascular structures $(8,14)$.

Another major finding is that the expression of AT2 receptors was higher during the follicular phase than during the luteal phase, which allows greater prostacycline synthesis. Comparative studies on human and murine cell lines have shown that PD123319 (a selective AT2 antagonist) inhibited radioactive iodine-labeled Ag coupling, while losartan did not influence this coupling, neither on human nor on murine preparations (9).

Hormonal changes are the main cause for both baby blues and postnatal depression. If during pregnancy hormone levels such as estrogen and progesterone are extremely high, after birth they drop sharply, leading to sadness or even depression. In addition, thyroid hormone levels may drop significantly after birth, and thyroid deficiency can lead to an increased state of fatigue and depression. Stress is another important factor in triggering postpartum depression, along with lack of sleep, new responsibilities that the mother has and fear of the unknown. Physical changes may be another cause of postpartum depression (11).

The treatment of postpartum depression consisted of antidepressant medication and hormone therapy, respectively estrogen therapy. Estrogen treatment for postpartum depression has been poorly studied. Some women taking estrogens have shown improvements in their health, however some of them have had to take an antidepressant at the same time, so it is hard to know if the effect was due exclusively to estrogen. However, estrogen therapy is unlikely to become a common treatment for postpartum depression because it increases the risk of deep vein thrombosis and endometrial cancer. Concomitant addition of progesterone reduces the risk of endometrial cancer of estrogen, but is known to be a trigger for postpartum depression, if given after birth. Statistics show that about $25 \%$ of mothers who do not receive treatment for postpartum depression continue to suffer from depression even one year after birth(14).

\section{CONCLUSIONS}

Considering that the status and type of the myometer angiotensin receptors is very unclear and little studied and that hormonal changes are the main cause for both baby blues and postnatal depression, further physiological, physiopathological and clinical studies are needed to thoroughly assess the involvement of renin-angyotensine-aldosteron system in the psychiatric disorders in pregnancy and postpartum.

\section{ACKNOWLEDGEMENTS AND DISCLOSURES}

The authors declare that they have no potential conflicts of interest to disclose 


\section{REFERENCES}

1. Abdalla S, Lother H, Abdel-tawab AM et al. The angiotensin II AT2 receptor is an AT1 receptor antagonist. J Biol Chem, 2001; 43: 39721-6.

2. Accorsi-Mendonça D, Corrêa FM, Anselmo-Franci JA, Paiva TB, de Oliveira AM. Angiotensin actions on the isolated rat uterus during the estrous cycle: influence of resting membrane potential and uterine morphology. Pharmacology, 2002; 65: 162-169.

3. Brailoiu E, Churamani D, Pandey V, Brailoiu GC, Tuluc F, Patel S, Dun NJ (2006). Messenger-specific role for nicotinic acid adenine dinucleotide phosphate in neuronal differentiation. J Biol Chem 281: 15923-15928.

4. Gard PR, Daw P, Mashhour ZS, Tran P. Interactions of angiotensin IV and oxytocin on behaviour in mice. J Renin Angiotensin Ald Syst, 2007; 8: 133-138.

5. Hannan RE, Gaspary TA, Davis E, Widdop RE. Differential regulation by AT1 and AT2 receptors of angiotensin II-stimulated cyclic GMP production in rat uterine artery and aorta. BJ Pharmacol, 2004; vol 141 (6): 1024-31.

6. Nagata S, Kato J, Sasaki K, Minamino N, Eto T, Kitamura K. Isolation and identification of proangiotensin-12, a possible component of the renin-angiotensin system. Biochem Biophys Res Commun, 2006; 350: 1026-1031.

7. Neves LA, Stovall K, Joyner J, Valdés G, Gallagher PE, Ferrario CM, Merrill DC, Brosnihan KB. ACE2 and ANG- (1-7) in the rat uterus during early and late gestation. Am J Physiol Regul Integr Comp Physiol, 2008; 294 :

R151-161.

8. Schrlau MG, Brailoiu, Patel S, Gogotsi Y, Dun NJ, Bau HH (2008). Carbon nanopipettes characterize calcium release pathways in breast cancer cells. Nanotechnology 19: 325102.

9. Varagic J, Trask AJ, Jessup JA, Chappell MC, Ferrario CM. New angiotensins. J Mol Med, 2008; 86: 663-671.

10. Vancea, Florin, Elements of psychopathology and psychiatry, Psychomedia Ed. , Sibiu, 2008.

11. Vancea, Florin, The Basics of Psychopathology, Psychomedia Ed., Sibiu , 2011.

12. Tudose, F, Psychopathology and psychiatry for psychologists, Infomedica Ed. , Buc ., 2002.

13. Widdop RE, Matrougui K, Levy BI, Henrion D. AT2 receptor-mediated relaxation is preserved after long-term AT1 receptor blockade. Hypertension. 2002; 40: 516-520.

14. Wray S, Kupittayanant S, Shmygol A, Smith RD, Burdyga T (2001). The physiological basis of uterine contractility: a brief review. Exp Physiol 86: 239-46.

\section{Correspondence:}

Cristina Gavrilescu,

MD, PhD, University of Medicine and Pharmacy „Grigore T. Popa”, Iasi, Universitatii street no 16, 700115, Iași, Romania, cristina.gavrilescu@umfiasi.ro

Submission:14sep2019

Acceptance: 18nov2019 



\title{
Importance of CAIDE risk score for the early diagnosis of Alzheimer dementia
}

\author{
Ioana A. Sandu, Adina C. Ilie, Ramona Ștefăniu, Anca I. Pîslaru, \\ Irina M. Abdulan, Ioana D. Alexa, Cristinel Ștefănescu
}

\begin{abstract}
Ioana A. Sandu - MD, PhD student, Assistant professor, "Grigore T. Popa” University of Medicine and Pharmacy Iași, Romania

Adina C. Ilie - MD, PhD, Lecturer, "Grigore T. Popa” University of Medicine and Pharmacy Iași, Romania

Ramona Ștefăniu - MD, PhD student, Assistant professor , "Grigore T. Popa" University of Medicine and Pharmacy Iași, Romania

Anca I. Pîslaru - MD, PhD, Lecturer, "Grigore T. Popa" University of Medicine and Pharmacy Iași, Romania

Irina M. Abdulan - MD, PhD student, Assistant professor , "Grigore T. Popa" University of Medicine and Pharmacy Iași, Romania

Ioana D. Alexa - MD, $\mathrm{PhD}$, senior geriatrics and gerontology, professor, "Grigore T. Popa" University of Medicine and Pharmacy Iași, Romania

Cristinel Ștefănescu - MD, PhD, senior psychiatrist, professor, "Grigore T. Popa" University of Medicine and Pharmacy Iași, Romania
\end{abstract}

\begin{abstract}
Alzheimer's disease is the most common type of dementia and accounts for about $60 \%-80 \%$ of diagnosed dementias. Currently, there are 5.3 million people in the United States diagnosed with $A D$, and this number is expected to increase markedly by 2050 . In Romania the number of diagnosticated cases went up to 4.4 million in 2011 , which represents $20.5 \%$ of the total population.

Alzheimer's disease (AD) is a critical public health problem with a significant social and financial burden on society. Paradoxically, the more the disease is detected later, the higher the overall cost of care, without taking into account the quality of life of the patient and the family, the actual human suffering caused by the disease. The most important thing is that there is no single test for Alzheimer's disease, so early identification of risk factors for Alzheimer's dementia is very important because the neurodegenerative processes of the disease can begin in the middle of life. Identifying these risk factors can shed light on the pathophysiology of Alzheimer's disease, thus providing new potential ways to prevent and treat it.
\end{abstract}

KEYWORDS:

Dementia, CAIDE score, Alzheimer, diagnostic 


\section{INTRODUCTION-IMPORTANCE OF} THE PROBLEM

Alzheimer disease (AD) is a critical public health problem with an enormous social and financial burden on society. $\mathrm{AD}$ is a chronic disease, a progressive neurodegenerative disorder with long preclinical and prodromal stages (20 years) and average clinical duration of 8-10 years. The disease has an estimated prevalence of $10-30 \%$ in the population $>65$ years, and an incidence of $1-3 \%$. Most AD patients $(>95 \%)$ have the sporadic form of disease, which is characterized by a late onset (80-90 years), and annually, in USA alone, about $\$ 200$ billion is spent on direct care of patients with dementia. $(1,2)$

In elderly patients dementia is most often an overlap between $\mathrm{AD}$ and vascular dementia, especially when the onset in the old-old who associate cardiovascular risk factors. Necroptic examination often shows signs of $\mathrm{AD}$, vascular and Lewy body dementia together. (3)

In view of supporting the above mentioned data, N.K. Seetlani et al. published in September 2016 the results of a transversal descriptive study concluding that the incidence of $\mathrm{AD}$ and vascular dementia is quite high in the population, and early detection and prompt treatment can reduce the burden of the disease in the general population.(4)

The early diagnostic efforts were focused on patients in the dementia stage of $\mathrm{AD}$, but recently the importance of a pre-dementia stage preceding the clinical onset of $\mathrm{AD}$ was recognized. Therefore, many studies are now being focused on individuals with normal cognitive status and modifiable cardiovascular risk factors, considered to be the best strategy to increase the prevalence and reduce the incidence of AD. (5)

The aim of this study was to present a simple method available to all physicians for identifying people at risk for AD based on the Cardiovascular Risk Factors, Aging and Dementia (CAIDE risk score.

Early identification of the risk factors for Alzheimer dementia is very important because the neurodegenerative processes of this disease can occur during midlife. Their identification can shed light on the pathophysiology of $\mathrm{AD}$, thus providing new potential modalities for its prevention and treatment.

\section{CAIDE RISK SCORE}

In 2006, the first risk score for the prediction of dementia in 20 years among middle-aged people was developed. Its purpose was to investigate the association between social status, lifestyle, cardiovascular risk factors and cognition and risk of dementia and structural brain changes. Professor $M$. Kivipelto is leading the CAIDE project aimed at identifying the individuals at high risk of dementia, in which preventive intensive treatment may improve the disease course, and developing a simple method for predicting the risk of dementia in middle-aged individuals based on the individual risk profile.(6)

The researchers had implemented this tool in a random sample of 2,000 middle-aged people, concurrently participating in 2 Finnish studies:

○ The Northern Karelia Study - The extremely high cardiovascular mortality had caused great concern among the local population. The action to reduce the problem was demanded in a petition addressed to the Finnish government signed by local community representatives. In response, the North Karelia project was launched in 1972 being aimed at developing a comprehensive community prevention program. After the first five years, prevention activities had also been initiated nationwide. The main goal was to reduce serum cholesterol, blood pressure and smoking, with lifestyle changes and improved drug treatment, especially for high blood pressure. Major decreases were recorded in serum cholesterol, blood pressure, and number of smokers. Coronary mortality decreased by $84 \%$ in the middle-aged population between 1972 and 2014. Approximately two-thirds of the decrease in mortality rate was accounted for by changes in risk factors and $1 / 3$ by improved new treatments developed since the 1980 s. $(7,8,9)$ 
Bulletin of Integrative Psychiatry $\bigcirc$ New Series $\bigcirc$ December 2019 ○ Year XXV ONo. 4 (83)/51

s

- The Framingham study was a reference study which ever since the 1960s has provided strong evidence of the possibly causal role of several lifestyle factors in the development of cardiovascular diseases (CVD). At that time, the Finnish men had the highest coronary heart disease mortality rate in the world, finding that generated great local concern. In 1972 , a pioneering project by a young leadership team and with many partners, the World Health Organization included, began to change the situation. The project was based on the results of the Framingham and other classical studies with the goal to develop a comprehensive prevention program to reduce the levels of risk factors in the population through general lifestyle changes in the Northern

\begin{tabular}{|c|c|c|c|c|}
\hline \multicolumn{2}{|l|}{ RISK FACTOR } & POINTS & $\begin{array}{l}\text { TOTAL } \\
\text { SCORE }\end{array}$ & $\begin{array}{l}\text { DEMENTIA } \\
\text { RISK }\end{array}$ \\
\hline \multirow[t]{3}{*}{ AGE } & $<47$ years & 0 & \multirow[t]{3}{*}{$0-5$} & \multirow[t]{3}{*}{$1 \%$} \\
\hline & $47-53$ years & 3 & & \\
\hline & $>53$ years & 4 & & \\
\hline \multirow{3}{*}{ EDUCATION } & $\geq 10$ years & 0 & \multirow{3}{*}{$6-7$} & \multirow{3}{*}{$1,9 \%$} \\
\hline & $7-9$ years & 2 & & \\
\hline & $\leq 6$ years & 3 & & \\
\hline \multirow[t]{2}{*}{ GENDER } & $\mathrm{F}$ & 0 & \multirow[t]{2}{*}{$8-9$} & \multirow[t]{2}{*}{$4,2 \%$} \\
\hline & $\mathrm{M}$ & 1 & & \\
\hline \multirow{2}{*}{ BLOOD PRESSURE } & $\leq 140 \mathrm{mmHg}$ & 0 & \multirow[t]{2}{*}{$10-11$} & \multirow[t]{2}{*}{$7,4 \%$} \\
\hline & $>140 \mathrm{mmHg}$ & 2 & & \\
\hline \multirow[t]{2}{*}{ BODY MASS INDEX $\left(\mathrm{kg} / \mathrm{m}^{2}\right)$} & $\leq 30$ & 0 & \multirow[t]{2}{*}{$12-15$} & \multirow[t]{2}{*}{$16,4 \%$} \\
\hline & $>30$ & 2 & & \\
\hline \multirow[t]{2}{*}{ HYPERCHOLESTEROLEMIA } & $\begin{array}{l}\text { YES } \\
<251,35 \mathrm{mg} / \mathrm{dl}\end{array}$ & 0 & & \\
\hline & $\begin{array}{l}\mathrm{NO} \\
>251,35 \mathrm{mg} / \mathrm{dl}\end{array}$ & 2 & & \\
\hline \multirow[t]{2}{*}{ PHYSICAL ACTIVITY } & YES & 0 & & \\
\hline & $\mathrm{NO}$ & 1 & & \\
\hline
\end{tabular}

Fig 1. The CAIDE risk score and interpretation.

This multidisciplinary study has provided over the past few years sufficient evidence that cardiovascular risk factors (hypertension, obesity, hypercholesterolemia, smoking, cardiovascular disease) and psychosocial factors contribute significantly to the cognitive decline (dementia and AD) and that a healthy diet can reduce the risk of disease. (11)
Karelia pilot area. Subsequently, the program was extended nationwide. Over the years, significant reductions in the levels of risk factor among the population associated with a dramatic decline in ageadjusted CVD mortality rates and public health improvement were recorded.(10)

Thus, M. Kivipelto et al. had focused on cardiovascular diseases and re-examined the same patients after 20 years for signs of dementia. Several midlife cardiovascular risk factors were studied to create the scoring tool, the scores being estimated based on $\beta$ coefficients and dementia risk score was the sum of these individual scores (range 0-15) quantified as follows in Fig 1. 
(n)

with unhealthy midlife lifestyle, such as obesity, hypertension and hypercholesterolemia increase the risk of dementia and AD later in life. (12)

Cardiovascular risk factors among adults have been consistently associated with structural brain aging, such brain diseases as white matter atrophy and abnormalities, as well as the decline in cognitive processing speed and executive function.

Epidemiological evidence suggests an association between $\mathrm{AD}$ and vascular risk factors, and their control could prevent the development of dementia. (13)

\section{o Age}

The most common risk factor for $\mathrm{AD}$ is aging, but $\mathrm{AD}$ is not a "normality" of aging; age increases the risk, but is not a direct cause of AD. Most people with AD are over 65 or older. After the age of 65, the risk of developing $\mathrm{AD}$ doubles every five years; after the age of 85 , the risk reaches almost onethird. (13)

- Education level

In 2011, E.S. Sharp et al. reported, in order to reinforce Katzman and Mortimer's conclusion, that a low education level is a risk factor for developing dementia. They suggested that the relationship between education and dementia may be more complex than previously described in literature. The results of the published study suggest that a low education level is associated with an increased risk of dementia. Moreover, the education level most commonly associated with the highest risk of dementia varies considerably depending on the region, as well as age, sex, race or ethnicity. $(14,15,16)$

○ Physical activity

Moderate exercise should be considered as a standard recommendation for reducing cognitive decline, as a result of the improvement in neurodegenerative mechanisms and increase in neuroplastic and neuroprotective neurotrophic factors. Therefore, it is suggested that exercise is an important neuroprotective modulator that brings significant control of the disease and amplifies brain functions. $(17,18,19)$
- Arterial blood pressure

It is a common and potentially modifiable risk factor not only for cardiovascular and cerebrovascular diseases but also for AD. Studies have shown that elevated blood pressure (BP), especially in midlife, is associated with higher $\mathrm{AD}$ risk later in life. Y.H. Shih et al. published the results of an original study in which they aimed at testing the possible relationship between hypertension (HTN) and late AD onset. He used two animal models (1) genetically modified pigs and (2) mice expressing three AD-related mutant genes in order to examine the role of HTN in the pathogenesis of AD. In the group of young animals, HTN has been shown to accelerate AD-associated pathologies, induces microglia activation and shrinkage of hippocampal dendritic complexity, and impairs hippocampusdependent learning and memory. These findings suggest that HTN accelerates AD onset. BP control, especially in midlife, is an important way of delaying the onset of AD. $(20,21,22,23)$

○ Cholesterol

The associations between cholesterol, stroke, cognitive impairment and dementia are complex and not fully understood, yet. Given the population aging, it is imperative to develop strategies for the prevention and treatment of dementia. High total serum cholesterol $(\mathrm{C})$ levels in middle-aged patients increase the risk of late-life $\mathrm{AD}$, and was also linked to specific $\mathrm{AD}$ changes occurring at brain level. Recent data suggest a bidirectional relationship between $\mathrm{C}$ and dementia; high $\mathrm{C}$ levels represent a risk factor for the development of AD in 20 years. (24)

Solomon et al. believe that doctors tend to confine $\mathrm{AD}$ and $\mathrm{VD}$ to geriatric age borders and address symptoms as they occur. The conclusion of their study highlights the importance of addressing risk factors during midlife before the disease or symptoms occur. High serum cholesterol during midlife increases the risk of both $\mathrm{AD}$ and VD. Moreover, dementia and cardiovascular disease represent major health problems, share many risk factors and often occur simultaneously, interacting with each other. Efficient management of these disorders 
justifies a cross-disciplinary approach. (24)

The CAIDE study later laid the foundation for the Finnish FINGER study to prevent cognitive impairment and disability. The Finnish Geriatric Intervention Study for the Prevention of Cognitive Disorders and Disability, a randomized controlled trial, aimed to assess a multidimensional approach for preventing cognitive decline in the elderly at high risk in the general population. Between September 7. 2009 and November 24, 2011, 2654 persons were enrolled and randomly assigned to the intervention or control group 25)

The results of this controlled study showed that multidimensional intervention could improve or preserve cognitive function and reduce the risk of developing new chronic diseases in the elderly at high risk in the general population. (26)

Currently, there is no effective treatment for dementia, and population screening is not supported as in the absence of diseasemodifying treatments there is no evidence that the benefit of screening exceeds potential risk. However, in the conversion of dementia, as a result of previous stages of cognitive decline, focusing on "modifying" cardiovascular risk factors has a great potential and to prevent or delay cognitive decline.(27)
The CAIDE dementia risk score was initially a new approach for predicting the risk of Alzheimer dementia, but it should be validated for Romania and further improved to increase its predictive value. This approach highlights the role of cardiovascular factors in the development of dementia and could help identify people who might benefit from intensive lifestyle and pharmacological interventions.

To this date, CAIDE data have resulted in nine dissertations and over thirty original scientific papers published in high impact journals. It is essential to further assess predictability in larger, less homogeneous populations and to determine whether it can be improved by taking into account other midlife risk factors.

Taking into account the presented data and the absence of data in the Romanian population, we aim to carry out a prospective study of the CAIDE score in the midlife general population. Thus, we started enrolling patients aged 40-65 years who will be divided into two groups: with or without cardiovascular risk factors, each group consisting of about 50 participants. They will be followed-up annually with respect to the cardiovascular risk factors, cognitive and nutritional status.

\section{CONCLUSIONS}

There is overwhelming and converging evidence in the literature showing that cardiovascular risk factors play a very important role in the etiology of AD. Even though for some of these factors the mechanisms that associate them with $\mathrm{AD}$ are very clear, for others the association with $\mathrm{AD}$ is much more complex and therefore further research is needed. Taking into account that these cardiovascular factors are currently the only ones known as modifying risk factors for AD, the possibility of intervening on them in order to prevent or delay the onset of $\mathrm{AD}$ deserves more dedicated research and rigorous prevention.

\section{ACKNOWLEDGEMENTS AND DISCLOSURES}

The authors declare that they have no conflict of interest related to this article.

\section{REFERENCES}

1. Masters CL., Bateman R., Blennow K., et al.: Alzheimer's disease Nature Reviews Disease Primers volume 1, Article number: 15056 (2015)

2. U.S. Department of Health and Human Services, National Institutes of Health, National Institute on Aging, Alzheimer's Disease Education \& Referral (ADEAR) Center (2014). Alzheimer's disease medications fact sheet (NIH 
. Publication No. 08-3431). National Institute on Aging. http://www.nia.nih.gov/alzheimers/publication/alzheimersdisease- medications-fact-sheet

3. https://www.verywellhealth.com/what-is-mixed-dementia-98748

4. Seetlani NK., Kumar N., Imran K., et al.: Alzheimer and vascular dementia in the elderly patients Pak, J Med Sci. 2016 Sep-Oct; 32(5): 1286-1290.

5. Crous-Bou M, Minguillón C, Gramunt N, et al.: Alzheimer's disease prevention: from risk factors to early intervention. Alzheimers Res Ther. 2017; 9(1): 71.

6. Kivipelto M., Ngandu T., Laatikainen T., et al.: Risk score for the prediction of dementia risk in 20 years among middle aged people: A longitudinal, population-based study. Lancet Neurol. 2006;5:735-741.

7. Puska P., Tuomilehto J., Nissinen A., et al.: The North Karelia Project. 20 Year Results and Experiences. Helsinki 1995.

8. Puska P., Vartiainen E., Tuomilehto J., et a1.: Changes in premature deaths in Finland: successful long-term prevention of cardiovascular diseases: Bulletin of the World Health Organization 1998; 76(4): 419-425.

9. Vartiainen E., Puska P., Pekkanen J. et al.: Changes in risk factor explain changes in mortality from ischaemic heart disease in Finland. BMJ 1994; 309: 23-27.

10. Puska P.: From Framingham to North Karelia: From descriptive epidemiology to public health action. Prog Cardiovasc Dis. 2010;53:15-20.

11. Kivipelto M., Ngandu T., Laatikainen T., et al.: Risk score for the prediction of dementia risk in 20 years among middle aged people: a longitudinal, population-based study Lancet Neurol, 5, 2006, 735-741

12. Ngandu T. : Lifestyle-related risk factors in dementia and mild cognitive impairment : A population-based study. Stockholm, Sweden, Karolinska University Press 2006, pp

13. Kivipelto M Helkala E-L Laakso MP et al. Midlife vascular risk factors and Alzheimer's disease in later life: longitudinal, population based study. BMJ. 2001; 322: 1447-1451

14. Sharp ES, Gatz M. Relationship between education and dementia: an updated systematic review. Alzheimer Dis Assoc Disord. 2011;25(4):289-304.

15. Katzman R. Education and the prevalence of dementia and Alzheimer's disease. Neurology. 1993;43:13-20.

16. Mortimer JA, Graves AB. Education and other socioeconomic determinants of dementia and Alzheimer's disease. Neurology. 1993;43:S39-S44.

17. Machado S, Filho ASS, Wilbert M, et al. Physical Exercise As Stabilizer For Alzheimer'S Disease Cognitive Decline: Current Status. Clin Pract Epidemiol Ment Health. 2017;13:181-184.

18. Pentikäinen H., Ngandu T., Liu Y, et al.: Cardiorespiratory fitness and brain volumes in men and women in the FINGER study, Age and Ageing, Volume 46, Issue 2, March 2017, 310-313,

19. Spartano NL., Ngandu T., Fitness and dementia risk, Neurology, Apr 2018, 90 (15), 675-676;

20. Shih YH, Wu SY, Yu M, et al. Hypertension Accelerates Alzheimer's Disease-Related Pathologies in Pigs and 3xTg Mice. Front Aging Neurosci. 2018;10:73.

21. Carnevale L., D’Angelosante V., Landolfi A., et al.: Brain MRI fiber-tracking reveals white matter alterations in hypertensive patients without damage at conventional neuroimaging, Cardiovasc. Res., Volume 114, Issue 11, 01 September 2018, 1536-1546,

22. Elias MF., Goodell AL., Dore GA.. Hypertension and cognitive functioning: a perspective in historical context. Hypertension. 2012; 60:260-268.

23. Iadecola C., Hypertension and Dementia, Hypertension. 2014; 64:3-5

24. Solomon A, Kivipelto M, Wolozin B, Zhou J, Whitmer RA. Midlife serum cholesterol and increased risk of Alzheimer's and vascular dementia three decades later. Dement Geriatr Cogn Disord. 2009;28(1):75-80.

25. Lehtisalo, Jenni et al. Dietary changes and cognition over 2 years within a multidomain intervention trial-The Finnish Geriatric Intervention Study to Prevent Cognitive Impairment and Disability (FINGER), Alzheimer's \& Dementia: The Journ. of the Alz. Asso., Volume 15, Issue 3, 410 - 417

26. Pentikäinen $\mathrm{H}$ et al. Cardiorespiratory Fitness and Cognition: Longitudinal Associations in the FINGER Study. J. Alzheimers Dis. 2019;68(3):961-968

27. Vartiainen E. The North Karelia Project: Cardiovascular disease prevention in Finland. Glob Cardiol Sci Pract. 2018(2):13.

\section{Correspondence:}

Adina C. Ilie,

MD, PhD, Lecturer, "Grigore T. Popa” University of Medicine and Pharmacy Iași, Romania,Universității Street nr.16, Iași, Romania, ioana.b.alexa@gmail.com 


\title{
Impact of cardiac anomalies in the prognosis of patients with velo-cardio-facial syndrome
}

\author{
Alexandra Maştaleru, Maria-Magdalena Leon-Constantin, \\ Irina Abdulan, Alexandra Jitaru, Eva Gavril, Mitu Florin
}

\begin{abstract}
Alexandra Maștaleru - Universitatea de Medicină şi Farmacie "Grigore T Popa" - Iasi, Romania, Facultatea de Medicină, Departamentul Medicale I, adresa: Strada Universităţii nr 16, Iasi, Romania; Spitalul Clinic de Recuperare - Clinica de Recuperare Cardiovasculară, Maria-Magdalena Leon-Constantin - Universitatea de Medicină și Farmacie "Grigore T Popa" Iasi, Romania, Facultatea de Medicină, Departamentul Medicale I, adresa: Strada Universităţii nr 16, Iasi, Romania; Spitalul Clinic de Recuperare - Clinica de Recuperare Cardiovasculară,

Irina Abdulan - Universitatea de Medicină și Farmacie "Grigore T Popa" - Iasi, Romania, Facultatea de Medicină, Departamentul Medicale I, adresa: Strada Universității nr 16, Iasi, Romania; Spitalul Clinic de Recuperare - Clinica de Recuperare Cardiovasculară,

Alexandra Jitaru - Universitatea de Medicină și Farmacie "Grigore T Popa" - Iasi, Romania, Facultatea de Medicină, Departamentul Medicale I, adresa: Strada Universității nr 16, Iasi, Romania; Spitalul Clinic de Recuperare - Clinica de Recuperare Cardiovasculară

Eva Gavril - Universitatea de Medicină și Farmacie "Grigore T Popa" - Iasi, Romania, Facultatea de Medicină, Departamentul Medicale I, adresa: Strada Universității nr 16, Iasi, Romania; Spitalul Clinic de Recuperare - Clinica de Recuperare Cardiovasculară

Florin Mitu - Universitatea de Medicină și Farmacie "Grigore T Popa" - Iasi, Romania, Facultatea de Medicină, Departamentul Medicale I, adresa: Strada Universității nr 16, Iasi, Romania; Spitalul Clinic de Recuperare - Șeful Clinicii de Recuperare Cardiovasculară
\end{abstract}

\section{ABSTRACT}

One of the most common multiple anomaly syndromes in human is the velo-cardio-facial syndrome (VCFS). A very important step in managing a patient with a $22 q 11.2$ deletion is to identify the exact phenotypic manifestations so that appropriate counseling and anticipatory care can be provided. Patients with VCFS have a 25 times higher rate of psychosis than general population. Therefore, it is almost certain that a genomic factor or factors in the deleted region influence brain development and/or function. Childhood psychiatric manifestations of VCFS include mood dysregulation, anxiety disorders, attention deficit hyperactivity disorder (ADHD) and autism spectrum disorders. VCFS is the most commonly 
r.m.\% known genetic risk factor for schizophrenia. The $25 \%$ risk of developing schizophrenia is a great concern of the patients and their families given its gravity and social stigma. Regarding the psychopharmacological treatment, the therapies need to be carefully chosen, taking into account literature data on tolerability and efficacy. Thus, it is particularly important to know the features and symptoms of the disease in order to a good evaluation and monitoring of the patient. A multidisciplinary approach is fundamental to ensure that the patient will be able to attain his or her maximal potential.

\section{KEYWORDS:}

Velo-cardio-facial syndrome, cardiac malformations, schizophrenia

\section{INTRODUCTION}

One of the most common multiple anomaly syndromes in human is the velo-cardio-facial syndrome (VCFS). Other names as DiGeorge sequence, 22q11 deletion syndrome, $\mathrm{CATCH}$ 22 , conotruncal anomalies face syndrome and Sedlačková syndrome have all been given to the same disorder (1,2). Approximately 6$10 \%$ of cases are familial, while most occur de novo. Nearly $75 \%$ of patients with a 22q11.2 deletion have a congenital heart malformation, as well as aortic arch anomalies (1).

VCFS syndrome has an extensive phenotype with more than 180 clinical features. It basically involves every organ and system. Early recognition of the deletion is important, so that the treatment of the involved organ anomalies can be initiated, screening for associated malformations performed and prevention of neuropsychological problems provided. A multidisciplinary approach is fundamental to ensure that the patient will be able to attain his or her maximal potential. Psychiatrists are an important part of the team that evaluate and treat these patients who frequently present a number of common psychiatric illnesses and phenotypic features including attention deficit disorder, schizophrenia or bipolar disorder. The psychiatric manifestations are highly variable, some individuals being essentially normal or at the mildest end of the spectrum, or some with most severe cases having life-threatening and life-impairing problems.

\section{MOLECULAR CHARACTERISTICS AND INHERITANCE PATTERN}

The 22q11.2 locus is flanked by chromosome specific, low copy repeats that share more than $97 \%$ sequence homology. This fact causes the region to be prone to misalignment of reduced copy repeats during meiosis. Therefore, deletion or duplication of the region can occur due to nonallelic homologous recombination events. Nearly $90 \%$ of patients with a deletion share a common $3-\mathrm{Mb}$ deletion, $8 \%$ have a smaller deletion $(1.5-\mathrm{Mb})$ and very rare cases have an even smaller one within the disease locus, called ,nested deletion”. The highly variable clinical presentation is not yet explained by the deletion size, therefore other undefined mechanisms must be involved $(3,4)$.

Most of the genes that lack in this disease have not been well characterized. Shorter deletions in the same region (contiguous gene deletion syndrome) appear in a small percentage of the affected individuals. However, the loss of a particular gene on chromosome $22, \underline{T B X 1}$, is probably responsible for most of the syndrome's characteristic signs (distinctive facial features, heart defects, hearing loss, low calcium levels and also behavioral problems). The increased risk of developing psychiatric and behavioral 
s

problems can also be explained by the loss of COMT gene, in the same region of chromosome 22 (5). However, some of the patients with classical features of the syndrome have smaller deletions that do not include TBX1, so the question remains as to whether other genes in the region contribute to the phenotype. Efforts to identify potential genetic modifiers of the cardiac phenotype are also underway $(6,7)$.

A person with a chromosome deletion has a $50 \%$ chance of transmitting the affection to their child (autosomal dominant transmission) (8). Yet, about $90 \%$ of the cases with a 22q11.2 deletion occur randomly during fertilization or fetal development, therefore, most of them are de novo (9).

\section{MANAGEMENT}

The most important step in managing a patient with a 22q11.2 deletion is to identify the exact phenotypic manifestations so that appropriate counseling and anticipatory care can be provided. Given the highly variable phenotype, the clinical evaluation will vary both in extent and by age. The International 22q11.2 Deletion Consortium provided guidelines on the management of the patients with VCFS (10).

\section{NEUROPSYCHIATRIC DISORDERS}

So far, it is not clear the biologic basis of mental illness in VCFS. However, the syndrome represents an excellent model for understanding psychiatric disorders, especially psychosis, in humans. Patients with VCFS have a 25 times higher rate of psychosis than general population. Therefore, it is almost certain that a genomic factor or factors in the deleted region influence brain development and/or function.

Childhood psychiatric manifestations of VCFS include mood dysregulation, anxiety disorders, attention deficit hyperactivity disorder (ADHD) and autism spectrum disorders (11). Attention deficit hyperactivity disorder (ADHD) was the most frequent disorder in children (37.10\%) and was overrepresented in males. Anxiety disorders were more prevalent than mood disorders at all ages, but especially in children and adolescents. In approximately $32 \%$ of individuals with VCFS, chronic psychosis presents between late adolescence and early adulthood, and most of these cases meet the criteria for schizophrenia. Anxiety and unipolar mood disorders were overrepresented in females. Psychotic disorders were present in $41 \%$ of adults over age 25. Males did not predominate in psychotic or autism spectrum disorders. Moreover, the adults show minimal resolution of psychiatric symptoms (12).

VCFS is the most commonly known genetic risk factor for schizophrenia. The $25 \%$ risk of developing schizophrenia is a great concern of the patients and their families given its gravity, social stigma and impact on functioning $(13,14,15,16)$. The schizophrenia associated with VCFS accounts for $0.5-1 \%$ of schizophrenia in the general population. There is no difference between this and other forms of schizophrenia regarding prodrome, age at onset, the core signs and symptoms, cognitive profile, except overall lower average IQ and the absence of gender differences $(17,18,19)$. Symptoms include delusions, hallucinations, disorganized thinking, emotional expression and/or behavior, as well as blunted affect, reduced speech, social withdrawal and motor disturbances $(20,21)$.

In the general population, psychiatric disorders such as anxiety disorders, schizophrenia and other psychotic disorders are effectively treated with both 
pros.

pharmacological and non-pharmacological therapies. For anxiety the latter can include cognitive behavioral therapy (CBT) and interpersonal psychotherapy (IPT). These recommendations are documented in the guidelines by the American Psychiatric Association (APA, United States of America) and the National Institute for Health and Care Excellence (NICE, United Kingdom). Clinicians may wonder if standard treatment strategies are feasible and effective in 22q11.2DS and if adaptations to treatment guidelines are required. For example, individuals with 22q11.2DS may need more time to establish a trusting relationship with clinicians, to process information, or may have difficulties understanding abstract information due to intellectual disabilities and deficits in socialization $(17,22)$.

Regarding the psychopharmacological treatment, the therapies need to be carefully chosen, taking into account literature data on tolerability and efficacy. Moreover, they seem to have a higher susceptibility to side effects than subjects with psychotic disorders (without VCFS). The antipsychotic medications have the potential to induce, exacerbate, or, interestingly, diminish preexisting movement disorders in some cases (23). Studies suggest an increased vulnerability to antipsychotic-related movement disorders in VCFS that may include drug-induced parkinsonism, dystonia and non-epileptic myoclonus (24, 25, 26). Other psychotropic medications commonly used in VCFS such as antidepressants and anticonvulsants can also cause adverse motor effects (27).

\section{SPEECH AND LANGUAGE IMPAIRMENT}

Studies report that 70 to $90 \%$ of the patients with VCFS present hypernasal speech, severe articulation impairment (28). Speech onset is usually mildly delayed and receptive language abilities exceed expressive. Some of them are related to unintelligible speech and incorrect management of these disorders in childhood (29). However, remediation of these problems has led to excellent prognosis in the large majority of cases.

\section{CONGENITAL HEART DISEASE}

Recent studies estimate that approximately $75-80 \%$ of patients with a $22 q 11.2$ deletion have congenital heart disease. These studies may overestimate the prevalence of cardiac defects in the deleted population given that children and adults without significant heart disease may escape diagnosis $(30,31)$.

The most common cardiac defects seen in the 22q11.2 deletion syndrome include a subset of conotruncal defects such as tetralogy of Fallot (26\%), interrupted aortic arch (10\%) or truncus arteriosus (10\%), pulmonary atresia with ventricular septal defect (24\%) and less commonly atrial septal defects $(30,32)$. The full range of aortic arch anomalies, including cervical aortic arch, double aortic arch, rightsided aortic arch and abnormal origin of the subclavian arteries (both aberrant and isolated subclavian arteries) have been observed (33). In addition to cardiovascular malformations, a subset of patients with the 22q11.2 deletion syndrome develops aortic root dilation over time, suggesting that this feature may be progressive. However, the clinical significance of this finding remains to be determined as there are no reports of aortic root dissection (34).

These diseases can be observed after a clinical examination to which are added paraclinical investigations: ECG, echocardiography, stress test, CT angiography, cardiac MRI. These cardiac diseases are compatible with life but require supervision and eventually surgical treatment. 


\section{CRANIOFACIAL DYSMORPHIA}

Patients with VCFS have a long face with a prominent upper jaw and an underdeveloped lower jaw, prominent nose with narrow nasal passages, long thin upper lip and a downslanting mouth. They also present flattening of the cheeks (4). However, the presence of these features as well as other facial findings is variable. Results from a prospective evaluation for ocular abnormalities in 33 patients with VCFS revealed hooding of the upper lids (41\%), ptosis (9\%), hooding of the lower lids (6\%), epicanthal folds (3\%) and distichiasis (abnormal growth of lashes from the orifices of the meibomian glands) (3\%). Strabismus was observed in $13 \%$ and amblyopia in $6 \%$ of the individuals $(3,6)$. The incidence of astigmatism, myopia and hyperopia was comparable to that in the general population. Ear abnormalities include overfolded or squared off helices, cupped, microtic and protuberant ears, also narrow external auditory meati.

\section{VELOPHARYNGEAL DYSFUNCTION}

Palatal anomalies are also common among children with VCFS, especially submucous cleft palate and occult submucous cleft palate (35). These clefts can be very difficult to identify without a nasopharyngoscopy. That is why several reports have significantly underestimated the frequency of clefting (36). It is for this reason that reports suggest that individuals with VCFS have "short palates" or hypernasal speech. More specifically, occult submucous cleft palate is an identifiable anomaly that is a form of cleft palate that often goes undetected because it requires endoscopic examination of the nasal surface of the velum (35). Stridor resulting from vascular ring, laryngomalacia and laryngeal web, laryngeal atresia and subglottic stenosis can also be found in these patients.

\section{IMMUNE DEFICIT}

Approximately $80 \%$ cases demonstrate some level of immunologic abnormality with most manifesting mild-to-moderate decrements in $\mathrm{T}$-cell numbers due to thymic hypoplasia and only a very rare minority $(0.5 \%)$ manifesting severe immunodeficiency that requires immediate medical attention. Patients may also experience humoral defects (26\%) and IgA deficiency (6\%) (37). In most of the cases, early childhood is marked by frequent respiratory infections, middle ear effusions and sinusitis. In the more severe cases, pneumonia and bronchitis may apear through childhood (28).

\section{HYPOCALCEMIA}

At least half of the infants with VCFS manifest hypocalcemia, which can result in hypocalcemic seizures if not recognized and treated appropriately. The hypocalcemia usually resolves by 1 year of age, but can reappear or present as isolated hypoparathyroidism for the first time at later ages (38).

\section{DIAGNOSIS}

The molecular diagnosis of a 22q11.2 deletion was previously made using fluorescence in situ hybridization of test probes from the 22q11.2 locus hybridized with metaphase chromosomes. While this approach reliably identified the typical 3-Mb deletion and some smaller deletions, it failed to detect the less common 'nested' or atypical deletions (3, 4, 39). Newer methods including MLPA and microarrays now identify both the common and atypical deletions in the region and are now the preferred methods of interrogation $(40,41)$.

\section{CLINICAL OUTCOME}

It is particularly important to know that features and symptoms, such as calcium homeostasis and neuropsychiatric issues, may 


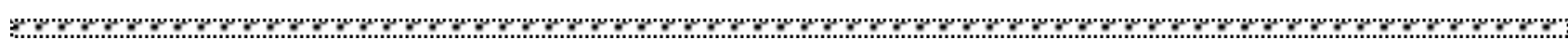
evolve over time and must be periodically reevaluated. Likewise, it is critical to screen parents for the 22q11.2 deletion in order to identify the previously undiagnosed adult as they have a $50 \%$ risk of recurrence in subsequent offspring and require clinical counseling to address their own clinical and neuropsychiatric needs.

Early reports revealed a high rate of mortality for patients with VCFS on account of inoperable cardiac malformations and severe infections. With medical and surgical advances, survival has significantly improved for all patients with congenital heart disease, but numerous studies suggest that cases with a malformation syndrome suffer worse clinical outcomes than those with apparently isolated congenital heart disease (31). To date, the management of the associated congenital heart malformations follows standard approaches, but as our understanding of the 22q11.2-deleted patients specific clinical challenges improve, care may soon be tailored to their specific needs (personalized, or genotype-specific, clinical management) (10, $31)$.

The multidisciplinary approach (geneticist, psychiatrist, cardiologist) is essential for the positive evolution of the patient with velocardiofacial syndrome. The patient requires periodic evaluation (at every 6 months) for monitoring and reassessment.

\section{ACKNOWLEDGEMENTS AND DISCLOSURES}

The authors declare that they have no potential conflicts of interest to disclose.

\section{REFERENCES}

1. Kobrynski LJ, Sullivan KE. Velocardiofacial syndrome, DiGeorge syndrome: the chromosome 22q11.2 deletion syndromes. Lancet. 2007; 370(9596):1443-1452.

2. Burnside, R. 22q11.21 Deletion Syndromes: A Review of Proximal, Central, and Distal Deletions and Their Associated Features. Cytogenetic and Genome Research, 2015; 146(2), 89-99.

3. Michaelovsky E, Frisch A, Carmel M et al. Genotype-phenotype correlation in 22q11.2 deletion syndrome. BMC Med Genet 2012; 13:122.

4. Verhagen JM, Diderich KE, Oudesluijs G et al. Phenotypic variability of atypical 22q11.2 deletions not including TBX1. Am J Med Genet A 2012; 158A:2412-2420.

5. Gao S, Li X, Amendt BA. Understanding the role of TBX1 as a candidate gene for 22q11.2 deletion syndrome. Curr Allergy Asthma Rep. 2013; 13(6):613-621.

6. Goldmuntz E, Driscoll DA, Emanuel BS et al. Evaluation of potential modifiers of the cardiac phenotype in the 22q11.2 deletion syndrome. Birth Defects Res A Clin Mol Teratol 2009; 85:125-129.

7. Guo T, McDonald-McGinn D, Blonska A et al. Genotype and cardiovascular phenotype correlations with TBX1 in 1,022 velo-cardio-facial/DiGeorge/22q11.2 deletion syndrome patients. Hum Mutat 2011; 32:1278- 1289.

8. Oskarsdottir S, Vujic M, Fasth A. Incidence and prevalence of the 22q11 deletion syndrome: a population-based study in Western Sweden. Arch Dis Child 2004; 89:148-151.

9. Cancrini C, Puliafito P, Digilio MC et al. Clinical features and follow-up in patients with $22 \mathrm{q} 11.2$ deletion syndrome. J Pediatr 2014; 164:1475-1480.

10. Bassett AS, McDonald-McGinn DM, Devriendt K et al. Practical guidelines for managing patients with $22 \mathrm{q} 11.2$ deletion syndrome. J Pediatr 2011; 159:332-339.

11. Feinstein C, Eliez S, Blasey C, Reiss AL. Psychiatric disorders and behavioral problems in children with velocardiofacial syndrome: usefulness as phenotypic indicators of schizophrenia risk. Biol Psychiatry. 2002; 51(4):3128 .

12. Gothelf D, Feinstein C, Thompson $\mathrm{T}$ el al. Risk factors for the emergence of psychotic disorders in adolescents with 22q11.2 deletion syndrome. Am J Psychiatry. 2007; 164(4):663-9.

13. Butcher NJ, Chow EW, Costain G et al. Functional outcomes of adults with $22 \mathrm{q} 11.2$ deletion syndrome. Genet Med. 2012;14(10):836-43. 
14. Hercher L, Bruenner G. Living with a child at risk for psychotic illness: the experience of parents coping with 22q11 deletion syndrome: an exploratory study. Am J Med Genet A. 2008;146A(18):2355-2360.

15. Karas DJ, Costain G, Chow EW, Bassett AS. Perceived burden and neuropsychiatric morbidities in adults with 22q11.2 deletion syndrome. J Intellect Disabil Res. 2014;58(2):198-210.

16. McDonald-McGinn DM, Sullivan KE, Marino B et al. 22q11.2 deletion syndrome. Nat Rev Dis Primers. 2015;1:15071.

17. Fung WL, Butcher NJ, Costain G et al. Practical guidelines for managing adults with 22q11.2 deletion syndrome. Genet Med. 2015;17(8):599-609.

18. Karayiorgou M, Simon TJ, Gogos JA. 22q11.2 microdeletions: linking DNA structural variation to brain dysfunction and schizophrenia. Nat Rev Neurosci. 2010;11(6):402-416.

19. van Amelsvoort T, Henry J, Morris R et al. Cognitive deficits associated with schizophrenia in velo-cardio-facial syndrome. Schizophr Res. 2004;70(2-3):223-232.

20. Tandon R, Gaebel W, Barch DM et al. Definition and description of schizophrenia in the DSM-5. Schizophr Res. 2013;150(1):3-10.

21. Walther S, Strik W. Motor symptoms and schizophrenia. Neuropsychobiology. 2012;66(2):77-92.

22. Buijs PCM, Bassett AS, Boot E. Non-pharmacological treatment of psychiatric disorders in individuals with 22q11.2 deletion syndrome; a systematic review. Am J Med Genet A. 2018;176(8):1742-1747.

23. Peluso MJ, Lewis SW, Barnes TR, Jones PB. Extrapyramidal motor side-effects of first- and second-generation antipsychotic drugs. Br J Psychiatry. 2012;200(5):387-392.

24. Boot E, Butcher NJ, van Amelsvoort TA et al. Movement disorders and other motor abnormalities in adults with 22q11.2 deletion syndrome. Am J Med Genet A. 2015;167A(3):639-645.

25. Butcher NJ, Marras C, Pondal M et al. Neuroimaging and clinical features in adults with a $22 \mathrm{q} 11.2$ deletion at risk of Parkinson's disease. Brain. 2017;140(5):1371-1383.

26. Kontoangelos K, Maillis A, Maltezou M et al. Acute Dystonia in a Patient with 22q11.2 Deletion Syndrome. Ment Illn. 2015;7(2):5902.

27. Kennedy GM, Lhatoo SD. CNS adverse events associated with antiepileptic drugs. CNS Drugs. 2008;22(9):739760 .

28. Shprintzen RJ. Velo-cardio-facial syndrome. In: Cassidy SB, Allanson J, editors. Management of Genetic Syndromes. 2. New York: Wiley-Liss; 2005b. pp. 615-632.

29. Golding-Kushner KJ. Therapy Techniques for Cleft Palate Speech and Related Disorders. San Diego: Singular Publishing Group; 2000.

30. Monteiro FP, Vieira TP, Sgardioli IC, et al. Defining new guidelines for screening the 22q11.2 deletion based on a clinical and dysmorphologic evaluation of 194 individuals and review of the literature. Eur J Pediatr. 2013; 172(7):927945.

31. Peyvandi S, Lupo PJ, Garbarini J et al. 22q11.2 deletions in patients with conotruncal defects: data from 1,610 consecutive cases. Pediatr Cardiol 2013; 34:1687-1694.

32. Momma K. Cardiovascular anomalies associated with chromosome 22q11.2 deletion syndrome. Am J Cardiol 2010; 105:1617- 1624 .

33. Fernández L, Nevado J, Santos F et al: A deletion and a duplication in distal 22q11.2 deletion syndrome region. Clinical implications and review. BMC Med Genet 2009; 10:48.

34. John AS, McDonald-McGinn DM, Zackai EH, Goldmuntz E. Aortic root dilation in patients with 22q11.2 deletion syndrome. Am J Med Genet A 2009; 149A:939-942.

35. Shprintzen RJ, Higgins AM, Antshel K et al. Velo-cardio-facial syndrome. Curr Opin Pediatr. 2005;17(6):725-730.

36. Oskarsdóttir S, Vujic M, Fasth A. Incidence and prevalence of the 22q11 deletion syndrome: a population-based study in Western Sweden. Arch Dis Child. 2004;89(2):148-151.

37. Agergaard P, Olesen C, Ostergaard JR et al. The prevalence of chromosome 22q11.2 deletions in 2,478 children with cardiovascular malformations. A population-based study. Am J Med Genet A 2012; 158A:498-508.

38. Habel A, Herriot R, Kumararatne D et al. Towards a safety net for management of 22q11.2 deletion syndrome: guidelines for our times. Eur J Pediatr. 2014;173(6):757-765.

39. Portnoi MF. Microduplication 22q11.2: a new chromosomal syndrome. Eur J Med Genet 2009; $52: 88$-93.

40. Ziolkowska L, Kawalec W, Turska-Kmiec A et al. Chromosome 22q11.2 microdeletion in children with conotruncal heart defects: frequency, associated cardiovascular anomalies, and outcome following cardiac surgery. Eur J Pediatr 2008;167:1135-1140. 
62/Bulletin of Integrative Psychiatry ONew Series O December 2019 ○ Year XXV ○ No. 4 (83)

(1) 41. O'Byrne ML, Yang W, Mercer-Rosa L et al. 22q11.2 deletion syndrome is associated with increased perioperative events and more complicated postoperative course in infants undergoing infant operative correction of truncus arteriosus communis or interrupted aortic arch. J Thorac Cardiovasc Surg 2014; 148:1597-1605.

\section{Correspondence:}

Maria-Magdalena Leon-Constantin,

Universitatea de Medicină și Farmacie "Grigore T Popa" - Iasi, Romania, Facultatea de Medicină, Departamentul Medicale I, Strada Universității nr 16, Iasi, Romania; Spitalul Clinic de Recuperare - Clinica de Recuperare Cardiovasculară, adresa: Str Pantelimon Halipa nr 14, Iasi, Romania e-mail: leon_mariamagdalena@yahoo.com 


\title{
Alternative therapies and management of dementia in Alzheimer's disease
}

\author{
Laura Cristina, Dana Făget, Vasile Chiriță, \\ Roxana Chiriță, Mirela Manea
}

Laura Cristina Popa - MD, Phd student, Prison Hospital Bucharest Jilava, "Carol Davila" University of Medicine and Pharmacy Bucharest

Dana Făget - MD, PhD, Prison Hospital Bucharest Jilava

Delia Marina Podea - MD, Phd, Personal Medical Center for Psychiatry "Dr.Podea Delia", Arad Vasile Chiriță - MD,PhD, professor, member of Romanian Academy, Institute of Psychiatry "Socola" Iași

Roxana Chiriță - MD,PhD, Institute of Psychiatry "Socola" Iași, "Grigore T. Popa" University of Medicine and Pharmacy, Iași

Mirela Manea - MD, PhD, "Alexandru Obregia" Psychiatry Hospital, Bucharest, "Carol Davila" University of Medicine and Pharmacy Bucharest

\begin{abstract}
Neurocognitive disorders are defined by an "significant cognitive impairment in one or more areas: complex attention, executive function, learning and memory, language, perceptual motor ability and social cognition. These dysfunctions represent a decline from a previous level of functioning, so dementia. does not refer to low or reduced intellectual functioning, or mental retardation, which are developmental and static disorders. "(1)

Dementia of the Alzheimer's type is the most common nosological form of dementia, characterized by memory loss and other cognitive skills severe enough to interfere with daily life. Dementia of the Alzheimer's type has a prevalence of $60-80 \%$ of dementia cases. (2)

The factors that differentiate the dementia subtypes are: "evolution over time, the specific areas affected and the associated symptoms" (5)

The therapeutic strategies are based on the increase of the cholinergic transmission and on the modeling of the glutamatergic transmission, validated etiopathogenic hypotheses in dementia Alzheimer's focus on acetylcholine transmission deficiency and NMDA receptor hyperactivity. (19)Patients diagnosed with a neurocognitive disorder such as dementia of the Alzheimer's type, represent a special group, with special needs, in which the concept of quality of life differs from that used for patients diagnosed with conditions that are certainly less disabling.

A series of prospective cohort studies have suggested that in addition to anti - dementia psychotropic therapy, regular physical activity associated with standardized herbal oily
\end{abstract}


s. maceration such as garlic (Allium sativum), hawthorn (Crataegus oxyacantha - linne) and white mistletoe (Viscum album) may have a real effect on risk factors (diabetes, HTA, cerebrovascular disorders, $\mathrm{X}$-metabolic syndrome).

This paper proposes an analysis of both current psychotropic therapy, risk factors and the impact of non-pharmacological treatment on the quality of life of people affected by this pathology.

\section{KEY WORDS:}

\section{Dementia of the Alzheimer's type, anti-dementia, alternative therapies, quality of life}

\section{INTODUCTION}

Neurocognitive disorders are defined by an "significant cognitive impairment in one or more areas: complex attention, executive function, learning and memory, language, perceptual motor ability and social cognition. These dysfunctions represent a decline from a previous level of functioning, so dementia. does not refer to low or reduced intellectual functioning, or mental retardation, which are developmental and static disorders. "(5)

Neurocognitive dysfunction mentioned above are commonly associated with behavioral symptoms. They reflect disruptions in one or more of these areas and are often complicated with behavioral symptoms. "(17)

Neurocognitive disorders have a wide range of subtypes, being classified based on etiological or pathological entities, which would have had an implication in the onset of cognitive decline.

The factors that differentiate the dementia subtypes are: "evolution over time, the specific areas affected and the associated symptoms" (1)

A classification based on the etiology of dementias will highlight the following groups: degenerative dementia (where dementia of Alzheimer's type is reported,), vascular dementia; dementia secondary to space occupying processes; secondary to infectious diseases; those produced by disturbances of internal homeostasis; secondary to endocrine and metabolic diseases; secondary to repeated cerebral microtrauma (boxer dementia); dementia secondary to hydrocephalus with normal pressure and dementia secondary to the consumption of psychoactive substances. Dementias can also be classified into cortical or subcortical subtypes, the Alzheimer's type is a dementia of the cortical category.

Both within ICD-10 Classification of mental and behavioral disorders, we find described within the organic mental disorders including symptomatic, dementia subtypes of Alzheimer's disease (with early onset, late onset, atypical or mixed type and unspecified form), as well as within DSM V Manual of diagnosis and statistical classification of mental disorders, in the subchapter dedicated to neurocognitive disorders.

Alzheimer's disease is defined as a degenerative cognitive disorder with progressive evolution leading to loss of selfmanagement capacity, associating both noncognitive psychiatric complications (behavioral disorders, depression, anxiety, delusion etc.) and somatic / neurological disorders that causepoor outcome. (3)

\section{ETIOLOGY}

Dementia of the Alzheimer's type is the most common nosological form of dementia, characterized by memory loss and other cognitive skills severe enough to interfere 


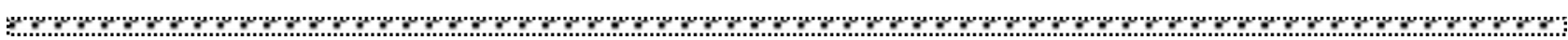

with daily life. Dementia of the Alzheimer's type has a prevalence of $60-80 \%$ of dementia cases. (2)

With the aging of the population, the prevalence of dementia is rising rapidly. Age is the main risk factor for dementia and prevalence doubles every 5 years, from about 1.9 percent at age 65 to 70 percent to 6.3 percent at age 75 to $80,21.7$ percent at age 85 to 90 , and 47.5 percent over 90 . (6)

The aging of the population associated with the increase of the prevalence of cognitive disorders, including dementia, automatically implies an increase of the expenses in the medical field, the elderly population being the main consumer of medical services.

Both direct costs are involved. resulting from the use of social assistance services, drug therapy and continuous care and indirect, caused by a decrease in productivity, resulting in the decreased ability to work and the loss of employment for the patient initially and subsequently for some family members.

The literature reinforces the involvement of genetic factors in the case of early-onset Alzheimer's disease, apparently discoveries have been made about the correlations between genetic changes and neurodegenerative mechanisms.(3)

This condition involves at least three etiopathogenic levels, as follows:

- Neurodegenerative elements (beta-amyloid, neurofibrils) correlated with genetic vulnerability (chromosome abnormalities 21, $14,9,4) ;(3)$

The efficiency of neurotransmitters, particularly acetylcholine (main neurotransmitter involved in cognition) is low, this being associated with the amplification of glutamate activity, especially in the moderate and severe stages of the disease, having as a consequence increased cerebral lesionality; (3)

Vascular-cerebral disorders, hypoxia, metabolic dysfunction (drug-induced hypercortisolemia, secondary to depressive disorder), disturb the balance of the neurofunctional unit, the neuronal binomial / glial cell. This imbalance increases the involvement of the glial cell, at which level glutamate is synthesized. Glutamate hyperactivity is thus a risk factor in the evolution of cerebral or neurodegenerative vascular lesions. (3)

Research on Alzheimer's dementia has undergone a paradigm shift, from the fact that it was regarded as a disease of the elderly, from a life-long perspective, today the evolution of the disease also involves lifestyle changes.

Genetic, psychological, lifestyle factors are involved in the etiopathogenesis of Alzheimer's type dementia; factors that, during the latent period of disease evolution, can act both independently and through mutual enhancement. Consequently, these risk factors are used to obtain risk scores in assessing the likelihood of dementia. Despite population differences, age, low education, and vascular risk factors were identified as key factors in all scoring systems. Risk scores can help identify high-risk individuals who may benefit from different interventions. The European Dementia Prevention Initiative (EDPI), an international collaboration, encourages the exchange of data between various randomized controlled trials. (4)

Although research has been conducted on the protective factors to prevent the onset of dementia, including vitamin $\mathrm{E}$, folic acid, vitamin B6 and vitamin B12, the results of 
.

clinical trials have been negative. Evidence from epidemiological studies on statins that may reduce the risk of dementia has not been confirmed; however, a 2009 Cochrane review did not reveal any effect of the use of older statins in the prevention of Alzheimer's or other types of dementia. (6)

Differential diagnoses with somatic diseases represent a crucial point in addressing this pathology, they must be made as early as possible. "These include treatable entities such as thyroid diseases, vitamin deficiencies, brain tumors, intoxication with medicinal products or drugs, chronic infections and severe depression (pseudodementia). (18)

Neuroimaging tests (CT scan-CT and nuclear magnetic resonance-MRI) are not specific for BA and may be normal in the early stages. However, CT and MRI help to exclude other conditions: primary and secondary neoplasms, multi-infarct dementia, diffuse white matter disease and normotensive hydrocephalus. As Alzheimer's disease progresses, diffuse cortical atrophy becomes visible, and detailed MRI examination reveals atrophy of the hippocampus (Figure 1). (18)

The electroencephalogram (EEG) may be normal or show nonspecific slowness. Routine examination of cerebrospinal fluid (CSF) is normal; More careful studies have shown a decrease in acetylcholine and amyloid $A \beta$ with an increase in your protein. The considerable increase of these levels is related to the normal elderly population and the usefulness of these determinations in diagnosis remains unclear. "(18)

\section{CURRENT THERAPEUTIC APPROACHES}

The therapeutic strategies are based on the increase of the cholinergic transmission and on the modeling of the glutamatergic transmission, hypotheses validated in the etiopathogenesis dementia of Alzheimer's type, the psychopharmacology focusing on the acetylcholine transmission deficit and the hyperactivity of NMDA receptors. (19)

Currently approved medication for dementia patients is limited to antidementials such as glutamatergic modulator (Memantine), acetylcholinesterase inhibitors (Donepezil, Galantamina), acetylcholinesterase inhibitor and butyrylcholinesterase (Rivastigmine) and adjuvant nootropic medication.

Pharmacokinetics and pharmacodynamics are significantly altered in the elderly. The treatment given to these persons must be "effective and with minimal side effects". (26) Neurocognitive disorder patients diagnosed with dementia of Alzheimer's type, are a special group with special needs, the concept of quality of life differs from that used for patients diagnosed with conditions that are clearly less debilitating.

\section{COMPONENTS OF ALTERNATIVE THERAPY}

Nonpharmacological therapies are considered therapeutic interventions that can be performed safely, quite cheaply compared to the costs associated with drug therapies, and whose effects can be monitored through evaluation scales. This type of therapy aims to facilitate, as much as possible, the maintenance of an effective cognition in the case of persons affected by dementia of Alzheiemer's type or from the mild cognitive disorder.

A series of prospective cohort studies have suggested that in addition to anti - dementia psychotropic therapy, regular physical activity associated with standardized maceration herbal oily such as garlic (Allium sativum), hawthorn (Crataegus oxyacantha - linne) and 
white mistletoe (Viscum album) can have a real effect on the risk factors involved in the etipoatogeny of Alzheimer's dementia: diabetes, HTA, cerebrovascular disorders, Xmetabolic syndrome.

In the absence of effective drug options for dementia, complementary medication (MC) have been thoroughly explored. Randomized controlled trials (RCTs) were conducted on a series of MC for dementia, cognitive decline and mild cognitive impairment (MCI), with many ongoing studies. (6)

\section{Garlic (Allium sativum)}

Allium sativum has been used for thousands of years for medical purposes; Sanskrit records indicate its medical use about 5000 years ago and has been used for at least 3000 years in Chinese medicine. It has been extensively studied in vitro in animal and human clinical trials and in epidemiological evaluations for its multiple medicinal properties. The quality of clinical trials is heterogeneous, making it difficult to compare them.

The antimicrobial, hypolipidemic, antioxidant and antithrombotic effects that have been attributed to garlic are supposed to be primarily linked to allicin, and the antineoplastic effects may be related to sulfur compounds or other unknown components.

Many randomized clinical studies have studied the effects of garlic on lipid levels, this role was underlined by two meta-analyzes conducted in 1993 and 1994, regarding the effect of garlic on total cholesterol, which revealed a significant reduction in total cholesterol level (9 up to 12\%) compared to placebo.

A more recent meta-analysis of 10 placebocontrolled studies using standard dry garlic powder showed significant decreases in total cholesterol levels (19.2 mg per dL [0.50 mmol per L]), low levels of lipoprotein cholesterol $(6,7 \mathrm{mg}$ per $\mathrm{dL}$ (0.20 mmol per L)) and triglyceride levels (21.1 $\mathrm{mg}$ per $\mathrm{dL}$ [0.24 mmol per L]) at eight to twelve weeks.

Researchers at the Curtin's Life Science Facility have found that a certain garlic extract could help or even prevent the destruction the blood-brain barrier. This would be a real help in treating dementia of Alzheimer's type.

Hawthorn. (Crataegus oxyacantha)

Another study by 2017 researchers at Banasthali University, Jaipur, India and the Pinnacle Biomedical Research Institute, Bhopal, India, demonstrates the promising effect of Crataegus oxyacantha (hawthorn) in improving learning and memory due to the presence of certain phytocoons.

Regarding cardiovascular effects, the primary activity of the hawthorn is to increase coronary blood flow, probably due to relaxation of the coronary arteries, resulting in direct increase in blood flow. Positive inotropic action of hawthorn may be due to $\mathrm{Na}+/ \mathrm{K}+$ inhibition, myocardial ATPase. It also lowers blood pressure, which results in increased effort tolerance during the early stage of congestive heart failure (ICC).

Surprisingly, hawthorn has the ability to adjust blood pressure (hTa / HTA). Since bioflavanoids dilate both peripheral and coronary blood vessels, it is recommended to use in angina pectoris.

The hawthorn increases the intracellular efficacy of vitamin $\mathrm{C}$, thus having a protective effect on oxidative processes.

Anti-inflammatory effects have been discovered by preventing the synthesis and release of pro-inflammatory markers such as histamines, prostaglandins, leukotrienes, etc. 


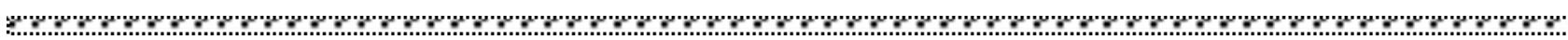

White mistletoe (Viscum album)

White mistletoe, known for immunomodulatory activity, is a real benefit in the prevention and therapeutic action of risk factors for dementia of Alzheimer's type by: homeostasis effect, stimulating effects on metabolism and beneficial action on the pancreas by regulating blood glucose.

Alternative and complementary therapies are used for dementia of Alzheimer's type in the prodromal phase, with the goal of reducing risk factors and at the same time improving quality of life, together with regular physical activity, a balanced diet containing fruits and vegetables rich in vitamin $\mathrm{C}$, unsaturated fatty acids, smoking cessation and intellectual activity.

The mechanisms by which exercise can improve the cognition of patients with MCI or dementia are: increased blood flow and oxygen supply to the brain, decreased blood pressure, reduced inflammatory markers, improved endothelial function. It may also increase the volume of the hippocampus. It has been shown in animal studies that exercise stimulates the proliferation of neurons in hippocampal areas. (20)

\section{METHODOLOGY}

In this study, PUBMED, the Central Register of Cochrane Controlled Studies, the site of the Alzheimer's association, NCBI, was used for a preliminary search of the specialized literature.

Input data were taken after they have been identified randomized controlled trials (RCTs) which have the relevant data for the work. Terms were used in the search algorithm such as, "Alzheimer's type dementia", "Alzheimer's disease", "antidementia therapies", "alternative dementia therapies", "cognitive methods", "risk factors", "dementia assisted protocols", "nutritional support "or" homeopathic therapy".

It was further examined the bibliography of studies identified in published meta-analyzes. The articles which proved to be duplicates or which did not meet the eligibility criteria imposed were not taken into account.

The process of searching and conducting the study took into account the PRISMA criteria.

At the same time, we have analyzed extensively the specialized literature on the subject of Alzheimer's type dementia.

\section{DISCUSSIONS}

So far there are no known means of preventing Alzheimer's type dementia.

Due to the limited effectiveness of the drug therapy used and the involvement of a large number of professionals (eg doctors, psychologists, occupational therapists, assistants, carers, etc.) research based on non / pharmacological treatment (NPT) becomes important in the complex and individualized management of Alzheimer's type dementia.

NPT can improve the quality of life (QoL) of patients diagnosed with MCI and / or Alzheimer's type dementia, being noninvasive and having reduced side effects. (8)

NPT interventions are numerous, they play a role in reducing patient symptoms, caregiver stress and can be both simple (eg environmental interventions) to more complex approaches (eg, virtual reality, home automation). (7)

Non-pharmacological therapies do not act on the etiopathogenic mechanisms of Alzeimer dementia. but to improve the quality of life of the patient and of the caregiver while 
Bulletin of Integrative Psychiatry O New Series O December 2019 ○ Year XXV ONo. 4 (83)/69

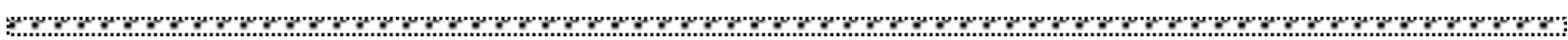
maintaining its functionality and factors as well as the impact of nonindependence as long as possible, however, a pharmacological treatment on the quality of direct effect of NPT on neuronal plasticity / adaptation cannot be ruled out, especially in life of patients diagnosed with dementia of the latent, early stages of the disease.

Alzheimer's type.

This research analyzes both the effects of current anti-dementia therapy and the risk

\section{ACKNOWLEDGEMENTS AND DISCLOSURES}

The authors declare that they have no potential conflicts of interest to disclose.

\section{REFERENCES}

1. Kaplan, Sadock's Comprehensive Textbook of Psychiatry Volume I/II - 10th Edition - Benjamin James Sadock, M.D.; Virginia Alcott Sadock, M.D.; Pedro Ruiz, M.D., 1191-1200

2. A. Capisizu, A. Zamfirescu, S.M. Aurelian, I. Dina: Rezultate ale studiului de prevalenţă privind comorbidităţile la diferiţi pacienţi1, Revista Română de Statistică nr. 5 / 2013

3. Psihiatrie clinică: Editura Medicală București 2013, 707-714

4. Imtiaz B., Tolppanen AM, Kivipelto M, Soininen H. : Future directions in Alzheimer's disease from risk factors to prevention, Biochem Pharmacol. 2014 Apr 15;88(4):661-70

5. DSM -5 Manual de diagnostic și clasificare statistică a tulburărilor mintale. Ediția a V-a. București :Editura Medicală Callistro, 2016, 591-614

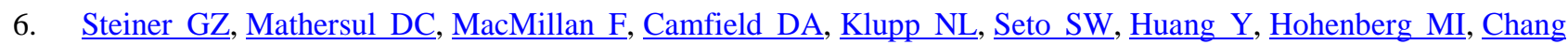
$\underline{\mathrm{DH}}$ A Systematic Review of Intervention Studies Examining Nutritional and Herbal Therapies for Mild Cognitive Impairment and Dementia Using Neuroimaging Methods: Study Characteristics and Intervention Efficacy. Evid Based Complement Alternat Med. 2017;2017:6083629.

7. McDermott O, Charlesworth G, Hogervorst E, Stoner C, Moniz-Cook E, Spector A, Csipke E, Orrell M. : Psychosocial interventions for people with dementia: a synthesis of systematic reviews, Aging Ment Health. 2019 Apr; 23(4):393-403.

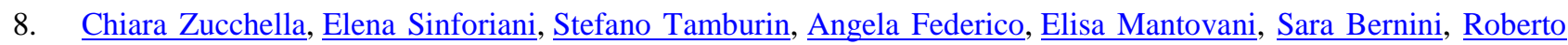
Casale, Michelangelo Bartolo: The Multidisciplinary Approach to Alzheimer's Disease and Dementia. A Narrative Review of Non-Pharmacological Treatment, Front Neurol. 2018; 9: 1058. Published online 2018

9. JAMA: Physical activity and cardiovascular Health NIH Consensus development panel on physical activity and cardiovascular heath, JAMA, 1996; 276(3):241-246.

10. Wong CW : Pharmacotherapy for dementia: a practical approach to the use of cholinesterase inhibitors and memantine. Drugs Aging (2016) 33:451-60

11. Carole Parsons, Sarah Gamble: Caregivers' perspectives and experiences of withdrawing acetylcholinesterase inhibitors and memantine in advanced dementia: a qualitative analysis of an online discussion forum, BMC Palliative Care, 2019 18:6

12. Puangthong U, Hsiung GR: Critical appraisal of the long-term impact of memantine in treatment of moderate to severe Alzheimer's disease. Neuropsychiatr Dis Treat. 2009;5:553-61

13. Hogan DB, Bailey P, Carswell A, Clarke B, Cohen C, Forbes D: Management of mild to moderate Alzheimer's disease and dementia. Alzheimers Dement. 2007;3(4):355-84.

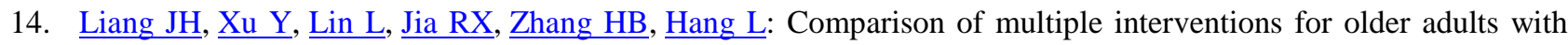
Alzheimer disease or mild cognitive impairment: A PRISMA-compliant network meta-analysis, Medicine (Baltimore). 2018 May;97(20):e10744.

15. Middleton LE, Black SE, Herrmann N, Oh PI, Regan K, Lanctot KL: Centre- versus home-based exercise among people with mci and mild dementia: study protocol for a randomized parallel-group trial, BMC Geriatr. 2018 Jan $25 ; 18(1): 27$ 
16. Genevieve Z. Steiner, Danielle C. Mathersul, Freya MacMillan, David A. Camfield, Nerida L. Klupp, Sai W. Seto,

Yong Huang, Mark I. Hohenberg, Dennis H. Chang: A Systematic Review of Intervention Studies Examining Nutritional and Herbal Therapies for Mild Cognitive Impairment and Dementia Using Neuroimaging Methods: Study Characteristics and Intervention Efficacy, Evid Based Complement Alternat Med. 2017; 2017: 6083629. Published online 2017 Feb 19

17. Kaplan, Sadock's - Synopsis of psychiatry. Behavioral sciences/ clinical psychiatry 11th edition- Benajmin James Sadock, M.D., Virginia Alcott Sadock, M.D., Pedro Ruiz, M.D. 704-741

18. Harrison. Manual de medicină. Ediția a 18-a

19. JURMED - Jurnal de sănătate psihiatrie 2017 ISSN 2501-188X, ISSN-L 250-188X

20. Revista Română de Psihiatrie: The impact of non-pharmacological treatment on symptom reduction and progression of mild cognitive impairment to dementia . Alexandru N. Pavel, Valentin P. Matei, Cătălina Tudose Vol XX, Nr 3, 2 septembrie 2018

21. Liu YH, Gao X, Na M, Kris-Etherton P, Mitchell D, Jensen G. Curr Dev Nutr. Dietary pattern score, diet quality, and major neurodegenerative diseases: a meta-analysis of observational cohort studies (OR33-07-19) eCollection 2019 Jun.

22. Booth V, Harwood R, Hancox JE, Hood-Moore V, Masud T, Logan P. Motivation as a mechanism underpinning exercise-based falls prevention programmes for older adults with cognitive impairment: a realist review. BMJ Open Jun 2019, 9(6):e024982

23. Baudrimont, M., Dubas, F., Joutel, A., Tournier-Lasserve, E. \& Bousser, M. G. Stroke 24, 122-125 (1993).

24. Haan MN and Wallace R (2004) Can dementia be prevented? Brain aging in a population-based context. Annu Rev Public Health 25: 1-24

25. Luchsinger JA et al. (2004) Hyperinsulinemia and risk of Alzheimer disease. Neurology 63: 1187-1192

26. Chui HC, Mack W, Jackson E, et al. Clinical criteria for the diagnosis of vascular dementia: a multicenter study of comparability and interrater reliability. Arch Neurol 2000

27. American Psychiatric Association, Diagnostic and Statistical Manual of Mental Disorders, Fourth Edition, Text Revision. Washington, DC American Psychiatric Association2000

\section{Correspondence:}

Laura Cristina Popa,

MD, Phd student, Prison Hospital Bucharest Jilava, "Carol Davila" University of Medicine and Pharmacy Bucharest, pcristina9025@gmail.com

Submission: 10 aug 2019

Acceptance: 29 oct 2019 


\title{
The impact of biochemical control on the quality of life of patients with acromegaly
}

\author{
Emilia Solomon, Cristina Preda, Cristina Maria Gavrilescu, \\ Radu Gheorghe Solomon, Dumitru Brănișteanu
}

\begin{abstract}
Emilia Solomon - MD, PhD Student, „Grigore T. Popa” University of Medicine and Pharmacy, Iaşi, Romania, Department of Endocrinology, CF University Hospital, Iaşi, Romania

Cristina Preda - Associate Professor, MD, PhD, „Grigore T. Popa” University of Medicine and Pharmacy, Iaşi, Department of Endocrinology, „Sf. Spiridon” Hospital, Iaşi, Romania

Cristina Maria Gavrilescu - Lecturer, MD, PhD, „Grigore T. Popa” University of Medicine and Pharmacy, Iași, Vth Medical and Geriatrics - Gerontology Clinic, Iași

Radu Gheorghe Solomon - DDS, MDSI, PhD Student ISUD, University Lucian Blaga Sibiu

Dumitru Brănișteanu - Professor, $\mathrm{MD}, \mathrm{PhD}$, „Grigore T. Popa” University of Medicine and Pharmacy, Iași, Department of Endocrinology, „Sf. Spiridon” Hospital, Iaşi, Romania
\end{abstract}

\begin{abstract}
Purpose: Quality of life (Qol) is undoubtedly important for patient case management. The current goal of a treatment extends therefore beyond biochemical monitoring, including the physical, mental and social state of wellbeing. We aimed to correlate disease activity with the perception of Qol in acromegalic patients.
\end{abstract}

Methods: We performed a single center cross-sectional study on 26 patients: 9 men (34.6\%) and 17 women $(65.4 \%)$, with a mean age of $53 \pm 11.5$ years. Eleven patients $(42.3 \%)$ had a biochemically controlled disease, while 15 subjects $(57.7 \%)$ had an active disease.

Results: The mean total score of the quality of life was $60.9 \pm 12.6$ in women, ranging from 40 to 85 , while for men, the mean total score was of $64.04 \pm 14.78$, ranging from 42 to 85 $(p=0.575)$. There was no significant difference between the mean AcroQol scores of patients with controlled or active disease $(62.54 \pm 13.42$ vs $61.23 \pm 13.46, p=0.804)$. Patients younger than 60 had a significantly lower total score compared to older patients, $(58.36 \pm 14.17 \mathrm{vs}$ $64.26 \pm 12.44, p=0.047)$. Rural residents also scored lower than patients belonging to the urban region: $(58.18 \pm 11.21$ vs $67.19 \pm 14.39, p=0.048)$. Disease duration was negatively correlated with total score on AcroQol $(r=-0.253, p=0.045)$. We did not find significant correlations between GH and IGF1 levels and AcroQol ( $p=0,622$ and $p=0.844$, respectively).

Conclusions: We found no significant differences between males and females, as well as between patients with active and controlled disease regarding the Qol, but other factors like 

age or locality provenience may play some role for the perceived health status and quality of life in acromegalic patients

\section{KEYWORDS:}

\section{Quality of life; acromegaly; biochemical control}

\section{INTRODUCTION}

Acromegaly is a rare and chronic disease with an insidious evolution. The average time from the onset of the disease until the patient is diagnosed is about 5 to 10 years $(1,2)$. The pathognomonic signs are the enlargement of the extremities, hands, feet, tongue, nasal pyramid, frontal bossing and lower jaw protrusion. These features are associated with comorbidities: generalized musculoskeletal pain, osteoporosis and hip fractures, impaired heart function, sleep apnea and the decrease of physical force $(3,4)$. The top 5 most common comorbidities of acromegaly are: hypertension, diabetes, hypothyroidism, arthralgia / synovitis and sleep apnea $(5,6)$. These serious and at times irreversible changes have already occurred by the moment of diagnosis, predisposing the patient to affective disorders, commonly depression. There is also a tendency to sleep disorders, impaired attention, memory and social isolation (7,8). All these disease-related comorbidities can severely affect the quality of life of acromegaly patients and may lead to psychological sequelae (9-14).

The concept of quality of life evaluates the patient's perception on his/her physical, psychological and social wellness. The factors that minimize disease burden are: emotional and mental wellbeing, interpersonal relations, material wellbeing, a satisfying career that implies competence and a strong professional background, independence and social integration $(15,16)$. Psychosocial factors influencing patient's life are: pain, decreased range of motion, difficulty in usual daily activities, financial difficulties and cognitive deficits (17).

Currently, the most commonly used questionnaires of quality of life are: Short Form 36 (SF-36), Functional Assessment of Chronic Illness Therapy (FACIT), Nottingham Health Profile (NHP), EuroQol and to assess the impact cancer EORTC (European Organization for Research and Treatment of Cancer) QLQ .

AcroQol is a standardized questionnaire specifically designed for patients diagnosed with acromegaly and conceived in 2002 $(15,18,19)$.

The medical goal in acromegaly is to reduce mortality and morbidity by obtaining a longterm biochemical control. Studies reported conflicting results concerning biochemical control as a beneficial factor for the quality of life. The research conducted by Shih-CheHua et al on 52 acromegaly subjects aged between 20-76 years did not find any significant difference of total AcroQol score between patients with controlled or active disease, but they noted higher scores in patients treated with lanreotide compared to the group that did not receive this specific treatment (20). These findings are supported by other researchers $(12,18,21)$. Other studies found, however, a positive correlation between biochemical control and a better quality of life $(22,23)$.

The aim of this paper was to evaluate the biochemical control as a predictor factor for quality of life in patients with acromegaly. 
Bulletin of Integrative Psychiatry O New Series O December 2019 ○ Year XXV ONo. 4 (83)/73

\section{MATERIALS AND METHODS}

We conducted a cross-sectional, descriptive, analytical study on 26 acromegaly patients undergoing treatment at the Endocrinology Clinic of St Spiridon Hospital of Iași.

Thirty acromegaly patients were invited to complete the AcroQol questionnaire between January 2015 and January 2018. The exclusion criteria were major psychiatric disorders, stressful life events over the past year or comorbid cancers. Four patients refused, therefore a total of 26 remaining patients (9 men and 17 women) participated to this study.

The study was approved by the local ethical committee of Grigore T Popa University of Medicine and Pharmacy and was carried out according to the Declaration of Helsinki. All patients gave their informed written consent.

All patients admitted to this study had a diagnosis unequivocally established by specific tests and IRM for the pituitary gland. Biochemical control was based on GH levels $<0.4 \mu \mathrm{g} / \mathrm{L}$ at $2 \mathrm{~h}$ during the OGTT test with $75 \mathrm{~g}$ glucose and IGF-1 within 2 age and gender adjusted SD. Standard biochemical analysis and hormonal parameters (basal GH, IGF-1, PRL, LH, FSH, TSH, free T4, plasmatic cortisol at $8 \mathrm{am}$, testosterone for men and estradiol for women) were collected.

\section{Evaluation of the quality of life}

Quality of life was evaluated using a selfadministrated specific questionnaire for acromegaly. AcroQol (the Acromegaly Quality of life Questionnaire) assesses a perceived health status by evaluating the domains of physical status, appearance and personal relations. It comprises 22 questions with five possible responses ranging from 1 to 5 with a maximum score of 110 . Higher scores for the global and for all 3 dimensions indicate a better Qol.

\section{Data analysis}

The data obtained were analyzed in SPSS-18 using descriptive statistics including frequency, percentage, mean and standard deviation to describe the personaldemographic factors, quality of life and hormonal status. Pearson's correlation test was used to determine the relationship between the quality of life and duration of illness, GH and IGF-1. The one-way ANOVA and the independent t-test were used to determine the relationship between some of the personal-demographic factors and the quality of life.

\section{RESULTS}

Sociodemographic and clinical characteristics

The study group was composed of 9 men (34.6\%) and 17 women (65.4\%), with a mean age of $53 \pm 11.5$ years, higher in women than in men $(55.1 \pm 11.37$ vs $48.9 \pm 11.22$, $(\mathrm{p}=0.194)$. The study group had a predominance of rural females with an education ranging from 8 to 16 (mean of $12.22 \pm 3.03$ for men and $10.88 \pm 2.34$ for women, $\mathrm{p}=0.268$ ) and duration of known illness ranging between 1-45 years with a mean of $10.8 \pm 10.29$ (mean of $13.77 \pm 12.21$ years for men and $9.23 \pm 9.13$ years for women, $\mathrm{p}=0.345$ ).

Most patients $(23,88.46 \%)$ presented with a macroadenoma and 21 patients $(80.76 \%)$ were submitted to transsphenoidal surgery. Nine of these patients were further radiotreated. Mean GH and IGF-1 levels were $2.15 \pm 2.66 \mathrm{ng} / \mathrm{ml}$ and $281.38 \pm 182.5 \mathrm{ng} / \mathrm{ml}$ respectively.

\section{Quality of life}

The mean total score of the quality of life was of $60.9 \pm 12.6$ in women, (ranging between 40 


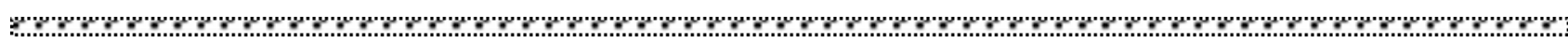

and 85), while in men, mean total score was of $64.04 \pm 14.78$, ranging between 42 and 85 $(\mathrm{p}=0.575)$. When patients younger than 60 years were compared with patients older than 60, a significant difference was noticed in the AcroQol $\quad(58.36 \pm 14.17$ vs $64.26 \pm 12.44$, $\mathrm{p}=0.047)$.

The physical dimension varied from 8 to 35 , with no significant differences between women and men $(21.59 \pm 6.4$ vs $22.22 \pm 6.91$, $\mathrm{p}=0.817$ ) or between patients younger and older than 60 years of age $(19.8 \pm 7.42$ vs $23.6 \pm 5.65, \mathrm{p}=0.216$ ).

The appearance dimension ranged from 10 to 31 , with no significant differences between women and men $(20.18 \pm 6.18$ vs $21.22 \pm 6.4$, $\mathrm{p}=0.689$ ) or between patients younger and older than 60 years of age $(19.2 \pm 6.18$ vs $21.7 \pm 6.17, \mathrm{p}=0.612$ ).

We also observed no significant differences regarding personal relationships between women and men ( 25.53 vs $26.44 ; \mathrm{p}=0.626$ ) and between younger and older patients (25.7 vs $25.94, \mathrm{p}=0.897$ ).

There was a significant negative correlation between the duration of disease and total AcroQol score $(r=-0.253, p=0.045)$, but no correlation between GH or IGF-1 levels and total AcroQol score $(\mathrm{r}=+0.101 ; \mathrm{p}=0.622$ and $\mathrm{r}=+0.041 ; \mathrm{p}=0.844$ for $\mathrm{GH}$ and IGF-1, respectively).

\section{Rural vs urban provenience}

Fifteen patients came from the countryside, while 11 lived in the city. Patients from the rural area had a lower AcroQol score (58.18 \pm 11.21 vs $67.19 \pm 14.39$ for the patients from the urban area, $\mathrm{p}=0.048$ ). They also scored poorer regarding personal relationships $(24.2$ \pm 4.2 vs $28.09 \pm 3.86, \mathrm{p}=0.024)$. There were no differences regarding the physical and appearance dimensions between the groups of countryside or city provenience $(20.07 \pm 5.15$ vs $24.18 \pm 7.49, \mathrm{p}=0.109$, and $20 \pm 6.57$ vs $21.27 \pm 5.75, \mathrm{p}=0.612$, respectively).

Relationship between illness perception and biochemical control

Eleven patients (42.3\%) had a biochemically controlled disease, while 15 subjects (57.69\%) had an active disease. Patients with controlled disease were not different from patients with active disease with respect to the total AcroQol score (62.54 \pm 13.42 vs $61.23 \pm$ 13.46, $(\mathrm{p}=0.804)$, physical dimension score, $(22.53 \pm 6.58$ vs $20.82 \pm 6.45, \quad(p=0.514)$, appearance score. $(20.73 \pm 6.26$ vs $20.40 \pm$ $6.28,(\mathrm{p}=0.896)$ or the personal relationships score $(26 \pm 4.64$ vs $25.65 \pm 4.34,(p=0.841)$.

\section{The effect of radiotherapy on quality of life}

The AcroQol global score of patients with acromegaly and submitted to radiotherapy did not differ from non-irradiated patients $(62.52$ \pm 14.77 vs $61.71 \pm 12.73, \mathrm{p}=0.885)$. No difference was observed between irradiated and non-irradiated patients also regarding any of the three domains of AcroQol: physical domain (23.44 \pm 7.37 vs $20.94 \pm 5.96$, $\mathrm{p}=0.357)$, appearance $(19.22 \pm 5.95$ vs 21.24 $\pm 6.31, \mathrm{p}=0.438)$ and personal relationships $(26.22 \pm 5.04$ vs $25.65 \pm 4.23$, $\mathrm{p}=0.760)$.

\section{DISCUSSION}

Medical intervention should not focus only on prolonging life span, but also on fulfilling the desire of patients to have a pleasant life, based on personal and social wellbeing.

Quality of life is a multidimensional complex that covers the physical wellbeing (the perception of the individual of his/her health), psychological aspects (subjective perception regarding the cognitive and affective state) and social aspects (aiming interpersonal relationships). Asthenia accompanied by lack of interest for the environment and usual 
activities and pain, especially related to osteoarticular complications, are common in acromegaly and can generate a high degree of suffering and disability, altering the quality of life (24-27).

In our transversal study, we found no significant differences between genders regarding the quality of life. Literature data is discordant. Whereas certain authors did not find, similar to us, any gender-related differences (12), others found a lower Qol in women $(18,28)$. An interesting study using 3D facial analysis stereophotography showed that men are more at risk to develop dysmorphic facial features, with more pronounced nose width, length and depth, face length, width, gonion-gnathion distances and nasofrontal and columella-labial angles (29). Despite these morphological findings, Qol seems to be significantly hampered to at least the same extent in both genders, if not even more in women. This discordance is caused by the fact that Qol is a subjective, self-perceived state of health, not necessarily overlapping the severity of clinical modifications. Body shape dissatisfaction is therefore more related to a lower Qol than the amplitude of dysmorphism. Women seem therefore more sensitive to body changes, especially facial features, than men. The Qol of acromegalic women could also be influenced by frequent sexual dysfunction concerning desire, arousal and satisfaction (30).

Our study showed that rural provenience was associated with lower quality of life. Patients from the countryside achieved a lower global score and also scored poorer at personal relationships, while no significance was reached regarding physical wellbeing and appearance satisfaction. These findings probably highlight the importance of a good neighborhood, the availability of facilities and the housing comfort and safety(31,32). Rural residents may also have issues accessing quality healthcare due to socioeconomic disadvantage or distance $(33,34)$.

Our younger patients dealing with acromegaly have lower quality of life. This finding is in accordance with other studies and it applies also to other dysmorphic conditions(16). Subjects under 60 years old are more interested to be accepted by the society, therefore body dysmorphism augments their adaptation stress, especially when the disease has a disfiguring nature leading to anthropometric changes and body image disturbance $(8,35)$. Older patients have different issues, such as understanding their disease and risk of acromegaly-related comorbidities, thereby accepting their disease condition with diminished stress (36).

Half of the patients with acromegaly have anxiety and insomnia related to the acceptance of the illness. The psychological component seems therefore to play an important for patient Qol (7). Coping strategies, such as problem- solving and positive thinking actions, may diminish psychological distress such as anxiety and depression also in acromegalic patients. Cognitive behavioral therapy such as the 'Think healthy' technique were promising also in acromegalic patients (37).

We did not find any correlation between the levels of GH or IGF-1 and the quality of life of our acromegalic patients. Our data are in line with those obtained by other authors $(21,38,39)$. In contrast, other authors suggested that patients with active acromegaly or higher IGF1 bioactivity may achieve lower AcroQoL scores when compared with patients having controlled disease $(23,40)$. 
(1) Although there are still inconsistencies concerning the benefit of a biochemical control on the Qol of acromegalic patients, the normalization of $\mathrm{GH}$ and IGF-1 levels may have an indirect effect by preventing comorbidities. Musculoskeletal pain is the most frequent complaint affecting up to $90 \%$ of patients dealing with acromegaly and is negatively correlated with the Qol (14). The therapy of acromegaly diminishes this complication, thereby possibly improving the Qol. Acromegalic patients treated with somatostatin receptor agonists scored higher at the AcroQol test than non-treated patients

\section{LIMITATIONS AND STRENGTHS}

The major limitation of our study is the small number of enrolled acromegalic subjects. Acromegaly is a rare disease, but our single center cross-sectional study could be improved by enlarging it to a multicenter study.

Our study's strength is the design originality, combining the assessment of gender, age, settlement and duration of the disease and its biochemical control on all the components of Qol. (20).

\section{CONCLUSIONS}

Quality of life is important as a tool for investigating the satisfaction of patients and the therapeutic impact on their wellbeing. Our study demonstrates that achieving a biochemical control does not entirely overlap an improvement of the quality of life of acromegalic patients. Other conditions, such as patient's age or settlement may have an important influence on the quality of life of acromegalic patients. Qol evaluation helps the clinician and the psychologist to offer adequate support for the patient. A holistic approach, rather than only achieving a biochemical control is the key for a better quality of life of acromegalic patients.

\section{ACKNOWLEDGE AND DISCLOSURE}

The authors declare that they have no conflicts of interest that would prejudice the impartiality of this scientific work.

\section{REFERENCES}

1 Melmed S, Casanueva FF, Klibanski A, Bronstein MD, Chanson P, et al. (2013) A consensus on the diagnosis and treatment of acromegaly complications, Pituitary. doi:10.1007/s11102-012-0420-x.

2 Siegel S, Streetz-Van.Der Werf C, Schott JS, Nolte K, Karges W, et al. (2013) Diagnostic delay is associated with psychosocial impairment in acromegaly, Pituitary..

3 Ben-Sholmo A, Sheppard MC, Stephens JM, Pulgar S, Melmed S. (2011) Clinical, quality of life, and economic value of acromegaly disease control, Pituitary.

4 Compostela AS, Giustina A, Chanson P, Kleinberg D, Bronstein MD, et al. (2014) Expert consensus document: A consensus on the medical treatment of acromegaly, Nat. Rev. Endocrinol.. doi:10.1038/nrendo.2014.21.

5 Arosio M, Reimondo G, Malchiodi E, Berchialla P, Borraccino A, et al. (2012) Predictors of morbidity and mortality in acromegaly: An Italian survey, Eur. J. Endocrinol. doi:10.1530/EJE-12-0084.

6 Placzek H, Xu Y, Mu Y, Begelman SM, Fisher M. (2016) Clinical and Economic Burden of Commercially Insured Patients with Acromegaly in the United States: A Retrospective Analysis, J. Manag. Care Spec. Pharm. doi:10.18553/jmcp.2015.21.12.1106.

7 Szczë̈niak D, Jawiarczyk-Przybyłowska A, Rymaszewska J. (2015) The quality of life and psychological, social and cognitive functioning of patients with acromegaly, Adv. Clin. Exp. Med.. doi:10.17219/acem/38156.

8 Conaglen HM, de Jong D, Crawford V, Elston MS, Conaglen JV. (2015) Body Image Disturbance in Acromegaly Patients Compared to Nonfunctioning Pituitary Adenoma Patients and Controls, Int. J. Endocrinol. doi:10.1155/2015/624872. 
r.n. 9 Anagnostis P, Efstathiadou ZA, Charizopoulou M, Selalmatzidou D, Karathanasi E, et al. (2014) Psychological profile and quality of life in patients with acromegaly in Greece. Is there any difference with other chronic diseases? Endocrine. doi:10.1007/s12020-014-0166-5.

10 Colao A, Pivonello R, Scarpa R, Vallone G, Ruosi C,et al. (2005) The acromegalic arthropathy., J. Endocrinol. Invest.

11 Dantas RAE, Passos KE, Porto LB, Zakir JCO, Reis MC, et al. (2013) Physical activities in daily life and functional capacity compared to disease activity control in acromegalic patients: impact in self-reported quality of life, Arq. Bras. Endocrinol. Metabol. doi:10.1590/S0004-27302013000700009.

12 Geraedts VJ, Andela CD, Stalla GK, Pereira AM, van Furth WR., et al. (2017) Predictors of quality of life in acromegaly: No consensus on biochemical parameters, Front. Endocrinol. (Lausanne).. doi:10.3389/fendo.2017.00040.

13 Miller A, Doll H, David J, Wass J. (2008) Impact of musculoskeletal disease on quality of life in long-standing acromegaly, Eur. J. Endocrinol. doi:10.1530/EJE-07-0838.

14 Wassenaar MJE, Biermasz NR, Kloppenburg M, va. der Klaauw AA, Tiemensma J, et al. (2010) Clinical osteoarthritis predicts physical and psychological QoL in acromegaly patients, Growth Horm. IGF Res. doi:10.1016/j.ghir.2010.02.003.

15 Crespo I, Santos A, Resmini E, Valassi E, Martínez-Mombla'n MA, et al. (2014) Improving quality of life in patients with pituitary tumors, US Endocrinol.

16 Gambin G, Molzahn A, Fuhrmann AC, Morais EP, Paskulin LM. (2015) Quality of life of older adults in rural southern Brazil, Rural Remote Health.

17 Muldoon MF, Barger SD, Flory JD, Manuck SB. (1998) What are quality of life measurements measuring?, BMJ. doi:10.1136/bmj.316.7130.542.

18 Webb SM, Badia X. (2016).Quality of Life in Acromegaly, Neuroendocrinology. doi:10.1159/000375451.

19 Webb SM, Badia X, Surinach NL, Astorga R, Benito P, et al. (2006) Validity and clinical applicability of the acromegaly quality of life questionnaire, AcroQoL: A 6-month prospective study, Eur. J. Endocrinol. doi:10.1530/eje.1.02214.

20 Hua SC, Yan YH, Chang TC. (2006) Associations of remission status and lanreotide treatment with quality of life in patients with treated acromegaly, Eur. J. Endocrinol. doi:10.1530/eje.1.02292.

21 T'Sjoen G, Bex M, Maiter D, Velkeniers B, Abs R. (2007) Health-related quality of life in acromegalic subjects: data from AcroBel, the Belgian Registry on acromegaly, Eur. J. Endocrinol. 157 411-417. doi:10.1530/eje-07-0356.

22 Paisley AN, Rowles SV, Roberts ME, Webb SM, Badia X, et al. Trainer. (2007) Treatment of acromegaly improves quality of life, measured by AcroQol, Clin. Endocrinol. (Oxf).. doi:10.1111/j.1365-2265.2007.02891.x.

23 Trepp R, Everts R, Stettler C, Fischli S, Allemann S, et al. (2005) Assessment of quality of life in patients with uncontrolled vs. controlled acromegaly using the Acromegaly Quality of Life Questionnaire (AcroQoL).(Erratum appears in Clin Endocrinol (Oxf). 2005 Aug;63(2):238), Clin. Endocrinol (Oxf).

24 Kauppinen-Mäkelin R, Sane T, Sintonen H, Markkanen H, Välimäki MJ, et al. (2006) Quality of life in treated patients with acromegaly, J. Clin. Endocrinol. Metab. doi:10.1210/jc.2006-0676.

25 Matta MP, Couture E, Cazals L, Vezzosi D, Bennet A,et al. (2008) Impaired quality of life of patients with acromegaly: Control of GH/IGF-I excess improves psychological subscale appearance, Eur. J. Endocrinol. $158305-$ 310. doi:10.1530/EJE-07-0697.

26 Psaras T, Honegger J, Gallwitz B, Milian M. (2011) Are there gender-specific differences concerning quality of life in treated acromegalic patients?, Exp. Clin. Endocrinol. Diabetes. doi:10.1055/s-0030-1267912.

27 Vandeva V, Yaneva M, Natchev E, Elenkova A, Kalinov K, et al. (2015) Disease control and treatment modalities have impact on quality of life in acromegaly evaluated by Acromegaly Quality of Life (AcroQoL) Questionnaire, Endocrine. doi:10.1007/s12020-014-0521-6.

28 Garduño-Pérez AA, Zamarripa-Escobedo R, Vergara-López A, Guillén-González MA, Escudero-Licona I. (2011) Artículo original Análisis de la calidad de vida en pacientes con acromegalia en el Centro Médico Nacional 20 de Noviembre, ISSSTE, 19 97-101.

29 Guo X, Meng T, Huang J, Wang X, Lian W, et al. (2018) 3D Facial Analysis in Acromegaly: Gender-Specific Features and Clinical Correlations, Front. Endocrinol. (Lausanne).. doi:10.3389/fendo.2018.00722.

30 Celik O, Kadioglu P. Quality of life in female patients with acromegaly. (2013) J. Endocrinol. Invest. doi: $10.3275 / 8761$.

31 Gobbens RJJ, Remmen R. (2019) The effects of sociodemographic factors on quality of life among people aged 50 years or older are not unequivocal: Comparing SF-12, WHOQOL-BREF, and WHOQOL-OLD, Clin. Interv. Aging. doi:10.2147/CIA.S189560. 

32 Puts MTE, Shekary N, Widdershoven G, Heldens J, Lips P, et al. (2007) What does quality of life mean to older frail and non-frail community-dwelling adults in the Netherlands?, Qual. Life Res. doi:10.1007/s11136-006-9121-0.

33 Mu R. (2014) Regional disparities in self-reported health: Evidence from Chinese older adults, Heal. Econ. (United Kingdom). doi:10.1002/hec.2929.

34 Zhou Z, Gao J, Lai S, Chen G. (2018) Urban-rural difference in the associations between living arrangements and the health-related quality of life (HRQOL) of the elderly in China-Evidence from Shaanxi province, PLoS One. doi:10.1371/journal.pone.0204118.

35 Dimopoulou C, Sievers C, Wittchen HU, Pieper L, Klotsche J, et al. (2010) Adverse anthropometric risk profile in biochemically controlled acromegalic patients: Comparison with an age- and gender-matched primary care population, Pituitary. doi:http://dx.doi.org/10.1007/s11102-010-0218-7.

36 Jackson Y, Flood E, Rhoten S, Janssen EM, Lundie M. (2019) AcroVoice: eliciting the patients' perspective on acromegaly disease activity, Pituitary. doi:10.1007/s11102-018-00933-9.

37 Kunzler LS, Naves LA, Casulari LA. (2018) Cognitive-behavioral therapy improves the quality of life of patients with acromegaly, Pituitary. 21 323-333. doi:10.1007/s11102-018-0887-1.

38 Postma M, Netea-Maier RT, van den Berg GP. (2012) Quality of life is impaired in association with the need for prolonged postoperative therapy by somatostatin analogs in patients with acromegaly, Eur. J. Endocrinol.

39 Rowles SV, Prieto L, Badia X, Shalet SM, Webb SM, Trainer PJ. (2005) Quality of life (QOL) in patients with acromegaly is severely impaired: Use of a novel measure of QOL: Acromegaly Quality of Life Questionnaire, J. Clin. Endocrinol. Metab.

40 Varewijck AJ, van der Lely AJ, Neggers SJ, Lamberts SW, Hofland LJ, et al. (2014) In active acromegaly, IGF1 bioactivity is related to soluble Klotho levels and quality of life, Endocr. Connect. doi:10.1530/ec-14-0028.

\section{Correspondence:}

Cristina Preda,

MD, PhD, professor, "Grigore T. Popa” University of Medicine and Pharmacy, No 16, Universităţii Street, Iaşi, 700115, Romania, cpreda1@yahoo.com

Submission: 05 sep2019

Acceptance: 29 nov2019 


\title{
Antipsychotic treatment in patients with dementia receiving palliative care: efficiency, fall risk and cognitive impact
}

\author{
Tudor Florea, Elena-Rodica Popescu, \\ Matei Palimariciuc, Roxana Chiriță
}

Tudor Florea - M.D., PhD. student, "Grigore T. Popa" University of Medicine and Pharmacy, Psychiatrist, "Sf. Sava” Hospital, Iași, Romania

Elena-Rodica Popescu - M.D., PhD Student, assistant professor Grigore T. Popa University of Medicine and Pharmacy, Iași; Psychiatrist, Socola Institute of Psychiatry, Iași

Matei Palimariciuc - M.D., PhD Student, assistant professor Grigore T. Popa University of Medicine and Pharmacy, Iași; junior psychiatrist, Socola Institute of Psychiatry, Iași

Roxana Chiriță - M.D., PhD, Professor of Psychiatry Grigore T. Popa University of Medicine and Pharmacy, Iași, Senior psychiatrist Socola Institute of Psychiatry, Iași

\begin{abstract}
Antipsychotics are widely used in treatment of elderly related psychiatric disorders such as delirium, organic hallucinosis. The long-term uses of such drugs are related with increased risks. The objective of this study is to determine efficiency of small doses of antipsychotics in relieving target symptoms and monitoring short-term use in patients diagnosed with dementia receiving palliative care. The study was conducted in a clinical department for palliative care reserved for patients with severe dementia over a period of 1 year. The study sample comprised 56 patients, 31 of which received antipsychotics. Measures used included MiniMental State Exam (MMSE), Neuropsychiatric Inventory Nursing Home Version (NPI-NH), Fall-Risk (FR) Scale, patient records, medication records and fall incidents. We found a significant improvement on NPI-NH Scale $(p<0.05)$ for patients that received antipsychotics and had psychosis, agitation, aggressiveness in accordance with clinical observations. There were no significant changes for $\operatorname{MMSE}(p=0.56)$ or FR Scale $(p=0.87)$. Small doses of antipsychotics have a beneficial impact in treating psychosis and agitation with aggressive behavior in patients with Dementia receiving palliative care. The study showed that the use of antipsychotic medication doesn't correlate with increased cognitive degradation or fall risk. The particularities of these cases need to be further explored.
\end{abstract}




\section{Antipsychotics, dementia, palliative care, risks.}

\section{INTRODUCTION}

Dementia is a progressive debilitating disease that has a devastating impact on the physical, emotional and financial aspect of patients, their families, caregivers and society. The major outcome of this progressive cognitive decline is the inability to function independently. (1) Due to its progressive nature, patients with dementia gradually lose autonomy, severe dementia being characterized by loss of capacity to provide self-care in daily activities, such as maintaining the body hygiene, drinking, eating, disturbance in gait, coordination, urinary and fecal incontinence. $(2,3)$

With the increase of life expectancy, the prevalence of dementia is projected to double every 20 years to approximately 82 billion in 2030 and 152 million by 2050. Worldwide, around 50 million people have dementia, yearly around 10 million new cases are reported. (4)

Severe dementia is often associated with many accumulated co-morbidities and require complex medical care. In contrast to cancer which usually follows an initial slow overall decline from high level of function, dementia follows a prolonged dwindling. (5) The need for the use of end of life care in both diseases have been shown to carry equal importance, thus having a great impact in the shifting strategies for dementia. (6) Many of these patients do not receive palliative care routinely, the main barrier for assessment of symptoms and providing adequate treatment being the inability to communicate. A multidisciplinary approach for neurodegeneration is necessary in developing strategies for future research. As a relatively new field, a solid evidence base for different aspects of dementia in palliative care is required in order to progress the current knowledge. (7)

However, the entire research framework needs to take into account the realities of care towards end-of-life and the frailty of these patients. In the process of studying different aspects of palliative care for dementia, the wellbeing of the patient take priority, thus limiting the usual tools for systematic investigation.

Antipsychotic drugs are widely used for various psychiatric disorders in patients with dementia. Precipitating factors play a key role in the acceleration of neurodegenerative processes; thus, the correct management of such disorders is of prime importance for the evolution of dementia. (8) Delirium is one of the most common causes for admission to a palliative care unit with higher rates seen at the end of life. (9) Also, it is one the most frequent reasons for hospital admittance of patients older than 65 years, with numbers rising over $50 \%$. (10) Until recently, atypical antipsychotics were used in the treatment of delirium, and other psychosis replacing the old "golden standard" Haloperidol. Numerous studies supported the assertion that Risperidone, Olanzapine and Quetiapine had the best results for delirium treatment. (11) Later studies showed a superior response to placebo over antipsychotics, when participants receive individualized nonpharmacologic measures, such as hydration, presence of family, reorientation, vision and hearing aids. $(12,13)$

Even though these facts are still to be proven right, antipsychotics play a key factor in treatment of agitation or psychosis in patients with dementia. Prevalence of psychosis 
among patients with Alzheimer's disease was reported to be $41 \%, 36 \%$ for delusions and $18 \%$ for hallucinations. (14) For patients in nursing home setting hallucinations and delusions are $22 \%$ and $14 \%$ of study subjects respectively. The persistence of symptoms range between 13\%-66\% for delusions and $25 \%-100 \%$ for hallucinations. Among individuals, $36 \%$ have signs of agitation, and $32 \%$ have aggressive behavior, the persistence of these symptoms ranging between 53\%$75 \%$. (15) In choosing the right antipsychotic treatment, expert opinion survey data indicate a higher propensity to Risperidone, Quetiapine and Olanzapine with the indication to avoid other psychiatric drugs in order to avoid more serious side effects. Also, the optimal duration of treatment ranges between 4 to 6 months for dangerous psychosis and dangerous agitation. For lesser agitation and danger, the dosage maintenance indication is in range of 1 to 3 months, afterwards taper and withdrawal. (16)

Conclusive data for patients with dementia in palliative care having antipsychotic treatment is lacking, even though effective strategies for such individuals, suffering of dangerous psychosis and agitation are needed.

\section{METHODS}

\section{Study setting}

The study has been conducted with the approval of Research Ethics Commission of University of Medicine and Pharmacy "Grigore T. Popa" Iasi. Prior to participating in the study, a first-degree relative or legal guardian signed an informed consent.

The present study was a 1-year single center, comparative study to assess the possible outcomes of cognition and fall risk after treatment with antipsychotic medication in therapeutic range for psychosis and severe agitation in patients with dementia in palliative care.

Patients' data was collected at the moment of admission. Mini-Mental State Examination (MMSE), Neuropsychiatric Inventory Nursing Home Version (NPI-NH) and Fall Risk (FR) Scale was performed on every new admission to the study with a reevaluation after 4 weeks. In cases of diagnosed psychosis or extreme agitation, according with International Classification of Diseases, $10^{\text {th }}$ Revision (ICD-10) diagnosis criteria and NPI$\mathrm{NH}$ score, antipsychotic medication was used. Except for antipsychotic medication no other medical intervention or medication change was performed on the selected lot. During the treatment period, patients received either Quetiapine (25-200mg) or Risperidone (0,25$2 \mathrm{mg}$ ). The doses were adapted to patient's weight, in order for the symptoms mentioned to be remitted. The study's design had no intention to compare antipsychotics or to determine dose efficiency.

\section{Participants}

Screening and demographic measurements included diagnosis of dementia according to ICD-10 criteria, anti-dementia medication, sex, age, weight, alcohol and tobacco consumption, medical and surgical history, full physical examination, laboratory analysis, and electrocardiogram. Inclusion criteria were: diagnosis of dementia with a MMSE score under 14, need for palliative care, treatment with anti-dementia medication and age over 65 years old. Exclusion consisted of prior history of psychiatric diagnosis.

Fifty-six patients that met the criteria were hospitalized during this period. From this lot, thirty-one patients received antipsychotics.

\section{Test batteries and statistics}

For the assessment of psychosis, agitation and aggressive behavior Neuropsychiatric 
Inventory Nursing Home Version (NPI-NH) scale was used at two distinctive moments, at the moment of entrance to the study and after 4 weeks. This instrument assesses the neuropsychiatric symptoms and psychopathology of patients with dementia, the information being gathered by professional caregivers. The test includes ten behavioral subsections and two types of neurovegetative changes. The subsections have each one frequency and one severity aspect built into the questionnaire. (17)

For the assessment of dementia and for screening purposes Mini-Mental State Examination (MMSE) was used at two distinct moments, at the moment of study entering and after 4 weeks. MMSE is a cognitive test that is commonly used in the diagnostic and assessment of dementia. (18) In order to assess the fall risk, we used a scale developed at "Socola" Institute of Psychiatry with ten items that account for fall events in latest month, disorientation, anxiety and agitation, loss of hearing and sight, balance and gait, use of opioids and sedative medication, age older than 65 years old, other symptoms connected with legs (pain, numbness, history of injury, surgical procedures, or other disorders) and the need for medical gait-assisting devices. Each of the items have a $1 / 0$ value, with the final result evaluating the fall risk. The scale development had as a basis the Downton fall risk index. (19)

Statistics was performed using analysis of variance for repeated measures (ANOVA). Statistic differences were tested first on the entire sample for each test, regardless of use of antipsychotics. Afterwards, the sample was split in treated "with-antipsychotics" and "without-antipsychotics" and afterwards tested for statistical significance.

\section{RESULTS}

Results and statistics are summarized in Table 1. Fifty-seven participants met the inclusion criteria, 31 received antipsychotics (9 receiving Quetiapine, 19 receiving Risperidone, 2 receiving Tiapride), 25 not meeting criteria for treatment with antipsychotics (had a low score on NCI-NH and didn't met the criteria for diagnostic). The patients were spread on a normal distribution chart with an average age of 82 years with a standard deviation (S.D) of 7.5 years. Patients with treatment had an average of 80.5 years and without treatment an average of 84.3 years, with S.D. of 7.5 and 7.0 respectively. (Fig. 1)

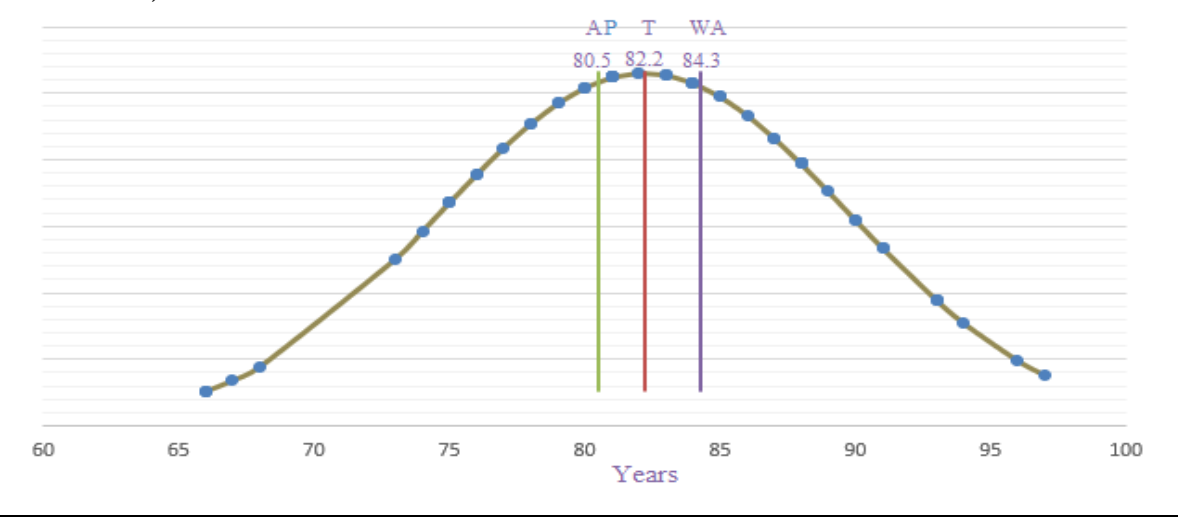

Figure 1. Normal distribution of age average

AP: Patients with antipsychotics, T: Total number of patients

WA: Patients without antipsychotics 
Bulletin of Integrative Psychiatry O New Series $\bigcirc$ December 2019 ○ Year XXV ONo. 4 (83)/83 s The oldest patient in our study had 97 years old, and the youngest 66. The oldest patient that received antipsychotics had 86 years old and the youngest 66 . None of the groups had any extrapyramidal symptoms (EPS), a and a number of three patients manifested light vertigo (two in antipsychotics group) for one to two days. Two patients had a diagnostic of Parkinson disease, one was number of 2 patients of the "withoutantipsychotics" group had a urinary infection

\begin{tabular}{|l|l|l|l|l|l|l|l|l|}
\hline \multicolumn{7}{|c|}{ Table I. Demographic data - Age (years) } \\
\hline & N & Min & Q1 & Q2 & Q3 & Max & Average & S.D. \\
\hline Total & 56 & 66 & 78 & 82 & 88 & 97 & 82.19 & 7.51 \\
\hline Females & 34 & & & & & & 82.88 & 7.3 \\
\hline Females-AP & 17 & & & & & & 80.2 & 7.22 \\
\hline Males & 22 & & & & & & 81.13 & 7.7 \\
\hline Males-AP & 14 & & & & & & 80.8 & 6.8 \\
\hline AP: Patients with antipsychotics, S. D.: standard deviation \\
\hline \multicolumn{78}{|l|}{} \\
\hline
\end{tabular}

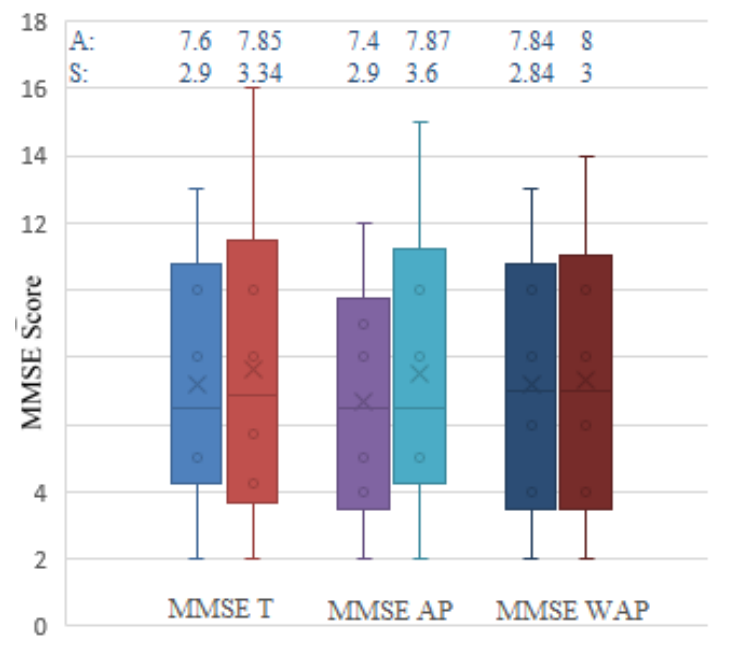

Figure 2. Interquartile Range - Mini Mental State Examination

MMSE T: total number of patients, AP: patients with antipsychotics, WAP: patients without antipsychotics, A: Average score, S: Standard Deviation

Between groups, the average testing score varied between 7.4 and 7.84 for MMSE and between 5.9 and 6.28 for Fall Risk. An overall slight improvement of the MMSE Score was noticed for patients that received antipsychotics. (Fig. 2) It was noticed a slight reduction of the Fall Risk Score averages between the two groups. (Fig. 3) This small improvement was further tested in order to find a statistical significance; the results disproved our hypothesis ( $p>0.05)$. (Table II)

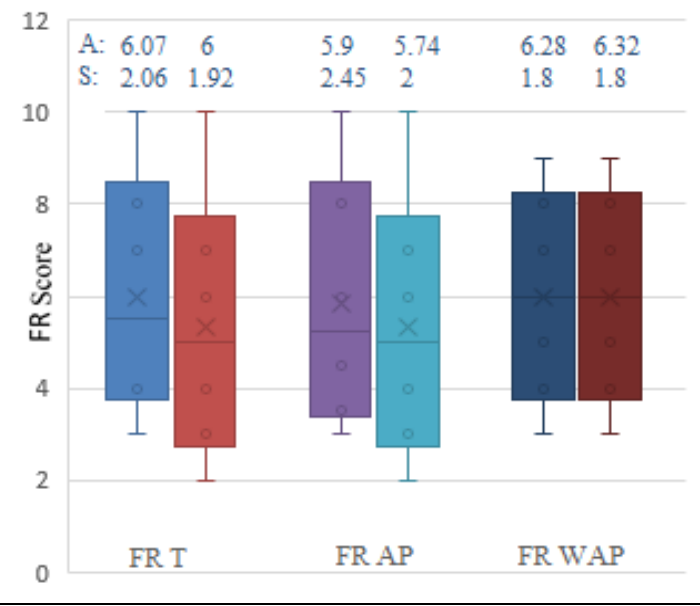

Figure 3. Interquartile Range - Fall Risk score

FR T: total number of patients, AP: patients with antipsychotics, WAP: patients without antipsychotics, A:

Average score, S: Standard Deviation

For the NPI-NH Score, the first data showed a noticeable improvement in score averages in total participants (Average 1st test 24.3 Average 2 nd test 10.6). When focused on the two groups (with/without antipsychotics AP/WAP) the averages dropped visibly for 
the "with-antipsychotics" group (Average from 35.1 to 12 ), and only a small difference for the group "without-antipsychotics" (Average from 11.4 to 8.9). In order to support these findings further statistical testing was performed.

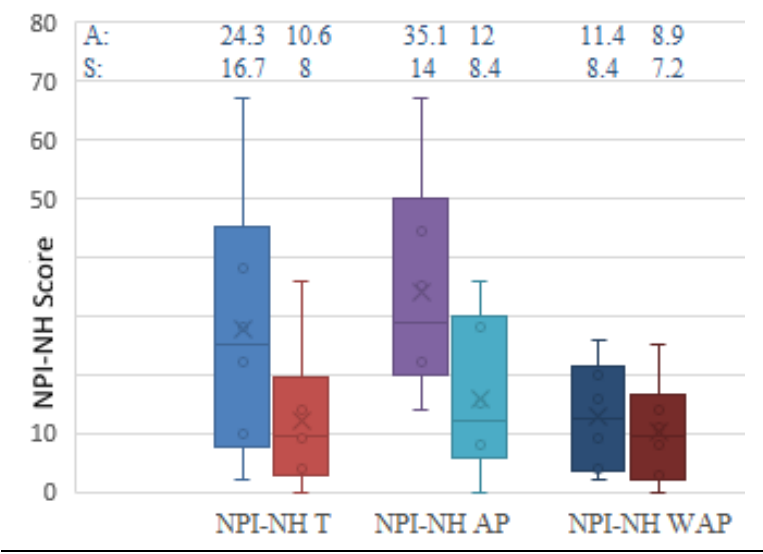

Figure 4. Interquartile Range for Neuropsychiatric Inventory Nursing Home Version (NPI-NH)

NPI-NH T: total number of patients, AP: patients with antipsychotics, WAP: patients without antipsychotics A: Average score, S: Standard Deviation
Antipsychotic medication reduced the NPINH Score $(-0.05 ; 95 \% \quad C I, p=2.48 E-07)$ assessed for the entire group, and for the "with-antipsychotic" group $(-0.05 ; 95 \% \mathrm{CI}$, $\mathrm{p}=5.9 \mathrm{E}-11)$. When tested, the "withoutantipsychotic" group the results were not statistically significant $(-0.05 ; 95 \% \quad \mathrm{CI}$, $\mathrm{p}=0.27$ ).

\begin{tabular}{|c|c|c|c|c|c|}
\hline \multicolumn{6}{|c|}{ Table II. The primary data for MMSE, FR and NPI-NH } \\
\hline ANOVA & & & & & \\
\hline Source of Variation: $M M S E$ & $\mathbf{N}$ & $M S$ & $\boldsymbol{F}$ & P-value & F crit \\
\hline Between Groups Total & 56 & 2.58 & 0.257 & 0.613 & 3.92 \\
\hline \multicolumn{6}{|l|}{ Source of Variation: FR } \\
\hline Between Groups Total & 56 & 0.14 & 0.035 & 0.85 & 3.93 \\
\hline Between Groups WAP & 25 & 0.02 & 0.006 & 0.94 & 4.04 \\
\hline Between Groups AP & 31 & 0.12 & 0.03 & 0.87 & 3.92 \\
\hline \multicolumn{6}{|l|}{ Source of Variation: NPI-NH } \\
\hline Between Groups Total & 56 & 5293.75 & 30.26 & $2.5 \mathrm{E}-07$ & 3.927 \\
\hline Between Groups WAP & 25 & 79.38 & 1.24 & 0.27 & 4.04 \\
\hline Between Groups AP & 31 & 8314.9 & 63.24 & $5.9 \mathrm{E}-11$ & 4.0 \\
\hline \multicolumn{6}{|c|}{$\begin{array}{l}\text { MMSE: Mini-Mental State Examination, FR: Fall Risk Score, NPI-NH: Neuropsychiatric Inventory } \\
\text { Nursing Home Version, S.D.: Standard Deviation, Total: Total number of patients, WAP: Patients } \\
\text { that had no antipsychotics, AP: Patients that received antipsychotics }\end{array}$} \\
\hline
\end{tabular}


Antipsychotics didn't improve MMSE Score $(-0.05 ; 95 \%$ CI, $\mathrm{p}=0.61$; F $<$ Fcrit $)$ or FR Score $(-0.05 ; \quad 95 \% \quad$ CI, $\quad \mathrm{p}=0.85 ; \quad \mathrm{F}<$ Fcrit $)$ respectively. (Table II)

For statistical significance F-Test had positive results only for patients "with-antipsychotics" on NPI-NH test and for total sample on NPINH test. The sample "without-antipsychotics" had negative F-Test results ( $\mathrm{F}<\mathrm{Fcrit})$.

\section{DISCUSSION}

The use of antipsychotics in elderly people is a common thing. For institutionalized patients, many of whom have dementia, the antipsychotic treatment has an extended use. (20)

During study development, a first issue encountered was the deficiency in objective signs and symptoms evaluation. A correct diagnostic assessment is becoming harder with age and severity of dementia. The items used for testing have a level of subjectivity built in (NPI-NH), thus an extra level of precaution in data gathering was needed.

The present study revealed that the short-term use of low doses of second-generation antipsychotics (Risperidone, Quetiapine) in patients with dementia in palliative care had a positive impact on NPI-NH scale and timid positive influence on MMSE scale (not statistically significant for MMSE). The current results are comparable with other studies for Risperidone and Quetiapine that may be more effective for particular symptoms, such as anger, aggression, and paranoid ideas. They do not appear to improve functioning, or quality of life. (21, 22, 23)

Our testing for cognitive impairment associated with psychosis or aggressive behavior showed no statistical significance before and after the use of antipsychotics followed by the reduction of symptoms as seen in other psychotic disorders. (24) Even though cognition testing may be affected through agitation and deficiencies in communication, we found that the sole use of MMSE doesn't account for a full cognitive test battery in severe dementia.

Dementia is a disease that is very often associated with increased fall risk. Factors that determine lack of equilibrium and gait disorders are numerous, intrinsic and extrinsic, some shared with older adults in general and others unique to the disease. (25) Complications from such events have a powerful impact on overall quality of life, care needs and mortality. (26)

During the study, some patients suffered falling events or loss of equilibrium. None suffered complications, none required interventions. We found no statistical difference between the two groups and no linking between the use of antipsychotics in small dosages and an increased fall risk. In palliative care, the independence of patients is of primordial importance. Lack of movement impairments and self-conducting behavior has a positive impact on overall quality of life, thus assessment for the right use of medication in preventing such deteriorating factors has a great importance in dementia. Costs associated with falling in elderly is another important aspect, thus making informed and documented decisions in the use of antipsychotics a key quality for every practitioner. (27)

The occurrence of other symptoms related to antipsychotics, such as EPS, were not encountered among our subjects. Our study design focused on the development of side effects in patients treated with antipsychotics, 


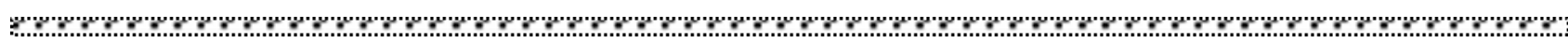
in quantities that we deemed safe for palliative care.

agitation without increasing the risk of falling or other major events, when the dosages of

Our findings showed the possibility of antipsychotics are kept in therapeutic range treating psychosis, aggressive behavior, with constant monitoring.

\section{CONCLUSIONS}

Associated pathology of dementia remains a challenging issue in palliative care for all practitioners. Comorbidities and increased risk factors make the treatment with antipsychotics a continuous struggle to finding the right balance between harm and remedy. Further studies are needed to understand and apply an objective and efficient way for diagnostic and assessment of different symptoms related to old age and severe dementia.

Second generation antipsychotics are useful in treating psychosis, aggressive behavior and agitation in patients with dementia in palliative care. Our study showed no increased fall risk.

Developing more efficient guidelines for the use of antipsychotics in palliative care, thus orienting practitioners in how to tailor and implement effective strategies is needed. Although our data are encouraging, more studies are needed in order to validate our assumptions and account for the varied pathophysiology, combination with other therapies, drugs and different social background.

\section{ACKNOWLEDGEMENTS AND DISCLOSURES}

The authors declare that they have no potential conflicts of interest to disclose.

\section{REFERENCES}

1. Chertkow H, Feldman HH, Jacova C, Massoud F. Definitions of dementia and predementia states in Alzheimer's disease and vascular cognitive impairment: consensus from the Canadian conference on diagnosis of dementia. Alzheimers Res Ther. 2013;5(Suppl 1):S2

2. Wu JM, Matthews CA, Vaughan CP, Markland AD. Urinary, fecal, and dual incontinence in older U S. Adults. J Am Geriatr Soc. 2015; 63 (5):947-953

3. Schafirovits-Morillo L, Suemoto CK. Severe dementia: A review about diagnoses, therapeutic management and ethical issues. Dement Neuropsychol. 2010;4(3):158-164

4. World Health Organisation: Dementia fact sheet. 2017. http://www.who.int/mediacentre/factsheets/fs362/en/.

5. Murray SA, Kendall M, Boyd K, Sheikh A. Illness trajectories and palliative care. BMJ. 2005;330(7498):10071011.

6. Hughes JC, Robinson L, Volicer L. Specialist palliative care in dementia. BMJ. 2005;330(7482):57-58.

7. Fox S, FitzGerald C, Harrison Dening K, et al. Better palliative care for people with a dementia: summary of interdisciplinary workshop highlighting current gaps and recommendations for future research. BMC Palliat Care. 2017;17(1):9.

8. Fong TG, Davis D, Growdon ME, Albuquerque A, Inouye SK. The interface between delirium and dementia in elderly adults. Lancet Neurol. 2015;14(8):823-832.

9. Hosie A, Davidson PM, Agar M, Sanderson CR, Phillips J. Delirium prevalence, incidence, and implications for screening in specialist palliative care inpatient settings: a systematic review. England; 2013 Jun.

10. Inouye SK, Westendorp RG, Saczynski JS. Delirium in elderly people. Lancet. 2014;383(9920):911-922.

11. Markowitz JD, Narasimhan M. Delirium and antipsychotics: a systematic review of epidemiology and somatic treatment options. Psychiatry (Edgmont). 2008;5(10):29-36. 
12. Agar MR, Lawlor PG, Quinn S, et al. Efficacy of Oral Risperidone, Haloperidol, or Placebo for Symptoms of Delirium Among Patients in Palliative Care: A Randomized Clinical Trial. JAMA Intern Med. 2017;177(1):34-42.

13. Boettger S, Jenewein J. Placebo might be superior to antipsychotics in management of delirium in the palliative care setting. Evid Based Med. 2017;22(4):152-153.

14. Ropacki SA, Jeste DV. Epidemiology of and risk factors for psychosis of Alzheimer's disease: a review of 55 studies published from 1990 to 2003. Am J Psychiatry. 2005;162(11):2022-2030.

15. Selbæk G1, Engedal K, Bergh S. The prevalence and course of neuropsychiatric symptoms in nursing home patients with dementia: a systematic review. J Am Med Dir Assoc. 2013 Mar;14(3):161-9.

16. Reus VI, Fochtmann LJ, Eyler AE, et al. The American Psychiatric Association Practice Guideline on the Use of Antipsychotics to Treat Agitation or Psychosis in Patients With Dementia. Am J Psychiatry. 2016;173(5):543-546.

17. Zuidema SU, Buursema AL, Gerritsen, Maarten G J M, et al. Assessing neuropsychiatric symptoms in nursing home patients with dementia: reliability and Reliable Change Index of the Neuropsychiatric Inventory and the CohenMansfield Agitation Inventory. Int J Geriatr Psychiatry. 2011;26(2):127-134.

18. Creavin ST, Wisniewski S, Noel-Storr AH, et al. Mini-Mental State Examination (MMSE) for the detection of dementia in clinically unevaluated people aged 65 and over in community and primary care populations. England; 2016 Jan 13.

19. da Costa BR, Rutjes AWS, Mendy A, Freund-Heritage R, Vieira ER. Can falls risk prediction tools correctly identify fall-prone elderly rehabilitation inpatients? A systematic review and meta-analysis. PLoS One. 2012;7(7):e41061.

20. Kamble P, Chen H, Sherer JT, Aparasu RR. Use of antipsychotics among elderly nursing home residents with dementia in the US: an analysis of National Survey Data. Drugs Aging. 2009;26(6):483-492.

21. Sultzer DL, Davis SM, Tariot PN, et al. Clinical symptom responses to atypical antipsychotic medications in Alzheimer's disease: phase 1 outcomes from the CATIE-AD effectiveness trial. Am J Psychiatry. 2008;165(7):844-854.

22. Schneider LS, Dagerman K, Insel PS. Efficacy and adverse effects of atypical antipsychotics for dementia: metaanalysis of randomized, placebo-controlled trials. Am J Geriatr Psychiatry. 2006;14(3):191-210.

23. Savaskan E, Schnitzler C, Schroder C, Cajochen C, Muller-Spahn F, Wirz-Justice A. Treatment of behavioural, cognitive and circadian rest-activity cycle disturbances in Alzheimer's disease: haloperidol vs. quetiapine. Int $\mathbf{J}$ Neuropsychopharmacol. 2006;9(5):507-516.

24. Sheffield JM, Karcher NR, Barch DM. Cognitive Deficits in Psychotic Disorders: A Lifespan Perspective. Neuropsychol Rev. 2018;28(4):509-533.

25. Fernando E, Fraser M, Hendriksen J, et al. Risk Factors Associated with Falls in Older Adults with Dementia: A Systematic Review. Physiother Can. 2017;69(2):161-170.

26. Burns E, Kakara R. Deaths from Falls Among Persons Aged /=65 Years - United States, 2007-2016. MMWR Morb Mortal Wkly Rep. 2018;67(18):509-514.

27. Stevens JA, Corso PS, Finkelstein EA, Miller TR. The costs of fatal and non-fatal falls among older adults. Inj Prev. 2006;12(5):290-295.

\section{Correspondence:}

Matei Palimariciuc,

MD, PhD student, "Socola” Institute of Psychiatry, Bucium street no. 36, Iași, Romania, 700282, matei.palimariciuc2000@gmail.com

Submission: 01 sep 2019

Acceptance: 24 nov 2019 



\title{
Pemphigus vulgaris triggered by psychological stress
}

\author{
Teona Asavei, Elena Porumb-Andrese, Dan Vâță, \\ Mihaela Paula Toader, Adriana Ionela Pătrașcu, Alina Ioana Halip, \\ Ioana Adriana Popescu, Laura Gheucă Solovăstru
}

Teona Asavei - M. D., Dermatology Clinic County Emergency Hospital “St. Spiridon” Iași Elena porumb-Andrese - M.D. PhD, Assistant Professor, Department of Dermatology "Grigore T. Popa" University of Medicine and Pharmacy Iasi, Romania

Dan Vâță - M.D. PhD, Lecturer, Department of Dermatology "Grigore T. Popa" University of Medicine and Pharmacy Iasi, Romania

Mihaela Paula Toader - M.D. PhD, Lecturer, Department of Dermatology "Grigore T. Popa" University of Dental Medicine Iasi, Romania

Adriana Ionela Pătrașcu - M. D., Dermatology Clinic County Emergency Hospital "St. Spiridon” Iași

Alina Ioana Halip - M.D. PhD Student, Assistant Professor, Department of Dermatology "Grigore T. Popa" University of Medicine and Pharmacy Iași, Romania

Ioana Adriana Popescu - M.D. PhD Student, Department of Dermatology "Grigore T. Popa" University of Medicine and Pharmacy Iași, Romania

Laura Gheucă Solovăstru - M.D. PhD, Associated Professor, Department of Dermatology "Grigore T. Popa" University of Medicine and Pharmacy Iași, Romania

\section{ABSTRACT}

Pemphigus vulgaris (PV) is a rare but severe autoimmune disease caused by autoantibodies directed against desmosomes, and clinically characterized by bullae and painful erosions of the skin and mucous membranes.

While the morphology is well defined, its etiopathogenesis remains a subject of research. PV, the most frequent and representative form of the autoimmune bullous dermatoses, has a poor prognosis in the absence of medical treatment. The onset and course of PV depend on a variable interaction between predisposing and inducing factors. Thus, drugs, viral infections (herpes simplex virus), physical agents, contact allergens, vaccinations, dietary factors, and psychological stress have been implicated in the disease. Stressful life events have been associated with the course of several autoimmune skin diseases and reported a possible factor in triggering and aggravating for pemphigus in predisposed patients. Psychological care, 

associated with the immunosuppressive treatment, should entail a better management of these patients.

\section{KEYWORDS:}

Pemphigus vulgaris, autoimmune bullous diseases, psychological stress, quality of life

\section{INTRODUCTION}

Pemphigus is a relatively rare but severe autoimmune bullous disease, involving the skin and mucous membranes. PV is caused by autoantibodies directed against desmosomes, and clinically characterized by bullae and painful erosions of the skin and mucous membranes. Although no clear etiology has been established for these diseases, developed autoantibodies against desmoglein 1 and desmoglein 3 seem to be responsible for blisters in patients. Aggressive and aberrant immune responses contribute to the development and progression of pemphigus via different mechanisms, including the production of autoantibodies by plasma B cells, the activity of autoreactive CD4+ T helper cells, and CD8+ T cells (1). The most common forms are pemphigus vulgaris and pemphigus foliaceus. The overall incidence of the disease, which carries substantial morbidity and is potentially fatal, varies from 0.75 to 5 cases per million per year. Epidemiologically, pathology is more common in the Jews and the Mediterranean region. In Jerusalem, the incidence is estimated at 16 cases/ 1 million people, while in France and Germany it is 1.3 cases / 1 million people (2). The disease does not discriminate between the genders and occurs most commonly in the 4th to 6th decades of life.

Clinically, PV initially presents with lesions on the oral mucosa, preceding skin lesions for several months. At this level, there can be observed erosions with a small tendency to spontaneous, painful healing. The lesions start as blisters which rupture easily leaving erosions and ulcers that can lead to serious life-threatening infections and metabolic abnormalities (2).

Due to the interaction of environmental and genetic factors, PV has a complex aetiopathogenesis. Thus, drugs, viral infections (herpes simplex virus), physical agents, contact allergens, vaccinations, dietary factors, and psychological stressors a have been implicated in the disease (3).

Systemic glucocorticoids and adjuvant immunosuppressive drugs are the mainstay of therapy for pemphigus vulgaris. It is known that long-term use of these therapeutic modalities is associated with an additional negative impact on patient's quality of life (4).

Although there is no way to prevent autoimmune diseases, some factors may trigger pemphigus initiation in susceptible individuals or be exacerbated in affected patients. Recognition of these triggers, based on the latest studies and experiences is essential and should be updated every few years.

\section{ETIOPATHOLOGY OF PEMPHIGUS VULGARIS}

In the majority of patients with pemphigus, no inducing agent seems to exist and the disease apparently starts in a spontaneous manner; however, in several cases, a meticulous clinical history detects the presence, often a slight hint of triggered factors. (4) 
The key of the etiopathogenesis of pemphigus was found by Beutner and Jordon found in $1964(5,8)$. They highlighted the presence of antibodies directed against an intercellular antigen of Malpighian epithelia (skin and mucous membranes) in sera of patients with pemphigus. But, the primary initiating stimulus for the production of pemphigus antibodies often remains unknown.

Recent studies support the role of genetic factors in pemphigus. $\mathrm{PV}$ is a polygenic disease, and an increased prevalence of low titers of disease-associated autoantibodies in healthy first-degree relatives of patients with pemphigus has been reported (5). The genetic contribution to the pathogenesis of $\mathrm{PV}$ is given by association with other autoimmune diseases and from the ethnic clustering of PV. Pemphigus is linked to autoimmune thyroid disease, type I diabetes, rheumatoid arthritis, and systemic lupus erythematosus. Also, the correlation between pemphigus and myasthenia gravis is well known (6). Several HLA alleles have been identified as risk factors, but the correlation between a certain HLA genetic profile and the patient's clinical profile is still unclear (7).

Environmental factors could be required to initiate and perpetuate the disease process.

Among the factors that induce pemphigus in genetically predisposed patients, they were identificated the following: 'thiol drugs' with an elevated risk for penicillamine, penicillin, cephalosporins or captopril; 'angiotensinconverting enzyme inhibitors' (elevated risk for enalapril and captopril); 'phenol drugs' (elevated risk for pyritinol and cephalosporins), and 'miscellaneous substances' with cytokines, pyrazolones and other nonsteroidal anti-inflammatory drugs (9).
Clinical reports and experimental investigations have pointed to the possible role of viral infections, in particular herpes virus infections, in the pathogenesis of $\mathrm{PV}$ (10).

The viral infection may only be an occasional factor triggering the outbreak or exacerbation of the autoimmune disorder through a nonspecific way in a genetically susceptible host. The same could be said for some anecdotal inductions of PV by other common viral infections (such as flu, cold, other infections of the upper respiratory tract), although in these cases a concurrent facilitating effect might be due to the use of drugs.

Some physical agents, such as sunburns, ionizing radiation, thermal or electrical burns, and surgical and even cosmetic procedures proved to be able to trigger pemphigus in predisposed individuals. The most important physical factor in inducing pemphigus in the ultraviolet radiation. The sunlight can induce a transient form of pemphigus in apparently healthy individuals, but in others only exacerbated a preexisting PV (10).

Several chemicals can exacerbate or even trigger PV with mediation of allergic contact dermatitis (10). The chemicals more implicated in this condition are implicated in various fields of work, such as photographic developing, dry cleaning, industrial solvent work, gardening, and chiefly intensive agriculture.

Among the pemphigus trigger factors, dietary factors were rarely discussed. it was proposed that dietary ingredients rich in thiols, isothiocyanates, phenols, and tannins be considered as possible triggers (11). 
s.

EMOTIONAL STRESS is reported as a potential trigger factor of pemphigus in predisposed patients. Stressful life events have been associated with the course of several autoimmune skin diseases and reported a possible factor in triggering and aggravating for pemphigus.

The skin, nervous system, and immune system are interconnected, use the same language and functionally represent a unique neuroimmunocutaneous system, which can well account for a pathogenic link between an intensive emotional stress and the onset of an autoimmune skin disorder (12). There are many studies about the role of emotional stress in the inducement or exacerbation of pemphigus, especially in individuals with a familial background of the disease and specific HLA typing $(13,14)$. A clinical investigation of 13 consecutive pemphigus patients with personality disorders revealed that 12 of them had experienced a stressful event during the year preceding the onset of the immune disorder (15).

Mazzotti (16) presented the relation between psychological stress and dysfunctional investments on appearance, using interviews and self-applicable questionnaires about dysfunctional investments on appearance, and anxiety and nosocomial depression, among 78 patients with diagnosed PV and PF. Those patients who presented psychological stress also presented higher levels of dysfunctional investments on the appearance.

Psychic stress affects the neuroendocrine system as it has been shown by Ader (17) that still reinforces the relationship between psyche, nervous system and endocrine system (psychohypothalamohypophysosurrenal axis).

Moreover, pemphigus patients experience a decrease in quality of life (QOL) affecting physical, psychological and social aspects. It is recommended that pemphigus patients need psychiatric assessment and intervention for any possible anxiety and nosocomial depression to prevent an exacerbation of the disease (18).

In addition, depression is also associated with pemphigus and pro-inflammatory cytokines and may impair sleep. Dermatologic disease evokes strong negative emotions, troublesome symptoms, and impaired social and professional functioning (19).

\section{CONCLUSIONS}

Now, although it is considered a rare disease, the incidence of pemphigus vulgaris is steadily increasing, being associated with a high degree of morbidity and occasional mortality. The cutaneous damage such as bullae formation, pain, itch, and associated functional limitations have a psycho-emotional impact on patients and can severely affect the patient's quality of life. These symptoms, by their despicable character, can have a significant burden on social function, independent of clinical severity.

The onset and course of PV depend on a variable interaction between predisposing and inducing factors. Thus, drugs, viral infections (herpes simplex virus), physical agents, contact allergens, vaccinations, dietary factors, and psychological stress have been implicated in the disease.

Emotional stress has a important role in the inducement or exacerbation of pemphigus, especially in individuals with a familial background of the disease and specific HLA typing. 
Specific psychological care and the prescription of a treatment if needed to pemphigus vulgaris patients, in addition to the immunosuppressive treatment, should entail a better management of these patients.

\section{ACKNOWLEDGEMENTS AND DISCLOSURES}

The authors have no potential conflict ofinterests to disclose.

\section{REFERENCES}

1. Amber KT, Staropoli P, Shiman MI, Elgart GW, Hertl M. Autoreactive T cells in the immune pathogenesis of pemphigus vulgaris. Exp Dermatol 2013; 22:699-704.

2. Bystryn IC, Rudolfh GL. Pemphigus. Lancet 2005; 366: 61-73.

3. Ruocco V, Ruocco E, Lo Schiavo A et al. Pemphigus: etiology, pathogenesis, and inducing or triggering factors: facts and controversies. Clin Dermatol 2013; 31: 374-38.

4. Hertl M, Jedlickova H, Karpati S et al. Pemphigus. S2 Guideline for diagnosis and treatment - guided by the European Dermatology Forum (EDF) in cooperation with the European Academy of Dermatology and Venereology (EADV). J Eur Acad Dermatol Venereol. 2015;29(3):405-414.

5. Ahmed AR, Carrozzo M, Caux F et al. Monopathogenic vs multipathogenic explanations of pemphigus pathophysiology. Exp Dermatol 25, 2016; 839-846.

6. Ruocco E, Wolf R, Ruocco V et al. Pemphigus: Associations and management guidelines: facts and controversies. Clin Dermatol 2013; 31: 382-390.

7. Vodo D, Sarig O and Sprecher E. The Genetics of Pemphigus Vulgaris. Front Med (Lausanne) 2018; 5: 226

8. Beutner E, Jordon R. Demonstration of skin antibodies in sera of pemphigus vulgaris patients by indirect immunofluorescent staining. Proc Soc Exp Biol Med 1964; 117:505-10.

9. Ruocco E, Aurilia A, Ruocco V. Precautions and suggestions for pemphigus patients.

Dermatology 2001; 203: 201-207.

10. Ruocco V, Ruocco E. Pemphigus and environmental factors. G Ital Dermatol Venereol 2003; 138:299-309.

11. Ruocco V, Brenner S, Ruocco E. Pemphigus and diet: does a link exist? Int J Dermatol 2001; 40:161-163.

12. Misery L. Skin, immunity and nervous system. Br J Dermatol 1997; 137:843-50.

13. Brenner S, Bar-Nathan EA. Pemphigus vulgaris triggered by emotional stress. J Am Acad Dermatol 1984; 11:524525

14. Morell-Dubois S, Carpentier O, Cottencin O et al. Stressful life events and pemphigus. Dermatology 2008; 216:104-108

15. Cremniter D, Baudin M, Roujeau JC, et al. Stressful life events as potential triggers of pemphigus. Arch Dermatol 1998; 134:1486-7.

16. Mazzotti E, Mozzetta A, Antinone V. et al. Psychological distress and investment in one's appearance in patients with pemphigus. JEADV 2011; 25:285-9.

17. Ader R, Cohen N, Felten D: Psychoneuroimmunology: interactions between the nervous system and the immune system. Lancet 1995; 345: 99-103.

18. Wohl Y, Mashiah J, Kutz A, et al. Pemphigus and depression comorbidity: a case control study. Eur J Dermatol 2015; 25:602-605

19. Gheuca Solovastru L, Vâță D, Stătescu L, Andrese E. - The pshychiatric burden of chronic dermatological diseases. Bulletin of Integrative Pshychiatry. 2014; 3(62): 31-41.

\section{Correspondence:}

Ioana Alina Halip,

MD, "Grigore T. Popa" University of Medicine and Pharmacy, Faculty of Medicine, Dermatology

Department, Str. Universitatii nr. 16, 700115, Iasi, Romania, e-mail: alina_ioana_g@yahoo.com

Submission: 12 oct 2019

Acceptance: 29 nov 2019 



\title{
Psycho-affective Implications in Dermatoaesthetics
}

\author{
Teona Asavei, Elena Porumb-Andrese, Dan Vâță, \\ Mihaela Paula Toader, Adriana Ionela Pătrașcu, Alina Ioana Halip, \\ Ioana Adriana Popescu, Laura Gheucă Solovăstru
}

Teona Asavei - M. D., Dermatology Clinic County Emergency Hospital "St. Spiridon" Iasi Elena porumb-Andrese - M.D. PhD, Assistant Professor, Department of Dermatology "Grigore T. Popa" University of Medicine and Pharmacy Iasi, Romania

Dan Vâță - M.D. PhD, Lecturer, Department of Dermatology "Grigore T. Popa" University of Medicine and Pharmacy Iasi, Romania

Mihaela Paula Toader - M.D. PhD, Lecturer, Department of Dermatology "Grigore T. Popa" University of Dental Medicine Iasi, Romania

Adriana Ionela Pătrașcu, - M. D., Dermatology Clinic County Emergency Hospital “St. Spiridon” Iași

Alina Ioana Halip - M.D. PhD Student, Assistant Professor, Department of Dermatology "Grigore T. Popa" University of Medicine and Pharmacy Iasi, Romania

Ioana Adriana Popescu - M.D. PhD Student, Department of Dermatology "Grigore T. Popa" University of Medicine and Pharmacy Iasi, Romania

Laura Gheucă Solovăstru - M.D. PhD, Associated Professor, Department of Dermatology "Grigore T. Popa" University of Medicine and Pharmacy Iasi, Romania

\begin{abstract}
Aesthetic Medicine comprises all medical procedures that have as objective improving the physical appearance with a major impact on the human psyche. This paper highlight the risks associated with medical procedures specifically on psycho-affective implications and the importance of interdisciplinary collaboration that can improve the quality of care in this new medical field.
\end{abstract}

KEYWORDS:

Mesotherapy, microneedling, botulinum toxin, peels, fillers, lasers 


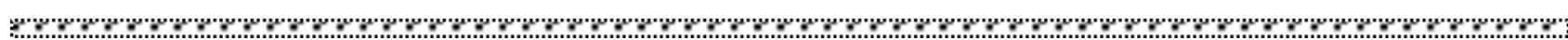

Skin diseases have a major psycho-emotional impact affecting both patient's integrity and his/her family and interpersonal relationships, the affective component playing an essential role in the management of patients with skin disorders.

Unlike internal diseases, skin disorders are characterized by the fact that the patient can see the disease and monitor its course, generating an emotional cascade dependent on the therapeutic response. Thus, the patient faces stigma, experiences social and physical avoidance being perceived by other people as having a contagious condition, even though the disease is autoimmune or just skin manifestations of some internal diseases. The feeling of shame, social isolation and depressive disorder associated with certain diseases increase the severity of the disease and pose a challenge for clinicians.

Another important aspect regarding the interaction between mind and skin, psychodermatology, is skin aging which leads to the loss of self-esteem, regret and internalization, as well as the obsessive desire to stop the aging process, which can sometimes result in an addiction difficult to control.

Skin aging is an inevitable physiological process based on complex mechanisms that include the gradual degradation of skin functions as well as significant histopathological changes. In fact, the aging process is the cumulative result of the permanent interaction between intrinsic and the extrinsic factors, characterized by an increased incidence of skin diseases and of developing cancer, as well as by aesthetic problems and the multiple methods of temporarily stopping the ageing process.

The management of skin aging involves the treatment of the stages of aging and photoaging, process requiring individualized approach, adapted to patient's age and in accordance with his/her wishes, as long as they comply with the dermatoaesthetic norms. At present, there are multiple methods both noninvasive and invasive to fight against skin aging, with significant implications in skin diseases.

Mesotherapy is one of the procedures used to rejuvenate and tone the skin, which involves the transdermal injection of a cocktail of multivitamins, enzymes, hormones, hyaluronic acid and natural plant extracts to stimulate fibroblasts and cellular interactions aimed to increase collagen and elastin production (1). It is also indicated in such skin diseases as psoriasis, alopecia and excess fat removal. The procedure is safe, and there are few side effects, such as erythema, edema or ecchymosis at the injection site (2). It is a relatively easy technique that requires accessible equipment and short-term training, being a minimally invasive way to achieve rapid results (3).

Another relatively new option is microneedling with wide applicability in dermatology. Besides its facial rejuvenation benefits, microneedling results in significant improvement of post-acne scar appearance by increasing type I, III, VII collagen levels and of general skin appearance, increased hair density in patients with androgenic alopecia and alopecia areata, as well as improved stretch mark appearance by increasing elastin fiber density. [2] The procedure involves creating micro-perforations at varying depths with the help of single-use needles, having a powerful stimulating effect of collagen and elastin fibers, both by the mechanical action and by introducing the active substances directly into the deep layers of the skin through the created channels. Contraindications to microneedling are 
s

limited and include inflammatory acne, active herpes labialis or other local infections, predisposition to develop keloids, and immunosuppression (4).

Botulinum toxin injection is one of the most popular techniques in dermatology. Botulinum toxin is a neurotoxin produced by Clostridium botulinum, types $\mathrm{A}$ and $\mathrm{B}$ being the most used medically. Toxin A is used for many conditions, especially in dermatology and for cosmetic purposes. Botulinum toxin is used to improve wrinkles on the forehead, glabella, outer corners of the eyes and nasolabial area. Other commonly encountered locations are wrinkles around the mouth and senescent neck changes. It can also be used to elevate the eyebrows and to treat conditions such as hyperhidrosis, lichen simplex, dyshidrotic eczema and acne vulgaris. The mechanism by which botulinum toxin acts is paralysis of the facial muscles by inhibiting the release of acetylcholine, effect that lasts 36 months with individual variations. The possible side effects of Botulinum toxin injection has minor side effects, including erythema, edema and pain at the injection site. Other reported side effects are nausea, flu-like symptoms and ptosis in the treatment of the glabellar region, ectropion following lower eyelid injection. All these potential adverse effects are temporary and gradually resolve as the toxin wears off $(5,6)$.

Currently, facial rejuvenation with fillers is the most popular method, a technique that provides cosmetic results previously obtained only surgically, with lower costs and shorter recovery time. Indications for fillers include cheek and chin volumization, correction of facial asymmetry and hand rejuvenation. Fillers can be classified as biodegradable and not biodegradable. Collagen and hyaluronic acid belong to the category of biodegradable fillers, with a short-term effect, being absorbed quite quickly by the body. Not biodegradable fillers cause a foreign body reaction with stimulation of collagen deposition around non-absorbable microspheres, and given their permanent nature their complications may be more longlasting and difficult to treat. Possible complications are ecchymosis, edema, hyperpigmentation, abscesses (rare complication, which may occur after the intervention (weeks or months) and may persist for weeks and recur periodically), reactivation of herpes infection, occurrence of nodular masses, foreign body granuloma, paresthesias, and tissue necrosis. The risks differ depending on the chosen filler product, its properties and injection requirements and can be prevented by a thorough knowledge of facial anatomy and the correct choice of the filler product according to the region to be treated $(7,8)$.

Chemical peels are a safe, rapid and low-cost method for the treatment of various skin conditions and facial rejuvenation. They are classified as superficial, medium and deep, the depth of peeling depending on the type and concentration of the acid used, patient's skin type and sensitivity. Superficial peels are based on salicylic acid, AHA, 10\%-20\% trichloroacetic acid and retinoic acid and are effective in dyschromia, acne, postinflammatory hyperpigmentation (2). Medium peels are used in case of solar lentigines, multiple keratoses, superficial scars and pigmentation disorders, while deep peels are effective in severe photoaging, deep wrinkles and scars, and occasionally in precancerous skin lesions (9).

Laser-based procedures fuel new innovations and clinical applications in the field of both skin diseases and aesthetics. In recent years, the role of these technologies has expanded significantly, currently being a therapeutic 


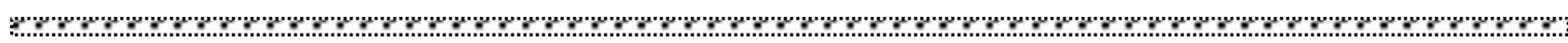
option in the treatment of vascular and these clinical entities. The numerous pigmented lesions, scars, and tattoo and noninvasive and invasive techniques represent unwanted hair removal. Vascular lesions are one of the most common diseases treated with a new approach in the treatment of skin diseases and also in aesthetic medicine.

lasers due to the ability of systems to specifically target intravascular oxyhemoglobin. Oxyhemoglobin absorbs the laser light which is then converted to heat and transferred to the vessel wall, causing coagulation and vessel closure. Hypertrophic scars and keloids are still a challenge due to the therapeutic difficulty and high recurrence rate following conventional treatments such as surgical removal, dermabrasion, radiation and intralesional therapy. Studies report improvements in hypertrophic scar appearance in terms of texture, erythema and pain following 1 or 2 sessions of pulsed dye laser (PDL) treatment. Adverse effects are minimal and may include purpura and depigmentation which remit gradually. To obtain a maximum effect, complementary therapies such as intralesional corticosteroids or 5-fluorouracil in case of resistant keloids can be added to these techniques. The numerous lasers types are subject to continuous development providing significant results in a wide range of skin conditions (10, 11).

The association between the psycho-affective component and dermatology denotes the importance of the multidisciplinary approach and individualized patient care, achieving the best possible wellbeing depending on both

Acceptance of aging can be especially difficult in people at risk (e.g. depression), which is why, before any procedure aimed to improve physical appearance, patient's mental must be assessed.

It is not uncommon for the doctor to be confronted with the request for exaggerated cosmetic procedure (e.g. enhancement of lip volume to such extent that it can alter patient's physiognomy), so it is important to have a complex dialogue with the patient in order to set the limits in advance and thus avoid the possible disappointments.

Cosmetic surgery addiction is another aspect to be followed in the doctor-patient relationship. When talking about addiction, psychiatric consultation can help the patient more than the requested cosmetic procedure by identifying the causes that led to that situation.

Because patients can often seek solutions to their problems from other specialists, interdisciplinary collaboration can improve the quality of care and sometimes may even direct patient approach to his/her true problem.

\section{ACKNOWLEDGEMENTS AND DISCLOSURES}

The authors declare that they have no potential conflicts of interest to disclose

\section{REFERENCES}

1. El-Domyati M., El-Ammawi T., Moawad O., El-Fakahany H., Medhat W., Mahoney M. et al. Efficacy of mesotherapy in facial rejuvenation: a histological and immunohistochemical evaluation. International $\mathrm{J}$ of Dermatol. 2012; 51(8): 913-919.

2. Lee J., Daniels M., Roth M. Mesotherapy, Microneedling, and Chemical Peels. Clinics in Plastic Surgery. 2016; 43(3): 583-595.

3. Sivagnanam G. Mesotherapy - The french connection. J of Pharmacol and Pharmacother. 2010; 1(1): 4-8. 
4. Alster T., Graham P. Microneedling. Dermatologic Surgery. 2018; 44(3): 397-404.

5. Satriyasa B. Botulinum toxin (Botox) A for reducing the appearance of facial wrinkles: a literature review of clinical use and pharmacological aspect. Clin Cosmet Investig Dermatol. 2019; 12: 223-228.

6. Small R. Botulinum toxin injection for facial wrinkles. Am Fam Physician. 2014; 90(3): 168-175.

7. Pavicic T., Funt D. Dermal fillers in aesthetics: an overview of adverse events and treatment approaches. Clin Cosmet Investig Dermatol. 2013; 295.

8. Lafaille P., Benedetto A. Fillers: Contraindications, side effects and precautions. J Cutan Aesthet Surg. 2010; 3(1): 16.

9. Devgan L., Singh P., Durairaj K. Minimally Invasive Facial Cosmetic Procedures. Otolaryngol Clin North Am. 2019; 52(3): 443-459.

10. Alster T., Husain Z. The role of lasers and intense pulsed light technology in dermatology. Clin Cosmet Investig Dermatol. 2016; 29.

11. Sieber D., Kenkel J. Noninvasive Methods for Lower Facial Rejuvenation. Clin Plast Surg. 2018; 45(4): $571-584$.

\section{Correspondence:}

Elena Porumb-Andrese,

M.D. PhD, Assistant Professor, Department of Dermatology "Grigore T. Popa" University of Medicine and Pharmacy Iasi, Romania, andrese.elena@yahoo.com

Submission: 28 aug 2019

Acceptance: 04 nov 2019 



\title{
The effect of antipsychotic treatment in hebephrenic schizophrenia on hospitalization indicators in an adult inpatient and outpatient population
}

\author{
Matei Palimariciuc, Tudor Florea, Vlad Teodor Iacob, \\ Bianca Georgiana Secrieru, Roxana Chiriță
}

Matei Palimariciuc - M.D., PhD Student, assistant professor Grigore T. Popa University of Medicine and Pharmacy, Iași; junior psychiatrist, Socola Institute of Psychiatry, Iași

Tudor Florea - M.D., PhD Student, Grigore T. Popa University of Medicine and Pharmacy, Iași.

Vlad Teodor Iacob - M.D., junior psychiatrist, Socola Institute of Psychiatry, Iași

Bianca Georgiana Secrieru - M.D., junior psychiatrist, Socola Institute of Psychiatry, Iași

Roxana Chiriță - M.D., PhD, Professor of Psychiatry Grigore T Popa University of Medicine and Pharmacy, Iași, Senior psychiatrist Socola Institute of Psychiatry, Iași

\begin{abstract}
Objectives: Out of all clinical forms of schizophrenia, the hebephrenic type is the least responsive to antipsychotic treatment and most difficult to manage. This characteristic results in a high average number of hospitalizations, more frequent institutionalization, generating additional cost for health care providers. With this argument in mind, we want to determine if there is a correlation between the primary hospitalization indicators and differences in antipsychotic treatment.
\end{abstract}

Methods: We anonymously collected data on all patients admitted in the Socola Institute of Psychiatry over the last five years with a confirmed diagnosis of hebephrenic schizophrenia. We logged the data regarding the age and sex of the patients, admission and discharge date, type of admission (inpatient or outpatient) as well as data regarding treatment recommendations at discharge. We performed statistical analysis, calculating for basic statistical indicators as well as variance, confidence interval, standard error and p-values.

Results: We included in our study 34 inpatients with hebephrenic schizophrenia, 19 outpatients and 4 institutionalized patients. Variance on all of the parameters we tested was 


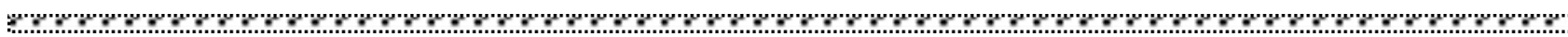
high resulting weak statistical significance. Statistically significant correlations were found between the type of antipsychotic treatment (typical, atypical, both) and hospitalization period and between the type of antipsychotic treatment (oral, depot) and duration between hospitalizations.

Conclusion: Our study found multiple correlations between the type of antipsychotic prescribed and hospitalization indicators, but due to the high variance of the samples, many of them proved not significant statistically. In the cases where a statistical significance was found, further investigation is necessary in order to establish the causal relationship between the parameters that we tested, and to establish if these correlations have a beneficial impact on the cost of the medical assistance and patients' quality of life.

\section{KEYWORDS:}

\section{Hebephrenic schizophrenia, antipsychotic treatment, hospitalization indicators}

\section{INTRODUCTION}

Schizophrenia is arguably one of the most puzzling, yet disabling of all mental disorders, with its severe and persistent psychotic manifestations accompanied by capricious cognitive deficits and profound psychosocial impairment. Although schizophrenia is discussed as if it is a single disease, it probably embodies a group of disorders with diverse etiologies, and it includes patients whose clinical presentations, treatment response, and illness trajectory vary. $(1,2,3)$ According to the DSM-IV-TR nosology, the subtypes in schizophrenia include the paranoid, disorganized (hebephrenic), catatonic, undifferentiated and residual. Although they are defined by the predominant symptomatology at the time of evaluation, the schizophrenia subtypes offer a limited value in clinical and research setting (e.g., prediction of illness trajectory, treatment response). (4, 5, 6, 7, 8, 9) Hebephrenic schizophrenia, is a form of schizophrenia in which the essential features are disorganized speech, disorganized behavior, flat or inappropriate affect, and the absence of symptoms that meet the criteria for the catatonic type. Delusions or hallucinations, if present, are fragmentary and not organized into a coherent theme, unlike the paranoid type. The disorganized speech may be accompanied by unprompted laughter, incongruous grinning and grimacing, and other oddities of behavior. The behavioral disorganization may lead to severe disruption in the ability to perform daily activities (e.g., showering, dressing, or preparing meals), which also leads to a run-down personal appearance, and their social behavior and their emotional responses that are inappropriate. A superficial and excessive preoccupation with religion, philosophy and other abstract themes may add to the listener's difficulty in following the train of thought. (2, $10,11,12,13,14,15)$ On average, hebephrenic schizophrenia has the age of onset during adolescence, most commonly between the age of 15 and 25 and tends to have a rather poor prognosis due to the rapid development of "negative" symptoms, particularly inappropriate or blunted affect and loss of initiative and volition. (14, 16, 17, 18, 19) Hebephrenia should normally be diagnosed for the first time only during adolescence or as young adults. According to the ICD-10, the premorbid personality is characteristically, but not undoubtedly, rather shy and desolate. For a confident diagnosis of hebephrenia, a period of 2 to 3 months of continuous observation is usually necessary, in order to ensure that the aforementioned characteristic behaviors are sustained. $(18,19)$ 
Bulletin of Integrative Psychiatry $\bigcirc$ New Series $\bigcirc$ December 2019 ○ Year XXV ONo. 4 (83)/103

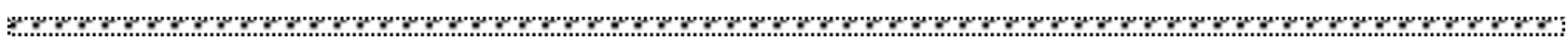

Hebephrenic vs Paranoid Schizophrenia

\begin{tabular}{|c|c|c|}
\hline Clinical Features & Hebephrenic & Paranoid \\
\hline Age of onset before age 25 yo & Likely & Less likely \\
\hline Marriage & Less & More \\
\hline Employment & Less & More \\
\hline Family history of schizophrenia & ++ & $+/-$ \\
\hline $\begin{array}{l}\text { Disorganized thought: } \\
\text { tangential, illogical, incoherent or irrelevant speech, loose } \\
\text { associations, blocking, or other formal thought disorders }\end{array}$ & ++ & $+/-$ \\
\hline $\begin{array}{l}\text { Affect changes: } \\
\text { Inappropriate affect, giggling, self-absorbed smiling, mood } \\
\text { inconsistent with expressed ideas; } \\
\text { flat affect, frozen, expressionless, impenetrable face }\end{array}$ & $\begin{array}{l}++ \\
++\end{array}$ & $\begin{array}{l}+/- \\
+1-\end{array}$ \\
\hline $\begin{array}{l}\text { Behavior symptoms: } \\
\text { Bizarre behavior, unusual, unpredictable, inappropriate, } \\
\text { irresponsible, purposeless or withdrawn behavior not in } \\
\text { keeping with sociocultural norms; } \\
\text { Motor symptoms, hebephrenic traits-habitual mannerisms of an } \\
\text { ordinary character, usually involving a single part of the body, } \\
\text { eg, grimaces, tics, moving lips soundlessly, fidgeting with } \\
\text { fingers, hand writing, thigh rubbing, etc; } \\
\text { Catatonic traits- physical activity of an extraordinary and } \\
\text { abnormal character, usually involving the whole body, eg, } \\
\text { posturing, stereotyping, waxy flexibility, negativism, stupor, } \\
\text { hyperkinesia, etc }\end{array}$ & ++ & $+1-$ \\
\hline $\begin{array}{l}\text { Delusions or hallucinations, persecution, control, passivity, } \\
\text { symbolism (primary delusions), thought broadcasting, } \\
\text { experiences or alienation, complete auditory hallucinations, } \\
\text { delusional perceptions, or hallucinations in any sensory } \\
\text { modality. }\end{array}$ & $+1-$ & ++ \\
\hline
\end{tabular}

Table 1. Traits present to a marked degree or of a persistent nature $(++)$; present to a mild degree or of a transient nature (+); absent (-). Adapted from Tsuang, M. T., \& Winokur, G. (1974). (20)

Treatment: Although it is considered as the subtype with the poorest prognosis, there are as of yet very few studies on hebephrenic schizophrenia to recommend the best course of action in regards to the treatment, particularly the medication. Henceforth, the following assessments are based on already existing data from medical literature concerning antipsychotic treatment in schizophrenia, regardless of its subtype.
First- versus second-generation antipsychotics: The debate about the comparative advantages and disadvantages of first-generation, respectively secondgeneration antipsychotics in treating schizophrenia is still ongoing. (21) A Systematic Review and Meta-analysis have shown few differences of clinical importance for core illness symptoms. Its evidence has shown a clinically important benefit of 
ryos

haloperidol over olanzapine for improving positive symptoms, but the benefit was scaledependent. It was seen when the Scale for the Assessment of Positive Symptoms was used but not when the Positive and Negative Syndrome Scale (PANSS) was used. Furthermore, it has shown a clinically important benefit of olanzapine over haloperidol in improving negative symptoms when PANSS and the Scale for the Assessment of Negative Symptoms were used. (21,22) A different Systematic Review and Meta-analysis presented evidence that the second-generation antipsychotics are associated with a small increased risk for diabetes compared with first-generation antipsychotics in people with schizophrenia. As a side note, regardless of type of antipsychotic, screening for diabetes in all people with schizophrenia should be routine. (23) Additionally, tardive dyskinesia and extrapyramidal side effects are frequent side effects of treatment with first-generation antipsychotics, one theory explaining the cause being the neuronal cell damage from free radicals induced by antipsychotics. This hypothesis is supported by evidence of elevated levels of lipid peroxidation products and decreased vitamin E levels in dyskinetic patients. (24)

Antipsychotic combinations vs monotherapy: Antipsychotic monotherapy is recognized as the treatment of choice for patients with schizophrenia. Nonetheless, the coprescription of more than one antipsychotic drug to an individual patient (polypharmacy) is suggested by some expert consensus guidelines as the last resort after exhausting monotherapy alternatives. More so, the empirical use of combinations of antipsychotic agents appears to be increasing with little research to support the relative efficacy, safety or cost-effectiveness of this practice. The pharmacological justifications for antipsychotic combinations include seeking to achieve greater therapeutic potential by optimization of dopamine $\mathrm{D}_{2}$ receptor occupancy, or activity across a wider range of receptors, on the basis that certain non-dopaminergic receptors, such as serotonergic, glutamatergic and adrenergic receptors, may be relevant to the pathogenesis of positive and negative symptoms. (25, 26, $27,28,29,30)$ A comparative study between U.S. and E.U. estimates that in the U.S. 33\% of patients receive two antipsychotics and almost $10 \%$ receive three, while in Europe, there are around $20 \%$ of patients with schizophrenia receiving combinations of antipsychotics. According to its data, when risperidone was added to clozapine, it showed a modest difference in the group of patients in terms of BPRS total symptoms. (31) Different open-label studies documented the fact that combinations involving antipsychotics resulted in some degree of symptom improvement. The combinations most commonly referred to in this limited literature were olanzapine with amisulpride or risperidone, and quetiapine with risperidone. However, on the basis of early case reports, these authors noted that combining aripiprazole with a non-clozapine secondgeneration antipsychotic could possibly worsen the psychosis. $(32,33,34,35,36,37$, 38, 39) Moreover, the prescription of combined antipsychotics includes the risk of adherence problems associated with a more complicated regimen and an increased adverse effect burden due to drug interactions. (40, 41, 42, 43) In certain clinical situations, antipsychotic co-treatment may be superior to monotherapy, however the available evidence for the overall efficacy of combining antipsychotics is sparse, thus being unable to draw firm conclusions. $(41,44)$

Oral vs depot antipsychotics: Non-adherence is a major challenge in schizophrenia 
\%

treatment. While long-acting (depot) antipsychotic medication are often recommended to address adherence problems, evidence on the comparative efficacy of depot versus oral antipsychotics is, as of yet, inconsistent. While no single intervention is universally effective, depot medication is considered one of the most important pharmacologic interventions available to address adherence problems in schizophrenia. However, the findings in the clinical literature regarding the comparative effectiveness of depot versus oral antipsychotics have been inconsistent. There is a hypothesis that states that the study design is an important factor possibly affecting estimates of comparative effectiveness of antipsychotic medications. (45, 46, 47, 48) Methodological limitations were found in most studies, leading to heterogeneity and difficulty interpreting data. The fundamental requirements for improved practice include better characterized patient groups (usually defined by treatment nonresponse), larger studies, longer observation times and more attention to safety/physical health concerns. (47)

\section{MATERIALS AND METHODS}

We searched the hospital's registry for patients with the diagnosis of hebephrenic schizophrenia, admitted between $1^{\text {st }}$ of January 2015 and November 2019. During this period, we found that there were 53 patients with the above-mentioned diagnosis accounting for 253 admissions. Out of the 53 patients, 16 were admitted as outpatients, with 37 admissions in total, and 4 were chronic, institutionalized patients. We decided to include them separately in our analysis in order to maintain a homogenous population.
We indexed data about the age and sex of the patients, the length of admissions as well as the time span between admissions. Further, we logged the treatment recommendations received by each patient, at each discharge. Using Microsoft Excel 2016 program we calculated basic statistical indicators such as mean and standard deviation. Analytical statistical indicators like variance, p-values, confidence intervals and standard error were calculated using the T-test, ANOVA analysis, and Regression analysis provided by the Microsoft Excel's Analysis ToolPak. We generated the normal distribution curves for each parameter that we analysed using the NORM.DIST function in Excel.

\section{RESULTS}

A number of 53 patients were admitted in Socola Institute of Psychiatry during 01.01.2015 and the 01.11.2019, with an average number of admissions per patient equal to 4.77 , or roughly 1 admission per year per patient. Out of the 53 patients, 17 were admitted as outpatients, 37 as inpatients and 4 were institutionalized. One of the institutionalized patients was treated as an inpatient since September 2018 and was included as for that moment in the inpatient category, and 4 patients were treated both as inpatients and as outpatients and were included in both categories. The inpatients had an average number of 1.21 admissions per year $(\sigma=1.02, \min =0.2, \max =4.2)$ and the outpatients had an average number of 0.66 admissions per year $(\sigma=0.46, \quad \min =0.2$, $\max =2$ ). These findings suggest that inpatients had poorer symptomatic control than outpatients, which on turn decided the type of admission for those patients. 


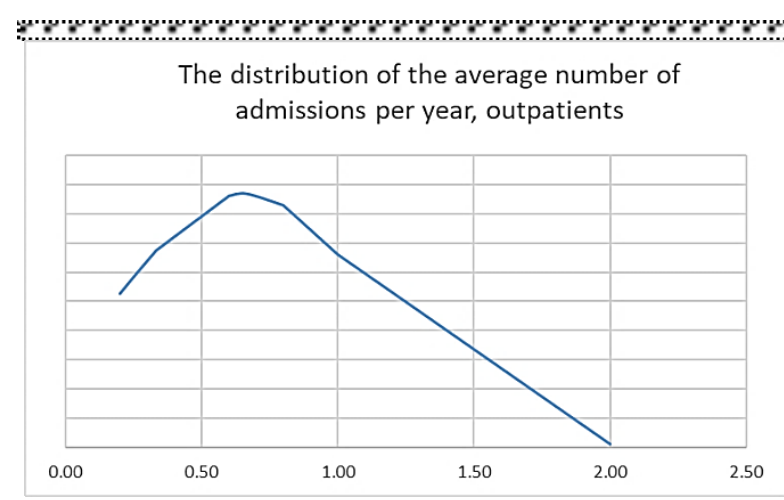

Figures 1 (left). displaying the distribution of the average number of admissions per year for outpatients.

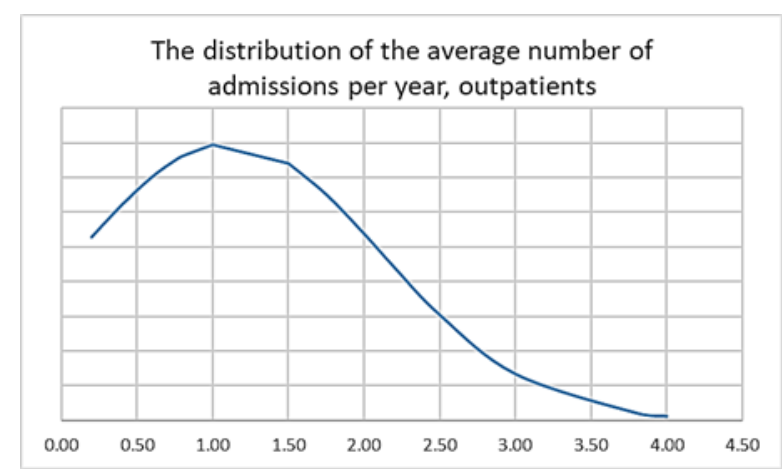

Figure 2 (right). displaying the distribution of the average number of admissions per year for inpatients.
Regarding the sex of the patients we found that males were overrepresented $(70 \%$ males, $30 \%$ females) in all of the categories taken together: $100 \%$ of the institutionalized patients $(n=4), 74 \%$ of the inpatients $(n=25)$. A closer to normal distribution was found in the outpatient category: $56 \%$ males $(n=9)$ and $44 \%$ females $(n=7)$.

In the outpatient group, male patients had fewer admissions per patient (1.77) while females had on average 3 admissions per patient. The difference between admission times differed significantly between sexes. When taken by admission length with no consideration for how many patients accounted for those admissions, male patients had a statistically significant $(\mathrm{p}=0.03)$ longer average (5.88 days, $\sigma=7.22$ ) than females (2.14 days, $\sigma=1.79$ ) or a $274 \%$ increase. However, when calculating for the average number of admission days per patient, the results were not statistically significant $(\mathrm{p}=0.12)$, with an average for males of 4.77 days $(\sigma=4.35)$ and an average of 2.75 days $(\sigma=2.18)$ for females.

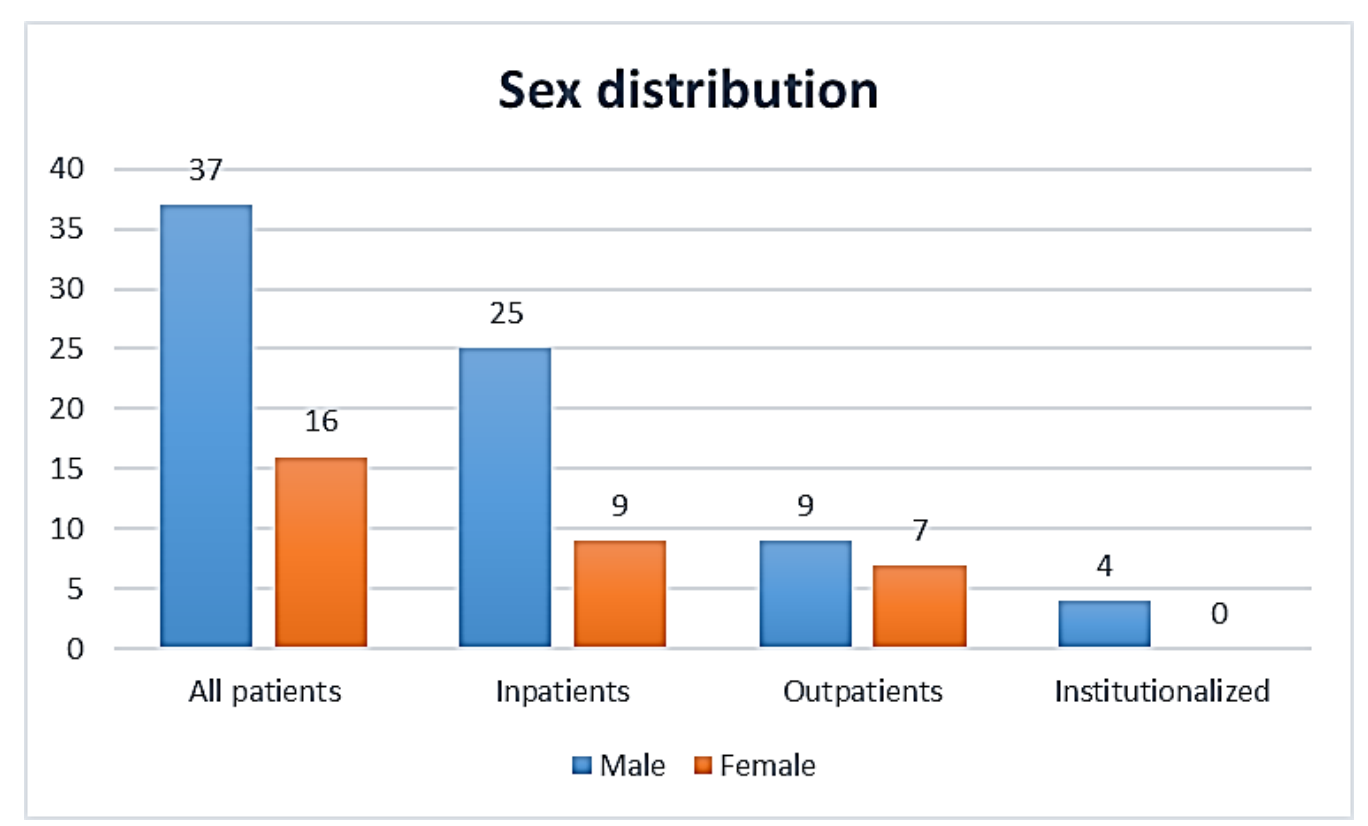

Figure 3. The sex distribution of patients in all of the categories. 
In the inpatient group, males had an average of 3.28 admissions per patient while females had on average 4 admissions per patient. In consideration to the lengths of admissions without taking into account the average days of admission per patient, male patients had a statistically significant $(\mathrm{p}=0.001)$ higher average $(155 \%)$ of 18.23 days $(\sigma=18.1)$ than female patients with an average of 11.75 days $(\sigma=4.57)$. This difference is slightly higher (157\%, p=0.01) when we took into consideration the average number of admission days per patient. In this situation male patients had an average of 20.8 days $(\sigma=13.75)$ and females had an average of 13.22 days.

In the inpatient group, female patients had $216 \%$ higher average hospitalization free days
(226 vs. $106 \mathrm{p}=0.003)$. In the outpatient group, males had a non-statistically significant higher hospitalization free days (312 vs. $433 \mathrm{p}=0.1$ ).

Age distribution followed a left shifted normal distribution in all patient categories with an average of 36.7 years at the time of admission. We performed a regression analysis because we wanted to see if there is a pattern between the age of the patient and admission period in the inpatient group. There is a slight increase $(\mathrm{R}=0.14)$ of hospitalization duration in elder patients but the result is not conclusive because of few data points. Furthermore, this slight increase could be accounted by the fact that elder patients have additional somatic disorders that require medical attention.

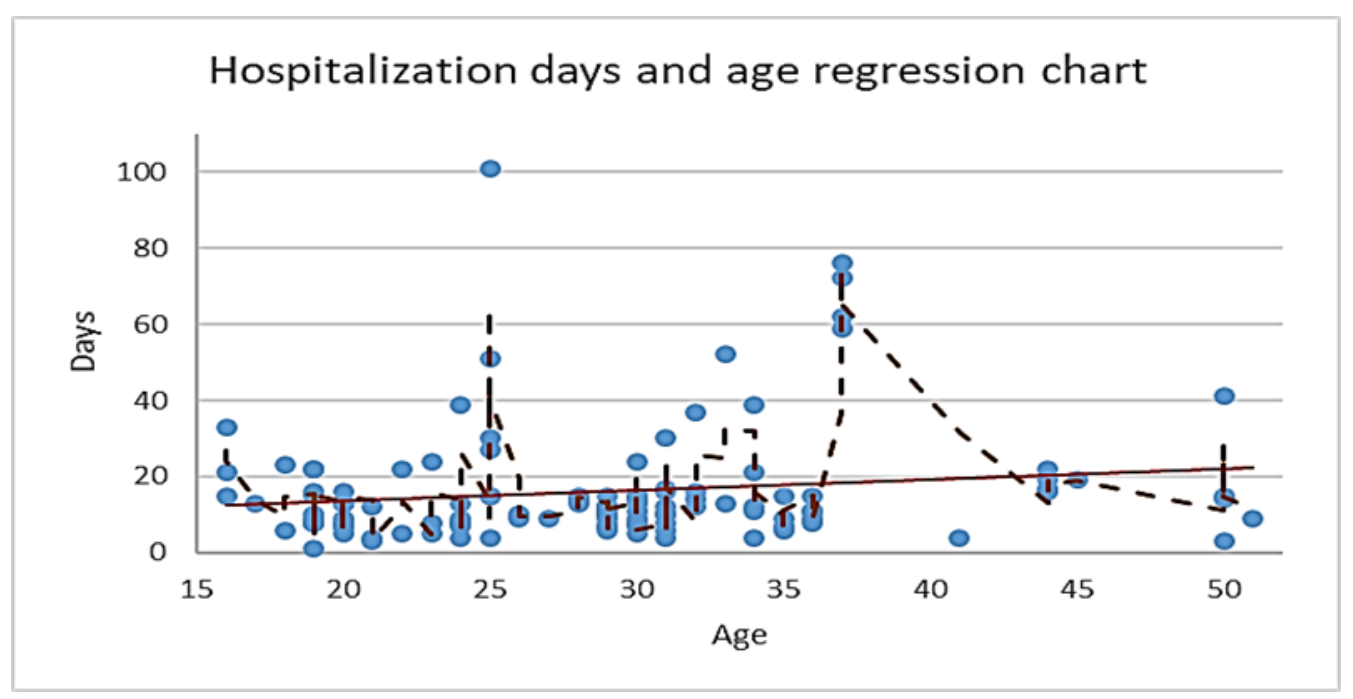

Figure 4. Age and hospitalization period regression chart, $\mathrm{R}=0.14$

We noticed 3 spikes in hospitalization period around patients aged 25-35 and we wanted to see if these were isolated cases of single patients or a more generalized trend. We performed another regression analysis, this time using the average hospitalization duration for each patient. The results in this case show no correlation between age and hospitalization duration $(\mathrm{R}=0.02)$ and it showed that the first spike was produced by 3 out of 8 patients aged 24 to 26 while the second and third spike are singular cases of patients with an long average admission period (43 days and 57 days). 
Average hospitalization days and age regression chart

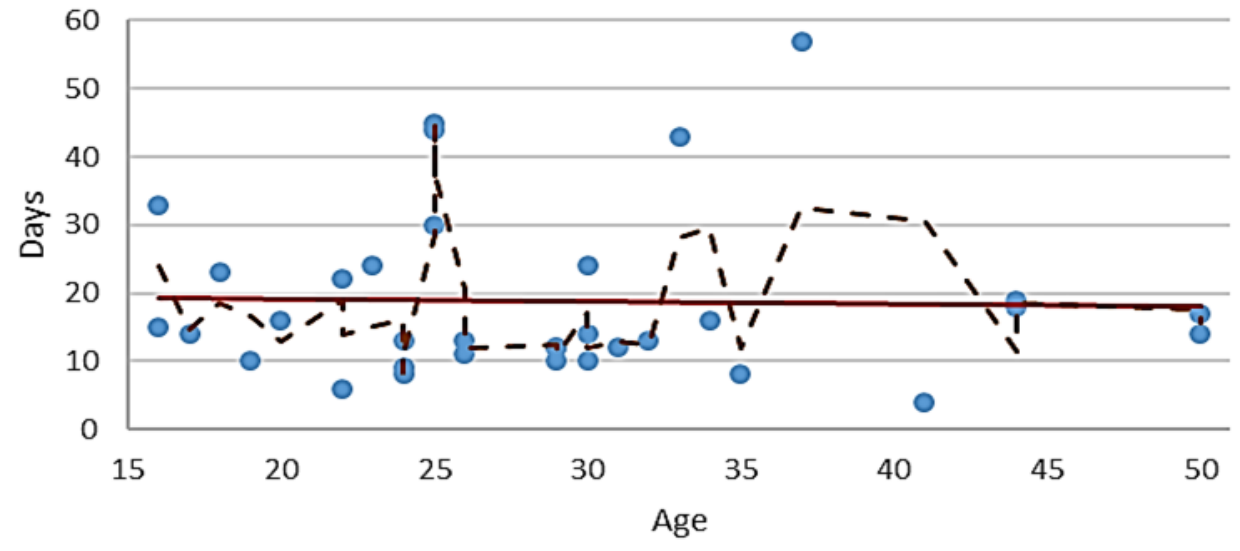

Figure 5. Average hospitalization days and age regression chart, $\mathrm{R}=0.02$

Average hospitalization duration was 16.25 days $(\sigma=15.49)$ and the average interval between hospitalizations was 143.93 days $(\sigma=174.89)$ for the inpatient group. For the outpatient group, the average duration of hospitalization was 4 days $(\sigma=5.2)$ and the interval between hospitalizations was 352 days $(\sigma=228.08)$.

In the outpatient group, 11 patients received atypical antipsychotic treatment (64\%) and 6 patients received typical antipsychotic treatment. We calculated the average day of admission between the groups and the results were 5.04 days of average hospitalization for patients receiving atypical antipsychotics and 1.33 days for patients receiving typical antipsychotics. The difference is statistically significant with a $p=0.003$. Oral antipsychotics were prescribed in 14 patients, the other 3 of the outpatient group received long action injectable antipsychotics (Depot). In this case, mean hospitalization period was on average 2.25 days for patients receiving Depot antipsychotics and 4.09 days for those receiving oral antipsychotics. The difference is not statistically significant with a $p$ value of 0.07. Three patients received dual antipsychotic treatment. In this case the average hospitalization days for those patients was 1 , compared to 3.88 days for patients that received singular antipsychotic therapy $(\mathrm{p}=0.001)$.

In the inpatient group, $70 \%$ of the patients $(n=25)$ received atypical antipsychotic treatment, $26 \% \quad(\mathrm{n}=9)$ received typical antipsychotics and $26 \%(n=9)$ received both typical and atypical antipsychotics. Mean hospitalization duration for patients receiving typical antipsychotics was 19.73 days $(\sigma=13.24) ; 17.22$ days $(\sigma=18.15)$ for patients receiving atypical antipsychotics and 12 days $(\sigma=6.07)$ for patients receiving both. Statistical significant differences were found for patients taking both typical and atypical antipsychotics versus patients taking atypical antipsychotics (12 days vs. 17.21 days, $\mathrm{p}=0.01$ ) and versus typical (12 days vs 19.73 days, $\mathrm{p}=0.02$ ). No statistically significant differences were found in hospitalization duration depending on whether or not patients received Oral vs Depot antipsychotics (16.07 days vs 15.33 days) or patients receiving a single antipsychotic agent or more (16.68 days versus 15.68 days). 


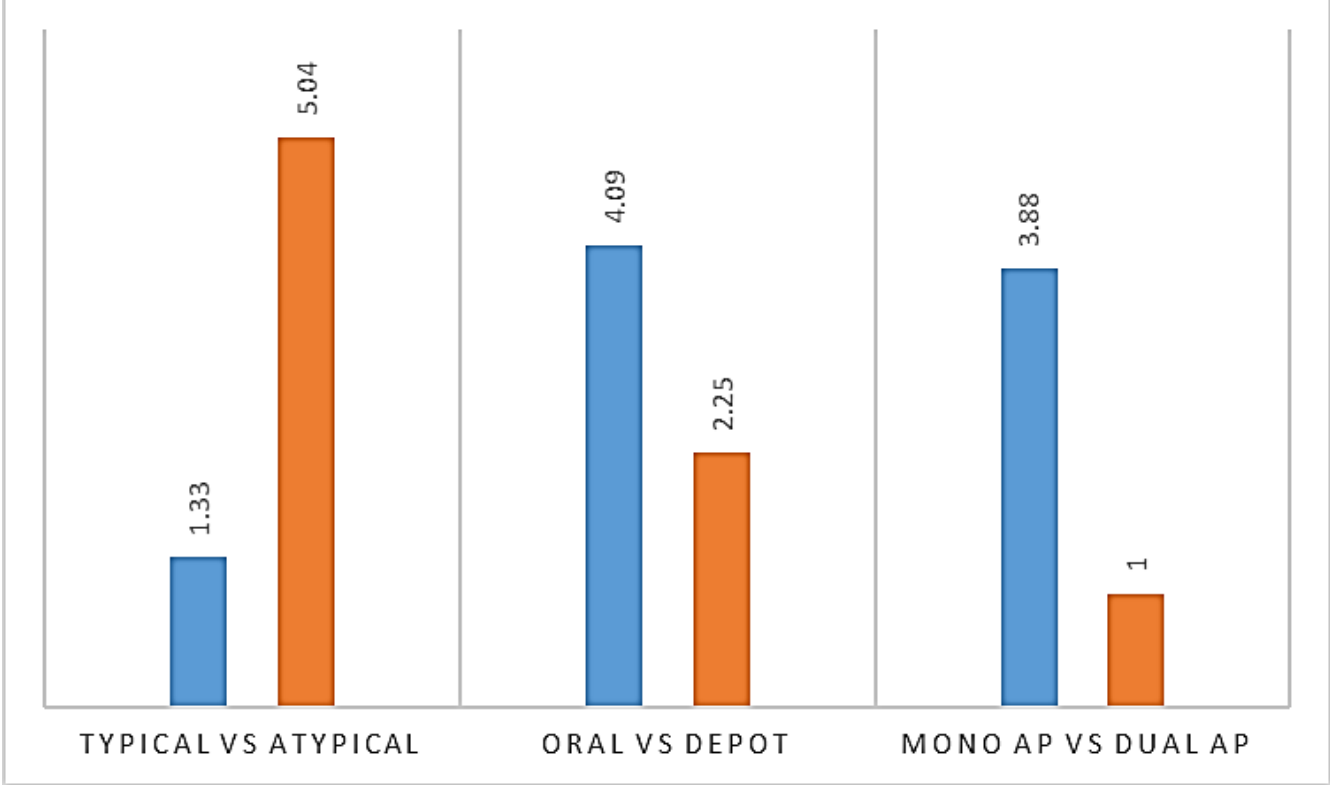

Figure 6. Difference in average hospitalization period in the outpatient group depending on the type of antipsychotic treatment received

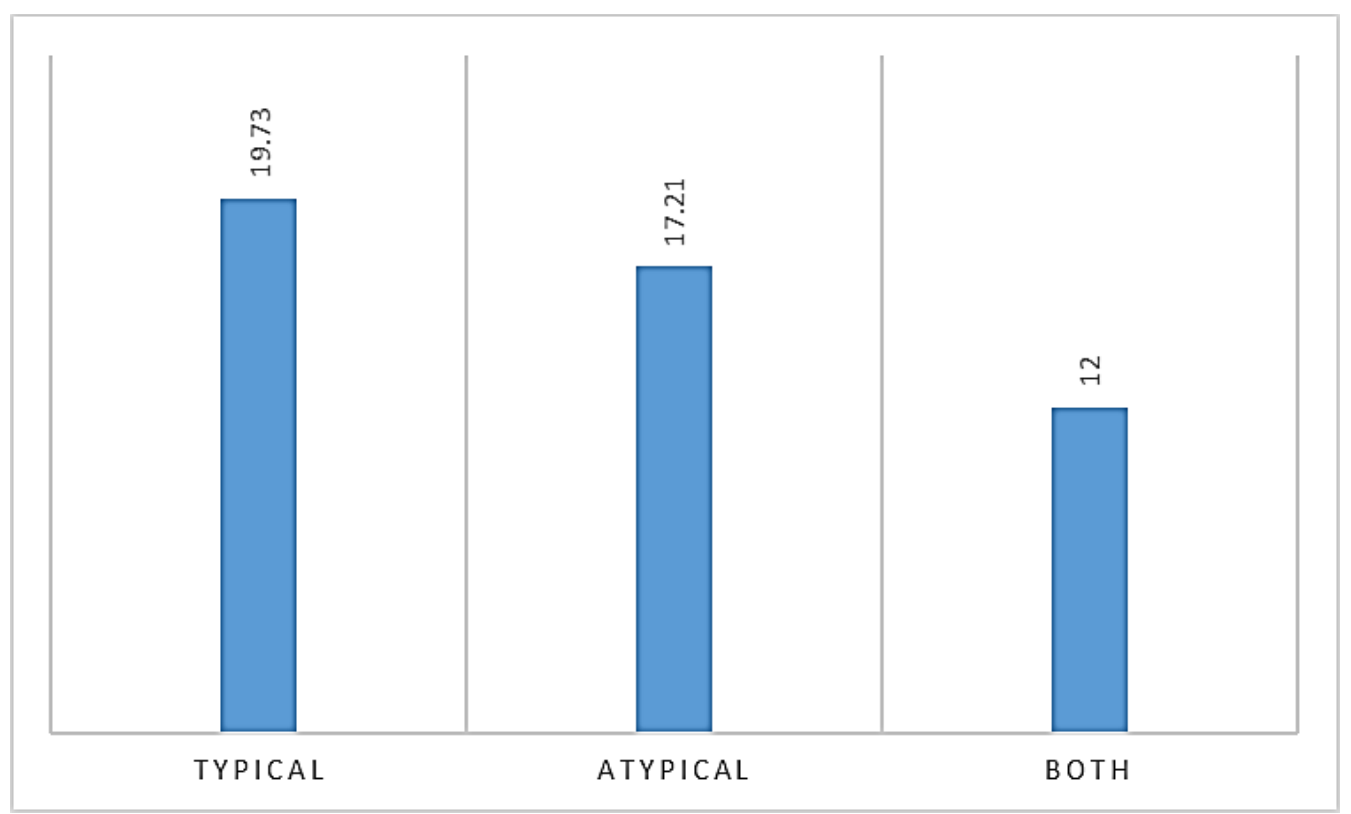

Figure 7. Differences in hospitalization days (inpatients) depending on the type of antipsychotic agent received.

Regarding the duration between admissions statistical significant differences $(\mathrm{p}=0.008)$ were found between patients receiving atypical antipsychotics (mean=161.83 days, $\sigma=161.13$ ) and patients receiving typical antipsychotics (mean=80.55 days, $\sigma=68.87$ ).
Patients receiving both typical and atypical antipsychotics had an average duration without admissions of 128 days but with very high variability $\sigma=228.89$ days, and no statistical significance compared to other groups. 


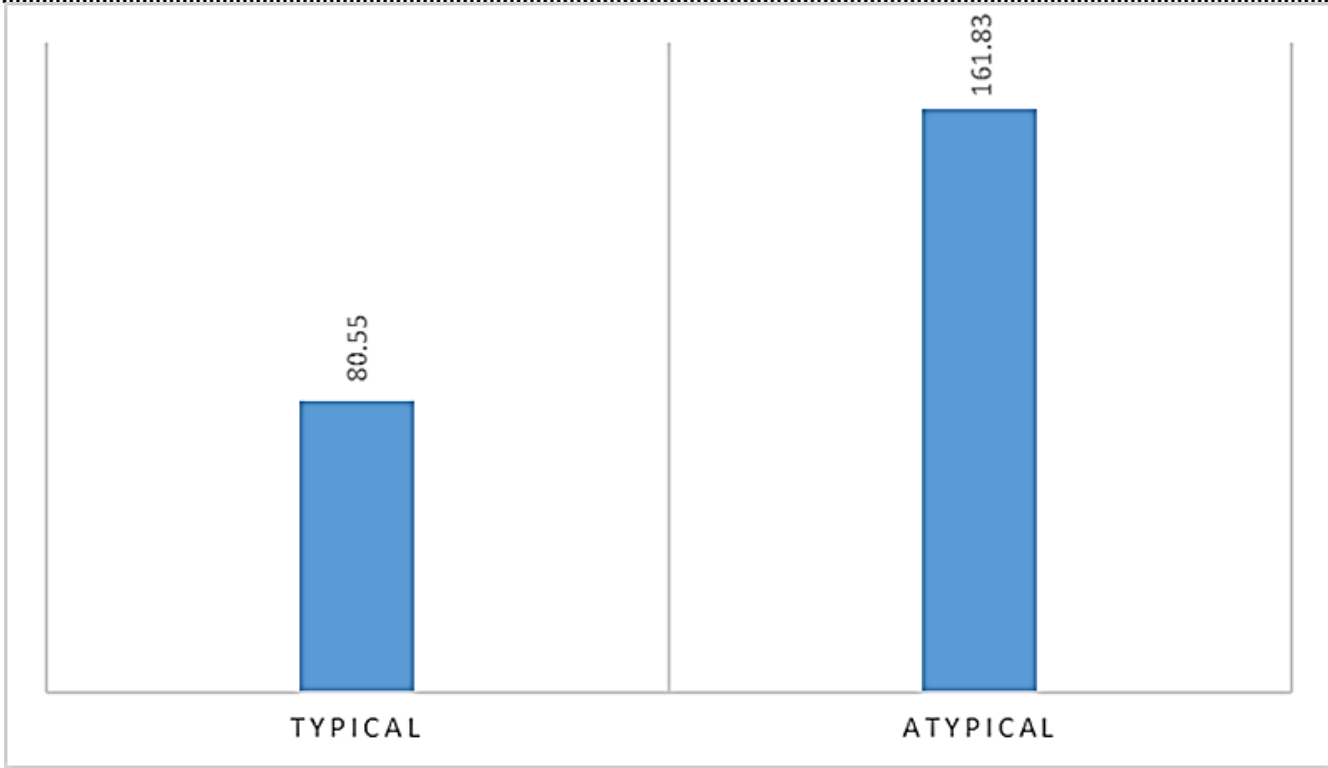

Figure 8. Difference in hospitalization free days in patients receiving typical vs atypical antipsychotics

Statistically significant differences $(\mathrm{p}=0.002)$ in admission free days were found in patients receiving oral versus depot antipsychotics (170.55 days, $\sigma=168.85$ vs. 64.37 days, $\sigma=99.52$ ). We found this result contra intuitive and we wanted to see if there is any correlation between hospitalization duration and hospitalization free days in this population. We theorized that the lower admission free duration is because patients came into the hospital to get their medication administered. A regression analysis showed that this is not the case as the majority of patients with admission free periods of around 30 days had admissions lasting between 5 and 12 days. No statistically significant difference was found in hospitalization free days between patients given a single antipsychotic agent and patients given two or more agents (147.5 days vs 139.7 days)

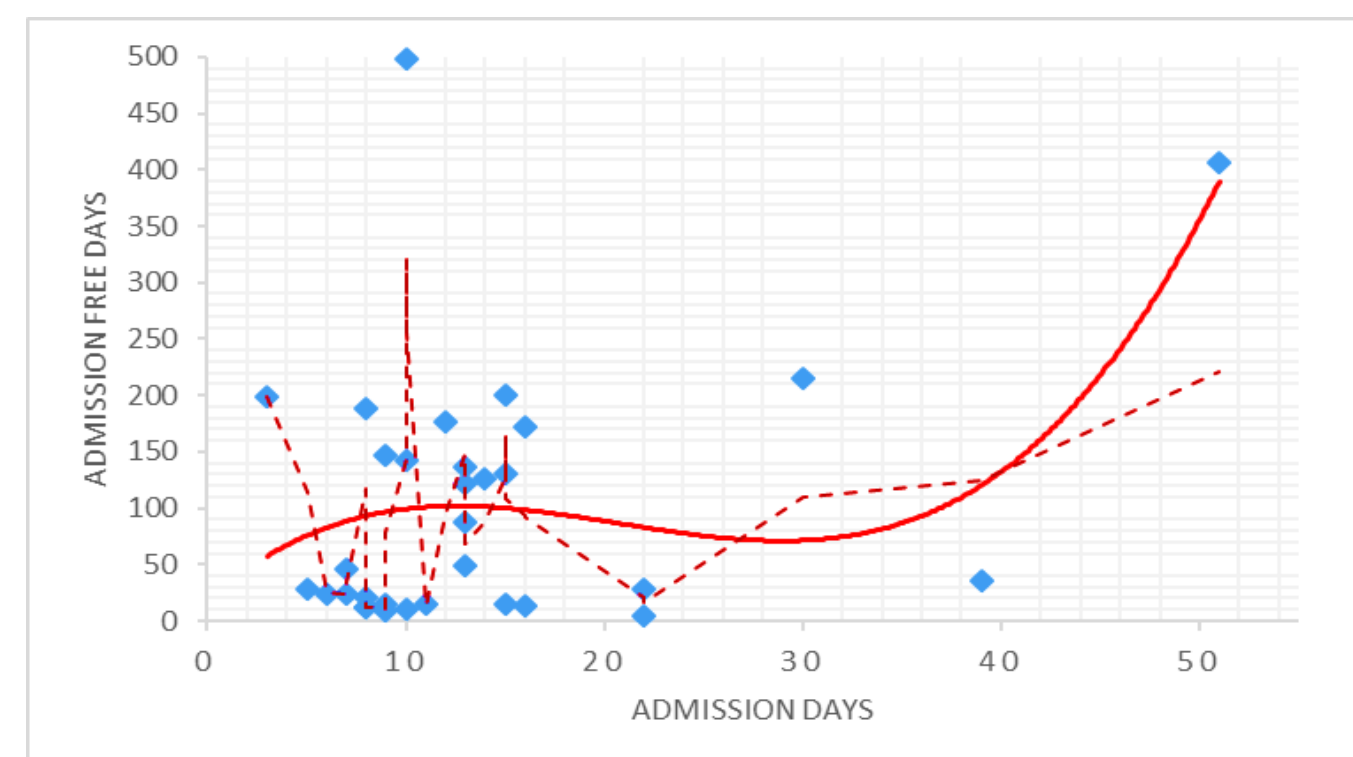

Figure 9. Regression chart. Horizontal axis: admission days, Vertical axis: admission free days. Polynomial trend line (continuous), Moving average line (dotted). $\mathrm{R}=0.32, \mathrm{p}=0.06$. 


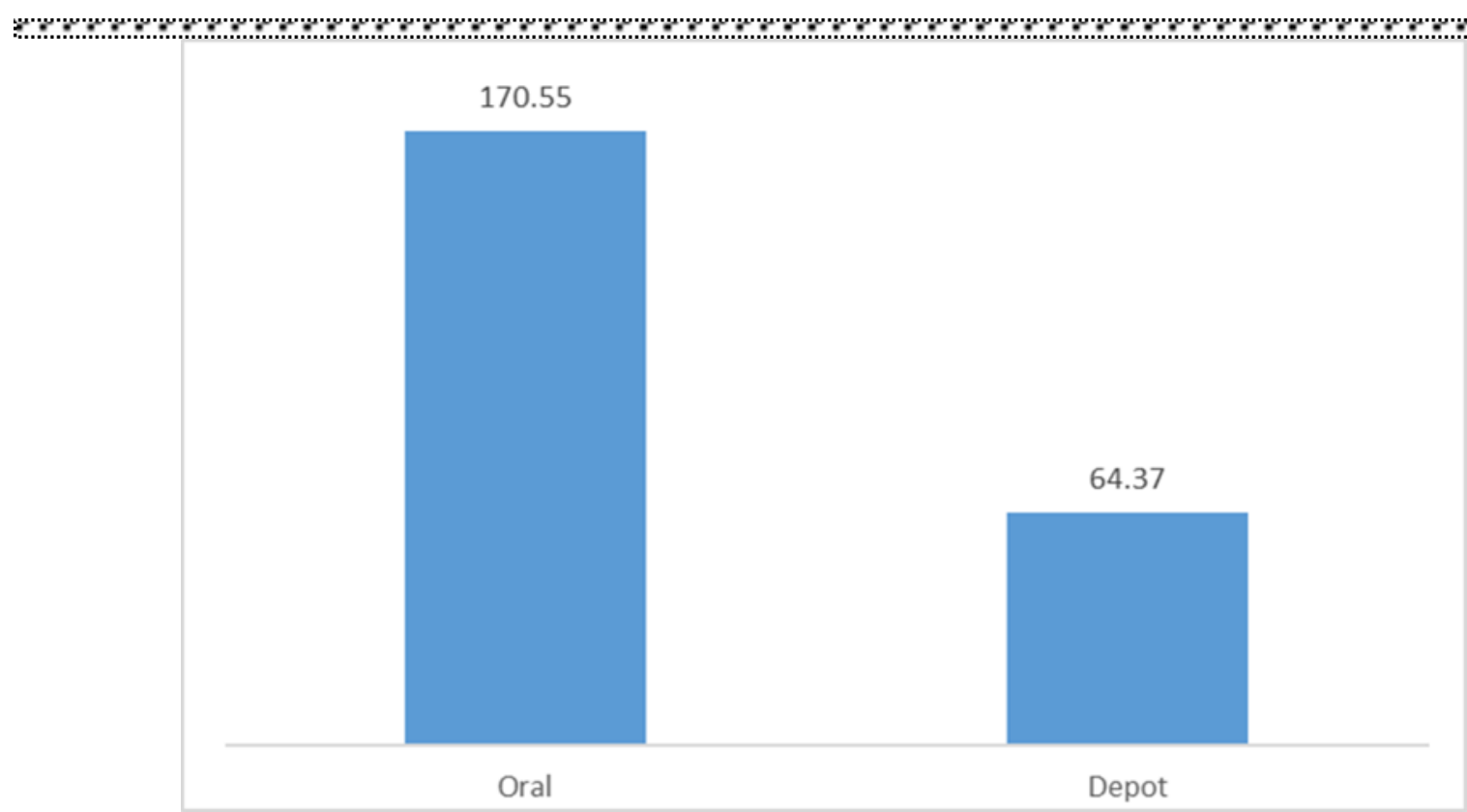

Figure 10. The difference in the inpatient group on hospitalization free days depending on the administration form of the antipsychotic drug.

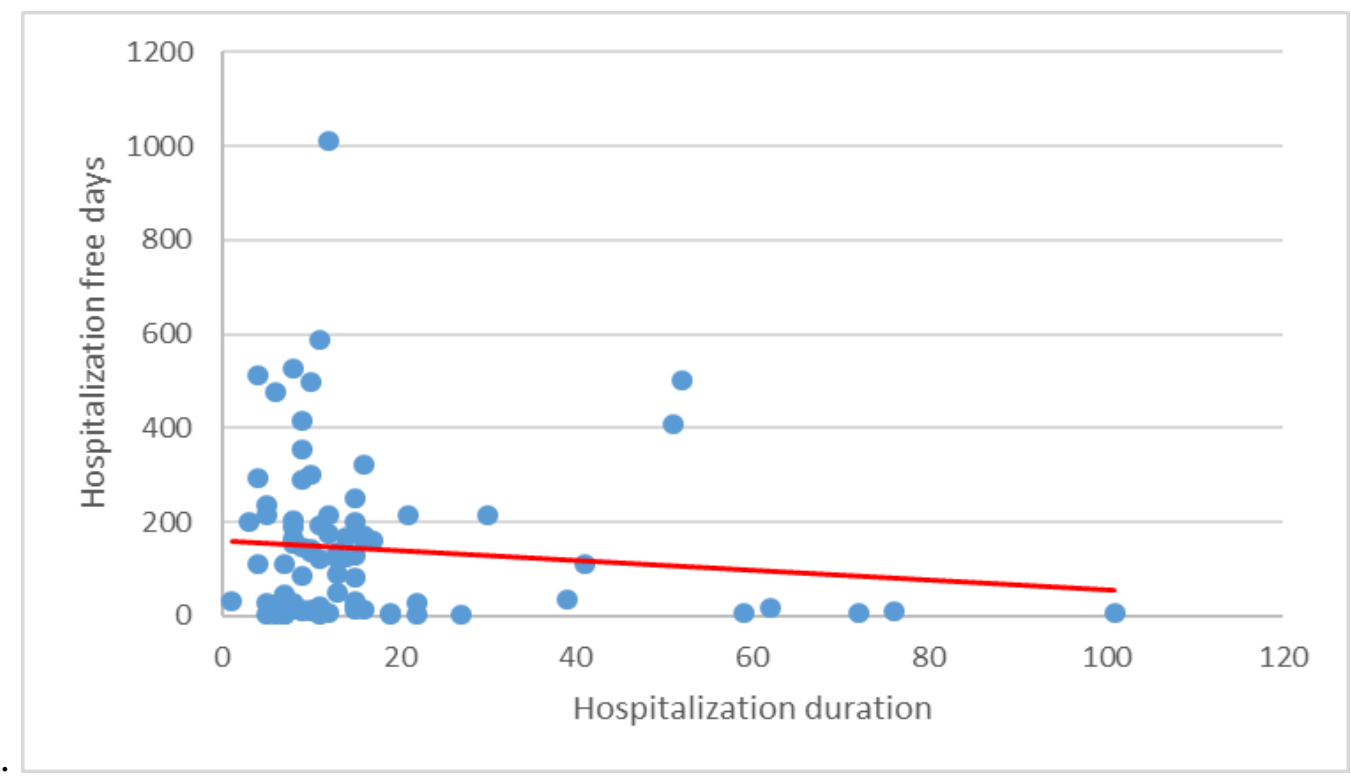

Figure 11. Regression chart between hospitalization free days and the next hospitalization duration, inpatients. $\mathrm{R}=0.1$.

\section{DISCUSSION}

A recent article published in July 2019 correlates the length of hospitalization for patients with schizophrenia and activity performance as it was measured using an adapted version of the Modified Barthel Index. (49) They have found that the optimal duration of hospitalization concerning increasing the global performance was between 20 and 50 days. The patients we included in our study had a lower mean hospitalization of 16.25 days in the inpatient category, with an average of 144 days between hospitalizations. Although hospitalization free days are not a direct measure of symptomatic control, we consider it a good indicator, especially because we did not found a positive correlation between a short hospitalization free duration and the 
n.mp\%

following hospitalization duration. (Figure

10)

In the outpatient group, patients were observed for a shorter period if they had received a typical antipsychotic agent, which suggests that in the case of a mild symptomatic relapse in patients with hebephrenic schizophrenia, these agents could be beneficial over newer agents. The same was true for patients receiving more than one antipsychotic agent, either it being typical or atypical. Inpatients required fewer days of hospitalization if they received a combination of a typical and an atypical antipsychotic over either class on its own. Contrary to how outpatients performed, inpatients had a longer hospitalization period under typical antipsychotics than atypical, although not statistically significant. This result is more evident when considering hospitalization free days in the category of patients that received typical AP vs the category that received atypical AP. In this situation, the difference is double in the favour of atypical AP's. The most surprising correlation we made is the fact that patients receiving long lasting injectable antipsychotics had lower hospitalization free days, which might suggest that the treatment compliance to this class is not as high as it was thought to be. We looked to see if the lower hospitalization free days was due to the necessity of administering the injection inside the hospital, expecting to see short hospitalization duration for those patients. As shown in figure 9, there is a group of patients that had admissions below the average, between 5 and 12 days that were admitted 30 days after the previous discharge. Even if we remove those patients from the analysis, we are still facing with 115 days of average duration between admissions which still is two thirds of what patients taking oral APs experience. We want to disclose that a number of variables could influence the results presented in this study. Firstly, this is a retrospective study and we cannot say that the type of medication that a patient received influenced the length of hospitalization and not otherwise, the hospitalization duration influenced the type of medication. This could especially be the case for the correlation between hospitalization free days and oral versus depot antipsychotic. In this case, there is a possibility that a number of patients with low compliance to oral treatment and high admission rates were switched to depot antipsychotics in order to increase the compliance, thus explaining the low hospitalization free days in the depot antipsychotic group. Secondly, the results are not conclusive due to the high variability of the data. In multiple cases the standard deviation for a certain data set was close to the average for that data set and in some cases, it exceeded the average.

\section{CONCLUSIONS}

1. Male patients had a higher number of hospitalization days both in the inpatient group (155\% $\mathrm{p}=0.001)$ and outpatient group $(274 \% \mathrm{p}=0.03)$.

2. In the inpatient group, female patients had $216 \%$ higher average hospitalization free days (226 vs. $106 \mathrm{p}=0.003)$. In the outpatient group, males had non-statistically significant higher hospitalization free days (312 vs. $433 \mathrm{p}=0.1$ ).

3. In the outpatient group, patients that received typical antipsychotics had fewer days of hospitalization that patients that received atypical antipsychotics ( 1.33 vs $5.04 \mathrm{p}=0.003$ )

4. In the outpatient group, patients that received two or more antipsychotics had a lower average hospitalization that patients that received one antipsychotic ( 1 vs $3.08, \mathrm{p}=0.001)$. 
5. In the inpatient group, patients that received both an atypical AP and a typical AP had fewer hospitalization days than patients that received only one type of AP (12 vs 17.21 for atypical $\mathrm{p}=0.01,12$ vs 19.73 for typical $\mathrm{p}=0.02$ )

6. In the inpatient group, patients that received atypical APs had a higher average hospitalization free day than patients that received typical APs ( 80 vs $161 \mathrm{p}=0.008$ )

7. Patients in the inpatient group that received depot APs had fewer average hospitalization free days than patients that received oral APs (64 vs $170 \mathrm{p}=0.002$ )

These results are compiled from a population of just 53 patients and as such, although $p$ values are indicative of acceptable statistical significance, averages are not highly suggestive due to the high variance represented in text but the standard deviance from the average $(\sigma)$. Finally, we want to stress that although correlations were found between the type of antipsychotic agent and admission days and admission free days respectively, no correlations were found between the admission length and admission free length for patients receiving the same antipsychotic agent. Further investigations have to be made in order to obtain a higher statistical evidence level, including interventional studies.

\section{ACKNOWLEDGEMENTS AND DISCLOSURES}

The authors declare that they have no potential conflicts of interest to disclose.

\section{REFERENCES}

1. Benjamin J. Sadock, Virginia A. Sadock. Kaplan \& Sadock's comprehensive textbook of psychiatry. Tenth Edition.Volume one.Wolters Kluwer, 3613-4098. 2017

2. Kaplan, H. I., Sadock, B. J., Grebb, J. A. Kaplan and Sadock's synopsis of psychiatry: Behavioral sciences, clinical psychiatry. Williams \& Wilkins Co., 649-750. 1994

3. Arieti, S. Schizophrenia. American Journal of Psychiatry, 128(3), 348-350. 1971

4. American Psychiatric Association Diagnostic and Statistical Manual of Mental Disorder, Fourth Edition, Text Revised. Washington, DC, American Psychiatric Press, 297-344. 2010

5. Fish, F. A guide to the Leonhard classification of chronic schizophrenia. Psychiatric Quarterly, 38(1), 438-450. 1964

6. Tsuang, M. T., Winokur, G. Criteria for subtyping schizophrenia: Clinical differentiation of hebephrenic and paranoid schizophrenia. Archives of General Psychiatry, 31(1), 43-47. 1974

7. Fenton, W. S., McGlashan, T. H. Natural history of schizophrenia subtypes: I. Longitudinal study of paranoid, hebephrenic, and undifferentiated schizophrenia. Archives of General Psychiatry, 48(11), 969-977. 1991

8. McGlashan, T. H., Fenton, W. S. Classical subtypes for schizophrenia: literature review for DSM-IV. Schizophrenia Bulletin, 17(4), 609-632. 1991

9. McGlashan, T. H., \& Fenton, W. S. Subtype progression and pathophysiologic deterioration in early schizophrenia. Schizophrenia Bulletin, 19(1), 71-84. 1993

10. Nasrallah, H. A., Smeltzer, D. J. Contemporary diagnosis and management of the patient with schizophrenia. Handbooks in Health Care. 2002

11. Williams, J., Farmer, A. E., Wessely, S., Castle, D. J., \& McGuffin, P. Heterogeneity in schizophrenia: an extended replication of the hebephrenic-like and paranoid-like subtypes. Psychiatry research, 49(3), 199-210. 1993

12. Winokur, G., Morrison, J., Clancy, J., Crowe, R. Iowa 500: the clinical and genetic distinction of hebephrenic and paranoid schizophrenia. Journal of Nervous and Mental Disease. 1974

13. Pfohl, B., Winokur, G. The evolution of symptoms in institutionalized hebephrenic/catatonic schizophrenics. The British Journal of Psychiatry, 141(6), 567-572. 1982

14. Pfohl, B., Winokur, G. The micropsychopathology of hebephrenic/catatonic schizophrenia. Journal of Nervous and Mental Disease. 1983

15. Rinsley, D. B. New Hope for the Diagnosis of Hebephrenic Schizophrenia?. American Journal of Psychiatry, 143(4), 560-b. 1986

16. Takeda, T., Watanabe, Y., Hasegawa, K. Behavior patterns of patients with hebephrenic schizophrenia when they attempt academic study. Psychiatry and clinical neurosciences, 58(2), 125-132. 2004 
нднд 17. Morrison, J. R. Changes in subtype diagnosis of schizophrenia: 1920-1966. American Journal of Psychiatry, 131(6), 674-677. 1974

18. World Health Organization: The ICD-10. Classification of Mental and Behavioural Disorders: Clinical Descriptions and Diagnostic Guidelines. World Health Organization. Geneva. 1992

19. Chiriță V., Papari A., Chiriță R. Tratat de psihiatrie, Volumul I, Editura Fundației „Andrei Șaguna”, Constanța, 271-332. 2009

20. Tsuang, M. T., Winokur, G. Criteria for subtyping schizophrenia: Clinical differentiation of hebephrenic and paranoid schizophrenia. Archives of General Psychiatry, 31(1), 43-47. 1974

21. Hartling, L., Abou-Setta, A. M., Dursun, S., Mousavi, S. S., Pasichnyk, D., Newton, A. S. Antipsychotics in adults with schizophrenia: comparative effectiveness of first-generation versus second-generation medications: a systematic review and meta-analysis. Annals of internal medicine, 157(7), 498-511. 2012

22. Leucht, S., Corves, C., Arbter, D., Engel, R. R., Li, C., Davis, J. M. Second-generation versus first-generation antipsychotic drugs for schizophrenia: a meta-analysis. The Lancet, 373(9657), 31-41. 2009

23. Smith, M., Hopkins, D., Peveler, R. C., Holt, R. I. G., Woodward, M., Ismail, K. First-v. second-generation antipsychotics and risk for diabetes in schizophrenia: systematic review and meta-analysis. The British Journal of Psychiatry, 192(6), 406-411. 2008

24. Kropp, S., Kern, V., Lange, K., Degner, D., Hajak, G., Kornhuber, J., Bleich, S., et. all. Oxidative stress during treatment with first-and second-generation antipsychotics. The Journal of neuropsychiatry and clinical neurosciences, 17(2), 227-231. 2005

25. Faries, D., Ascher-Svanum, H., Zhu, B., Correll, C., Kane, J. Antipsychotic monotherapy and polypharmacy in the naturalistic treatment of schizophrenia with atypical antipsychotics. BMC psychiatry, 5(1), 26. 2005

26. Barnes, T. R., Paton, C. Antipsychotic polypharmacy in schizophrenia. CNS drugs, 25(5), 383-399. 2011

27. Freudenreich, O., Goff, D. C. Antipsychotic combination therapy in schizophrenia. A review of efficacy and risks of current combinations. Acta Psychiatrica Scandinavica, 106(5), 323-330. 2002

28. Azorin, J. M., Spiegel, R., Remington, G., Vanelle, J. M., Péré, J. J., Giguere, M., Bourdeix, I. A double-blind comparative study of clozapine and risperidone in the management of severe chronic schizophrenia. American Journal of Psychiatry, 158(8), 1305-1313. 2001

29. Sommer, I. E., Begemann, M. J., Temmerman, A., \& Leucht, S. Pharmacological augmentation strategies for schizophrenia patients with insufficient response to clozapine: a quantitative literature review. Schizophrenia bulletin, 38(5), 1003-1011. 2011

30. Stahl, S. M., \& Grady, M. M. A critical review of atypical antipsychotic utilization: comparing monotherapy with polypharmacy and augmentation. Current medicinal chemistry, 11(3), 313-327. 2004

31. Goodwin, G., Fleischhacker, W., Arango, C., Baumann, P., Davidson, M., De Hert, M., Naber, D, et all. Advantages and disadvantages of combination treatment with antipsychotics: ECNP Consensus Meeting, March 2008, Nice. European Neuropsychopharmacology, 19(7), 520-532. 2009

32. Barnes, T. R., Paton, C. Antipsychotic polypharmacy in schizophrenia. CNS drugs, 25(5), 383-399. 2011

33. Bondolfi, G., Dufour, H., Patris, M., May, J. P., Billeter, U., Eap, C. B., Baumann, P. Risperidone versus clozapine in treatment-resistant chronic schizophrenia: a randomized double-blind study. American Journal of Psychiatry, 155(4), 499-504. 1998

34. Buchanan, R. W., Kirkpatrick, B., Bryant, N., Ball, P. Fluoxetine augmentation of clozapine treatment in patients with schizophrenia. The American journal of psychiatry. 1996

35. Cascade, E. F., Kalali, A. H., Buckley, P. F. Current management of schizophrenia: antipsychotic monotherapy versus combination therapy. psychiatry (Edgmont), 5(5), 28. 2008

36. Centorrino, F., Fogarty, K. V., Sani, G., Salvatore, P., Cincotta, S. L., Hennen, J., Baldessarini, R. J., et all. Use of combinations of antipsychotics: McLean Hospital inpatients, 2002. Human Psychopharmacology: Clinical and Experimental, 20(7), 485-492. 2005

37. Chang, J. S., Ahn, Y. M., Park, H. J., Lee, K. Y., Kim, S. H., Kang, U. G., Kim, Y. S. Aripiprazole augmentation in clozapine-treated patients with refractory schizophrenia: an 8-week, randomized, double-blind, placebo-controlled trial. The Journal of clinical psychiatry, 69(5), 720-731. 2008

38. Correll, C. U., Rummel-Kluge, C., Corves, C., Kane, J. M., Leucht, S. Antipsychotic combinations vs monotherapy in schizophrenia: a meta-analysis of randomized controlled trials. Schizophrenia bulletin, 35(2), $443-457$. 2008

39. Honer, W. G., Thornton, A. E., Chen, E. Y., Chan, R. C., Wong, J. O., Bergmann, A., Williams, R., et all. Clozapine alone versus clozapine and risperidone with refractory schizophrenia. New England Journal of Medicine, 354(5), 472-482. 2006

40. Ruiz, A., Brañas, A., Vicens, M., Orozco, A., Lahera, G. Antipsychotic monotherapy versus combination in schizophrenia: Are there differences in cognition?. European Psychiatry, 33, S334. 2016

41. Miller, A. L., Craig, C. S. Combination antipsychotics: pros, cons, and questions. Schizophrenia Bulletin, 28(1), 105-109. 2002

42. Kontaxakis, V. P., Ferentinos, P. P., Havaki-Kontaxaki, B. J., Roukas, D. K. Randomized controlled augmentation trials in clozapine-resistant schizophrenic patients: a critical review. European Psychiatry, 20(5-6), 409-415. 2005 

43. Kreyenbuhl, J., Valenstein, M., McCarthy, J. F., Ganoczy, D., Blow, F. C. Long-term combination antipsychotic treatment in VA patients with schizophrenia. Schizophrenia research, 84(1), 90-99. 2006

44. Paton, C., Whittington, C., Barnes, T. R. Augmentation with a second antipsychotic in patients with schizophrenia who partially respond to clozapine: a meta-analysis. Journal of clinical psychopharmacology, 27(2), 198-204. 2007

45. Johnson, D. A. W. Oral versus depot medication in schizophrenia. Acta Psychiatrica Scandinavica, 63(S291), 5660. 1981

46. Kirson, N. Y., Weiden, P. J., Yermakov, S., Huang, W., Samuelson, T., Offord, S. J., Wong, B. J., et all. Efficacy and effectiveness of depot versus oral antipsychotics in schizophrenia: synthesizing results across different research designs. The Journal of clinical psychiatry, 74(6), 568-575. 2013

47. Leucht, C., Heres, S., Kane, J. M., Kissling, W., Davis, J. M., Leucht, S. Oral versus depot antipsychotic drugs for schizophrenia-a critical systematic review and meta-analysis of randomised long-term trials. Schizophrenia research, 127(1-3), 83-92. 2011

48. Muirhead, D., Harvey, C., Ingram, G. Effectiveness of community treatment orders for treatment of schizophrenia with oral or depot antipsychotic medication: clinical outcomes. Australian and New Zealand journal of psychiatry, 40(67), 596-605. 2006

49. Bian, Y., Lin, C., Yang, F., Han, X., Zhang, J., Ma, B., Wang, Z., et all. The Optimal Length of Hospitalization for Functional Recovery of Schizophrenia Patients, a Real-World Study in Chinese People. Psychiatric Quarterly, 90(3), 661-670. 2019

\section{Correspondence:}

\section{Tudor Florea,}

MD, Phd stud, psychiatrist, "Socola” Institute of Psychiatry, Iași, Romania, no. 36 Str. Bucium, tudor.cdflorea@gmail.com

Submission: 05 sep 2019

Acceptance: 12 nov 2019 



\section{Humanistic Contributions}





\title{
Health communication between theory and medical practice: the case of Romania
}

\author{
Laura Pricop, Roxana Chiriță, \\ Ana Caterina Cristofor
}

\begin{abstract}
Laura Pricop - PhD., researcher, Institute for Interdisciplinary Research, Social Sciences and Humanities Research Department,"Alexandru Ioan Cuza" University of Iași,

Roxana Chiriță - Professor, PhD., MD, Grigore T. Popa University of Medicine and Pharmacy Iaşi Ana Caterina Cristofor - Assitant Professor, PhD., MD, Grigore T. Popa University of Medicine and Pharmacy Iași
\end{abstract}

\begin{abstract}
The positive correlations between communication in the healthcare domain, the quality of health services and the satisfaction extent of their beneficiaries are demonstrated in the present study. Considering the positive effects, upon patients, of communication in the healthcare field, the study aims at offering new data on the dynamics of the theories and practices of communication in this domain, special stress being laid on the fact that at least for East Europe, in Romania, all these aspects represent a real emergency, caused by the alarmingly increased dissatisfaction and distrust of Romanians in the public healthcare system. Accordingly, the study attempts to enrich the existing knowledge and understanding of the new directions of the communication theories and practices in the healthcare field. The scope of the research is a multiple one: providing a general perspective upon the already justified and validated theoretical and practical grounds that may renew the communicational attitudes manifested in the direct health providers-beneficiaries interactions; launching discussions among the specialists of the field as to the possibilities, opportunities, and efficiency of such theories' and practices' application in the actual underfunded health systems; rendering aware and more responsible the young specialists entering the domain, for building up their own style of communication, while convincing the policymakers to pay more attention - when elaborating their public health strategies - to the importance of communication, which may assure a higher quality of the healthcare services.
\end{abstract}

\section{KEYWORDS:}

Healthcare communication, medical humanities, interdisciplinarity, people-centred medicine. 


\section{INTRODUCTION}

In the last 30 years, the researches and studies dedicated to health communication have witnessed an unprecedented advance. The constant preoccupations of the specialists and practitioners in medicine, communication sciences, philosophy, ethics, public health for the development and improvement of the theoretical and practical applications in healthcare communication contributed to increasing the quality of public health services (1). In this respect, physician-patient communication is viewed as the main mechanism that may equally contribute to improving patient's health and medical care (2). Based on this assertion, the present study aims at elucidating and at substantiating the role of communication in medical fields, by an interdisciplinary methodology focused on a common public health and social paradigm, while also considering the contexts within which the processes are developing, as well as the degree of difficulty of communication's content. Equally, the study will provide arguments for consolidating the median position of the theories and strategies of communication, known as playing a double role: negotiating the distance between physician and patient, on one side, and the one between the medical theory and practice, on the other. Once accepted, the idea that communication in healthcare systems may occupy such a privileged position will orientate medical practice along its humanistic direction. Such an attitude is possible by simply leaving aside the simplistic conceptualizations of the communication theories, uncapable of going beyond an "administrative" - type communication, namely of merely collecting basic information about the patient: name, age, etc., and by abandoning the communication models usually applied when selling and promoting pharmaceutical products. Such models make use of persuasive or rewarding strategies which, from an ethical perspective, are situated on the narrow border between morality and immorality. Application of such typologies in the physician-patient communication, which was the case of the Romanian space immediately after the fall of the communist regime, is undoubtedly a special situation, more so than that, even if only partially applied, the intensity of such models is still and easily traceable in everyday practice. From this perspective, in the Romanian space, communication within the health system at all its levels, starting from prevention, from interprofessional communication and collaboration, up to the physician-patient communication, favorized, as a direct consequence of the influence of the abovementioned model, an intense development of rhetoric elements, to the detriment of the logical or ethical ones. In Romania, acceptance of the "sale or seller" communication pattern was favorized by the fall of the communist regime. At the global level, the specialists in communication in the healthcare system (3) referred to the same period, taking the year 1989 as a reference, as to one in which communication in the health system began its development as an independent discipline, by an increased number of published studies and researches dedicated to the domain. This interest on communication both in the public space and in the health domain was manifested in Romania quite late, as a consequence of the socio-political-economic climate. The attempts made at synchronization with the dynamics of the investigations devoted to communication, performed at the international level, occurred at the beginning of the 2000's. However, the process was rapid, so that several disciplines of the communication sciences, physician-patient 


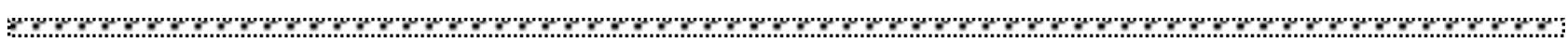

communication strategies included, entered the curricula of the Romanian universities. Even so, along with more than 15 years, the Romanian public health system did not improve. Underfunding of the system and doctors' migration (4) represent other acute aspects of the public health system in Romania, to which one should add patients' negative perception on the quality of the health services provided here $(5,6)$.

The present research, aimed at sketching an integrated theoretical perspective on the physician-patient communication within the context of communication and also on the difficulties here manifested, shall first discuss the results obtained through the application of the new strategies and micro strategies of physician-patient communication, especially those reconfiguring the new, people-centered paradigm within which medicine advances. Such recent approaches demonstrated clinically and statistically their contribution to the improvement of the quality of health services and of patients' satisfaction, in parallels with the decrease of the costs involved (1,2,7). On the other side, application of the same strategies also evidenced the effects an incorrect communication with the patients may induce, namely "discontinuity of care, compromise of patient safety, patient dissatisfaction and inefficient use of valuable resources, both in unnecessary investigations and physician work time, as well as economic consequences" (8). Aso, in this study, the expression people-centered involves "adopting the perspectives of individuals, carers, families and communities as participants in, and beneficiaries of trusted health systems that are organized around the comprehensive needs of people, rather than individual diseases, and that respect social preferences" (9). All these soft shifts of accent from the health system towards the person, from the typologies of the diseases towards the suffering subject, considered in the medical practice according to the newly introduced health policies require, at another level, equally qualitative modifications of the communication patterns, strategies, and micro strategies. This creates the need of retheorizing, re-sizing and re-constructing the paradigm of communication in the medical domain, a necessity backed up, on one side, by the practical progress of medicine, by an extended access of the patient to information about his/her disease and treatment, provided by other sources than those offered by the physician, on the other. The new, peoplecentered turn of the communication in the health system, rebuilt with elements taken over - as the present investigation proposes from the philosophy of communication, from ethics, theories of argumentation, logic, and epistemology, might lead to the humanistic opening the medicine of today needs for its general evolution, and not only at national level.

\section{FROM THEORY TO MEDICAL}

\section{PRACTICE BY THE PASSAGE OPENED} BY MEDICAL HUMANITIES

The main issue of medicine practice is shifting from the theories which actually are the essence of what one calls the science of medicine to the practical application of such theoretical knowledge. The present study tries to demonstrate that, in medicine, this transition from theory to practice or from practice to theory depends, to a considerable extent, on communication. Development of certain communication theories adapted to the field of medicine and sketching of specific communication techniques and strategies in public health: prevention, information, public education, on one side, and interprofessional communication, and that between the provider of medical services and beneficiaries, on the other, might assure the 
r.\%\% transfer of information from the objective zone of knowledge towards the subjective/situated knowledge (10), as well as the effects of this type of knowledge upon the milieu within which medicine acts as a science. In such a context, situated knowledge may be understood, on one side, as knowledge of disease through its experiencing in one's own body, or as empirical knowledge, namely observance of the characteristic manifestations and of its evolution, and the stages of treatment, either as a specialist in medicine or as a next-of-kin of the suffering person. In the advance of the humanistic perspective in medicine, situated knowledge should contribute decisively to the development of objective knowledge. As the amalgamation of the two types of knowledge - objective versus subjective - is impossible (11), we believe that the two dimensions may be integrated through communication. In proposing such an exercise, a series of premises are to be considered. Epistemologically, once accepted that medicine is characterized by a fundamental, never-to-be-solved duality, being concomitantly a science and an art, we shall approach this situation first from an interdisciplinary perspective. Another reason for which this perspective imposes itself as a methodology refers to the epistemological assertion of the present study, namely that application of theoretical knowledge to medical practice, as terms epistemai and technai (science and art) $(12,13)$ suggest that this might be possible in cases in which interactions among individuals occur only through communication. As any practical activity means "not only the making of whatever one can make; it is also choice and decision possibilities" (13), according to the new paradigm, in which medicine advances as a people-centered/ patient-centered discipline $(9,14)$, physician's practical options and his

decisions should have in view patient's choices and decisions, as well.

Methodologically, placing in the same plan of theoretical knowledge and of situated knowledge, derived from medical practice and communication within an interdisciplinary background, would bring about several benefits. Thus, an integrated perspective upon communication in public health domains would be achieved. From the - equally theoretical and practical - the perspective of ethics, epistemology and philosophy of communication, communication in healthcare fields might improve both its theoretical basis and the practice of communication with the patients, by leaving aside the traditional, pathologized forms of communication, at least at the level of the physician-patient communication registered in Romania. Its introduction among the other medical sciences, e.g. clinical medicine, diabetology, psychiatry, would add value to medical practice and provide new ways for correcting some complex situations of communication, with a high degree of unpredictibility

\section{THEORY AND PRACTICE: DIFFICULTIES AND TENSIONS IN HEALTHCARE COMMUNICATION}

Suffering, fear, shame when faced with one's own helplessness and decay, hope, love, the concern for the dear ones, manifested in cases of various diseases, transform the human experience, adding to one's profound humanity. In such an extreme human experience, the patient develops a relationship with the physician, with the providers of health services, with the healthcare systems, with their legislative and administrative components. Such meetings are essential, as they may offer hope and trust, they may help the suffering one to prepare to live with his own suffering, to control it, or to manage the end of his life. According to a humanistic 
r s

approach, this might be a definition of what includes the expression "healthcare communication". In an even narrower perspective, healthcare communication is the meeting between two persons who talk about health, malady, life, death - viewed from inside a hospital. Once such simple definitions are accepted, healthcare communication appears rather as a theorized practice, which permanently involves the need of readapting the same communication principles to new contexts. A repetitive mechanism which evidences the differences it thus created. Transposed to the level of physician-patient interaction, the paradoxical effect of repetition and of difference evidences beyond any doubt that the dialogue is a heterogeneous one, impossibly to be compared among either physicians or hospitals. Such a situation creates major barriers in medical communication (16). Apart from good command over the medical knowledge in his domain, for granting highquality services to his patients, a doctor should also master the inter-human dialogue. The benefits brought about by a correct physician-patient communication may considerably add to the satisfaction of the latter (17), and equally of the former one (18). Also, positive psychological effects resulting from a proper physician-patient dialogue has been registered, capable of improving the mental health, the tolerance capacity and the life quality of both partners (19). Especially important for the Romanian space is the absence of any policy capable of supporting and financing directly people's education as to an efficient and qualitative communication with the physicians and with all health services providers.

Adverse preventable events have negative effects upon the medical result, such as prolonged suffering, patient's dissatisfaction, enormous annual costs for medical assistance
(20). Patients who could not develop a good communication with the physician have, on average, 3 times more chances to face an adverse preventable event (21). Consequently, going beyond the communication barriers in the physician-patient relation are essential for attaining increased efficiency of the medical services and lower annual costs in the field. Most part of the communication difficulties are caused, in Romania, by the fact that the population is not educated and informed as to the role of patients, on one side, and by the lack of an extensive training of healthcare providers (physicians, nurses, hospital attendants, administrative staff) in the art of communication.

A cross-sectional study performed in the Cluj county suggests that, on average, the population has only minimum, inadequated and marginal medical knowledge (22), which is also the case at national level, especially in rural areas, a situation which increases the risks of mortality and morbidity. At the same time, the lack of basic medical knowledge prevents the patient from developing a homogeneous dialogue with the physician. In such situations, the patient is not part of the dialogue, as he cannot be viewed as an active participant. Based on a transversal analysis in Romania, out of the 84 physician-patient interactions they had in the study, it was determined that the interaction was overall insufficient on average(23). Special mention is made regarding the lack of support towards the patient when expressing his/her fears and questions, lack of adaptation to his/her language and level of understanding (involving adaptation of the medical jargon). Even if, organically, these elements of communication are not part of a physician's professional knowledge, they are essential for an efficient treatment of the patients, so that communication abilities should be here included. It is already known the fact that the 
r

Romanian medical universities have introduced communication as a discipline of study for future specialists, however, no current methods are applied for current doctors in this domain as most of them did not have this discipline in their university curricula.

Even if the Romanian health system changed its structure, comparatively with that of the communist period, the last 25 years had no impact upon modification of medical staff's mentality as to the manner of approach towards the patients. Many physicians and nurses still have a paternalistic outlook, according to which it is not important to explain to the patients the procedure or treatment to be applied (24). Such paternalistic attitudes generate patient's dissatisfaction. According to the epidemiological studies performed (25), the first two causes that have induced dissatisfaction are the barriers of communication and the lack of esteem of the medical staff for the patient. To change this situation, more efforts should be made in Romania for educating and developing the inter-human communication abilities of actual and future physicians. Stress should be also laid on the health education of the population. This type of long-term interventions may diminish the tension still present in physicianpatient communication, reduce considerably the national level of morbidity and mortality, while attenuating the medical costs in the health system.
In a patient-centered medical process, all persons involved should equally contribute to the decision-making process. Under such circumstances, patients should not be passive, but active, expressing their fears, ask questions and observing the medical advice they receive (26). A patient should have an equal power in decision-making, since the treatment is not only a result of passive consumption. During the medical treatment, the patient must be proactive, endure, leave aside certain comfort habits, and act as the most important member of the medical team (27). A change in this healthcare paradigm is to treat the patient as a customer and not as a participant to the discussion, which is the result of the asymmetry in the physicianpatient relation. Lacking medical education, the patient experiences a higher pressure in assuming the responsibility of the decision in the same manner as the specialists of the field (28).

Quite frequently, in Romania, the medical staff does not involve the patient in the health services applied (24), not considering him/her an active participant in the curing process, yet only a passive presence. If co-opting the patient to the decision-making of the treatment, he/she may become more aware of the possible options at hand and may decide the best path to be followed. Under certain circumstances, this may also include refusal of the treatment. Table 1 illustrates the manner in which the physician might adapt his approach for offering a qualitative medical service, in which the patient is viewed as having an equal contribution.

\begin{tabular}{|l|l|}
\hline \multicolumn{2}{|l|}{ Table 1. Essential elements of a common physician-patient decision making. } \\
\hline 1. & Full defining and explaining the medical issue \\
\hline 2. & Presentation of options \\
\hline 3. & Discussing benefits and disadvantages \\
\hline 4. & Establishment of patient's values and preferences \\
\hline 5. & Discussing patient's self-efficiency capacities \\
\hline 6. & Presentation of the known situation and offering of recommendations \\
\hline
\end{tabular}


Bulletin of Integrative Psychiatry $\bigcirc$ New Series $\bigcirc$ December 2019 ○ Year XXV ONo. 4 (83)/125 (1)

\begin{tabular}{|l|l|}
\hline 7. & Checking and elucidating the patient's correct understanding of the medical situation \\
\hline 8. & Making or rejecting certain decisions \\
\hline 9. & Organization of future monitorization \\
\hline
\end{tabular}

According to the ideas of L. Millenson, what differentiates the patient-centered treatment is the fact that the medical decisions taken are based on the collaboration with the patient, and not only on physician's ideas. Accordingly, the physician is expected to share his position, even if this is uncomfortable to him (29).

\begin{tabular}{|l|l|}
\hline Table 2. Necessary practices for the implementation of patient-centered treatments. \\
\hline 1 & Constant access to medical care \\
\hline 2 & Patient's involvement in medical care activity \\
\hline 3 & Clinical information supporting a high-quality medical care \\
\hline 4 & Coordination of medical care \\
\hline 5 & Constant consideration of patients' feed-back \\
\hline 6 & Publicly valid information about the medical practices \\
\hline 7 & Complex and integrated care offered by the medical supplier \\
\hline
\end{tabular}

(30)

\section{CONCLUSIONS}

In the public health field, communication appears as a basic element which assures the practical application of medicine as a science. Even if characterized by a different register vs medicine, a good physician-patient communication - of the type described in the present study - has the effect of a therapeutical procedure. As healthcare providers are not the exclusive representatives of this relation, patients, in their turn, have the responsibility of being active partners in the physicianpatient equation. Within the context considered in the present investigation, namely the case of Romania, both elements of the equation: healthcare providers and patients, have their weak points. In the first case, only part of the physicians, mainly those with ages under 40 years, might have attended adequate communication training courses. As to the patients, most of them do not have a minimum medical education, so that their coopting in making decisions about the treatment remains only a working hypothesis.

\section{ACKNOWLEDGMENTS AND DISCLOSURES}

The authors declare that they have no potential conflicts of interest to disclose.

\section{REFERENCES}

1. Ha, J. F., \& Longnecker, N. (2010). Doctor-patient communication: a review. The Ochsner journal, 10(1), 38-43.

2. Duffy FD, Gordon GH, Whelan G, Cole-Kelly K, Frankel R, Buffone N, Lofton S, Wallace

M, Goode L, Langdon L. (2004). Participants in the American Academy on Physician and Patient's Conference on Education and Evaluation of Competence in Communication and Interpersonal Skills. Acad Med., 79(6):495-507.

3. Thompson LT, Dorsei MA, Miller IK, Parrot R (eds.). (2003). Handbook of Health 


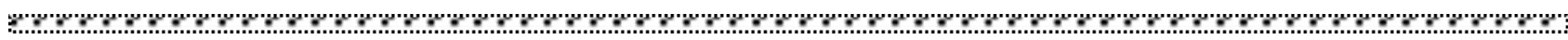
Communication. Lawrence Erlbaum Associates, Publishers Mahwah: New Jersy, London.

4. Stafford, N. (2014). Romanian health system is in crisis as doctors leave for better working life. BMJ, 348(jan22 2), g430-g430. doi:10.1136/bmj.g430.

5. Tereanu, C., Ghelase, M. S., Sampietro, G., Furtunescu, F. L., Dragoescu, A., Molnar, A.,

Dragomir, M. I. (2017). Measuring Patient Safety Culture in Romania Using the Hospital Survey on Patient Safety Culture (HSOPSC). Current health sciences journal, 43(1): 31-40. doi:10.12865/CHSJ.43.01.05

6. Murgu, A., Boldureanu, G. Pricop, C.L., Vodă, I.A., Costuleanu,L.C. (2017).The Quality of the Healthcare Services in Romania in Comparison with EU. An approach from the perspective of patient, doctor and hospital management. Bulletin of Integrative Psychiatry, 3 (74):15 - 27.

7. DiMatteo M. R. (1998). The role of the physician in the emerging health care

environment. The Western journal of medicine, 168(5), 328-333.

8. Vermeir, P., Vandijck, D., Degroote, S., Peleman, R., Verhaeghe, R., Mortier, E., ...

Vogelaers, D. (2015). Communication in healthcare: a narrative review of the literature and practical recommendations. International journal of clinical practice, 69(11): 1257-1267. doi:10.1111/ijcp.12686.

9. World Health Organization.(2018). Improving the quality of health services, tools and

resources. Turning recommendations into practice. Geneva, Licence: CCBY-NC-SA3.0IGO available at: http://apps.who.int/iris

10. Haraway, D. (1988). Situated Knowledges: The Science Question in Feminism and the

Privilege of Partial Perspective. Feminist Studies, 14(3): 575-599. doi:10.2307/3178066.

11. Nagel, T.(2009). Perspectiva de nicăieri. Traducere Bogdan Lepădatu, Editura Vellant: București.

12. Saunders J. (2000). The practice of clinical medicine as an art and as a science. Medical Humanities, 26:18-22.

13. Gadamer, G.H. (1996). The enigma of health. The art of healing in a scientific age.

Translated byJason Gaiger and Nicholas Walker, Stanford University Press: Stanford, California.

14. Epstein, M.R., Street, L. R. Jr. (2011). The Values and Value of Patient-Centered Care.

Ann Fam Med, 11 9:100-103; doi:10.1370/afm.1239

15. Pricop, C.L., (2016). Repetition and difference in doctor - patient interaction. Bulletin of Integrative Psychiatry, 3: $63-71$.

16. Hurtig, R. R., Alper, R. M., \& Berkowitz, B. (2018). The cost of not addressing the communication barriers faced by hospitalized patients. Perspectives of the ASHA special interest groups, 3(12): 99112. doi:10.1044/persp3.SIG12.99.

17. Biglu, M. H., Nateq, F., Ghojazadeh, M., \& Asgharzadeh, A. (2017). Communication

Skills of Physicians and Patients' Satisfaction. Materia socio-medica, 29(3): 192-195. doi:10.5455/msm.2017.29.192195.

18. Ranjan, P., Kumari, A., \& Chakrawarty, A. (2015). How can Doctors Improve their

Communication Skills? Journal of clinical and diagnostic research: JCDR. 9(3): JE01-JE4. doi:10.7860/JCDR/2015/12072.5712.

19. Stewart, M. A. (1995). Effective physician-patient communication and health outcomes: a

review. CMAJ : Canadian Medical Association journal - journal de l'Association medicale canadienne, 152(9): 14231433.

20. David G, Gunnarsson CL, Waters HC, Horblyuk R, Kaplan HS. (2013). Economic measurement of medical errors using a hospital claims database. Value in Health. 16:305310. doi: 10.1016/j.jval.2012.11.010.

21. Bartlett, G., Blais, R., Tamblyn, R., Clermont, R. J., \& MacGibbon, B. (2008). Impact of patient communication problems on the risk of preventable adverse events in acute care settings. CMAJ : Canadian Medical Association journal - journal de l'Association medicale canadienne.178(12): 1555-1562. doi:10.1503/cmaj.070690.

22. Blaga, O. \& Brînzaniuc, A. \& Sirlincan, E. \& Baba, C. \& Cherecheş, R. (2013). Assessing health literacy in rural settings: A pilot study in rural

areas of Cluj County, Romania. Global health promotion. 20. 10.1177/1757975913502686.

23 Ildikó, A., Ábráma, Z., Ceanaa, D., Sebesia,S., Fărcaú D., Gáspárikc, A. (2014).

Shortages of doctor-patient communication. Teaching patients to communicate effectively.

Procedia - Social and Behavioral Sciences 142: 376 - 379. 
24. Popa, D., Druguș, D., Leașu, F., Azoicăi, D., Repanovici, A., \& Rogozea, L. M. (2017).

Patients' perceptions of healthcare professionalism-a Romanian experience. BMC health

services research. 17(1): 463, doi:10.1186/s12913-017-2412-z

25. Pichert JW, Miller CS, Hollo AH, Gauld-Jaeger J, Federspiel CF, Hickson GB. (1998).

What health professionals can do to identify and resolve patient dissatisfaction. (6):303-12.

26. Légaré, F., Adekpedjou, R., Stacey, D., Turcotte, S., Kryworuchko, J., Graham, I. D.,

Donner-Banzhoff, N. (2018). Interventions for increasing the use of shared decision making by healthcare professionals. The Cochrane database of systematic reviews, 7(7): CD006732.

27. Mol, A. (2008).The Logic of Care: Health and the Problem of Patient Choice,

London: Culture Unbound: Journal of Current Cultural Research. 4: 533-535.

28. Deber, R. B., Kraetschmer, N., Urowitz, S., \& Sharpe, N. (2005). Patient, consumer, client, or customer: what do people want to be called?. Health expectations : an international journal of public participation in health care and health policy, 8(4): 345-351.

29. Millenson M. L. (2014). New roles and rules for patient-centered care. Journal of general internal medicine, 29(7): 979-980. doi:10.1007/s11606-014-2788-y

30. Davis, K., Schoenbaum, S. C., \& Audet, A. M. (2005). A 2020 vision of patient-centered

primary care. Journal of general internal medicine, 20(10): 953-957. doi:10.1111/j.1525-1497.2005.0178.x

\section{Corespondence:}

\section{Laura Pricop,}

Phd., researcher, Institute for Interdisciplinary Research, Social Sciences and Humanities Research Department,"Alexandru Ioan Cuza" University of Iasi, Lascar Catargi, 54, 700107, Iași, Romania, laura.pricop@uaic.ro

Submission: 20 aug 2019

Acceptance: 28 oct 2019 



\title{
Traditional "roots" as a remedy for living abroad. A perspective on Romanian immigrants' behaviour
}

\author{
Adina Hulubaș
}

Adina Hulubaș - PhD, Senior Researcher, Romanian Academy - Iași Subsidiary

\begin{abstract}
The article makes use of data collected throughout a scientific project on migration to argue that cultural heritage plays an important role in the effort to cope with new environments. The analysis is focused on traditional memory and folk customs that are completely different from cultural practices specific to host countries. Romanian immigrants tend to become more aware of their legacy after they experience migration challenges. Mental instability and anxiety finds solutions in Orthodox religion and traditional behaviour.
\end{abstract}

\section{KEYWORDS:}

Migration psychology, calendar customs, family traditions, taboo, cultural heritage

\section{INTRODUCTION}

Migration has become a complex and definitory theme for societal studies as early as the end of 80's. However, the "debates are now more divisive than ever" (Levitt 2019, 213). Economic dates, statistics, law infringements, remittances seem to be on the front screen while socio-anthpologic issues always escape attention, or at best they are viewed as less relevant. The fact that in 2017 as much as 3.400 patients from The Psychiatric Institute Socola from Iași were diagnosed as suffering from a severe disorder, called "Italy Syndrome", shows that migration should be treated as a phenomenon that puts pressure on more than economy. Synthetically defined as ,continuous sorrow associated with chronic physical pain" (Niţu 2014,72 ), this mental affliction is considered a new disease caused by socio-political circumstances that force people to accep difficult work opportunities, such as living 24/7 with old, disabled Italian people. Despite being a recent challenge for Romanian psychiatrists, in 2005 The Pan-American Division of the Royal College of Psychiatrists organised a symposium on "Migration and Mental Illness Around the World". 


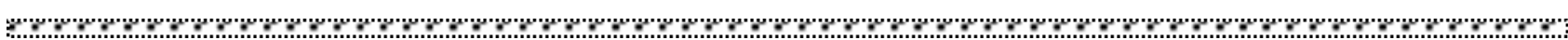

Individuals make groups and nations are moving with them through the world. The necessity to prevent illness and treat this continuously changing environment with specific instruments has been stated just as early as migration studies appeared: "a complementary perspective is taken in migration psychology, where the conceptual focus is at the microlevel. Migration psychology is the study of individual behaviour with respect to movement across space. Studies in this field often deal with the subjective correlates of migration behaviour such as underlying attitudes, values, perceptions, and migration intentions" (Fawcet 1985, 5).

The following lines address to such reactions and practices that reveal an acutization of traditional behaviour after immigration. The data has been collected from 2004 and 2019. The 53 interviewed subjects come from various settlements in Romania and The Republic of Moldova. Their immigration destinations are Italy (45 informants), Spain (7) and Greece (1). Seventeen persons chose to return home after they spent seven to twenty years in these countries. I talked with eleven men, while the rest of the subjects are women. The age varies from 23 to 69 , with only two informants in their twenties. A 60inquiries questionnaire is used as a starting point for the discussion, with the intention to obtain semi-directive interviews. Cultural heritage as a key aspect was the pillar of discussions that often provoked intense states of mind to the subjects.

Speaking about the concept of home, since migration somehow multiplies homes while leaving the person with the feeling that there can be a home no more, informants revealed their profound identity, and also a vulnerable one. „To be rooted is perhaps the most important and least recognized need of the human soul. It is one of the hardest to define" (Weil 2003, 43). What are traditional roots in a society ruled by consumerism, political correctness and pragmatic relationships? The answer may be found in C.T.'s words who lives in Morlupo, near Rome. This is how she responded in August 2019, when asked if she maintains traditional customs: "if you give up your customs, then what do you have left?!"

\section{A QUESTION OF (DOUBLE) IDENTITY}

A dichotomy created by Peggy Levitt and Nina Glick-Schiller (2004: 1010) can be used to understand the challenge faced by immigrants each day, and in our case, their reactions to traditional holidays (E.G. Orthodox Easter, Christmas) or rites of passage (baptisms, weddings, funerals). The authors speak about a demeanour that indicates the immigrants" "ways of being" in opposition to their "ways of belonging". Technical amenities may change daily social interactions (on-line tickets for buses, team lunch at McDonald's), but identity (id est belonging) is expressed by spending winter holidays with the family in Romania or eating Romanian food for special family meals. Nevertheless, this constant shift between the two social personalities is stressful, especially for the first generation immigrants who had the opportunity to come in contact with folk knowledge.

I.T., a man who came to live in Italy 22 years ago, declared that answering to the questionnaire on Romanian cultural practices made him feel relieved. He had cried several times during the interview in a manly manner, and tried to explain how he felt after talking about traditional food and his dream plan to return to Romania in his first day as a retired citizen. His wife helped him find his words and she said it was "like a confession in the church". E.C., a woman who has spent her last seventeen years in Rome, sighed when I 
s

turned off the recorder and gasped: "this interview was like a psychotherapy session".

The social mask wears people out because of the initial feeling that caused migration. A recent book on contemporary art summed this phenomenon up in its title: When home won't let you stay (Respini, Erikson 2019). Socioeconomic difficulties from Romania and political instability induced a state of insecurity, translated into the frustration that your own home land does not care for you. Moreover, it rejects you, since people less educated than you, who disobey the law and common sense are having a thriving life full of opportunities.

The vast majority of subjects declared that they left for economic purposes. At the end of the day a satisfying income is not enough though. V.B., who decided to return to Chişinău after having spent fifteen years in Italy, told me in a heart aching tone: "don't you ever think that one can sleep well on a foreign pillow! May it be filled with money!". Hence, subjects live with a split mind: emotional bonds are causing sorrow, while as pragmatic reason keeps them trapped in an unfamiliar world. G.P., a Moldovan woman living in Iași since 1992, called life in a foreign country ,a yoke" (Rom. giugu' străinătății). Traditional culture may sometimes have a soothing effect.

\section{SOMETHING IS MISSING}

Migration inevitably causes a feeling of displacement, despite the rational decision to leave the country of origin. Time only adds to this self-perception and subjects who experience important melancholy episodes are more likely to return to their country of origin. D.M., a highly educated man from Chișinău confessed: "I missed everything [when I lived in Italy]. I am born near the woods (Rom. codri), ... of course, we carried our customs with us, but still...”. When he finally returned to The Republic of Moldova for good he experienced tachycardia and an intense desire to fall on his knees and kiss the earth beneath his feet. The exact gesture was actually performed by V.C., a Moldovan woman who stayed for nine years in Rome. When she arrived at a crossroads in her home country, she kneeled in front of a crucifix (Rom. troiță) and kissed the ground.

This latent soul pain was also indicated by a younger subject, who apparently doesn't need much from Romania anymore. D.T. is 30 and a graduate from "Babeș-Bolyai University". She decided to work in her mother's pizzeria near the Colosseum in 2011. The young lady easily declared in the beginning of the interview that the only things that still connect her with Romania now are the Easter, Christmas, sometimes her relative's birthdays and her grandmother. Soon after, she recalled the specific sensation from her childhood years and her words became less firm: "Here, I never feel the holidays [spirit], when it's Christmas, when it's Easter, I think of home continuously. I think about my grandmother; I think about sarmale [minced meat cabbage rolls]". Later in the discussion she admits the whole truth: "I think I lost something of myself. Something is missing. 10 percent of me can't be expressed, because the Italians don't know what No, bine! [“well, fine!"] means. This is what I miss, to express myself in my language".

David Sutton argues that "the memory of taste and smell leads to the emotional effect and the sense of emotional/embodied plenitude" (Sutton 2001, 82), an interpretation that can easily be proved by culinary preferences of the vast majority of immigrants. Moreover, the British food historian uses Fernandez' concept of "returning to the whole" (1986) to develop the idea of recreating familiar surroundings. "Eating food from home 


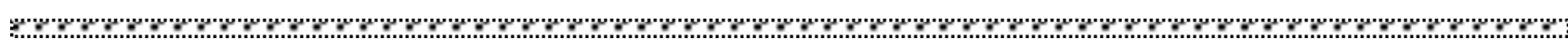

becomes a particularly marked cultural site for the re-imagining of 'worlds' displaced in space and/or in time" (Sutton 2001: 84).

Migrants behave culturally in a regressus at utterum pattern, that assures them a relative sensation of safety. Food, loving grandparents and the special context of holidays induce a relaxing state of mind to a certain point. Speaking in your native language, however, needs a specific community in host countries. D.T. acknowledges linguistically her deepest identity - she comes from Transylvania were Romanian language is spoken slowly and musically, a thing that cannot be apprehended by Italians or Romanians from other parts of the country. This correlation between language and psychologic comfort is efficiently used in marketing strategies. A chain of Romanian stores from Italy is called Acasă [Home] and displays labels in Romanian language first, with an Italian approximate translation underneath.

You are among your people, buy as much as you can is a message that has long been proved persuasive anywhere in the world. This lead to misappropriations of traditional heritage for commercial reasons and now UNESCO actively fights against such cultural lies/ thefts. For example, the famous song $E l$ Condor Pasa is in fact a traditional Andean song, and communities that still transmit this music line never received any of the deserved intellectual property funds. Ioana Repciuc wrote a review on a book that details this economic stratagem and she concludes that despite "the irresistible force of the progress myth", advertisement uses manipulation through magic, since domestic wealth is promised in a traditional imaginary $(2018,3)$.

Romanian immigrants build this folk-like world for themselves, often in an artificial manner. "Immigrants assume their minority status as a unique chance to resist on an emotional level and use fragmented reflections of their culture to preserve the feeling of general safety" in the attempt to recreate home (Hulubaș 2016, 77). In August 2019, I entered in L.N.'s house in Rome and I noticed a red towel on the table that used to be sold in communist stores called "Artizanat" as traditionally woven pieces of ceremonial cloth. She answered happily that it belongs to "her Romania" and showed me several more objects around, all commercial pieces of wood, clay pottery and also Romanian flags. Her traditional outfit is kept in the closet near Asian traditional dresses, since she is involved in community charity work. Such micro-worlds that are carefully built by immigrants translate into the relieving self-induced conclusion that individuals have their own place in a melting pot of nations and cultural practices.

E.C. admitted that she suffered from a serious breakdown for several years because of the compromise she accepted, to live abroad. She turned to Orthodox religion in a more dedicated manner than before migration and she is now "better". Faith can also compensate the feeling of unfamiliarity brought by host countries.

\section{WHAT DEFINES US}

Often immigrants see themselves in two new lights: ignored customs make them resonate intensely while being far from home, and Orthodox belief becomes essential in regaining a comforting state of mind. V.G.V. left The Republic of Moldova in 2005 and is still in Rome today. She declared that "faith defines us, Romanians" and implicitly created an opposition between Catholic religion and Orthodox. This cultural difference is mostly visible during Easter time, when Romanians have to wait for one more week to be able to celebrate properly. Furthermore, EastEuropean countries dye ritual red eggs for the 


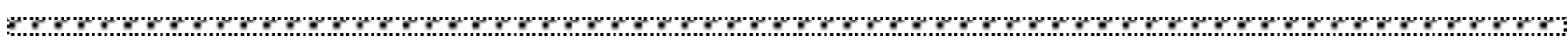

occasion. I.N., a Bulgarian woman living in Munich faced the new world in the confused eyes of her offspring when they did not understand the trouble of organizing a parallel holiday: "It was very difficult for me to explain to my children why there are no red eggs here in Germany. So I told them that we are Bulgarians, our Easter is not on that day and our eggs are red" (Krăsteva-Blagoeva 2009, 261). We are not them, this is who we are refers to faith and tradition.

N.B., who lives in Italy since 2008 and even graduated from a college in Rome, declared out rightly: "it is common law (Rom. lege), there is no Easter without red eggs", a conviction that was expressed by other informants too. Another cultural practice that opposes Italian behaviour and is closely related to Orthodox religion was described by M.T. When I asked her if she ever does her laundry on Sundays she firmly said no. "This is how I grew up, no! (id est this is what my parents taught me to do). Come what may [I just won’t wash]!”.

Such taboos as working on a holy day reconfirm personal attachment to traditional values, since Christianity is deeply embedded in folk culture. Mircea Eliade created the concept of cosmic Christianity, "a new religious creation, specific to South-East Europe" (1980, 246). This mixture between heathen convictions and dogmatic rules allows Romanian people to harmoniously bond together contrary precepts from a historical point of view. Almost all of the inteviewed subjects have in their houses from abroad Orthodox icons and ritual lamps (Rom. candele) that they use for worshiping. C.T. displays such an image of Jesus Christ entering Jerusalem, just above the threshold of her house in Italy. What was uncommon though was the fact that underneath this sacred object she nailed a horseshoe. Two separate layers of religious culture are blended to secure a dangerous space: the doorway.

Deep down at the origin of Romanian beliefs related to the threshold we find the cult of Penates Gods, who were believed to lie under this transition space. Even today we are familiar with the taboo of hugging someone on the threshold or to give something away over it. Pregnant women are forbidden to linger on the doorstep for too long, while as alms for dead children are placed on the threshold, since the departed ones from the family are assimilated with Penates Gods in Romanian traditional thinking. Having a preChristian symbol of good luck in this point of the house shows, on a psychological level, vulnerability in front of what may enter the door, and, on a cultural level, an active transmission of archetypes.

The horse is still used as a forgotten apotropaion in Romania, since it is believed he can ward-off evil. Numerous old and new buildings here contain a detail called horses: the beams coming from under the roof are carved to suggest a stylized horse head. That point of the construction is vulnerable, this is where evil spirits may penetrate through, so the symbol of an animal (who can immediately perceive danger and fight it in nature) is used to secure the entrance. In the past, horse skulls were placed in poles to protect vineyards from vermin, while in United Kingdom, Ireland, Finland, Sweden, Germany such crania used to be put under the house floor, in the wall near the hearth or in churches under the pavement. A huge literature exists on the topic ${ }^{1}$, and the vitality of this belief seems to be remarkable.

\footnotetext{
${ }^{1}$ See, for example, Sonja Hukantaival, Horse Skulls and "Alder Horse": the Horse as a Depositional Sacrfice in Buildings, in "Archaeologia Baltica", vol. XI. Edited by Audronè Bliujiené, Klaipeda, Klaipeda University Press, 2009.
} 


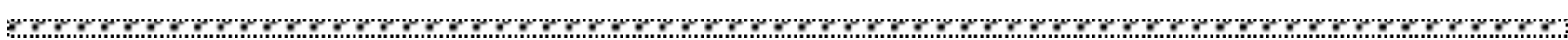

The horse shoe is obviously a familiar sight from childhood, and I did not expect the subject to explain the symbolic evolution of what makes her comfortable to see when exiting the house. The two sacred figures invoked in C.T.'s case are powerful and able to protect the entire family from unhappy events. The discussion was rather focused on the modern alternatives to holidays and spending time, which she denied and motivated her choice with this sentence: "No matter what, you are a Romanian!"

D.T. wears a traditional shirt as often as he can and admits that being dressed like that makes him feel "completely different", in the sense of being self-confident. "Private devotional activities may also be linked with positive self-regard via processes of religious role taking" (Ellison 1993, 1027). Such handsewed shirts are frequently chosen as church outfit by Romanian immigrants. Varvara Buzilă, an renowed ethnologist from Chișinău, calls this element of the old clothing a shield. V.G.V. referred to the pattern on such shirts as something holy that you take with you when you wander the world. Religion and tradition are in consequence similar from a psycho-cultural point of view: they state your distinct identity by keeping you protected from social harm, and they put your mind at ease.

R.I. declared that when she wears this traditional shirt for church she feels at home, and the fact that other Romanians in the church wear it too make the moment beautiful. A social bond is created and again, the need to find again the childhood feeling of being in your own safe house is expressed. Most of the immigrants gave this formula: "exactly as at home/ as in Romania" as a first answer to the question "what do you eat for special meals?". Such cultural practices are meant to reassure the self that nothing major has changed, he/she is away, but safe.

\section{ROOTEDNESS}

It can hardly be called a coincidence that a famous festival organized yearly in Rome (three editions up to this point) is entitled Roots Fest. Immigrants need to know that their internal foundation is stable. The image of the tree in this life situation is also folkloric. A tree is prepared ritually for all the Romanian rites of passage: the bathing water after baptism is poured at a fruit tree (a gesture also performed by immigrants), the wedding used to be announced by decorated fir trees tied to the gate of the brides' homes and trees ornamented with sweets and ritual bread are given away as essential alms for the deceased.

Songs that used to be used for ceremonial mourning also contain the alliteration "omule/ pomule" [man-tree] and a folk riddle has the answer "the human being" to the following definition: "I have/ A tree/ With its branches going down/ And its roots up" (Niculescu 1973, 3). We become our ancestors by choosing to live a similar life, where culture sets things straight. Numerous examples of inappropriate behaviour in host countries is justified in this context. G.D. came back from thirteen years spent in Torino and she told me that she risked being fined for not respecting regulated hours, but she never took the garbage out after the night fall. "This is what I heard [it must be done], I know this is right, since my grandmother taught me that".

The taboo refers to the fact that you will get poor if you take the garbage out, since it represents a part of your material possibilities. The sun goes down in the other world at night, and your luck might stay there with the garbage you took out in the dark. Such adventurous culturally justified infringements 
were also admitted by subjects living in Zaragoza, Spain, but in this particular case the figure of the grandmother stands out once more.

The authority of the elders is not negotiable in traditional communities. They are right and regulations become irrelevant, since tradition

\section{ACKNOWLEDGEMENTS AND DISCLOSURES}

This work was supported by a grant of the Romanian Ministry of Research and Innovation, CCCDI - UEFISCDI, project number PN-III-P1-1.2-PCCDI-2017-0116, within PNCDI III.

\section{REFERENECES}

1.Mircea Eliade, De la Zalmoxis la Genghis-Han, Editura Ştiinţifică şi Enciclopedică, Bucharest, 1980.

2.James T. Fawcet, Migration psychology: New behavioral models, in "Population and Environment", vol. 8, issue 1-2, 1985 , p. 5-14.

3.James W. Fernandez, Persuasions and Performances: The Play of Tropes in Culture. Bloomington, Indiana University Press, 198

4.Adina Hulubaș, The Broken Mirror: Eastern-European Migrants' Attempt at Recreating Home in Host Societies. An Ethnographic Perspective, in Travel and Intercultural Communication in Europe, edited by Oana Cogeanu, Iaşi, Editura Universităţii „Alexandru Ioan Cuza”, Iaşi, 2016, p. 69-81.

5.Evgenia Krăsteva-Blagoeva, Food and Migration: the Case of Bulgarians in Munich, in Klaus Roth, Robert Hayden (editors), Migration in, from and to the Southeastern Europe I. Historical and cultural aspects, "Ethnologia Balkanica", vol. 13, 2009, p. 249-268.

6.Peggy Levitt, Nina Glick-Schiller, Conceptualizing Simultuneity. A Transnational Social Field Perspective on Society, in "International Migration Review”, 38(3), 2004, p. 1002-1039.

Peggy Levitt, Words that make worlds, in When home won't let you stay: Migration through Contemporary Art. Yale University Press, 2019.

7.Radu Niculescu (editor), Bulgăre de aur în piele de taur. Ghicitori, ediţie îngrijită, prefaţă, bibliografie şi index bibliografic de Radu Niculescu, Editura Minerva, Bucharest, 1975.

Amalia Nitu, Abuzul și neglijarea copiilor, in "Revista de investigare a criminalitatii”, vol. 7, iss. 1, 2014, p. 71-77. 8.Ioana Repciuc, Florin Dumitrescu, Tradiții la supraofertă. Între socoteala din agenție și cea de la raft, in "Diacronia", no. 8, 2018, p. 1-4.

9.Eva Respini, Ruth Erickson (editors), When home won't let you stay: Migration through Contemporary Art. Yale University Press, 2019.

10.David Sutton, Remembrance of Repasts: An Anthropology of Food and Memory, New York, Berg, 2001.

11.Simone Weil, The need for roots- prelude to a declaration of duties toward mankind, London, Routledge, 2003.

\section{Corespondence:}

Adina Hulubaș, 



\section{BPI Bulletin of Integrative \\ Psychiatry \\ Bubetia de Psihistrie lategratiod}

Case Reports 



\title{
Anxiety and panic disorders in the dental office
}

\author{
Crînguța Paraschiv, Irina Eșanu, Roxana Mihaela Barbu, \\ Diana Luchian, Irina Gavril, Cristina Maria Gavrilescu
}

Crînguța Paraschiv- MD, PhD "Gr. T. Popa" University of medicine and Pharmacy Iași, Romania, Faculty of Medicine, The Internal Medical Clinic of the Clinical Hospital CF Iași

Irina Eșanu - "Gr. T. Popa" University of medicine and Pharmacy Iași, Romania, Faculty of Medicine, The Internal Medical Clinic of the Clinical Hospital CF Iași

Roxana Mihaela Barbu - "Gr. T. Popa" University of medicine and Pharmacy Iași, Romania, Faculty of Medicine, The Internal Medical Clinic of the Clinical Hospital CF Iași

Diana Luchian - "Gr. T. Popa" University of medicine and Pharmacy Iași, Romania, Faculty of Medicine, The Internal Medical Clinic of the Clinical Hospital CF Iași

Irina Gavril - "Gr. T. Popa" University of medicine and Pharmacy Iași, Romania, Faculty of Medicine, The Internal Medical Clinic of the Clinical Hospital CF Iași

Cristina Maria Gavrilescu - "Gr. T. Popa" University of medicine and Pharmacy Iași, Romania, Faculty of Medicine, The Internal Medical Clinic of the Clinical Hospital CF Iași

\begin{abstract}
Background: Panic attack is a frequent clinical situation that all physicians can face regardless of their specialty and that can raise special diagnostic problems because it may mimic other medical conditions, some of them life threatening. Objective: The purpose of this paper is to provide a summary of symptoms and signs and differential diagnosis problems of the panic attack. Methods: We present the clinical case of a 59-year-old hypertensive and previously treated by radiofrequency catheter ablation for paroxysmal supraventricular tachycardia who had a panic attack in the waiting room of a dental office. Discussions: Data on trigger factors (including dental procedure or situations), differential diagnosis and treatment implications are discussed. Conclusions: The diagnostic of the panic attack requires caution due to symptoms that may lead to confusion with other diseases and due to comorbidities that may accompany or predispose to it. Dentists should make the distinction between ordinary dental anxiety or fear and panic disorder in order to be able to provide appropriate treatment.
\end{abstract}




\section{BACKGROUND}

Anxiety and panic disorders are extremely common in dental office and represent a considerable source of stress for both dentist and patient. Treating this patients is very difficult because they are very sensitive at painful stimulus, they have an increased pain perception so they risk to be misdiagnosed. Also usually the patients will remain with an exaggerate memory of pain and unpleasant dental experience so they will present in the dental office only in emergency situations that will require difficult procedures leading to reinforcement of their anxiety.(1) These patients need to be identified by the dentist by interviews, anxiety scales and objective assessment in order to be able to distinguish ordinary dental anxiety or fear from panic disorder and to provide a previously appropriate treatment (psychotherapeutic, pharmacological or a combination of both) depending on the clinical situations and the patient characteristics.

Dental anxiety is a specific anxiety toward the dentist or dental procedures or even to the thought of visiting the dental office. (2) Dental phobia is an extremely severe, overwhelming and irrational fear leading to complete avoidance of going to the dentist. Dental anxiety may be the result of multiple factors, such as previous dental or other traumatic experience, especially in childhood (conditioning experiences), perception of the lying back in a dental chair as a vulnerable position, perception of accessing the mouth as a space invasion, fear of needles, sensory triggers (turbine drills, screams, specific smell, visualization of dental instruments or blood, vibrations).
The panic attack corresponds to an episode of extreme anxiety accompanied by symptoms and physical signs with a sudden onset and limited duration. Most often the attack occurs unexpected, in an unpredictable way, without a clear trigger factor. Typically the symptoms will reach a peak within 10 minutes and they last for about 20 to 30 minutes but the duration can vary from minutes to hours. The panic attack is marked by intense physical manifestations associated with psychic symptoms. It must be remembered that several signs may be associated but at least 4 of the following symptoms must occur brutal and paroxysmal for positive diagnosis. (3)

- cardiorespiratory complaints (palpitation, chest pain or discomfort, dyspnea ).

- neurovegetative complaints ( flushes, sweating, pallor, chills or heat sensation, trembling or shaking, tingling sensations, paresthesia, nausea, abdominal pain, tunnel vision, flashing vision)

- vestibular complaints, less frequently (feeling dizzy, unsteady, light- headed or feeling of fainting)

- psychic symptoms (fear of losing control or "going crazy", fear of dying, a sense of things being unreal (derealization) or feeling detached from oneself (depersonalization)

- behavioral symptoms associated with panic attack (immobilization or hyperactivity with escape behavior, avoidance, aggressivity)

Panic disorder is characterized by recurrent attacks of severe anxiety (panic), which are not limited to any particular situation and are therefore unpredictable and unexpected. This 
is why the patient worries about additional attacks and their consequences and adopt maladaptive change in behavior in order to avoid them.(4) The diagnosis of panic disorder implies that the attacks occurs unexpected and it cannot be attributable to toxic substance (drug abuse, medication even withdrawal effect) or medical condition (hyperthyroidism, cardiopulmonary disorders)(5). In order to differentiate from other anxiety disorders we mention that the anxiety episodes do not occur only in response to feared situations (as in social anxiety disorder), to phobic objects (as in specific phobia) or to reminders of traumatic events (as in posttraumatic stress disorder).

\section{CASE PRESENTATION}

$\mathrm{CA}$ is an 59-year-old female patient hospitalized in emergency for sudden onset of palpitations, chest pain, dizziness, dyspnea, headache, paresthesia, tinnitus, extreme anxiety, sweating, abdominal pain, flushing. The crisis has started in the waiting room of the dental office before the dental check itself. The patient said she was hypertensive and ten years ago she was treated by radiofrequency catheter ablation for paroxysmal supraventricular tachycardia. For those diseases she is taking chronic medication: telmisartan $40 \mathrm{mg} /$ day. After the ablation procedure the patient experienced more episodes of palpitation and anxiety but in the last year she is having one or two attacks a week with an unexpected and rapid onset. Every time during the crisis she has measured her blood pressure several times using automatic monitor and even though she is taking the sublingual captopril pills that doctor has recommended in those situations the blood pressure continues to increase as well as the panic degree which is why she was repeatedly admitted in the emergency services. The last time she presented in the emergency room she had very high blood pressure with hand and face paresthesia and important dizziness and for this reason a stroke was suspected. Cerebral CT scan has invalidated this diagnosis. The patient was not a smoker, alcohol or coffee consumer and she comes from the rural environment therefore she usually gets to the hospital being driven by her husband. When we asked, she wasn't able to identify a clear trigger for her attacks except the periods when her husband was not home for several hours because she was always afraid that she will have another attack and she will be alone without the possibility to arrive in time at the hospital.

Clinical examination reveals a very anxious patient, facial flushing, sweat skin, normal pulmonary auscultation, a BP of 190/100mmHg, HR of 120 bpm, rhythmic heart sounds, diffuse abdominal pain on palpation. Our clinical diagnostic assumptions were hypertension (hypertensive urgency), panic attack, angina pectoris attack or even myocardial infarction, pheochromocytoma, paroxysmal supraventricular tachycardia, hyperthyroidism, spasmophilia.

An ECG performed during this admission showed sinus rhythm and no signs of ischemia with a heart rate of $104 / \mathrm{min}$. Chest X-ray was normal without signs of pulmonary congestion, the echocardiography revealed slight left ventricular hypertrophy, a normal left ventricular ejection fraction (62\%) without regional wall motion abnormalities and intact valves. Abdominal and thyroid ultrasound were normal. Repeated 24 hours Holter monitoring after the acute episode did not record arrhythmic episodes. Her laboratory results revealed a slight increase of serum cholesterol of $260 \mathrm{mg} / \mathrm{dl}$ (normal value, below $200 \mathrm{mg} / \mathrm{dl}$ ) and LDL cholesterol of 140 $\mathrm{mg} / \mathrm{dl}$ (normal value below $70 \mathrm{mg} / \mathrm{dl}$ ); and triglyceride level of $160 \mathrm{mg} / \mathrm{dl}$ (normal range, 40-150 mg/dl), with normal values of 
r.\%

glycaemia, calcium, CK - MB and troponin levels, The thyroid hormones were in normal limits so we excluded hyperthyroidism. In order to eliminate a pheocromocitoma we also performed a fractionated plasma free metanephrine level and a 24-hour urine metanephrines and they were in normal limits. We requested also a neurological consult that denied epilepsy and transient ischemic accident and a psychological consult which diagnosed panic disorder and recommended psychological counseling

After gathering all necessary data, we concluded on the following diagnoses: essential hypertension third degree with high additional risk, panic disorder, dyslipidemia. The patient was treated with a benzodiazepine (alprazolam 0,5 mg), sublingual captopril 25 $\mathrm{mg}$ repeated twice, amlodipine $10 \mathrm{mg}$. The patient had already taken telmisartan and betaxolol in the morning. She was discharged on dietary salt restriction, telmisartan 80 $\mathrm{mg} /$ day + betaxolol $20 \mathrm{mg}$, atorvastatin $10 \mathrm{mg}$, escitalopram (an antidepressant of the selective serotonin reuptake inhibitor classSSRI) and xanax $0,25 \mathrm{mg} \quad \mathrm{x} 3 /$ day (benzodiazepines may also be used in combination with SSRI during the first weeks before the onset of efficacy of the antidepressants, psychological therapy. In acute panic attacks lorazepam melting tablets at a dose of $1.0 \mathrm{mg}$ may be used. Also captopril $25 \mathrm{mg}$ repeated if necessary and amlodipine will be used if the attack is associated with hypertensive urgency.

\section{DISCUSSIONS}

This case is illustrative for the panic attack because the patient showed a multitude of symptoms and physical signs associated with an episode of extreme anxiety with sudden onset. However the final diagnosis is panic disorder because the patient has recurrent panic attacks (2 to 3 times a week) which are not limited to any particular situation and therefore are unpredictable (she is always afraid that she will have another attack). Our patient does not manifest anxiety about ordinary day-to-day situations as in generalized anxiety disorder (6). Other psychiatric disorders that may also manifest with panic attacks (bipolar disorder, depressive disorder, phobic disorders) must be ruled out in differential diagnosis. (7)

Although unexpected episodes are required for the diagnosis, many patients with panic disorder may also have expected panic attacks in response to a known trigger. The panic attack in our patient could not be attributed to drug abuse, caffeine, alcohol or tobacco consumption, medication (sympathomimetics, decongestants, corticoids, levothyroxine) or withdrawal syndrome (benzodiazepines, opiate drugs, alcohol, tobacco). However our patient developed a panic attack while she was waiting in a dental office, therefore, in our opinion, psychological stress, dental fear and sensory stimulus (turbine drills, specific smell) might acted as triggers. Many evidence suggests that dental anxiety is frequently associated with other psychiatric disorders, the most common comorbid being anxietyrelated disorders.(8) Also the patients with panic disorder may have a panic attack during de dental procedure due to pain stimulation and to the epinephrine added in dental anesthetics especially in the case of the accidental injection into a vein or if the patient has pre-existing medical conditions, such as high blood pressure and cardiac issues. (9)

Although the diagnosis of panic attack is essentially clinical it may raise important differential problems because the symptoms and physical signs may mimic other medical conditions especially cardiovascular diseases, some of them life threatening. Also many of 
r \%

these conditions are common comorbidities.

Our patient was repeatedly admitted in the emergency services. Palpitation, chest pain and shortness of breath are very common symptoms in the panic attack, therefore a diagnosis of exclusion of cardiovascular illnesses (including hypertensive emergency or urgency, angina, myocardial infarction, arrhythmia or acute heart failure) must be performed in emergency before diagnosing a panic attack. In our patient blood pressure was high but electrocardiogram show no signs of ischemia or arrhythmia, normal myocardial enzymes eliminated an acute coronary syndrome. Normal pulmonary auscultation and chest X-ray excluded pulmonary edema, pulmonary embolism, pneumothorax or asthma attack. We also evaluate our patient for endocrine pathologies (she had a normal hormonal profile) because her panic attacks were accompanied by significant neurovegetative complaints (flushes, sweating, trembling) that may mimic crisis of hyperthyroidism or pheochromocytoma (a neuroendocrine tumor that secretes high amounts of catecholamine). Neurological consult and CT scan invalidated the stroke.

In acute panic attacks the doctor must use reassuring measures: isolate the patient from trigger factors, adopt a calm attitude, inform about the lack of gravity of the crisis and its transitory nature, encourage slow abdominal breathing to avoid hyperventilation (breathing with the hand in front of the mouth or in a paper bag). In case of failure, a benzodiazepine with a short half-life will be administrated oral or sublingual (alprazolam $0.25 \mathrm{mg}$ or $0.5 \mathrm{mg}$ for example). If the panic attack occurs on the dental chair the dentist must stop immediately any procedure, remove everything from the mouth, seat the patient up, check his pulse and blood pressure. It might be appropriate for the dentist to step away slightly because it can seem quite overpowering to have a dentist so close. Reassuring measures and anxiolytics will be administrated. (10)

The treatment for panic disorder combine common lifestyle recommendations (patient education, avoiding possible triggers, physical activity, improving sleep quality), psychotherapy (relaxation technics, cognitive behavior therapy, join a support group) and medication. Selective serotonin reuptake inhibitors (SSRIs) are generally considered first-line therapy but they have a delay in onset of action. To prevent relapse the treatment should be used for 12 month after the improvement of the symptoms. Benzodiazepines are used in combination to reduce anxiety but only for a short-term basis because of their high risk of dependence. Dental treatment in patients with panic disorder implies several measures: establishing a trust-based relationship between the patient and dentist, administration of the routine medication including on the day of the dental procedure, psychotherapy and anxiolytic premedication, avoiding added epinephrine in dental anesthetics, quality analgesia.

\section{CONCLUSIONS}

The panic attack corresponds to a brutal episode of extremely intense anxiety, accompanied by symptoms and physical signs that evoke a medical or surgical emergency. Although the diagnosis is essentially clinical, it may raise important differential problems because symptoms may mimic other medical conditions some of them life threatening. The diagnosis may be even more complicated because many diseases in differential diagnosis may be present as comorbidities. 

Dentists should make the distinction between ordinary dental anxiety or fear, panic attack and panic disorder in order to be able to provide an appropriate treatment.

\section{ACKNOWLEDGEMENTS AND DISCLOSURES}

The authors declare that they have no potential conflicts of interest to disclose.

\section{REFERENCES}

1. Appukuttan D- Strategies to manage patients with dental anxiety and dental phobia: literature review $\underline{\mathrm{Clinical}}$, Cosmetic and Investigational Dentistry, 2016, 8:35-50

2. Eitner S, Wichmann M, Paulsen A, Holst S. Dental anxiety - an epidemiological study on its clinical correlation and effects on oral health. J Oral Rehabil. 2006;33(8):588-593.

3. Dominique Servant, Émilie Walczak Crise d'angoisse aiguë et attaque de panique la revue du praticien. 2012, 62, 555-558

4. Amy B. Locke, Nell Kirst, Cameron G. Shultz - Diagnosis and Management of Generalized Anxiety Disorder and Panic Disorder in Adults Am Fam Physician. 2015. 1;91(9):617-624.

5. Lydiard RB. Recognition and treatment of panic disorder. J Clin Psychiatry. 2007;68(11):e26.

6. Hoge EA, Ivkovic A, Fricchione GL. Generalized anxiety disorder: diagnosis and treatment. BMJ. 2012;345:e7500.

7. Harri Halonen, Jenna Nissinen, Heli Lehtiniemi, Tuula Salo, Pirkko Riipinen, and Jouko Miettunen The Association Between Dental Anxiety And Psychiatric Disorders And Symptoms: A Systematic Review Clin Pract Epidemiol Ment Health. 2018; 14: 207-222

8. Halonen H., Salo T., Hakko H., Räsänen P. The association between dental anxiety, general clinical anxiety and depression among finnish university students. Oral Health Dent. Manag. 2014;13(2):320-325

9. Caroline Menzies. Epinephrine in Dental Anesthetics Can Cause Panic Attack Health, 2010

10. Craske MG, Kircanski K, Epstein A, et al.; DSM V Anxiety; OC Spectrum; Posttraumatic and Dissociative Disorder Work Group. Panic disorder: a review of DSM-IV panic disorder and proposals for DSM-V. Depress Anxiety. 2010;27(2):93-112.

\section{Correspondence:}

Irina Eșanu,

DMD, PhD, "Gr.T. Popa" University of Medicine and Pharmacy Iași, Romania, Faculty of Dental Medicine, The Internal Medical Clinic of the Clinical Hospital CF Iași, esanu1925@ gmail.com

Submission: 01 sep 2019

Acceptance: 19 nov 2019 



\section{Book review}

\section{Author: Mihai Șleahtițchi Review signed by Sănduleac Sergiu}

Mihai Şleahtițchi - Panopticon. Special techniques of deep penetration of social representations, Editions Junimea, Iași, 2018.

Sănduleac Sergiu - Associate Professor, Ph.D. "Ion Creangă” State Pedagogical University Chișinău, sergiu.sanduleac@upsc.md

Some words about the author: Mihai Şleahtițchi is Ph.D. in psychology and also Ph.D. in pedagogy. He holds the founding member of the National Observatory of Social Psychology (2000), the College Logos Plural (2001), the Institute for community development (2004), the Open University "Europedia" (2010) and of the Center for Personal and Professional Development (2016).

During his long career he held important positions in the management of higher education beginning from Head of Department and Dean of Faculty at the „A. Russo" State University of Balti (1990-2005); Vice-Rector and President of the Scientific Council at the Free International University of Moldova (2005-2009; 2016-2017); Member of the Council for Strategic and Institutional Development of the "A. Russo" State University of Balti (2015-present).

He also held important positions in Moldavian Central Public Administration:
Government of the Republic of Moldova, Ministry of Education, Minister of Education (2011 - 2012); Presidency of the Republic of Moldova, Advisor to the President of the Republic of Moldova in the field of culture, education, and science (2012-2016).

He has benefited from training and research internships in the USA, Great Britain, Germany, France, Egypt, Romania, and Russia. He is a full member of several scientific and professional associations and is employed in various research programs, masters and doctorates.

Until now he has published as an author, coauthor or coordinator approximately 200 scientific articles and more than 15 books, including: The universe of social representations (1995), Leaders (1998), Anatomy of the post-totalitarian society (2002), Manipulation in post-totalitarianism (2008), Treatise on the structural analysis of social representations (2016), and the last one 


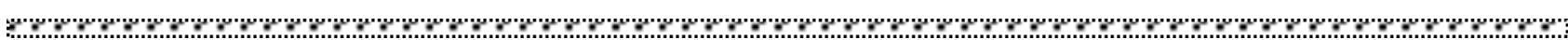

Panopticon, Special techniques of deep penetration of social representations (2018).

The present work represents a real pearl in the structural analysis of social representations with an immeasurable contribution in the scientific literature both from the Republic of Moldova and from Romania.

The author exposes with much rigor and depth the specificity of the social representations taking into account every aspect that has been debated so far, starting with the history of social representations, defining problems and discussions on the object and structure of social representation, ending with identifying the way of organizing social representations in practice, establishing their content, and verifying the centrality of the elements of a social representation.

I will note that the work is a very complex one, due both to the phenomenon studied, the accuracy of the collected information, but also to the exasperated presentation of the facets of social representation through the presentation of some new concepts founded and scientifically proven.

The book is divided into three major parts. In the first part of the paper "The era of social representations," the author makes a historical incursion starting from the most rudimentary interpretations of the social representations, ending with conclusive explanations regarding the human and society through the prism of the social representations that express the central and common concept of the socio-human sciences. The review of the specialized literature allows the author to conclude that the focus should not only be placed on the community as an autonomous or separate social structure on the individual but on the interaction between these two. Thus the author brings a new vision in the conception of the interpretation of social representations that places social psychology from a broader perspective. Thus, the necessity of resizing the research area would appear, which would allow more conclusive explanations regarding human and society.

The second part of the book "The status of social representations" is dedicated to the identification of the position of social representations in the system of human and social sciences. In this part of the text, the author explained deeply the problem of definitions and different approaches of social representations.

The material is very well structured and clarifies the difference from the perspective of the literature analysis on social representations. The author offers the perspective to perceive this difference by highlighting the conceptual delimitations that place the reader in the situation of understanding: what is the difference between social representation and a cognitive representation or possibly a collective representation, being presented arguments in the existence of at least epistemological differences presented in a table. The author does not leave out the view and other opinions that have been presented regarding the social representations, which serve as a basis to look for and analyze the given topic more deeply, so we find in the manual explanations about social representations versus scientific representations. In this context is rendered the difference between everyday thinking and professional scientific thinking where thoughtful man amateur to virtuoso turn scientific concepts in judgments invoice street, which finally constitutes true social representations.

The author continues with a list of topics that debate the difference between social representations and social cognitions, 
traditional symbolic images or ideologies, values, thêmata or nexus.

Thêmata helps to stand a life of social representation as a form of subordinated structures; nexus is affective node common prologue to a large number of individuals in a community that serves as the basis of social representations.

Nexus imposes itself as a form of social thinking complementary to the central core with affective value, being classified as a separate mode of social thinking. Finally, the author manages to identify two essential characteristics of nexus that he presents in the first part of the work: the possibility of nexus to cancel the difference intra and inter-groups that can cause adhesion or rejection towards the object unconditionally.

Immediately after this important incursion in the subject of social representations, the author does not hesitate to present a synthesis right in the middle of the work of all those exposed to present his own, modern vision on the studied issues.

The second half of the paper strikes us with the practical aspect that the author exposes with the luxury of detail presented in six parts. Here we find all the explanatory and interpretive principles and techniques regarding the study of social representations, their content, identification of the way of organizing social representations, verification of the centrality of the elements of social representation, a finding of the mute areas and a glossary of all the notions used in this work. One of the merits of the volume is that it offers a critical and ample analysis of social representations, realized from a modern perspective and with its own constraints regarding this concept. Even the name of the book is very suggestive and releases the author's idea of a comprehensive analysis of the interior at a single glance. 



\section{Instructions for authors}

The Bulletin of Integrative Psychiatry publishes blind peer reviewed articles, reviews, updates, meta analyses, original papers, case reports in the following fields of research: psychiatry correlated with philosophy, ethics, meta ethics, bioethics, aesthetics, economy, sports, nutrition, law, forensic medicine, political sciences, communication science ,sociology, social assistance, anthropology, cultural anthropology, literature, religion. The journal is published quarterly in English.

Articles are submitted to the discussions in meetings of the Editorial Board, being subjected to a blind peer review evaluation from two specialists in the field.

Evaluating the scientific value and originality of the article, as well as its layout, grammar and structure and the way in which the guidelines for publication have been observed, the final publication decision is made by the editor-in- chief and the advisory board. It is also required that the article admitted for publication should represent a substantial contribution in the field, and the data included are correct and pertinent.

There are no author fees and all articles are made free access on line.

In the Declaration of Interests, authors must indicate any financial and personal relationships with other people or organizations that could influence in an incorrect way their work.

Conflict of interests can refer to financial relationships and academic competition.

Authors should not submit articles that have been published or sent for publication to other journals.

Bulletin of Integrative Psychiatry, accept for publication the following types of works (articles): reviews, updates, meta analysis, original papers, case report

Fields of research: psychiatry correlated with philosophy, ethics, metaethics, bioethics, esthetics, economy, sports, nutrition, law, forensic medicine, political sciences, communicational sciences, sociology, social assistance, anthropology, cultural anthropology, literature, religion etc.

\section{Manuscript Criteria and Information}

Manuscripts and all attached files should be submitted in electronic form and on paper.

The electronic form should be submitted, either on compact disk or by e-mail (see at end). It is preferable that two copies (in English and Romanian) of the manuscript, printed on one side of A4 paper format, single-spaced, with $2 \mathrm{~cm}$ margins, be also submitted to the same address. The manuscript should be accompanied by a cover letter including the statement on authorship responsibilities form, the statement on ethical considerations and the statement on financial disclosure (For more information please see directions on website).

\section{Authorship}

All named authors should meet the criteria for authorship as stated in the "Uniform Requirements for Manuscripts Submitted to Biomedical Journals: Writing and Editing for Biomedical Publication" issued by the International Committee of Medical Journal Editors (www.icmje.org). 


\section{Ethical considerations}

If the scientific project involves human subjects or experimental animals, authors must state in the manuscript that the protocol has been approved by the Ethics Committee of the institution within which the research work was undertaken. All authors are responsible for adhering to guidelines on good publication practice.

\section{Financial Disclosure}

The manuscript should be accompanied by a cover letter including the statement on financial disclosure. The statement on conflicts of interest will be published at the end of the paper. Please submit all requested signed documents by regular mail to the Secretariat. Scanned copies sent electronically and fax submissions are not acceptable.

\section{Corrections}

Scientific fraud is rare events; however, they have a very serious impact on the integrity of the scientific community. If the Editorial Board uncovers possible evidence of such problems it will reserves the right to take all steps it considers necessary for the elucidation of the situation, including possibility to publish errata, corrigenda, or retractions.

\section{Copyright}

The papers published in the Journal and protected by copyright. Their full or partial publication in other journal is allowed only with the written approval of the publisher.

\section{Manuscript Preparation}

- Romanian authors should send both the Romanian and English version of the article, including title, abstract and key words. Foreign authors should send the English version of the article.

- Manuscripts must be prepared in conformity to the "Uniform Requirements for Manuscripts Submitted to Biomedical Journals: Writing and Editing for Biomedical Publication" issued by the International Committee of Medical Journal Editors (www.icmje.org).

- Articles must be written in Microsoft Word, Style: Normal + Justify, Font: Times New Roman, size 12. All manuscripts must be typed single-spaced. Original source files (not PDF files), are required. In text editing, do not use spacing with spacebar, or paragraph mark, use only Enter or Tab key.

- Subheadings of the article should be left-justified, typed with capital letters, Font: Times New Roman, size 12.

- The abstracts and Key words must be written in Microsoft Word, Style: Normal + Justify, Font: Times New Roman, size 12.

- Use as few formatting commands as possible:

○ input your text continuously (without breaks);

o do not use different types of fonts to highlight your text;

$\circ$ any word or phrase that you would like to emphasize should be indicated throughout the text by underlining;

○ use only the "Enter" key to indicate the end of the end of paragraphs, headings, lists etc.;

o do not use the "Space Bar" to indicate paragraphs, but only the "Tab" key

- Figures must be cited in order in the text using Arabic numerals, (e.g., fig.2). Their width should be max. $13,5 \mathrm{~cm}$. The figures have to satisfy the following conditions: 
- Black and white photographs with good contrast, with recommended size;

- Scanned photograph with a resolution of minimum 300 dpi and edited on a computer, original file $(* J P G)$;

- Illustrations (drawings, charts) created on a computer, cited in the text, original file (*XLS, *CDR). Every figure should be accompanied by a title and a legend.

- Tables, numbered consecutively with Latin numerals (e.g., Tab. II), should have a width of max. 13,5 cm. Every table should be also accompanied by a title and a legend. The distribution of tables and figures in the text should be balanced.

- Please do not import tables or figures into the text document, but only specify their insertion in text (e.g., Table No.III insertion). They have to be sent in separate files. Files should be labeled with appropriate and descriptive file names.

- Abbreviations shall be avoid. If used, will occur preceded by the full term at their first apparition in text. A list of all used abbreviations shall be made at the end of the article,

- Separate pages: tables, graphics, pictures and schemes will appear on separate pages.

- You may use a common compression program: ARJ, RAR or ZIP.

\section{Manuscript organization}

Article title: titles should be short, specific, and descriptive, emphasizing the main point of the article. Avoid a 2-part title, if at all possible. Do not make a declarative statement in the title. Title length, including punctuation and spaces, ideally should be under 100 characters and must not exceed 150 characters.

\section{Manuscript Size}

- Original paper - 8 pages/3500 words;

- Review and update - 8 pages/3500 words;

- Case report - 4 pages/1700 words;

- Clinical notes - 3 pages/1300 words;

- Letters to editor, information scientific reunions - one page/450 words.

Author(s). First name, middle initials and surname of the authors, without any scientific, didactic or military degrees; (e.g., Mircea A Popescut, Aura Vasilescu, not Popescu M.A., Vasilescu A.).

Footnote that specifies the authors' scientific titles, professional title, name and address of their workplaces (institution and department) for each author; contact details of the corresponding author (full address, telephone number, fax number, e-mail address) and the address of the institution and department where the study has been carried out. Contact details will be published unless otherwise requested by the author.

Abstracts in in English and Romanian, should have max. 300 words. For original articles is advisable to include five paragraphs, labeled Background, Objective(s), Method(s), Result(s), and Conclusion(s).

Keywords maximum of 6 keywords (minimum of 3). Keywords should not repeat the title of the manuscript. 
(1)

Original papers organized in:

- Introduction (no more than $25 \%$ of the text), material and methods, results, comments or discussions and acknowledgements.

- Material and methods have to be described in enough detail to permit reproduction by other teams. The same product names should be used throughout the text (with the brand name in parenthesis at the first use).

- Results should be presented concisely. Tables and figures should not duplicate text.

- Discussions should set the results in context and set forth the major conclusions of the authors.

- Information from the Introduction or Results should not be repeated unless necessary for clarity. The discussion should also include a comparison among the obtained results and other studies from the literature, with explanations or hypothesis on the observed differences, comments on the importance of the study and the actual status of the investigated subject, unsolved problems, questions to be answered in the future.

- Acknowledgements section must disclose any substantive conflicts of interest in addition to the customary recognition of non-authors who have been helpful to the work described.

References. References should be numbered consecutively in the order in which they are first mentioned in the text. Identify references in text, tables, and legends by Arabic numerals in parentheses. The reference list will include only the references cited in the text (identified by Arabic numerals in parentheses, not in square brackets and not bold). All authors should be listed when four or less; when five or more, list only the first three and add "et al" (Popescu I, Popescu I, Vasile V. et al). The name of the Journals cited in the References should be abbreviated according to ISI Journal Title Abbreviations.

\section{It is absolutely imperative that references to be entered in the text!!}

\section{Examples:}

- Reference to a journal publication:

Amura SG.: Neurotransmitter transportor: recent progress. Ann Rev Neurosci 1993; 16; 73-93.

Tonis PJ, von Sandick JW, Nieweg OE, et al.: The hidden sentinel node,in breast cancer. Eur J Nucl Med 2002; 29: 305-311

\section{- Reference to a book:}

Ashcroft FM.: Ion channels and disease, San Diego, London: Academic Press, 2000, pp. 26-52.

\section{- Reference to a chapter in an edited book:}

Pandiom MR, Fischer DA. Immunoradiometric assays. In: Scabes CG, editor. Handbook of Endocrine Research Techniques. New York, London: Academic Press, 1993, 26-52 The punctuation and the general aspect of the text format must comply with the rules mentioned above. This is a mandatory and eliminatory condition.

\section{ACKNOWLEDGMENTS AND DISCLOSURE}

Authors: an "author" is generally considered to be someone who has made substantive intellectual contributions to a published study, and biomedical authorship continues to have important academic, social, and financial implications (1). An author must take responsibility for at least one 


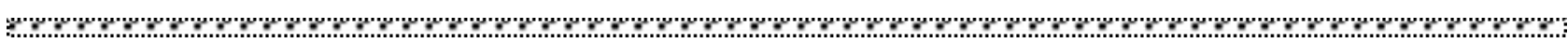
component of the work, should be able to identify who is responsible for each other component, and should ideally be confident in their co-authors' ability and integrity.

We strongly encourage developing and implementing a contributor ship policy, as well as a policy on identifying who is responsible for the integrity of the work as a whole.

Disclosure: The authors must declare if they have or not a potential conflicts of interest to disclose. Acknowledgments: All contributors who do not meet the criteria for authorship should be listed in an acknowledgments section. Authors should declare whether they had assistance with study design, data collection, data analysis, or manuscript preparation. If such assistance was available, the authors should disclose the identity of the individuals who provided this assistance and the entity that supported it in the published article. Financial and material support should also be acknowledged.

\section{PEER REVIEW PROCESS}

Although the practice of peer review started 300 years ago, only since 198s the process has been active to analyze if articles sent to journals are well-written, correctly edited and represent reliable sources of information.

All manuscripts intended for publication will be subject to blind peer-review by a committee of experts which assesses the scientific and statistical correctness of articles submitted. The committee receives the manuscripts without knowing the authors' name and proposes possible changes, which will be transmitted to the authors by the medium of Editorial Board. The authors have the obligation to oversee the text in English language with the help of a professional translator.

When submitting a paper, a confirmation email is automatically sent back to the author. It contains a unique registration number used as a referral in further correspondence.

Initially, the editorial team verifies whether the manuscript complies with the editing instructions. If the paper does not meet the necessary requirements, it is rejected and the corresponding author is notified to correct the errors. If all instructions for editing have been followed accordingly, the editor selects two reviewers that will independently evaluate the paper. They have high expertise in the "peer-review" system and are well-known specialists in the field. The reviewers have all academic affiliations and may be already accredited by the Journal or specifically contacted for certain papers. Their affiliation is usually different from the one of submitting authors.

The editor sends the paper in both electronic and printed format to each reviewer with the invitation to evaluate it within 15 days. The reviewers will analyze the paper from several perspectives such as clarity, objectivity of data, scientific quality and relevance. A scale from 1 to 5 is used, where 5 is excellent and 1 is poor. The reviewers score the paper accordingly and issue a recommendation. The existence of a manuscript under review is not revealed to anyone other than peer reviewers and editorial staff. Peer reviewers remain anonymous and are expected to maintain strict confidentiality. After the review process has been completed, authors will be informed by mail of the Editor's decision.

Reviewers should inform the editor about suspected plagiarism. 

Interests and disclosure form", which you can download from the website of Bulletin of Integrative Psychiatry (www.buletindepsihiatrie.ro).

\section{Ethical Considerations}

Authors of articles should sign a statement assuming the responsibility for the originality, property rights and ethical implications of their work. Authors should obtain permission or copy right to publish figures, images or tables from other journals whose material they use.

A written consent must be obtained from patients when personal information or images of patients are included in the article. Authors must state that the protocol has been approved by the Ethics Committee of the institution where the research was conducted.

\section{Address to send the manuscripts is:}

Buletin de Psihiatrie Integrativa/ Institutul de Psihiatrie "Socola" Iasi

Lecturer Alexandra Bolos: Institutul de Psihiatrie "Socola” Iasi, Șos. Bucium 36, 700282, Iasi, jud. Iasi; E-mail: contact@ buletindepsihiatrie.ro 